\title{
WestVirginiaUniversity
}

THE RESEARCH REPOSITORY @ WVU

Graduate Theses, Dissertations, and Problem Reports

2013

\section{Analysis of Shale Production Performance Using Decline Curve Methods}

Brad Thomas Nelson

West Virginia University

Follow this and additional works at: https://researchrepository.wvu.edu/etd

\section{Recommended Citation}

Nelson, Brad Thomas, "Analysis of Shale Production Performance Using Decline Curve Methods" (2013). Graduate Theses, Dissertations, and Problem Reports. 3397.

https://researchrepository.wvu.edu/etd/3397

This Thesis is protected by copyright and/or related rights. It has been brought to you by the The Research Repository @ WVU with permission from the rights-holder(s). You are free to use this Thesis in any way that is permitted by the copyright and related rights legislation that applies to your use. For other uses you must obtain permission from the rights-holder(s) directly, unless additional rights are indicated by a Creative Commons license in the record and/ or on the work itself. This Thesis has been accepted for inclusion in WVU Graduate Theses, Dissertations, and Problem Reports collection by an authorized administrator of The Research Repository @ WVU. For more information, please contact researchrepository@mail.wvu.edu. 
Analysis of Shale Production Performance Using Decline Curve Methods

Brad Thomas Nelson

Thesis submitted to the

Benjamin M. Statler College of Engineering and Mineral Resources at West Virginia University

In Partial fulfillment of the requirements

For the degree of

Master of Science

In

Petroleum and Natural Gas Engineering

Khashayar Aminian, Ph.D., Chair

Samuel Ameri, M.S.

Ebrahim Fathi, Ph.D.

Department of Petroleum and Natural Gas Engineering

Morgantown, West Virginia

2013

Keywords: Decline Curves, Marcellus Shale, Horizontal Wells, Gas Production Prediction

Copyright 2013 Brad Thomas Nelson 


\section{ABSTRACT \\ Analysis of Shale Production Performance Using Decline Curve Methods}

\section{Brad Thomas Nelson}

With the recent development of shale gas reservoirs such as the Marcellus using horizontal drilling and fracturing, it has become necessary to evaluate the amount of gas recoverable for both economic and operational purposes. As a result of limited production history, the production behavior of horizontal well producing from Marcellus shale has not been well established. A technique in accomplishing the estimation of future production history would be most useful to the industry.

Decline curve analysis (DCA) methods have been utilized successfully in various hydrocarbon plays throughout the world in approximating future production. Several DCA models have been proposed specifically for unconventional gas reservoirs. However, their applicability to production data from Marcellus shale wells has not been attempted. Four sets of simulated Marcellus shale production profiles were generated in this study. They included production from a 3000 feet-long horizontal well containing seven hydraulic fracture stages (a hydraulic fracture spacing of 500 feet) and thirteen fractures (a hydraulic fracture spacing of 250 feet). Two sets were simulated using a dual porosity model with adsorbed gas and two sets were simulated using a dual porosity model without adsorbed gas. The most appropriate DCA models for each set were selected based on the entire production profile (30 years). Subsequently, a technique was developed to predict the long term DCA model parameters based on the limited production history via dimensionless log-log plots. Finally, the developed methodology was applied to the limited field production data from a horizontal well containing eight hydraulic fracture stages (a hydraulic fracture spacing of 429 feet). The comparison of the predicted future production rates with those rates predicted by history matching with a commercial reservoir simulator confirmed the reliability of methodology developed in this study. 


\section{Acknowledgements}

I would like to thank my advisor, Dr. Aminian, for his guidance during the research

process. In addition, I express my gratitude to committee members Prof. Ameri and Dr. Fathi for academic support. 


\section{TABLE OF CONTENTS}

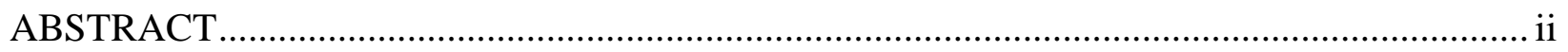

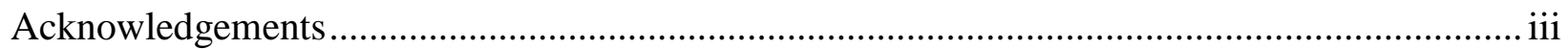

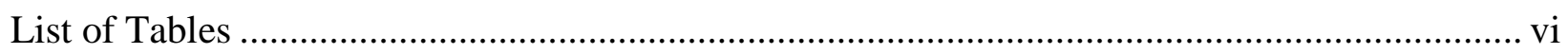

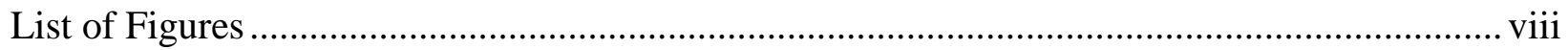

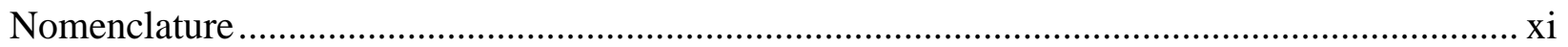

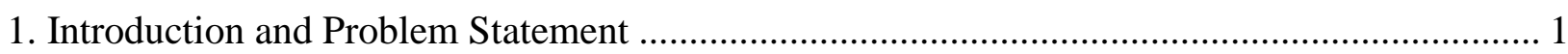

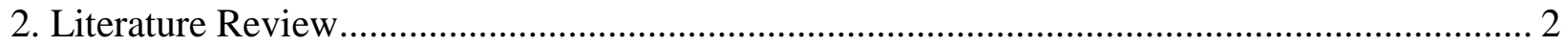

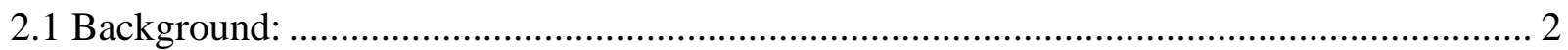

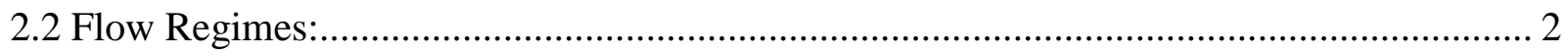

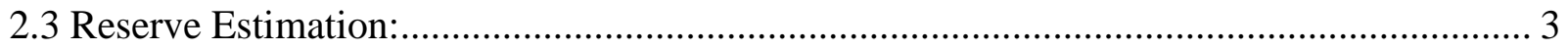

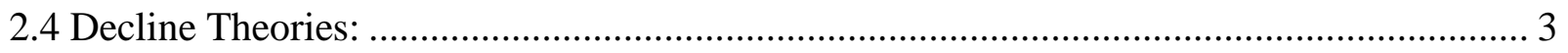

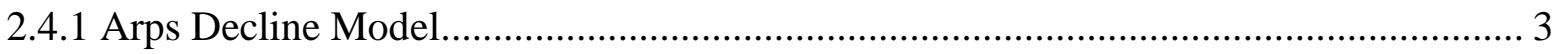

2.4.2 Power Law Exponential Decline Model (PLE):……............................................... 5

2.4.3 Stretched Exponential Decline Model (SEPD): ................................................................ 6

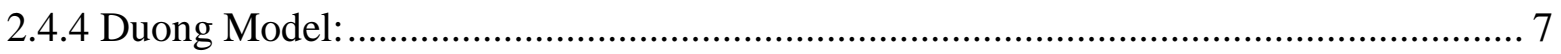

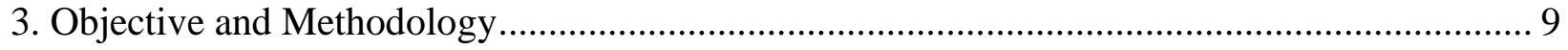

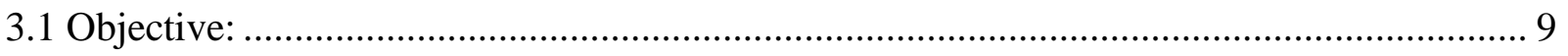

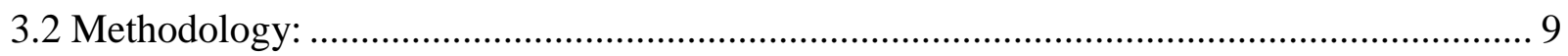

3.2.1 Development of a Marcellus Shale Reservoir Model:................................................ 10

3.2.2 Application of Decline Curve Analysis Techniques to Simulated Data: ..................... 12

3.2.3 Application of Selected DCA Models to Varying Simulated Production Times:........ 12

3.2.4 Validation Against Field Data: ................................................................................... 13

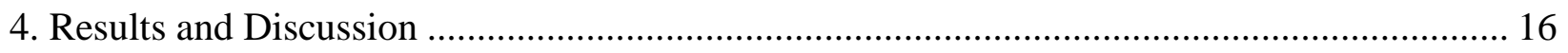

4.1 Development of a Marcellus Shale Reservoir Model: ..................................................... 16

4.2 Application of Decline Curve Analysis Techniques to Simulated Data: ............................ 18

4.3 Application of Selected DCA Models to Varying Simulated Production Times:................ 35

4.4 Validation Against Field Data:...................................................................................... 43

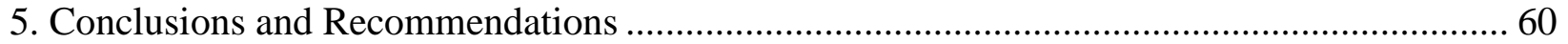

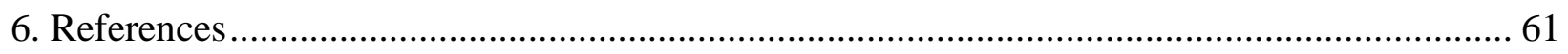




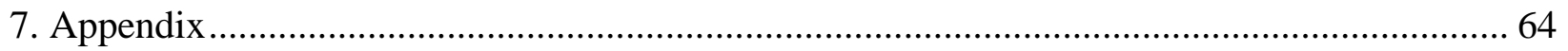

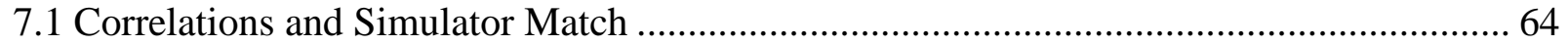

7.2 Well 1 - 13 Fracs (Adsorbed Gas) Predictions............................................................. 90 


\section{List of Tables}

Table 1: Eclipse Basic Model Parameters ………………......................................................... 11

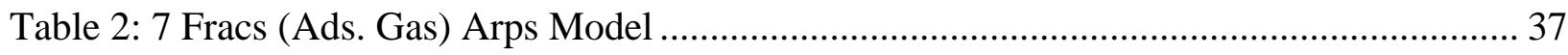

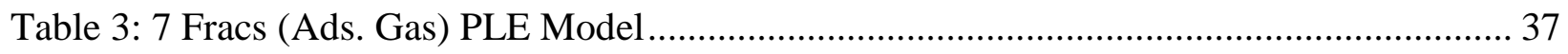

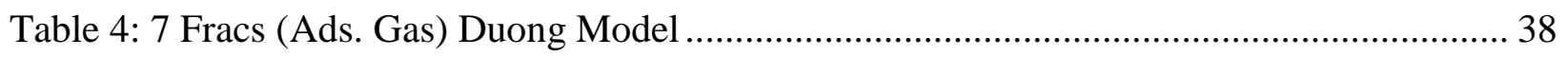

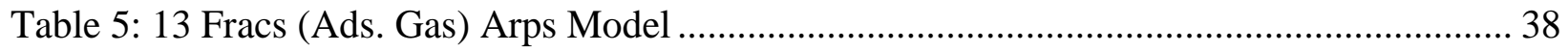

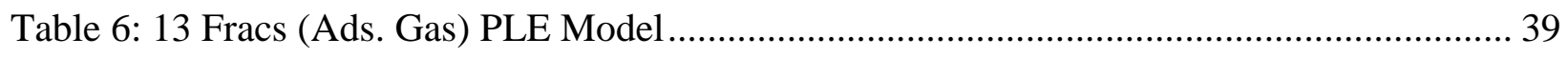

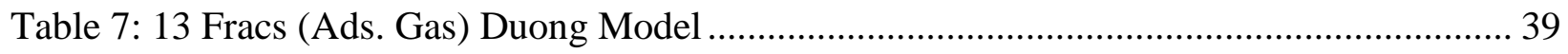

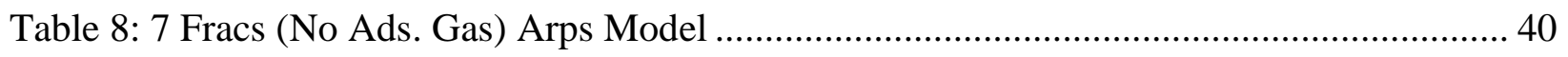

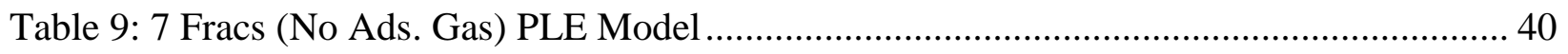

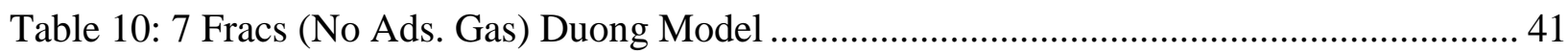

Table 11: 13 Fracs (No Ads. Gas) Arps Model ………………............................................. 41

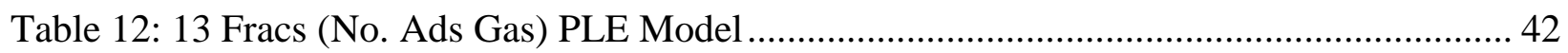

Table 13: 13 Fracs (No. Ads Gas) Duong Model ………........................................................ 42

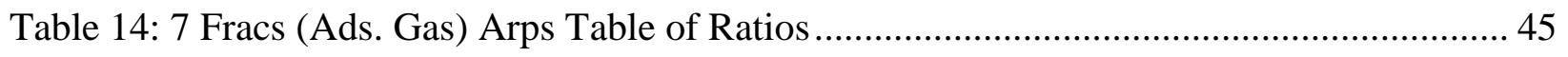

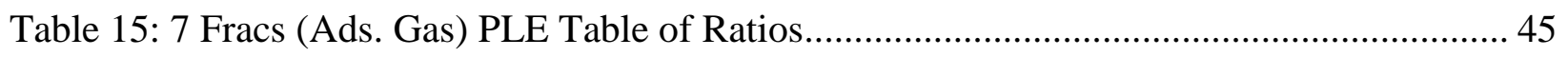

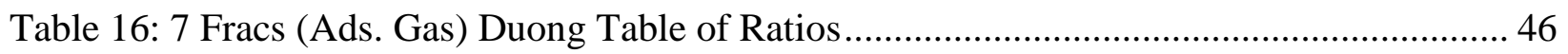

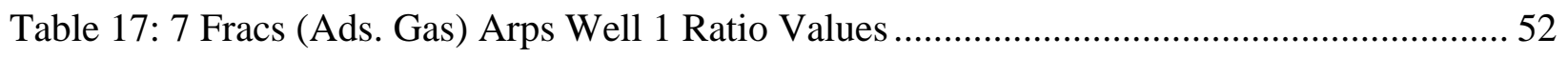

Table 21: 7 Fracs (Ads. Gas) PLE Well 1 Ratio Values.................................................................. 52

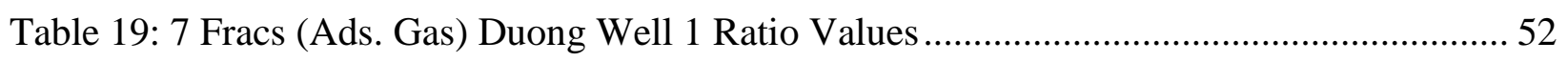

Table 20: 7 Fracs (Ads. Gas) Arps Well 1 Actual and Predicted Values ......................................5 54

Table 21: 7 Fracs (Ads. Gas) PLE Well 1 Actual and Predicted Values........................................ 55

Table 22: 7 Fracs (Ads. Gas) Duong Well 1 Actual and Predicted Values ................................... 55

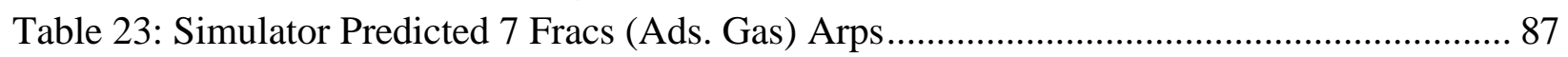

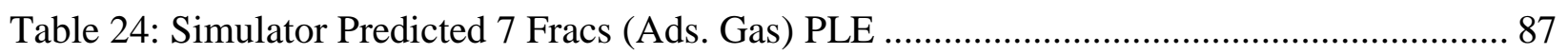

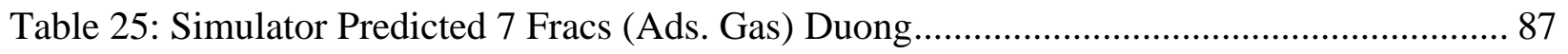

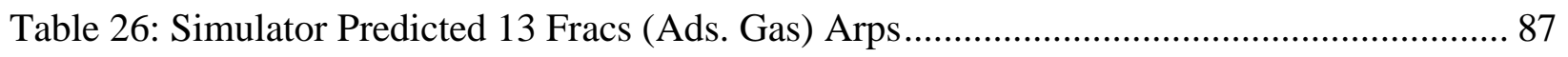

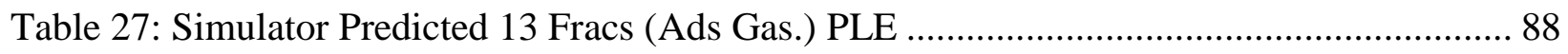

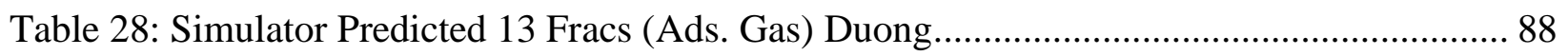

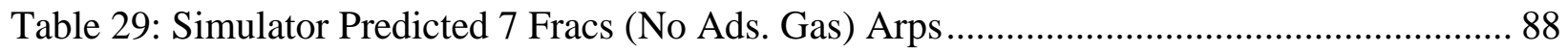

Table 30: Simulator Predicted 7 Fracs (No Ads. Gas) PLE ........................................................... 88

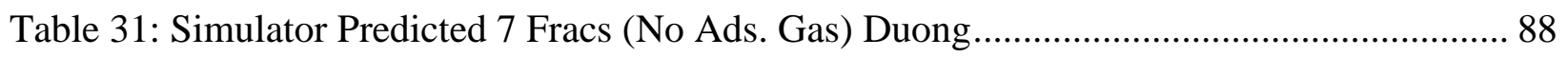

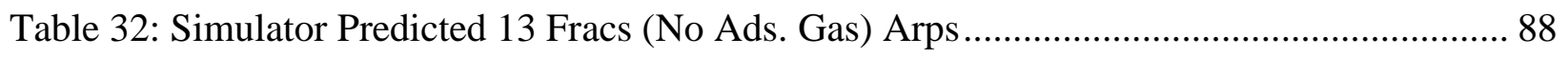

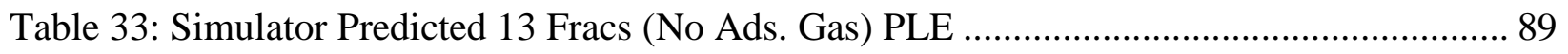

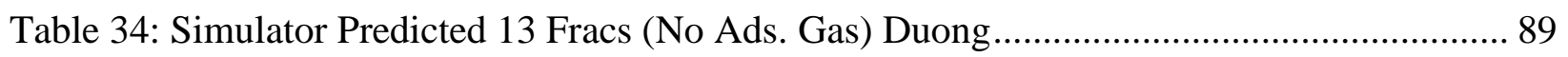

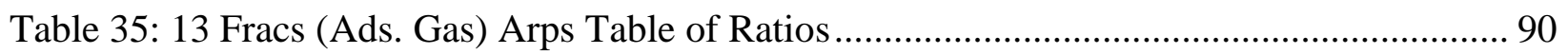

Table 36: 13 Fracs (Ads. Gas) PLE Table of Ratios.................................................................... 90

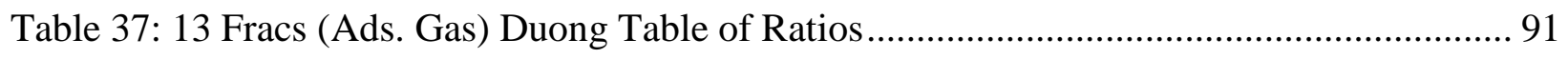

Table 38: 13 Fracs (Ads. Gas) Arps Well 1 Ratio Values ............................................................... 96 
Table 39: 13 Fracs (Ads. Gas) PLE Well 1 Ratio Values....................................................... 97

Table 40: 13 Fracs (Ads. Gas) Duong Well 1 Ratio Values ..................................................... 97

Table 41: 13 Fracs (Ads. Gas) Arps Well 1 Actual and Predicted Values ................................. 97

Table 42: 13 Fracs (Ads. Gas) PLE Well 1 Actual and Predicted Values .................................. 97

Table 43: 13 Fracs (Ads. Gas) Duong Well 1 Actual and Predicted Values .............................. 98 


\section{List of Figures}

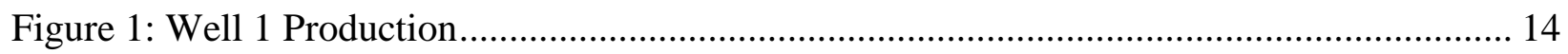

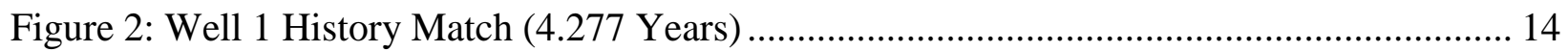

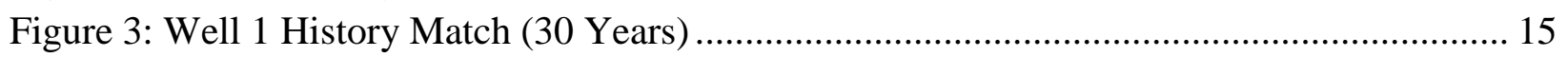

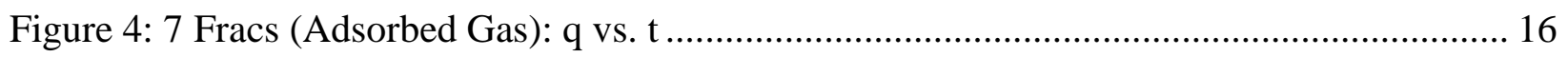

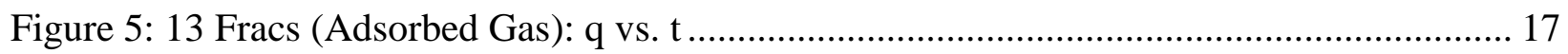

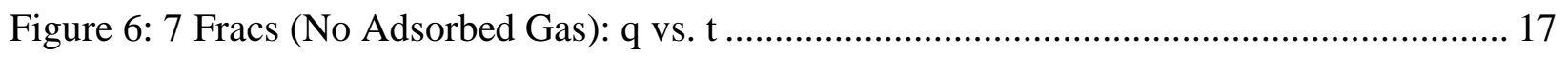

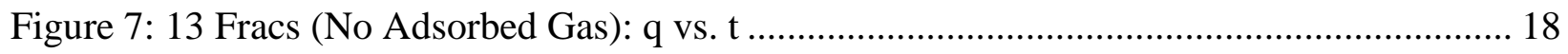

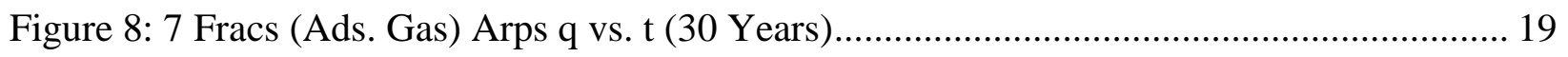

Figure 9: 7 Fracs (Ads. Gas) PLE q vs. t (30 Years) ................................................................. 20

Figure 10: 7 Fracs (Ads. Gas) Duong q vs. t (30 Years) ............................................................. 20

Figure 11: 7 Fracs (Ads. Gas) q vs. t Comparison - Years 0-2 ................................................. 21

Figure 12: 7 Fracs (Ads. Gas) q vs. t Comparison - Years 2-5 .................................................. 21

Figure 13: 7 Fracs (Ads. Gas) q vs. t Comparison - Years 5-10 ……………………….............. 22

Figure 14: 7 Fracs (Ads. Gas) q vs. t Comparison - Years 10-20 …............................................ 22

Figure 15: 7 Fracs (Ads. Gas) q vs. t Comparison - Years 20-30 .............................................. 23

Figure 16: 13 Fracs (Ads. Gas) Arps q vs. t (30 Years).......................................................... 23

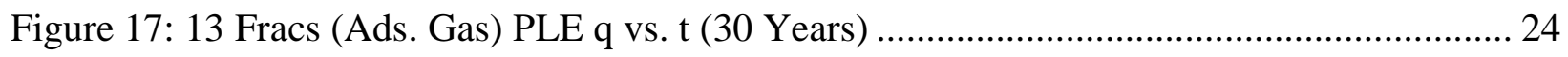

Figure 18: 13 Fracs (Ads. Gas) Duong q vs. t (30 Years) ......................................................... 24

Figure 19: 13 Fracs (Ads. Gas) q vs. t Comparison - Years 0-2 ………………………......... 25

Figure 20: 13 Fracs (Ads. Gas) q vs. t Comparison - Years 2-5 …............................................. 25

Figure 21: 13 Fracs (Ads. Gas) q vs. t Comparison - Years 5-10 ................................................. 26

Figure 22: 13 Fracs (Ads. Gas) q vs. t Comparison - Years 10-20 …………………................... 26

Figure 23: 13 Fracs (Ads. Gas) q vs. t Comparison - Years 20-30 …………........................... 27

Figure 24: 7 Fracs (No Ads. Gas) Arps q vs. t (30 Years)........................................................... 27

Figure 25: 7 Fracs (No Ads. Gas) PLE q vs. t (30 Years) ......................................................... 28

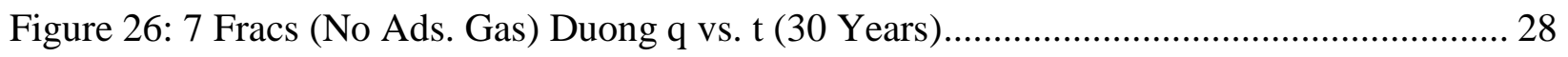

Figure 27: 7 Fracs (No Ads. Gas) q vs. t Comparison - Years 0-2 ……..................................... 29

Figure 28: 7 Fracs (No Ads. Gas) q vs. t Comparison - Years 2-5 …………............................... 29

Figure 29: 7 Fracs (No Ads. Gas) q vs. t Comparison - Years 5-10 ………………................... 30

Figure 30: 7 Fracs (No Ads. Gas) q vs. t Comparison - Years 10-20 ......................................... 30

Figure 31: 7 Fracs (No Ads. Gas) q vs. t Comparison - Years 20-30 ........................................ 31

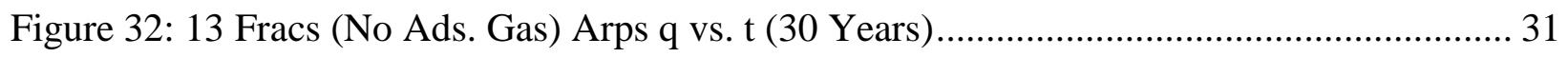

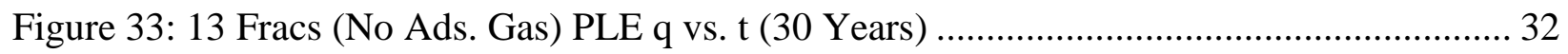

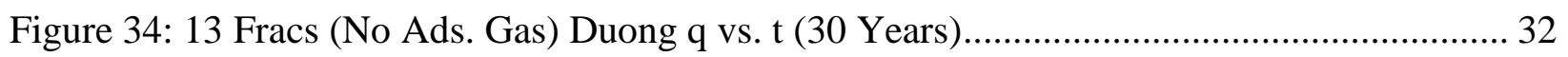

Figure 35: 13 Fracs (No Ads. Gas) q vs. t Comparison - Years 0-2 ……………...................... 33

Figure 36: 13 Fracs (No Ads. Gas) q vs. t Comparison - Years 2-5 ………………………....... 33

Figure 37: 13 Fracs (No Ads. Gas) q vs. t Comparison - Years 5-10 .......................................... 34

Figure 38: 13 Fracs (No Ads. Gas) q vs. t Comparison - Years 10-20 ......................................... 34 
Figure 39: 13 Fracs (No Ads. Gas) q vs. t Comparison - Years 20-30 ......................................... 35

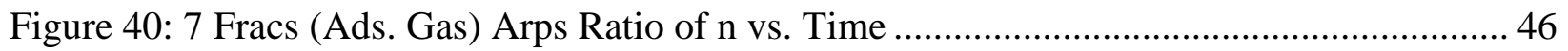

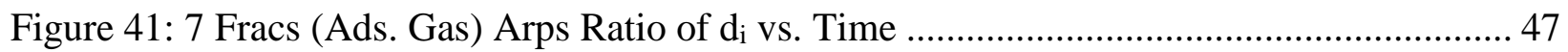

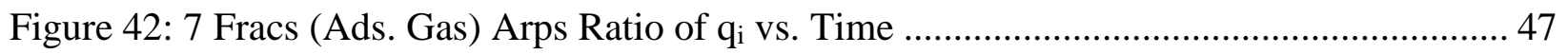

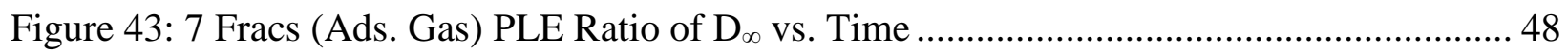

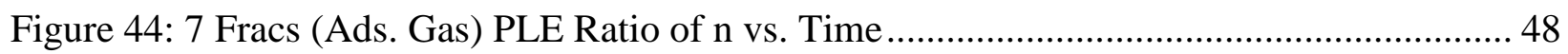

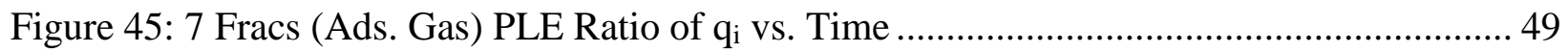

Figure 46: 7 Fracs (Ads. Gas) PLE Ratio of $\mathrm{D}_{1}$ vs. Time.......................................................... 49

Figure 47: 7 Fracs (Ads. Gas) Duong Ratio of a vs. Time …………........................................ 50

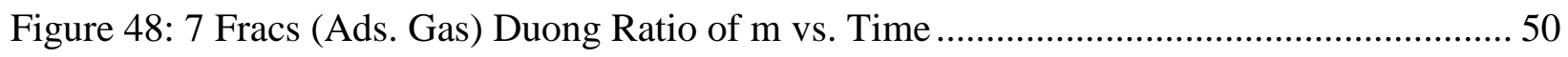

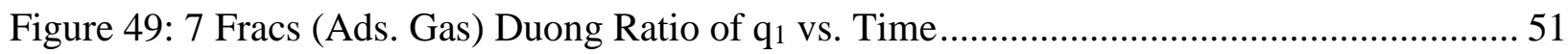

Figure 50: 7 Fracs (Ads. Gas) Duong Ratio of $\mathrm{q}_{\infty}$ vs. Time …………....................................... 51

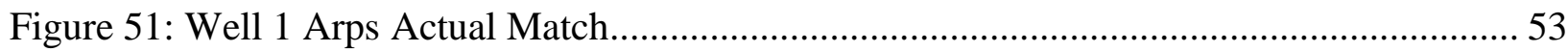

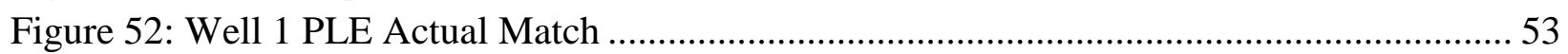

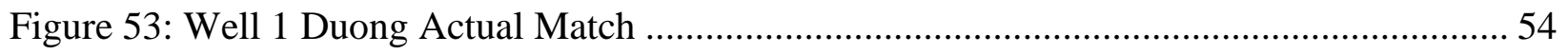

Figure 54: Well 1 - 7 Fracs (Ads. Gas) Arps Predicted Match...................................................... 56

Figure 55: Well 1 - 7 Fracs (Ads. Gas) PLE Predicted Match …………….................................. 56

Figure 56: Well 1 - 7 Fracs (Ads. Gas) Duong Predicted Match.................................................. 57

Figure 57: 7 Fracs (Ads. Gas) 30 Year Well 1 Predicted Comparison.......................................... 58

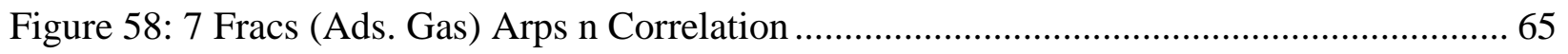

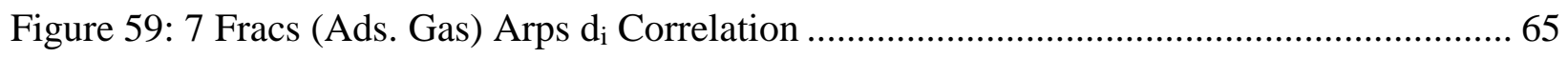

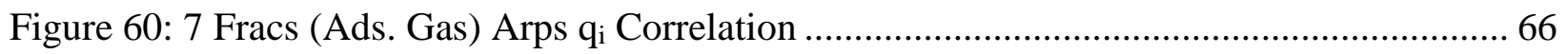

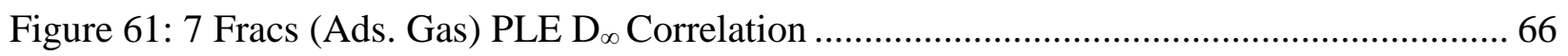

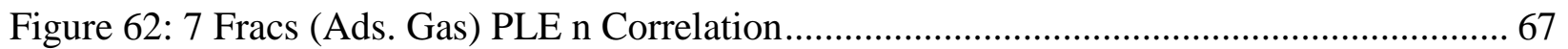

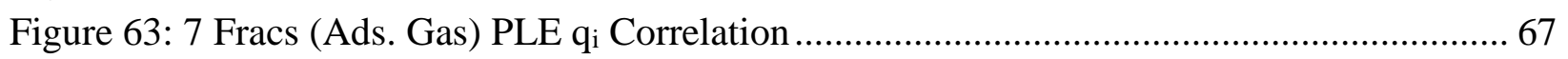

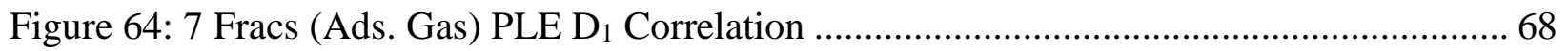

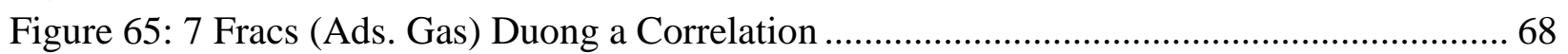

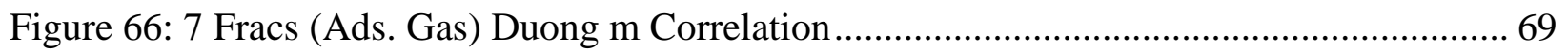

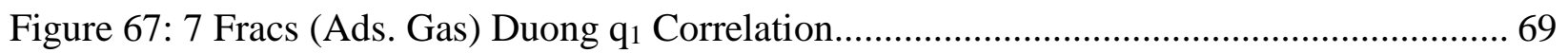

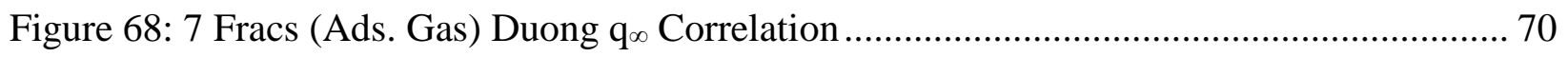

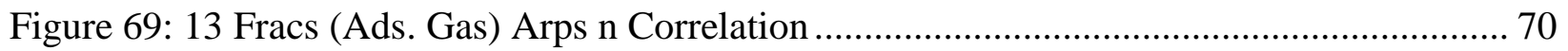

Figure 70: 13 Fracs (Ads. Gas) Arps $d_{i}$ Correlation ................................................................. 71

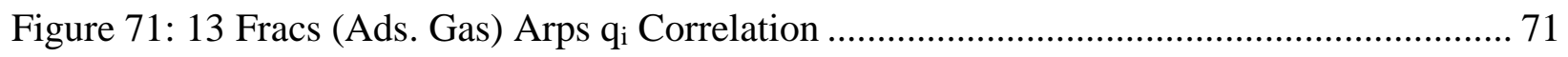

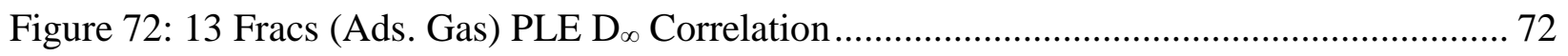

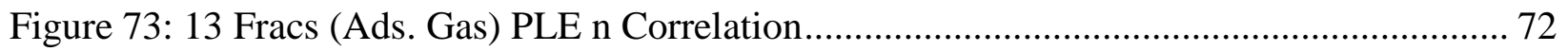

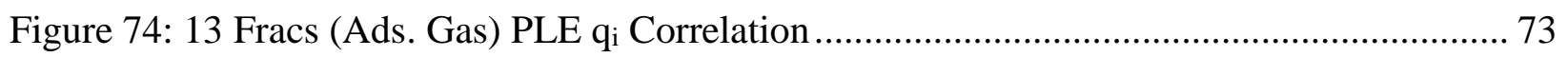

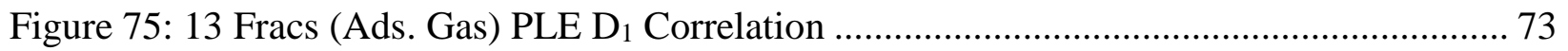

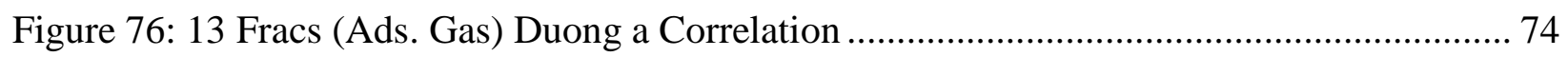

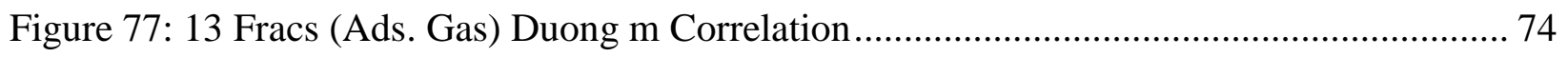

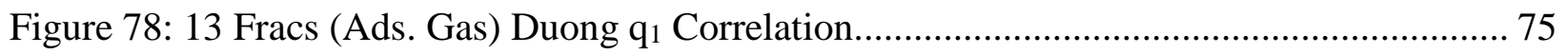




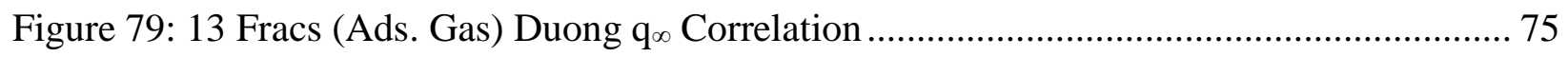

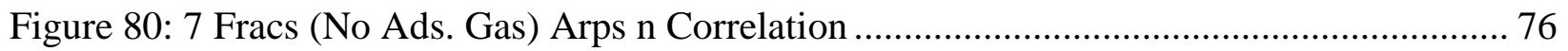

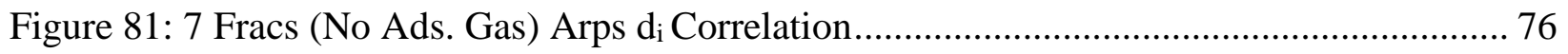

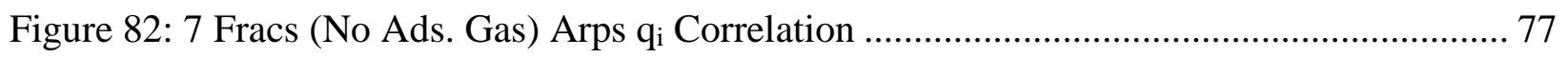

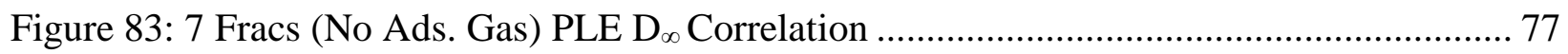

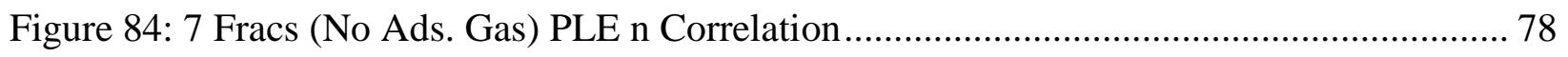

Figure 85: 7 Fracs (No Ads. Gas) PLE qi Correlation ................................................................ 78

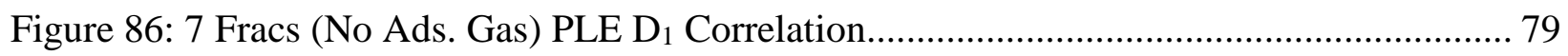

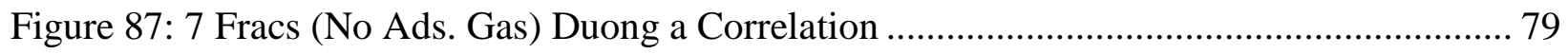

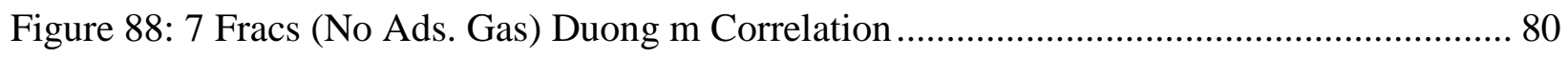

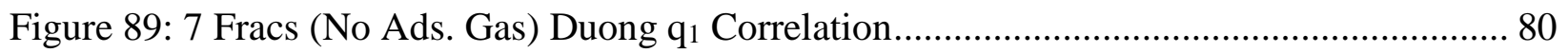

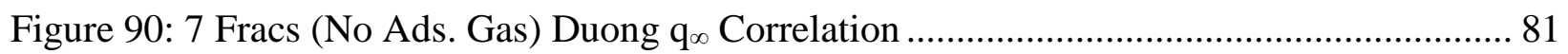

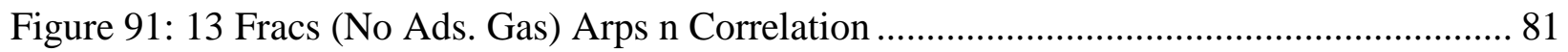

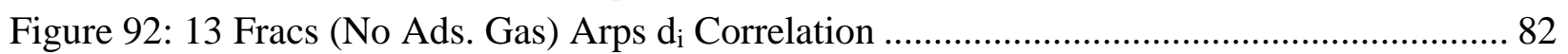

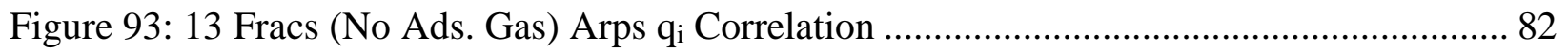

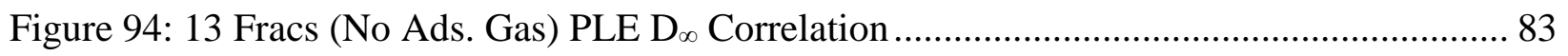

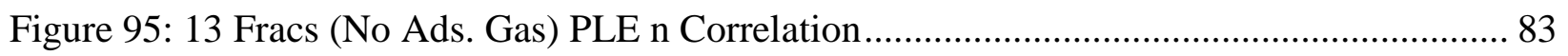

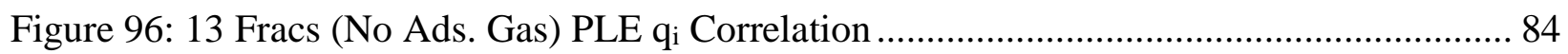

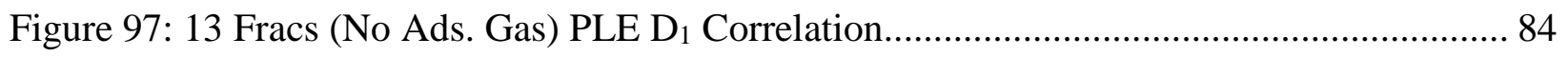

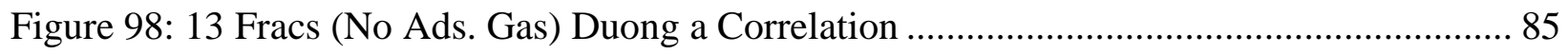

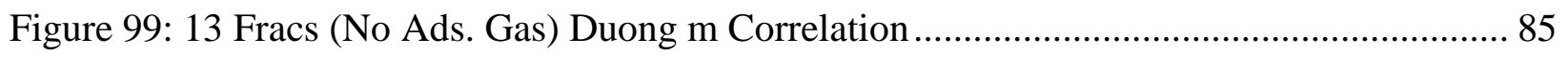

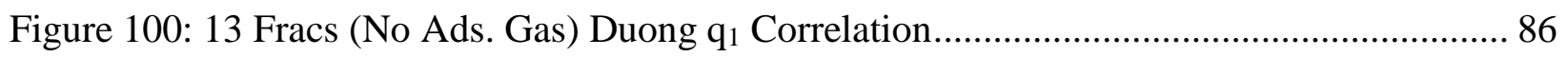

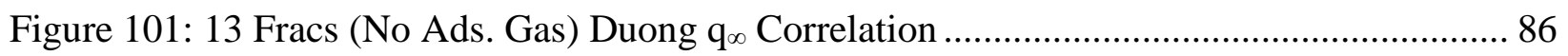

Figure 102: 13 Fracs (Ads. Gas) Arps Ratio of n vs. Time ..................................................... 91

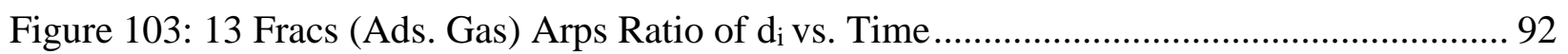

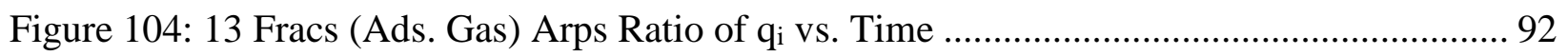

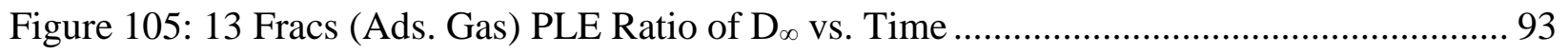

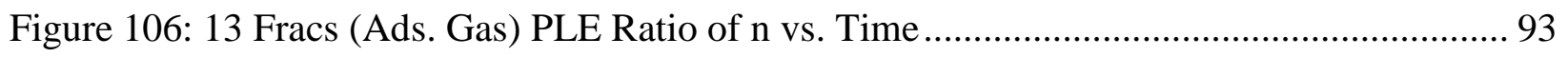

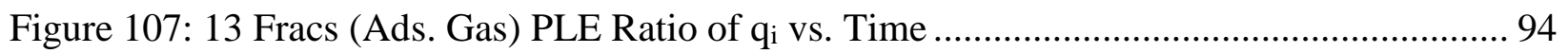

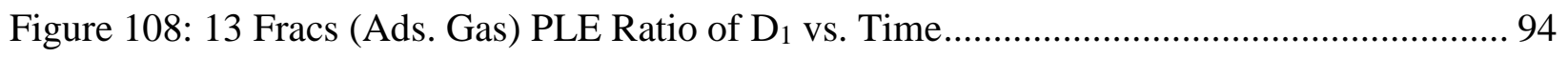

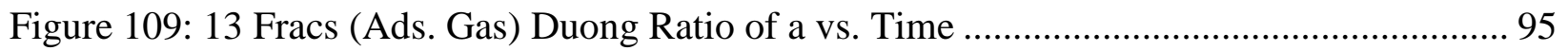

Figure 110: 13 Fracs (Ads. Gas) Duong Ratio of m vs. Time ..................................................... 95

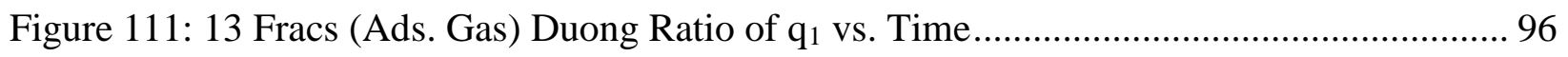

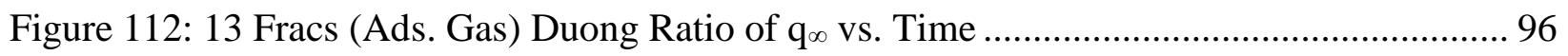

Figure 113: Well 1 - 13 Fracs (Ads. Gas) Arps Predicted Match.................................................... 98

Figure 114: Well 1 - 13 Fracs (Ads. Gas) PLE Predicted Match ................................................ 99

Figure 115: Well 1 - 13 Fracs (Ads. Gas) Duong Predicted Match............................................... 99

Figure 116: 13 Fracs (Ads. Gas) 30 Year Well 1 Predicted Comparison..................................... 100 


\section{$\underline{\text { Nomenclature }}$}

$\mathrm{D}=$ Initial decline rate, $1 /$ time

$\mathrm{q}_{0}=$ Initial rate, volume/time

$\mathrm{n}=$ Constant loss ratio or time ratio, dimensionless

$\mathrm{G}_{\mathrm{p}}=$ Cumulative gas production, volume

$\mathrm{D}_{\infty}=$ Loss ratio at $(\mathrm{t}=\infty), 1 /$ time

$\mathrm{D}_{1}=$ Loss ratio at $(\mathrm{t}=1), 1 /$ time

$\tau=$ Characteristic time constant, time

$\mathrm{Q}=$ Cumulative production, volume

$\Gamma=$ Gamma function, dimensionless

$q=$ Flow rate, volume/time

$\mathrm{a}=$ Vertical axis intercept of $\mathrm{q} / \mathrm{G}_{\mathrm{p}}$ vs. time plot, dimensionless

$\mathrm{m}=$ Slope of $\log -\log$ plot of $\mathrm{q} / \mathrm{G}_{\mathrm{p}}$ vs. time plot, dimensionless

$\mathrm{t}(\mathrm{a}, \mathrm{m})=$ Duong time function, dimensionless

$\mathrm{q}_{1}=$ Slope of $\mathrm{q}$ vs. $\mathrm{t}(\mathrm{a}, \mathrm{m})$ plot, volume

$\mathrm{q}_{\infty}=$ Vertical axis intercept of $\mathrm{q}$ vs. $\mathrm{t}(\mathrm{a}, \mathrm{m})$ plot, dimensionless 


\section{Introduction and Problem Statement}

With the recent development of shale gas reservoirs such as the Marcellus using horizontal drilling and fracturing, it has become necessary to evaluate the amount of gas recoverable for both economic and operational purposes. With the limited production from the Marcellus, little is known about predicting future reserves. The production behavior from the Marcellus has not been well established. A technique in accomplishing the estimation of future production history would be most useful to the industry.

One way of evaluating recoverable hydrocarbons is through Decline Curve Analysis (DCA) models. Traditional methods for DCA focused mainly on the equations formulated by Arps in 1945 (Kanfar, 2012). The Arps method works well for reservoirs which exhibit boundary dominated flow (BDF) to abandonment (Kanfar, 2012). This becomes problematic in shale gas reservoirs which have long transient flow regimes for most of their production life (Kanfar, 2012). Arps' method will overestimate reserves when applied to shale gas reservoirs under transient flow (Kanfar, 2012). Overestimation of reserves resulted in development of further techniques such as the Power Law Exponential Decline (PLE) and the Duong method which more accurately forecast production during transient flow followed by boundary dominated flow (Joshi, 2013). Other commonly employed models are the Stretched Exponential Decline (SEPD) and the Logistic Growth Model (LGM).

Specifically, future production behavior is to be determined in shale gas using the Arps, PLE, and Duong methods of decline curve analysis for a shale gas reservoir containing both seven and thirteen fractures with and without adsorbed gas. 


\section{$\underline{\text { 2. Literature Review }}$}

\subsection{Background:}

The hydraulic fracturing process involves injecting water, proppants, and chemicals into a well under high pressure to increase formation permeability (Hassett, 2013). Proppants remain within the reservoir fractures, holding them open and allowing for greater quantities of gas or oil to escape. Chemicals, such as corrosion inhibitors, are also added to protect equipment in the well bore. Increasing the volume of oil or gas produced from a reservoir contributes to greater economic well-being for all parties involved. Horizontal drilling allows operators to minimize surface impacts in surrounding communities. Using a single well pad, six to eight horizontal wells are often drilled. In the past, each well required a separate pad. As a result of horizontal drilling and fracturing, the global power balance between importing and exporting petroleum producing countries is changing. In addition, burning natural gas is better for the environment, as it emits about one-half the carbon dioxide emissions of coal (Hassett, 2013). The development of the Barnett shale in Texas, USA with these technologies was responsible for the increase in gas production nationwide (Belvalkar, 2010).

\subsection{Flow Regimes:}

Several flow periods exist during the life of a shale gas well. These include formation linear flow, fracture interference flow, linear flow in un-stimulated matrix, and boundary dominated flow (Joshi, 2013). Determining flow type can be accomplished by fitting a negative half-slope line or a negative quarter slope line to a $\log$-log plot of flow rate versus time (Joshi, 2012). A negative half-slope indicates linear flow and a negative quarter slope indicates bi-linear flow (Joshi, 2012). Formation linear flow occurs when fracture boundaries have not been reached; in many wells lasting the majority of production life (Joshi, 2012). Fracture interference flow is dependent upon fracture spacing and permeability, with many current wells not having 
reached this phase (Joshi, 2012). Linear flow in un-stimulated matrix is not usually seen within the economic life of a well, and is similar to formation linear flow (Joshi, 2012). Boundary dominated flow occurs during the end of well life, when the boundaries of the reservoir are encountered (Joshi, 2012).

\subsection{Reserve Estimation:}

Prior to the development of DCA models, estimation of oil reserves was accomplished by calculating the contents of a reservoir based on saturation and percentage of recoverable oil over a certain known area (Valko, 2010). This resulted in a very rough estimate of recoverable hydrocarbons (Valko, 2010). Decline Curve Analysis (DCA) models are frequently employed by professionals in the petroleum and natural gas industries to determine production from wells with limited production history. A technique for predicting production using DCA models would allow for rapid determination of production characteristics.

\subsection{Decline Theories:}

Several of the most useful and popular decline curve analysis techniques are presented below. Each model works best for a specific situation during the life of a well.

\subsubsection{Arps Decline Model}

The following technique developed by J.J. Arps in 1945 to estimate the reserves from a reservoir was based on the ability of past production to be an indicator of future reservoir performance (Valko, 2010). In addition, the Arps model is based on the observation that a well's loss ratio, shown below, is usually constant with time (Arps, 1945; Fetkovitch et al. 1996; Joshi, 2010). During BDF, the three types of decline visible in production rates are Exponential, Hyperbolic, and Harmonic (Kanfar, 2012).

The loss ratio is given as, 


$$
\frac{1}{D}=-\frac{q}{d q / d t}
$$

The loss ratio derivative,

$$
n=\frac{d}{d t}\left[-\frac{q}{d q / d t}\right]
$$

The three declines have " $n$ " values from 0 to 1 . A " $n$ " value of 0 indicates exponential decline. Values $0<n<1$ indicate hyperbolic decline, and a " $n$ " value equal to 1 indicates harmonic decline. In 1980, Fetkovitch used models initially presented by Arps in 1945 combined with constant - pressure infinite acting radial flow solutions to form a type curve (Kanfar, 2012).

The Arps hyperbolic model,

$$
q=q_{0}(1+n D t)^{-1 / n}
$$

Where:

$$
\begin{gathered}
q_{0}=\text { intial rate, } \text { volume } / \text { time } \\
D=\text { initial decline rate }, 1 / \text { time } \\
n=\text { constant loss ratio, dimensionless }
\end{gathered}
$$

The hyperbolic model is limited to " $n$ " values between 0 and 1 (Kanfar, 2012). It is often seen in shale reservoirs that " $n$ " values greater than 1 match data (Kanfar, 2012). During transient linear flow, a " $n$ " value of 2 can be observed, while during bi-linear flow, a " $n$ " value of 4 can be seen (Kanfar, 2012). Periods of extended bi-linear and linear flow regimes as a result of micro and nano Darcy permeability in shale cause " $n$ " values to be greater than 1 (Joshi, 2012). A cumulative production relationship can also be given by the following (Mishra, 2012):

$$
G_{p}=\frac{q_{i}^{n}}{D_{i}(n-1)}\left(q(t)^{(1-n)}-q_{i}^{(1-n)}\right)
$$


Where:

$$
G_{p}=\text { Cumulative production, volume }
$$

\subsubsection{Power Law Exponential Decline Model (PLE):}

Power Law DCA methods were developed specifically for low permeability reservoirs such as shale (Ilk et al. 2008; Seshadri, 2010). This is accomplished by matching early transient data but not overestimating reserves (Ilk et al. 2008; Seshadri, 2010). By accounting for the change from transient to boundary dominated flow, the PLE model can match many unconventional formations. PLE was developed by Ilk et al. (2008) as a modification of Arps' exponential decline (Seshadri, 2010).

The PLE model,

$$
q=q_{0} \exp \left(-D_{\infty} t-\frac{D_{1}}{n} t^{n}\right)
$$

Where:

$$
\begin{gathered}
q_{0}=\text { intial rate }, \frac{\text { volume }}{\text { time }} \\
D=\text { Arps }^{\prime} \text { decline constant }, 1 / \text { time } \\
D_{\infty}=\text { loss rato at }(t=\infty), 1 / \text { time } \\
D_{1}=\text { loss rato at }(t=1), 1 / \text { time } \\
n=\text { time exponent, dimensionless }
\end{gathered}
$$

During early times, the " $D_{\infty} t$ " term is insignificant. This reduces equation (5) to a power law function which tends to better match early production data. At late times, “ $D_{\infty} t$ " becomes dominant and the model matches the loss ratio of exponential decline. The " $D_{\infty}$ " term sets a limit on the lowest point of decline which prevents reserve overestimation (Seshadri, 2010). No 
cumulative time relation exists for the PLE model because of the introduction of the " $D_{\infty}$ " term (Okouma, 2012).

\subsubsection{Stretched Exponential Decline Model (SEPD):}

First proposed by Valko (2009) and Valko and Lee (2010), the SEPD model was

developed to fit transient flow regimes (Joshi, 2013; Kanfar, 2012). This method has been shown to work well for production data greater than three years in other studies (Joshi, 2013). SEPD does not consider late time behavior like the PLE model (Kanfar, 2012).

The SEPD model,

$$
q=q_{0} \exp \left[-\left(\frac{t}{\tau}\right)^{n}\right]
$$

Where:

$$
\begin{gathered}
q_{0}=\text { intial production rate, } \text { volume } / \text { time } \\
\tau=\left(\frac{n}{D_{1}}\right)^{1 / n}=\text { characteristic time constant, time } \\
n=\text { exponent }, \text { dimensionless }
\end{gathered}
$$

" $\tau$ " and " $n$ " are shape and scale factors, while " $q_{0}$ " signifies the start of the production curve (Joshi, 2013). A cumulative-time relationship is given by:

$$
Q=\frac{q_{0} \tau}{n}\left\{\Gamma\left[\frac{1}{n}\right]-\Gamma\left[\frac{1}{n},\left(\frac{\tau}{n}\right)^{n}\right]\right\}
$$

Where:

$$
Q=\text { cumulative production, volume }
$$




$$
\begin{gathered}
\Gamma\left[\frac{1}{n}\right]=\text { complete gamma function } \\
\Gamma\left[\frac{1}{n},\left(\frac{\tau}{n}\right)^{n}\right]=\text { incomplete gamma function }
\end{gathered}
$$

\subsubsection{Duong Model:}

The basis for the Duong model is that production rate and time would form a straight line, or power law relationship, when plotted on a log-log scale (Kanfar, 2012; Duong 2011). Long duration linear flow is assumed in this model (Joshi, 2013). Two equations are used to calculate the model parameters (Joshi, 2013). Model parameters " $a$ " and " $m$ " are determined using the following equation:

$$
\frac{q}{G_{p}}=a t^{-m}
$$

Where:

$$
\begin{gathered}
q=\text { flowrate, } \text { volume } / \text { time } \\
\qquad G_{p}=\text { cumulative gas production } \\
a=\text { vertical axis intercept of } \log -\log \text { plot of } \frac{q}{G_{p}} \text { vs.t } \\
m=\text { slope of } \log -\log \text { plot of } \frac{q}{G_{p}} \text { vs.t }
\end{gathered}
$$

A plot of " $q$ " versus " $t(a, m)$ " is generated next in order to determine model parameters " $q_{1}$ " and " $q_{\infty} "$, where:

$$
t(a, m)=t^{-m} e^{\frac{a}{1-m}\left(t^{1-m}-1\right)}
$$


After obtaining a straight line for this plot, the slope corresponds to " $q_{1}$ " while the intercept corresponds to " $q_{\infty}$ " (Kanfar, 2012). The production rate equation can now be given as:

$$
q=q_{1} t(a, m)+q_{\infty} \ldots \ldots \ldots .(10)
$$

The " $q_{\infty}$ " term was added to the equation to account for data which did not run through the origin on a plot of " $q$ " versus " $t(a, m)$ ", and can be positive or negative (Kanfar, 2012). A cumulative production formula can be used when " $q_{\infty}$ " is equal to zero (Kanfar, 2012). It is given as:

$$
G_{p}=\frac{q_{1} t(a, m)}{a t^{-m}}
$$

If the above equation (11) is used when " $q_{\infty}$ " is not equal to zero, cumulative production values will be incorrect due to the increasing effect of " $q_{\infty}$ " in the production rate equation (10) at long production times (Kanfar, 2012). 


\section{Objective and Methodology}

\subsection{Objective:}

Two main objectives are contained within the scope of the following analysis.

1) The first is to determine which decline curve analysis model is most appropriate for simulated Marcellus shale data.

2) Using the appropriate DCA method, the second objective is to devise a technique for predicting future Marcellus shale production with limited production history.

\subsection{Methodology:}

The procedure for developing a technique for predicting future production is divided into three steps.

1) Simulate thirty-year production history for a horizontal well completed in a shale formation with seven and thirteen hydraulic fracture stages including and excluding adsorbed using the Eclipse reservoir simulation software, creating four possible reservoir scenarios.

2) Apply Arps, PLE, SEPD, and Duong decline curve analysis methods to the simulated thirty-year production history in order determine which model best fits the entire production history.

3) Apply the decline curve analysis methods to the truncated simulated data and determine DCA model parameters for different of production time.

4) Establish a correlation to predict DCA model parameters for thirty-year production based on the short production history. Use this technique to validate field data. 


\subsubsection{Development of a Marcellus Shale Reservoir Model:}

Generating a production profile to accurately represent production data from the Marcellus shale was accomplished with the use of a commercial reservoir simulator (Eclipse by Schlumberger). Production for a 3000 feet long horizontal well completed in an ultra-low permeability shale formation containing multiple fracture stages was simulated using the dual porosity reservoir model. Table 1 summarizes the basic input into the Eclipse reservoir simulation software. Four thirty-year production profiles were simulated. The first contained seven hydraulic fractures stages (a hydraulic fracture spacing of 500 feet). The second contained thirteen hydraulic fracture stages (a hydraulic fracture spacing of 250 feet). The third and fourth contained seven and thirteen hydraulic fracture stages, respectively, but with the exclusion of adsorbed gas from the model. 
Table 1: Eclipse Basic Model Parameters (Belyadi, 2010)

\begin{tabular}{|c|c|}
\hline \multicolumn{2}{|c|}{ Basic Model Parameters } \\
\hline \multicolumn{2}{|l|}{ Reservoir Parameters } \\
\hline Depth, ft. & 7000 \\
\hline Thickness, ft. & 75 \\
\hline Length, ft. & 4000 \\
\hline Width, ft. & 2000 \\
\hline Initial pressure, psia & 3000 \\
\hline Water saturation, fraction & 0.15 \\
\hline Temperature, ${ }^{\circ} \mathrm{F}$ & 120 \\
\hline \multicolumn{2}{|l|}{ Rock Properties } \\
\hline type & Dual Porosity \\
\hline Fissure Porosity, frac. & 0.005 \\
\hline Matrix Porosity, frac. & 0.05 \\
\hline Fissure perm, $i, j, k$, md & $0.002,0.002,0.0002$ \\
\hline Matrix perm, $i, j, k$, md & $0.0004,0.0004,0.00004$ \\
\hline Fissure Spacing, $\sigma, 1 / \mathrm{ft}^{2}$ & 0.0073 \\
\hline Compressibility, 1/psia & $1 \times 10^{-6}$ \\
\hline Density, $l b / f t^{3}$ & 150 \\
\hline \multicolumn{2}{|l|}{ Hydraulic Fracture Properties } \\
\hline Half length, $f t$. & 500 \\
\hline Width, in & 0.01 \\
\hline Top of Fracture, $f t$. & 7000 \\
\hline Bottom of Fracture, ft. & 7075 \\
\hline Permeability, md & 2000 \\
\hline Porosity, fraction & 0.2 \\
\hline Number of fracture stages & 7,13 \\
\hline Stage Spacing, ft. & 500,250 \\
\hline \multicolumn{2}{|l|}{ Well Production Controls } \\
\hline$P_{w f,} p s i a$ & 500 \\
\hline \multicolumn{2}{|l|}{ Adsorption } \\
\hline Diffusion Coefficient, $f t^{2} /$ day & 1 \\
\hline Sorption Time, day & 62 \\
\hline Langmuir Pressure, psia & 635 \\
\hline Langmuir Concentration, MSCF/ton & 0.08899 \\
\hline
\end{tabular}




\subsubsection{Application of Decline Curve Analysis Techniques to Simulated Data:}

The Arps, PLE, SEPD, and Duong methods were first applied to all four sets of simulated Marcellus shale production profiles. Each of the four scenarios was evaluated for applicability by using the nonlinear-regression method in Microsoft Excel as proposed by Towler (2002). A spreadsheet was set up containing cells for each parameter of every DCA model. For every model, a column with the appropriate production rate equation, $q^{\prime}$, the errors squared, $\left(q-q^{\prime}\right)^{2}$, and total errors squared, $\left(q-q_{\text {average }}\right)^{2}$, was then generated, where " $q$ " corresponds to the flow rate from simulated production data. A cell for the sum of errors squared, $S_{\mathrm{SE}}$, and total errors squared, $S_{\mathrm{ST}}$, was also created. The regression coefficient was also generated in a cell by using the following formula:

$$
R^{2}=1-\frac{S_{S E}}{S_{S T}}
$$

By using Microsoft Excel's built-in Solver function and setting the objective cell containing $R^{2}$ equal to one while changing the appropriate variable cells for each DCA model, the best fit to simulated production data could be obtained.

\subsubsection{Application of Selected DCA Models to Varying Simulated Production Times:}

The simulated production profiles for each case were truncated at different production times to generate a series of production profiles with limited production history. Using the DCA models from step two, the model constants for the production profiles with production times of two, three, four, five, seven, ten, fifteen, twenty, twenty-five, and thirty years were estimated. Tables for each DCA model constant were then compiled to study the trend of each constant as a function of production time. Finally, a predictive method was established to estimate long-term DCA model constants from the constant obtained using the limited production history. 


\subsubsection{Validation Against Field Data:}

After obtaining results with simulated data, it becomes necessary to confirm results with actual field data. Using field data extends the application of the procedure outlined thus far. Marcellus well production history is not readily available with detailed information on fracture spacing. Utilizing an actual Marcellus horizontal well containing seven or thirteen fracture stages would be optimal. However, this data was not available or known to exist. To accomplish this task, data from a well in Upshur County, West Virginia (Well 1), API number 4709703527, was used containing 4.274 years of production history and eight fracture stages. Well 1 is 3000 feet in horizontal length, thus having a fracture spacing of 429 feet. It is assumed that the reservoir from which Well 1 is producing has adsorbed gas, as this is common in the Marcellus shale. Therefore, only comparisons to the adsorbed gas scenarios from above of seven and thirteen fractures will be shown (500 feet and 250 feet hydraulic fracture spacing, respectively).

Well 1 data was history matched with a dual porosity model using Eclipse in order to determine production at points in time beyond 4.274 years. Well 1 production and the corresponding Eclipse history match can be seen in Figure 1, Figure 2, and Figure 3. 


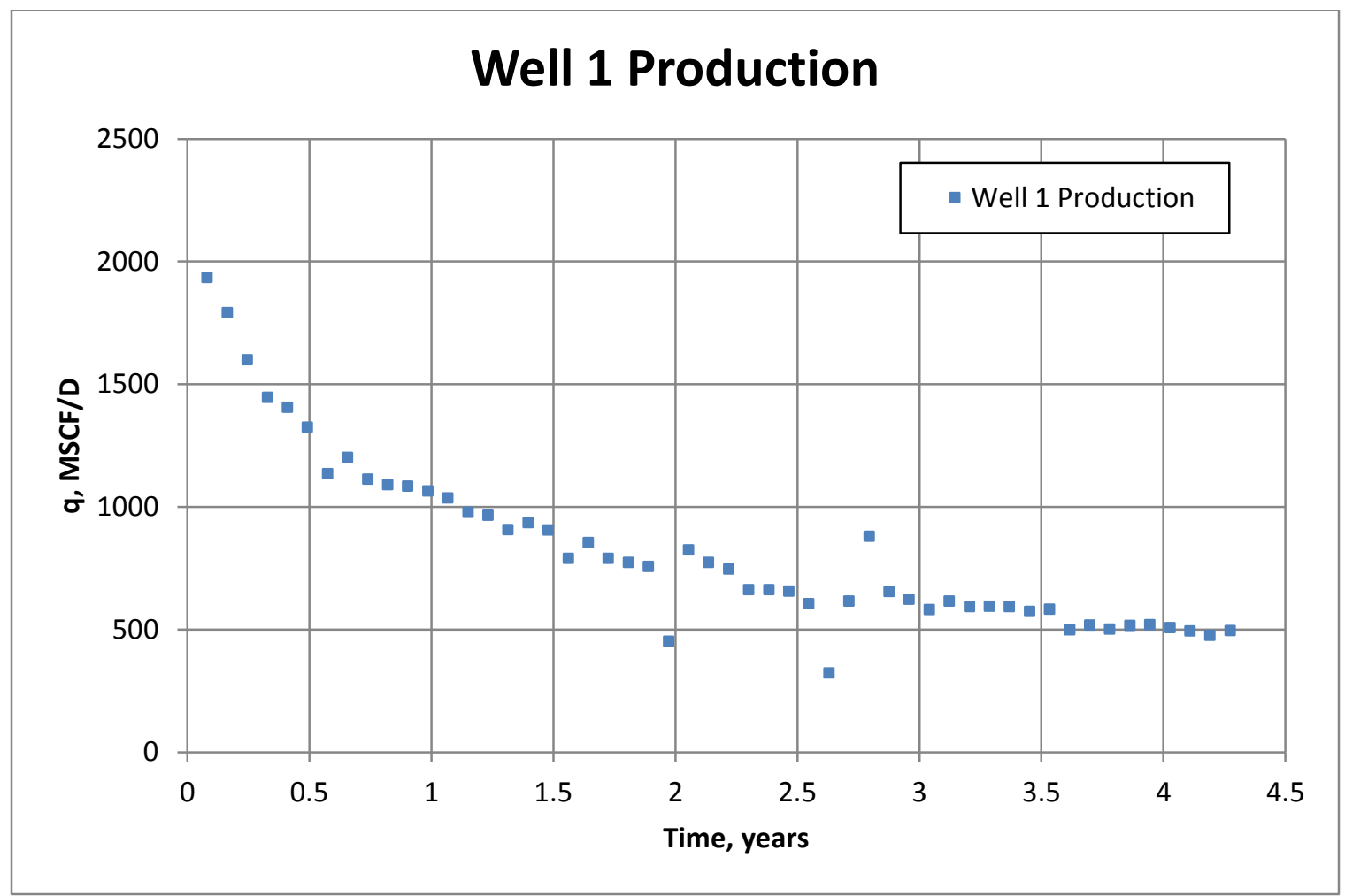

Figure 1: Well 1 Production

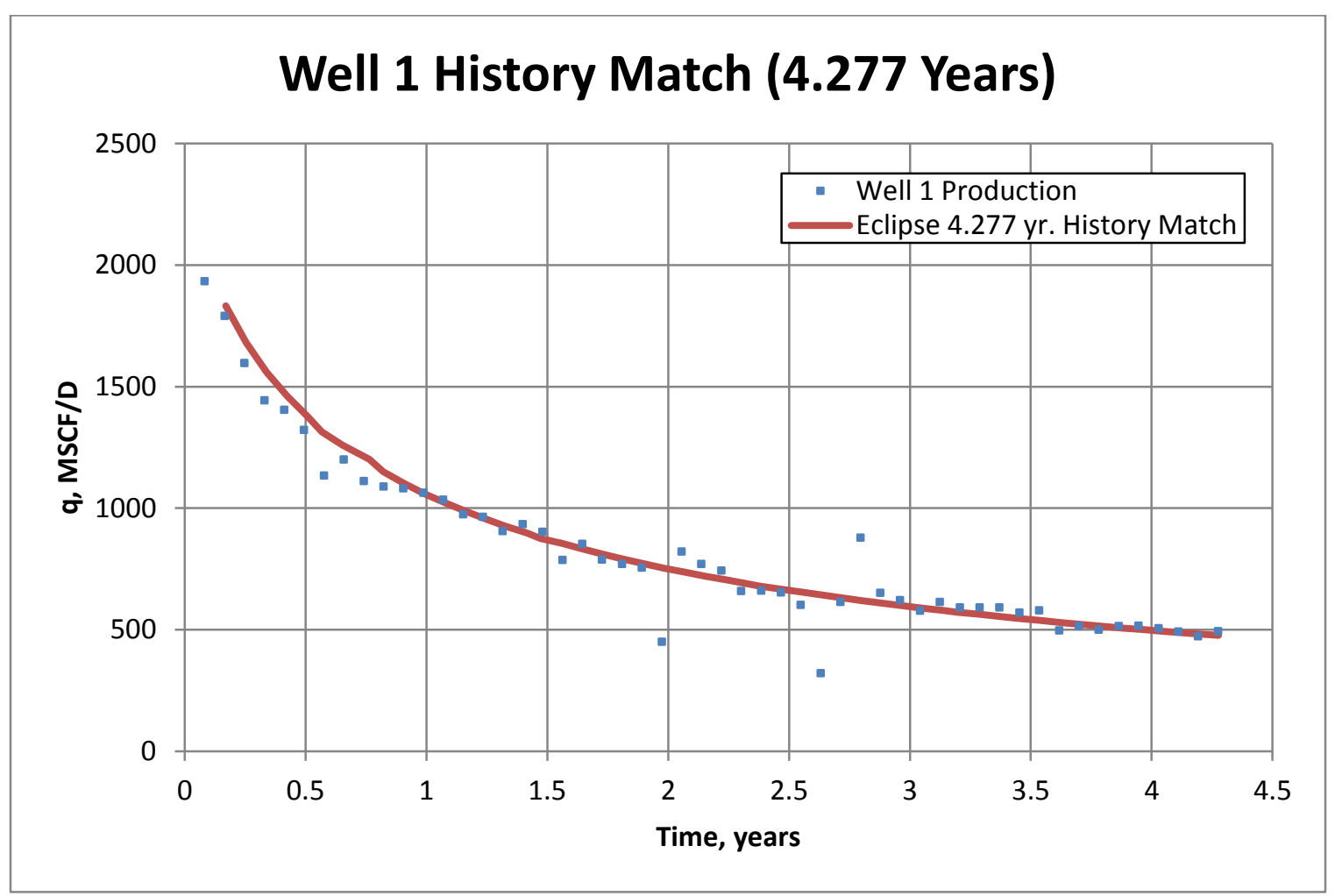

Figure 2: Well 1 History Match (4.277 Years) 


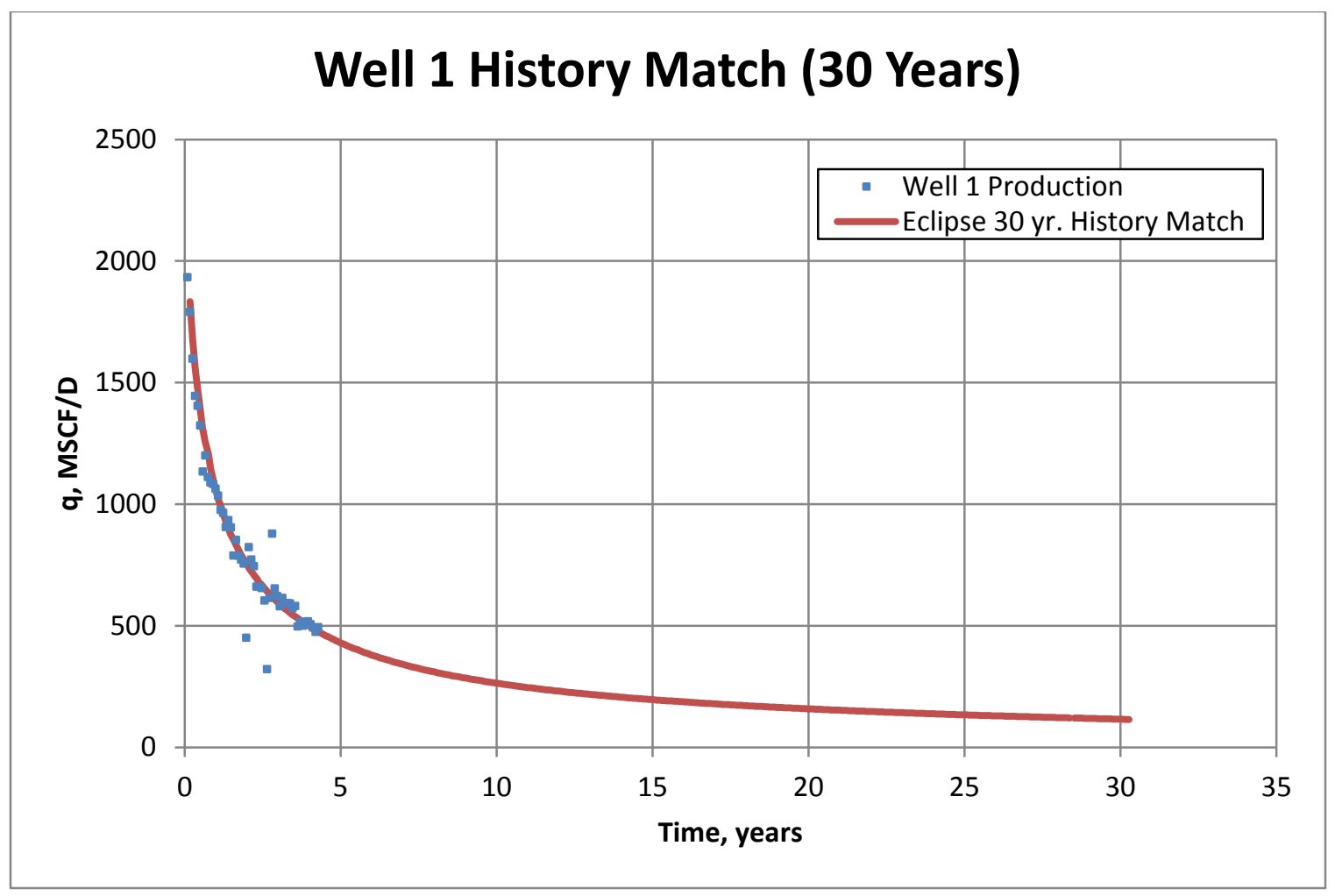

Figure 3: Well 1 History Match (30 Years) 


\section{Results and Discussion}

\subsection{Development of a Marcellus Shale Reservoir Model:}

Data generated from Eclipse for the four scenarios is shown below in Figure 4, Figure 5,

Figure 6, and Figure 7. Matching DCA models for each scenario are shown in section 4.2.

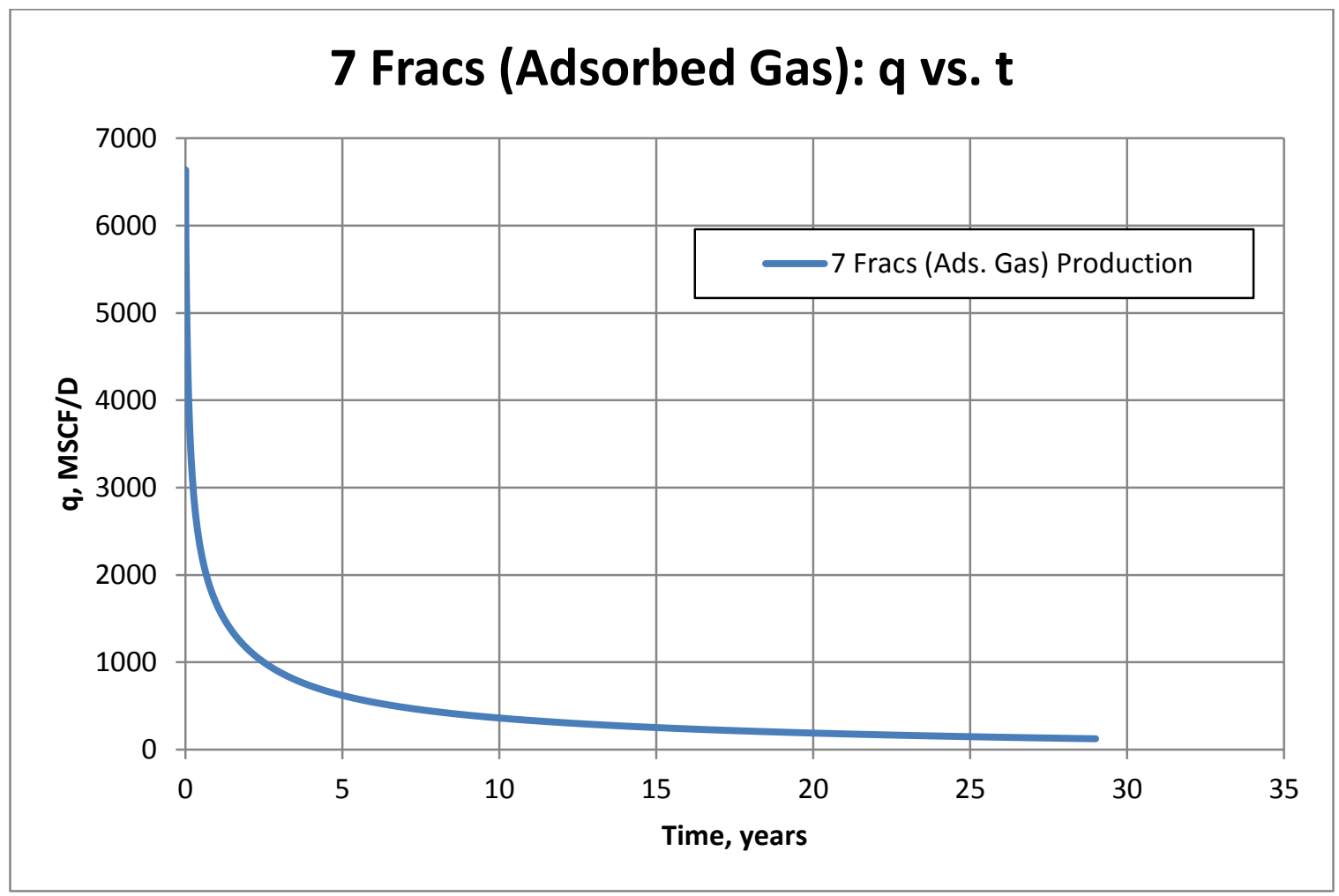

Figure 4: 7 Fracs (Adsorbed Gas): q vs. $t$ 


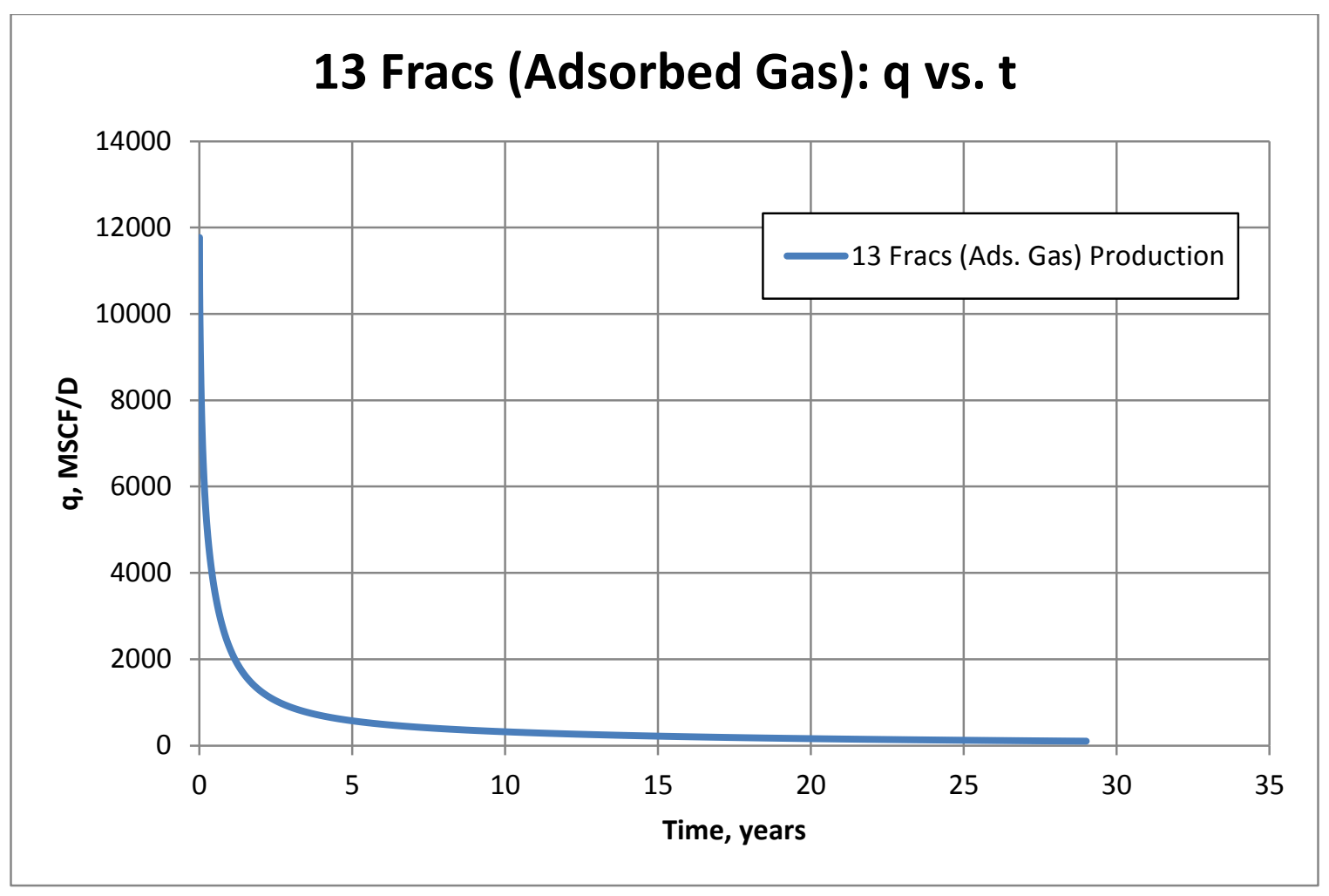

Figure 5: 13 Fracs (Adsorbed Gas): q vs. t

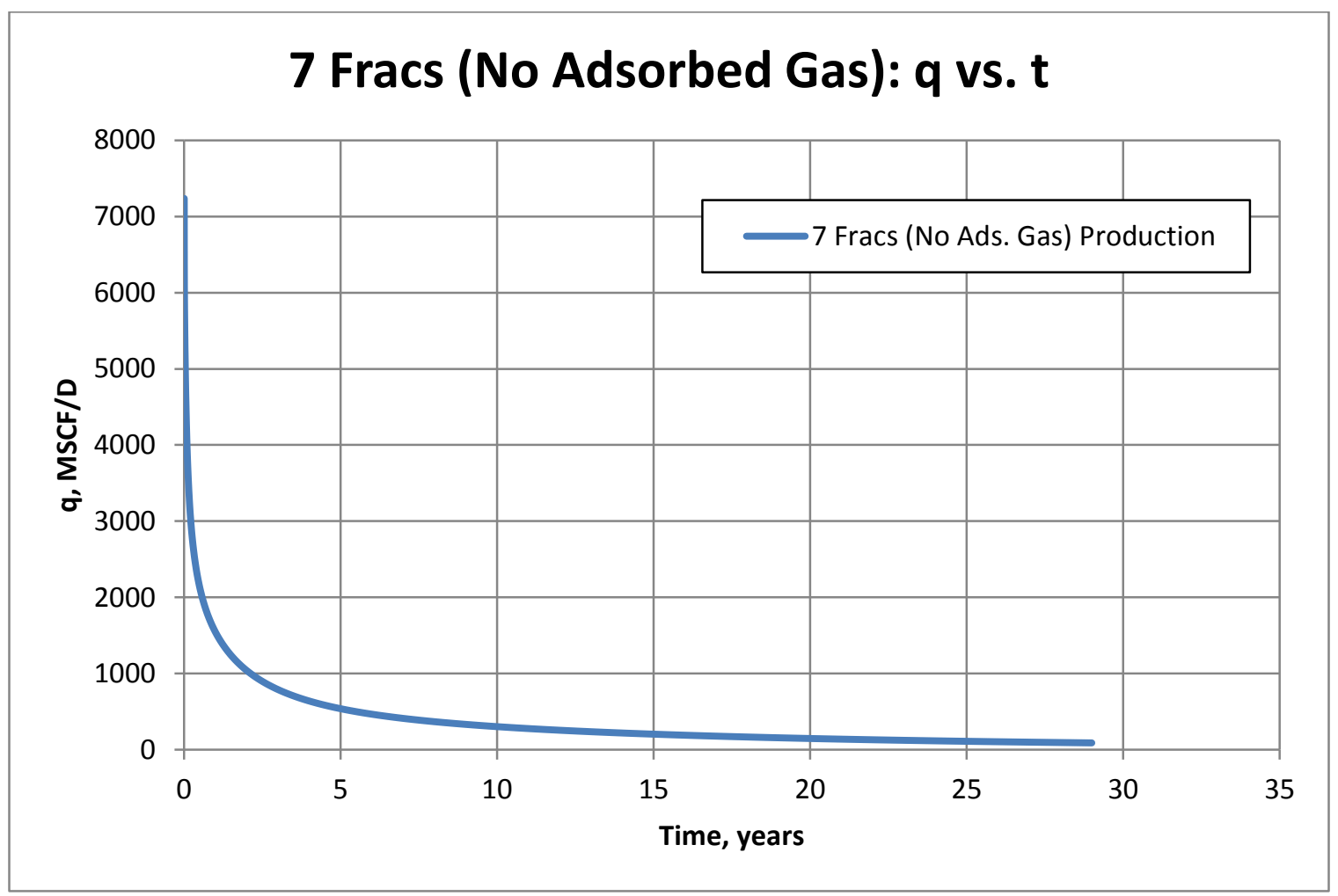

Figure 6: 7 Fracs (No Adsorbed Gas): q vs. t 


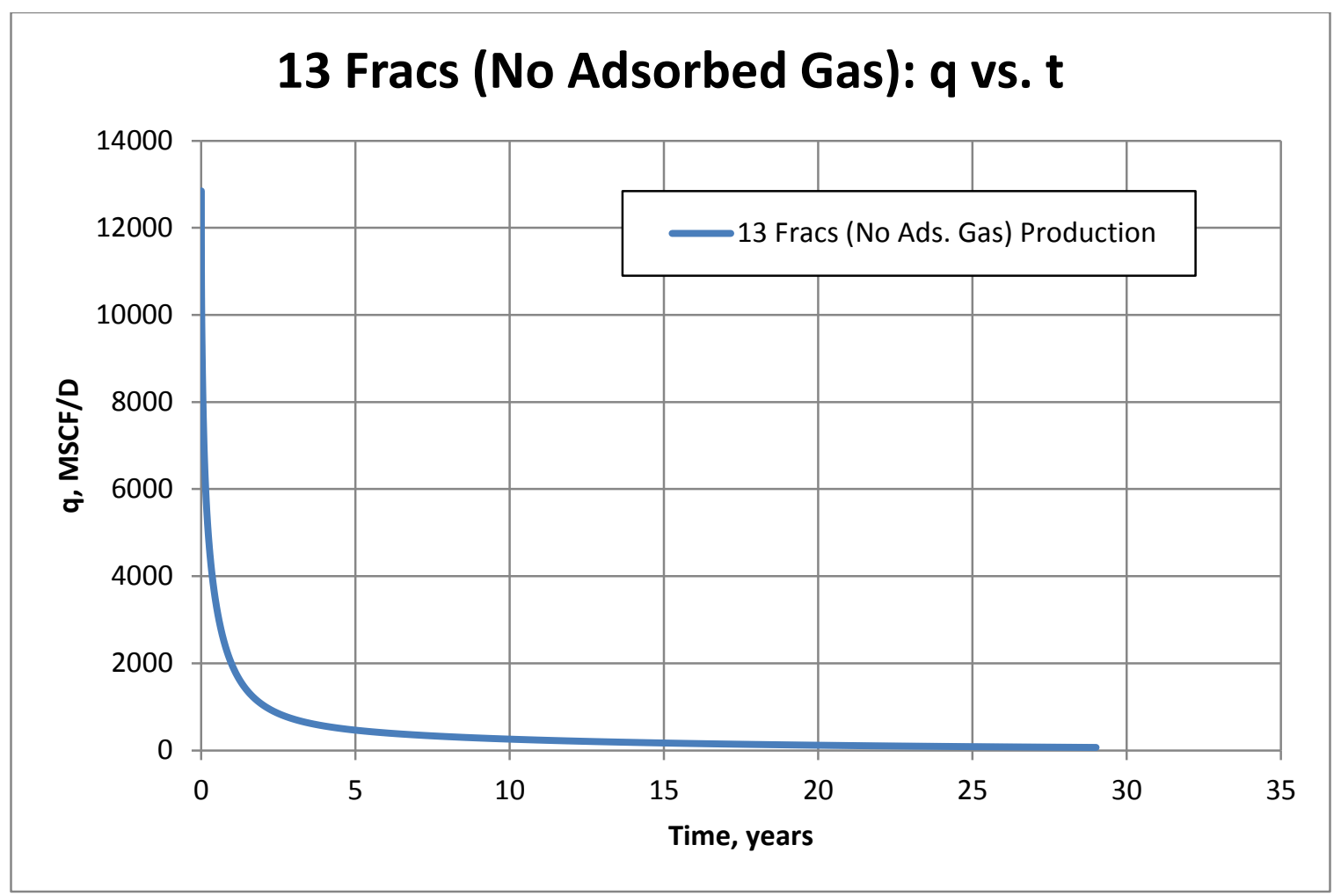

Figure 7: 13 Fracs (No Adsorbed Gas): q vs. t

\subsection{Application of Decline Curve Analysis Techniques to Simulated Data:}

After generating data from Eclipse and plotting the flow rate as a function of time, appropriate DCA models could be applied to the simulator results. The methodology described above was utilized in generating a comparison between the simulator and DCA model. Matching the appropriate DCA model to all simulated data yielded the results shown below seven fractures with gas adsorption as shown in Figure 8 through Figure 10. A detailed comparison can be seen in Figure 11 through Figure 15. DCA models applied to thirteen fractures having adsorbed gas can be seen in Figure 16 through Figure 18, while a detailed comparison can be seen in Figure 19 through Figure 23. Seven fractures having no adsorbed gas DCA matches can be seen in Figure 24 through Figure 26, while a detailed comparison can be seen in Figure 27 through Figure 31. 
Finally, thirteen fractures having no adsorbed gas DCA matches can be seen in Figure 32 through Figure 34, while a detailed comparison can be seen in Figure 35 through Figure 39.

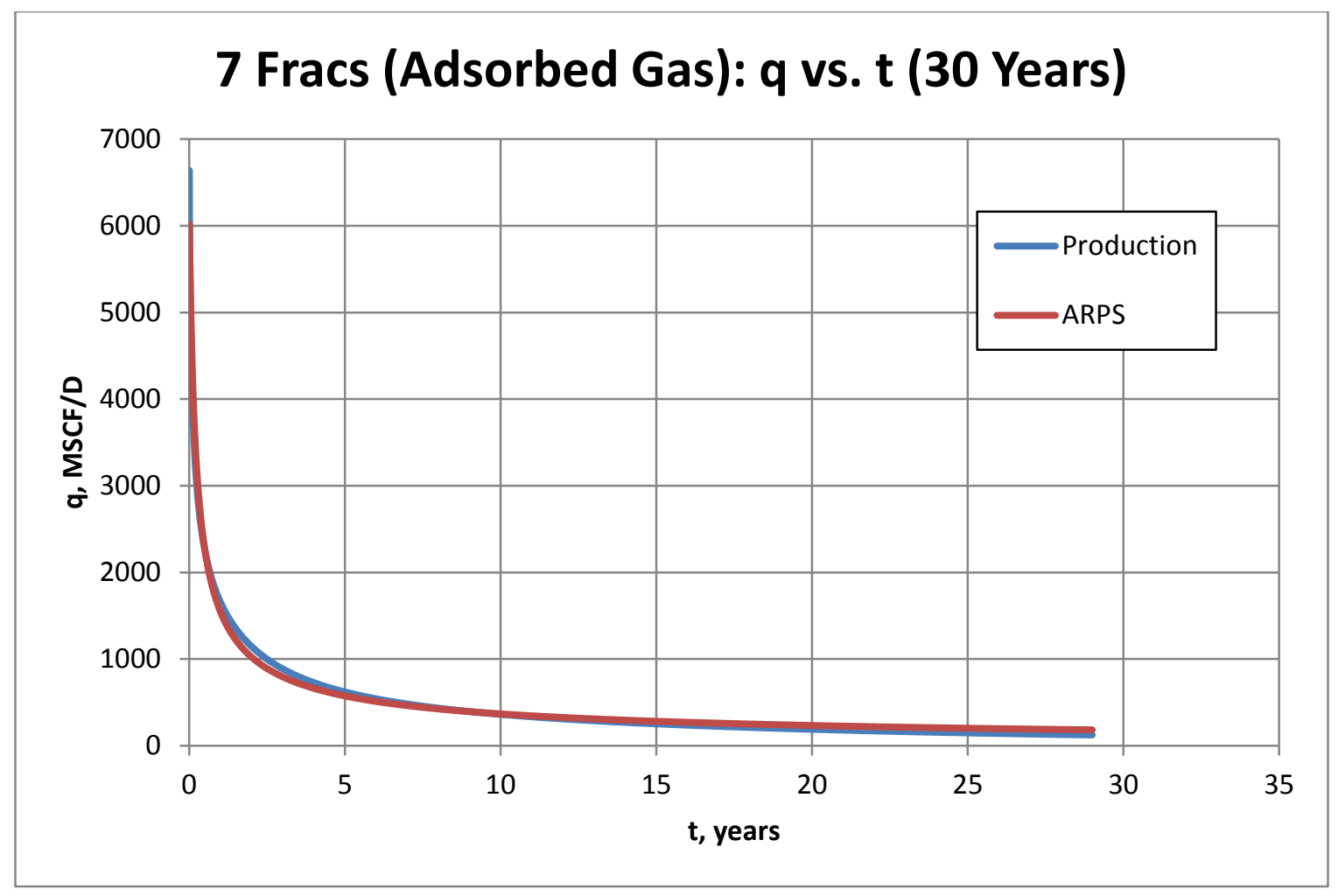

Figure 8: 7 Fracs (Ads. Gas) Arps q vs. t (30 Years) 


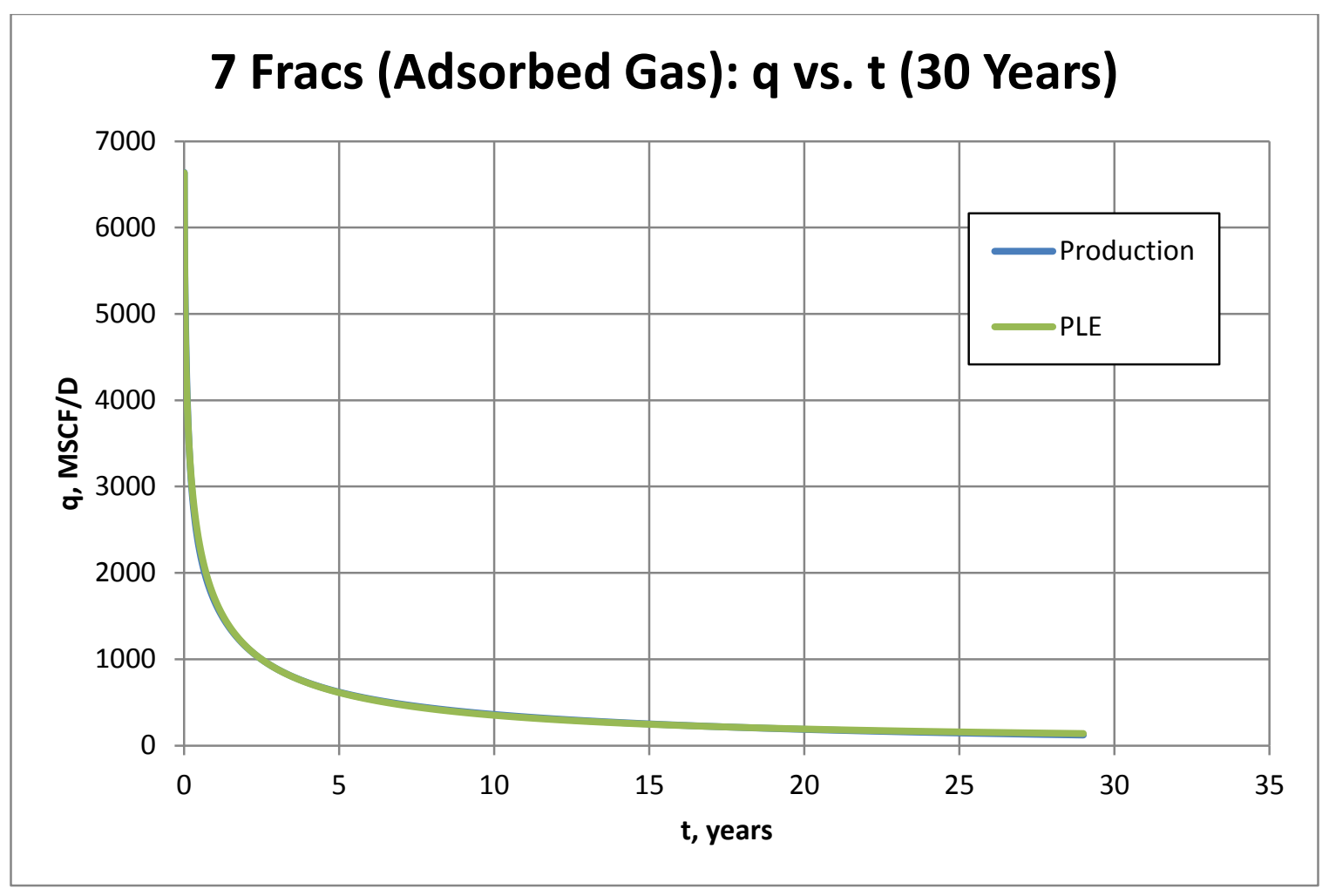

Figure 9: 7 Fracs (Ads. Gas) PLE q vs. t (30 Years)

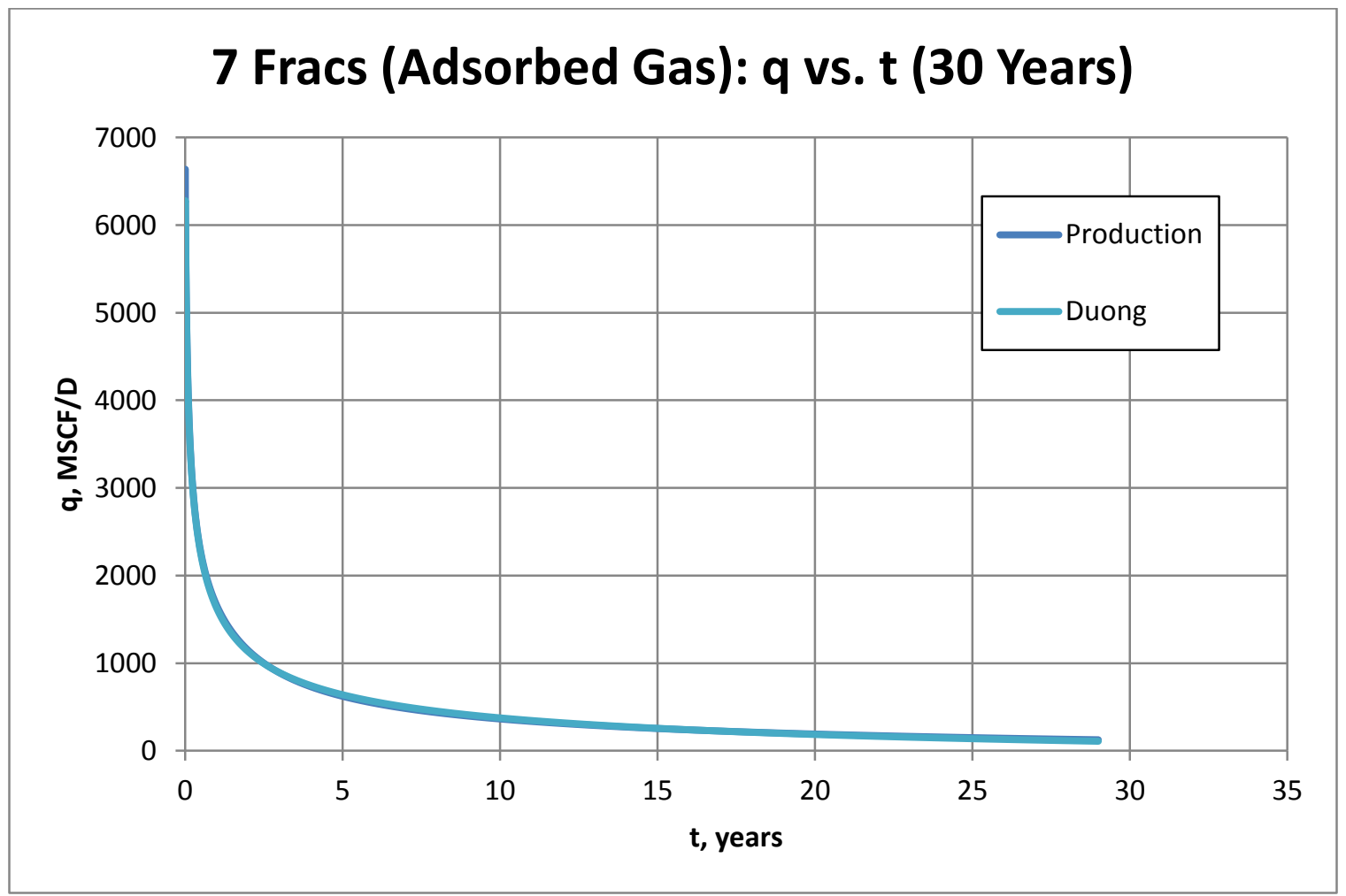

Figure 10: 7 Fracs (Ads. Gas) Duong q vs. t (30 Years) 


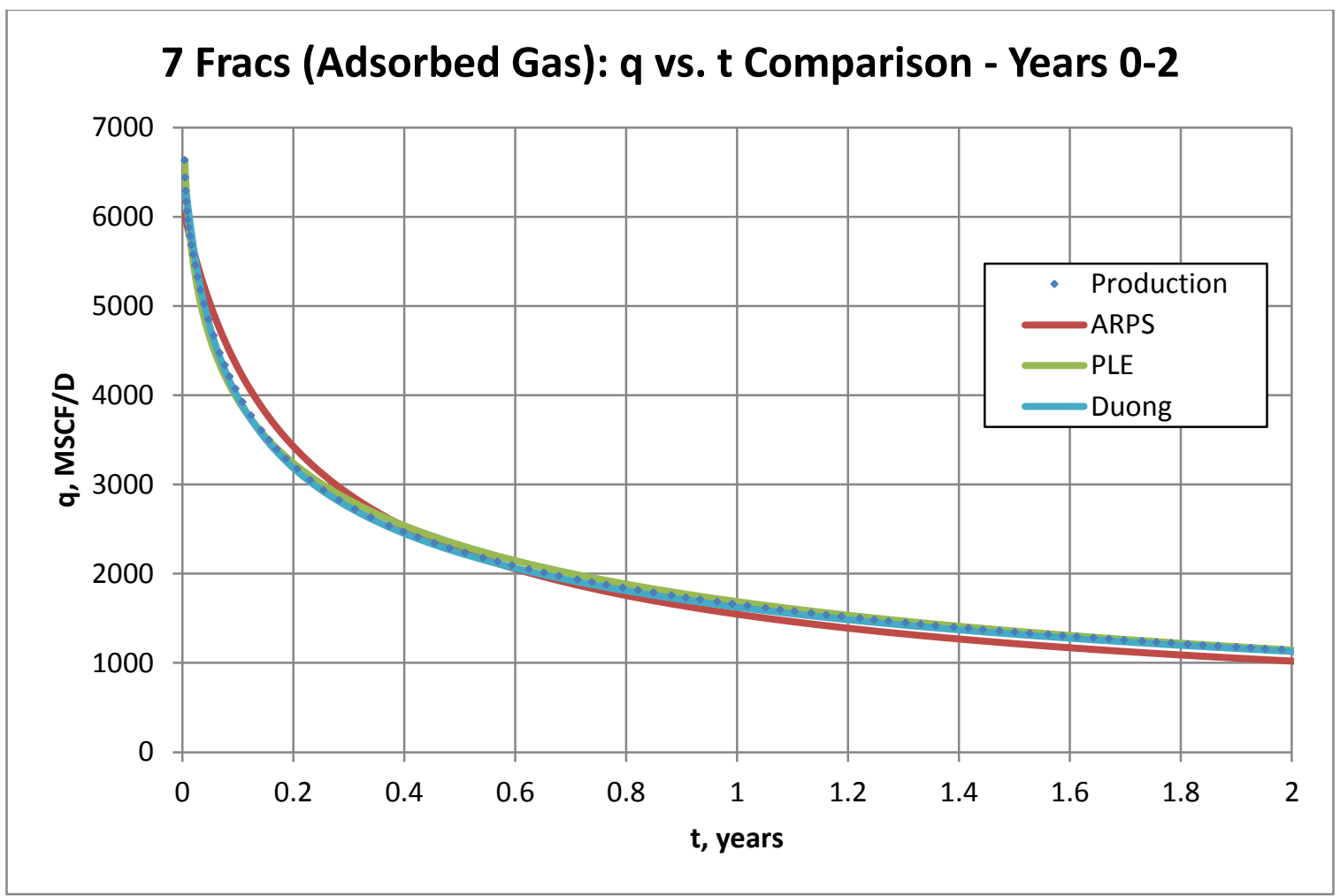

Figure 11: 7 Fracs (Ads. Gas) q vs. t Comparison - Years 0-2

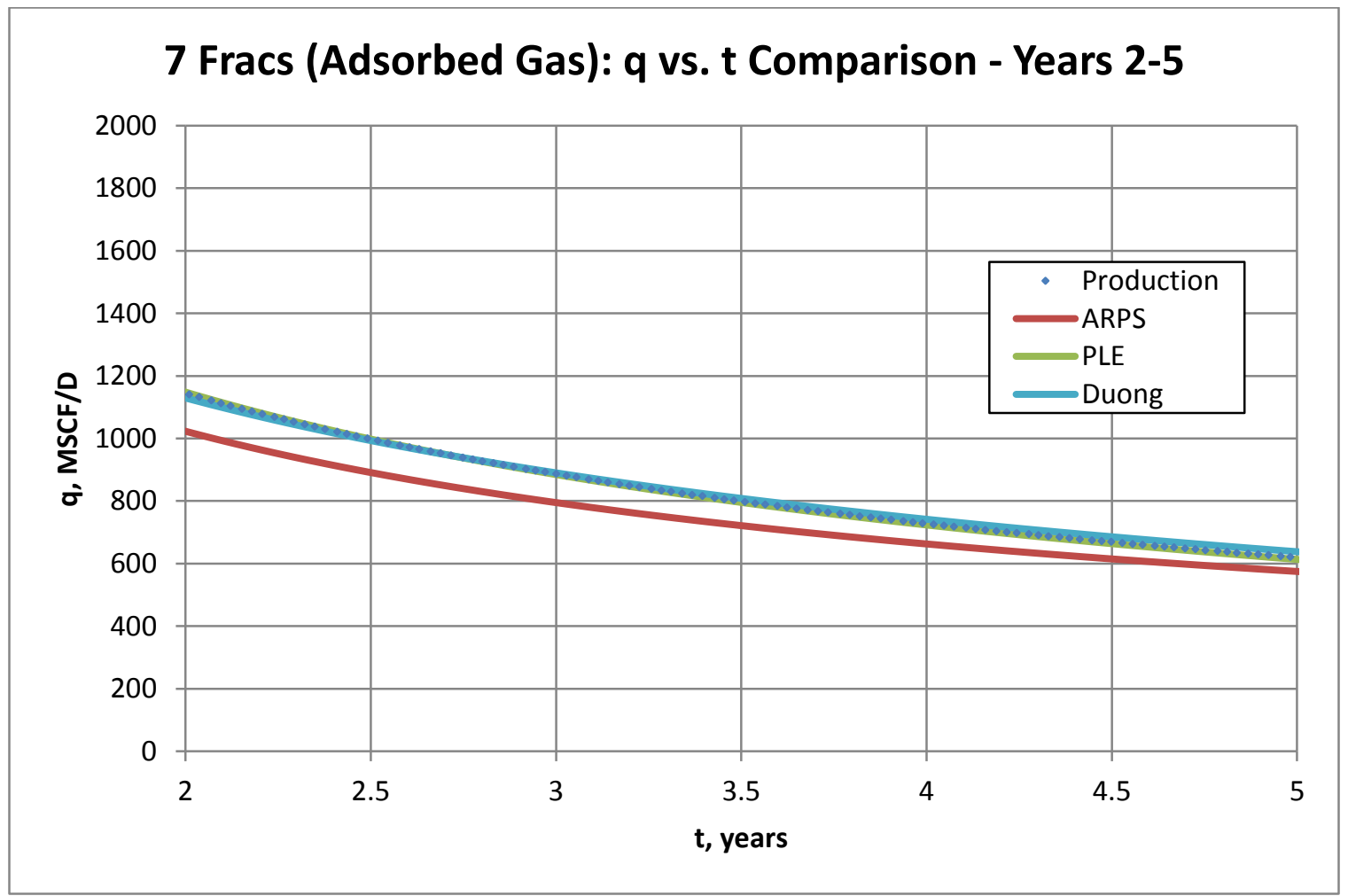

Figure 12: 7 Fracs (Ads. Gas) q vs. t Comparison - Years 2-5 


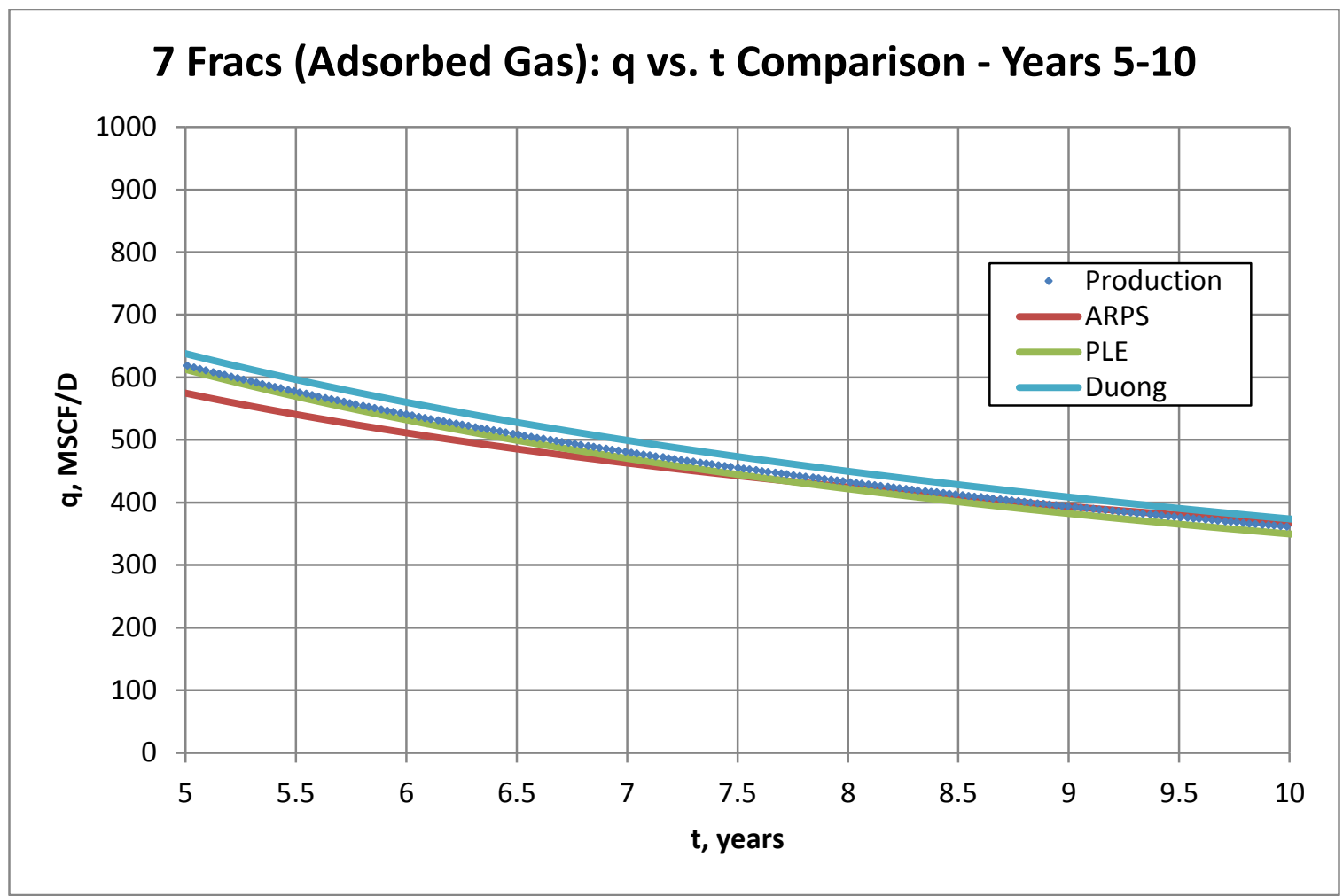

Figure 13: 7 Fracs (Ads. Gas) q vs. t Comparison - Years 5-10

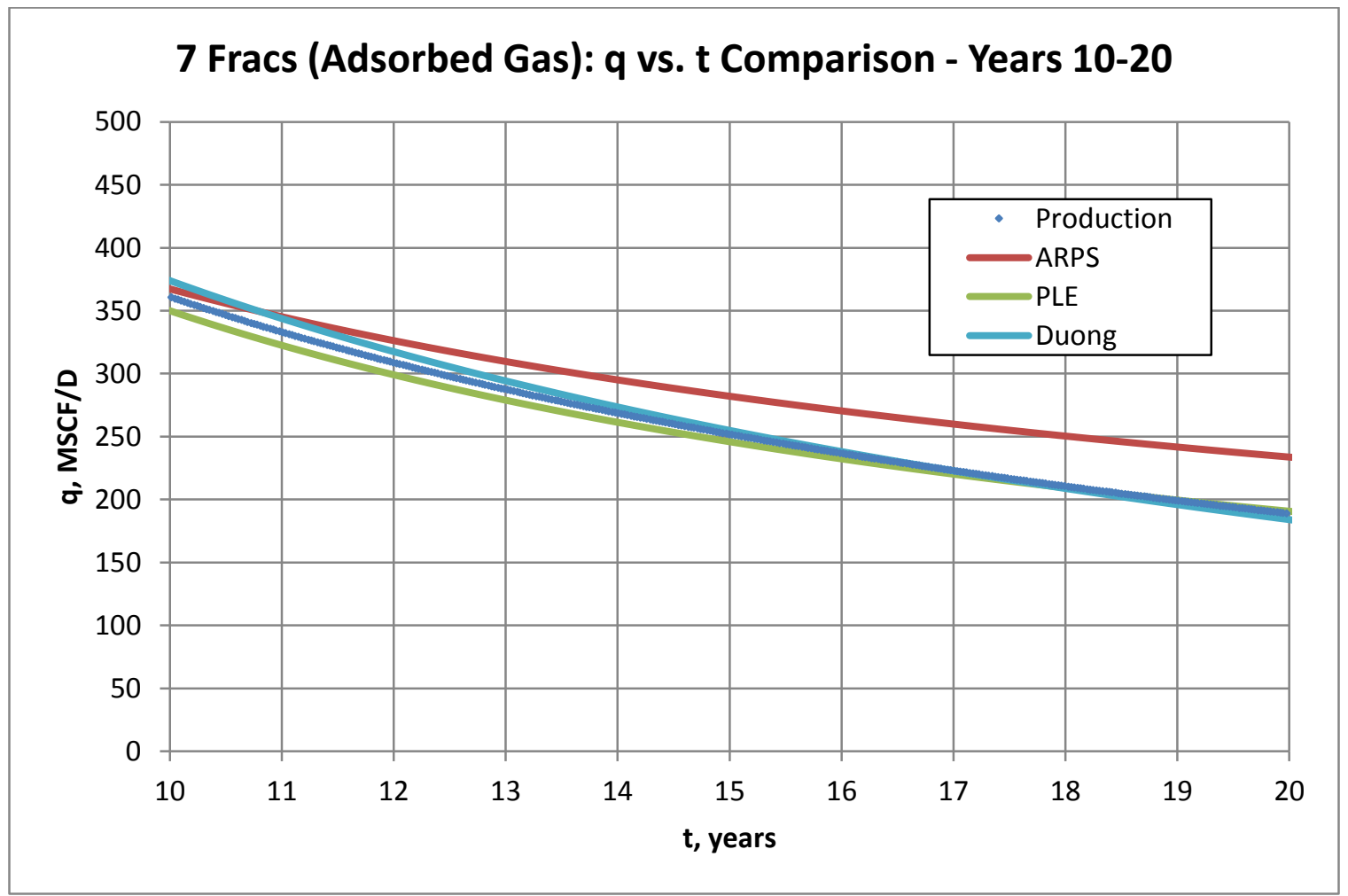

Figure 14: 7 Fracs (Ads. Gas) q vs. t Comparison - Years 10-20 


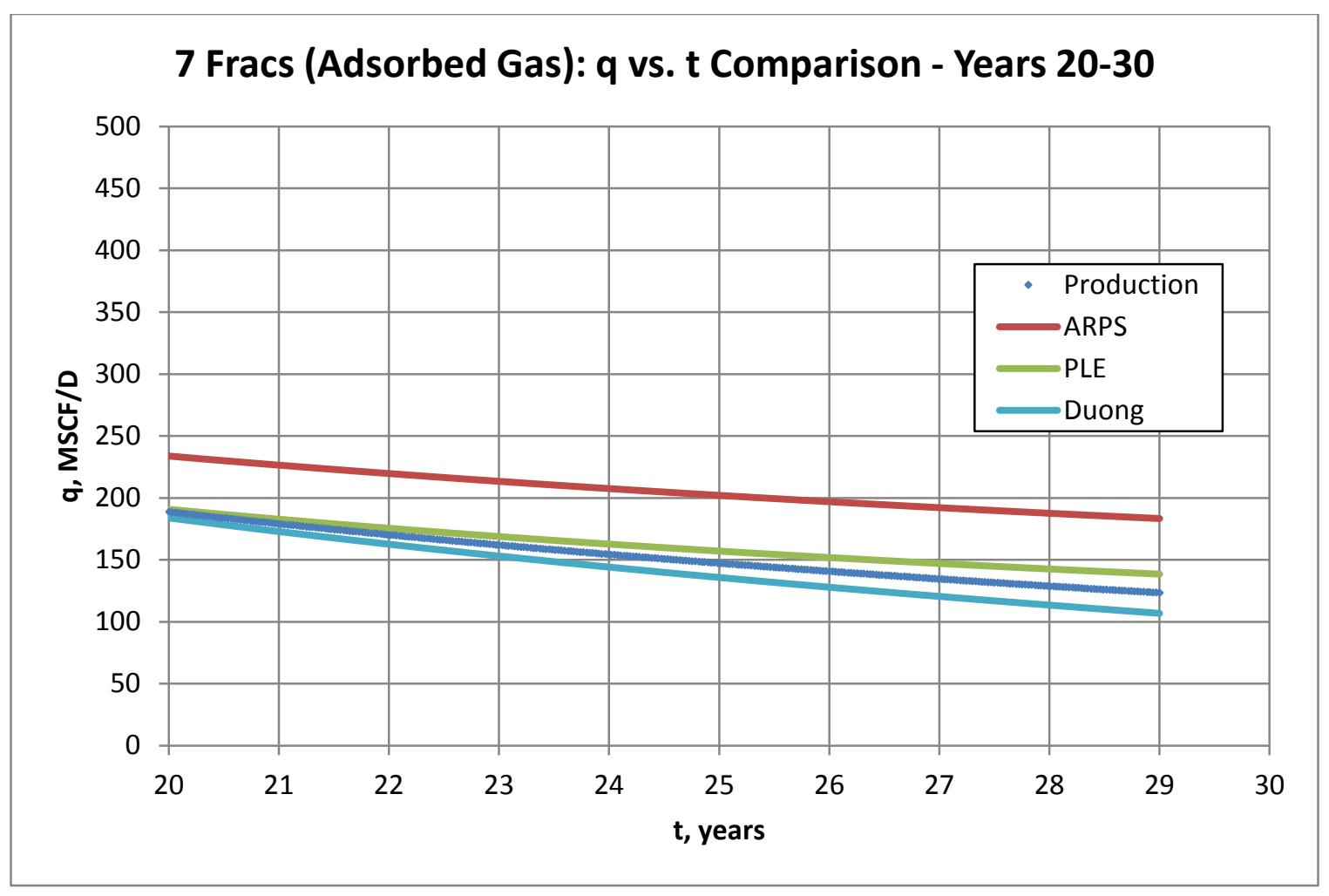

Figure 15: 7 Fracs (Ads. Gas) q vs. t Comparison - Years 20-30

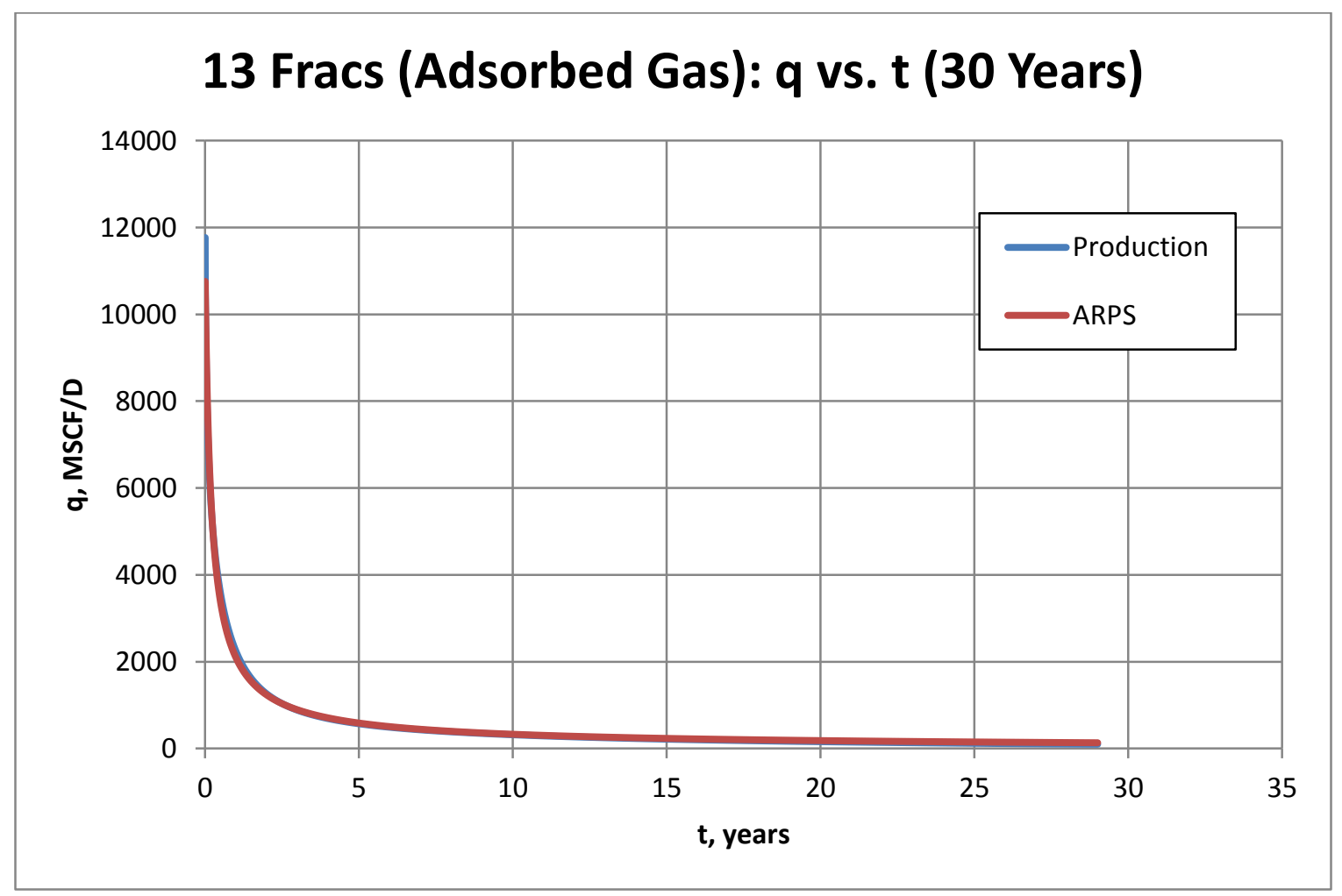

Figure 16: 13 Fracs (Ads. Gas) Arps q vs. t (30 Years) 


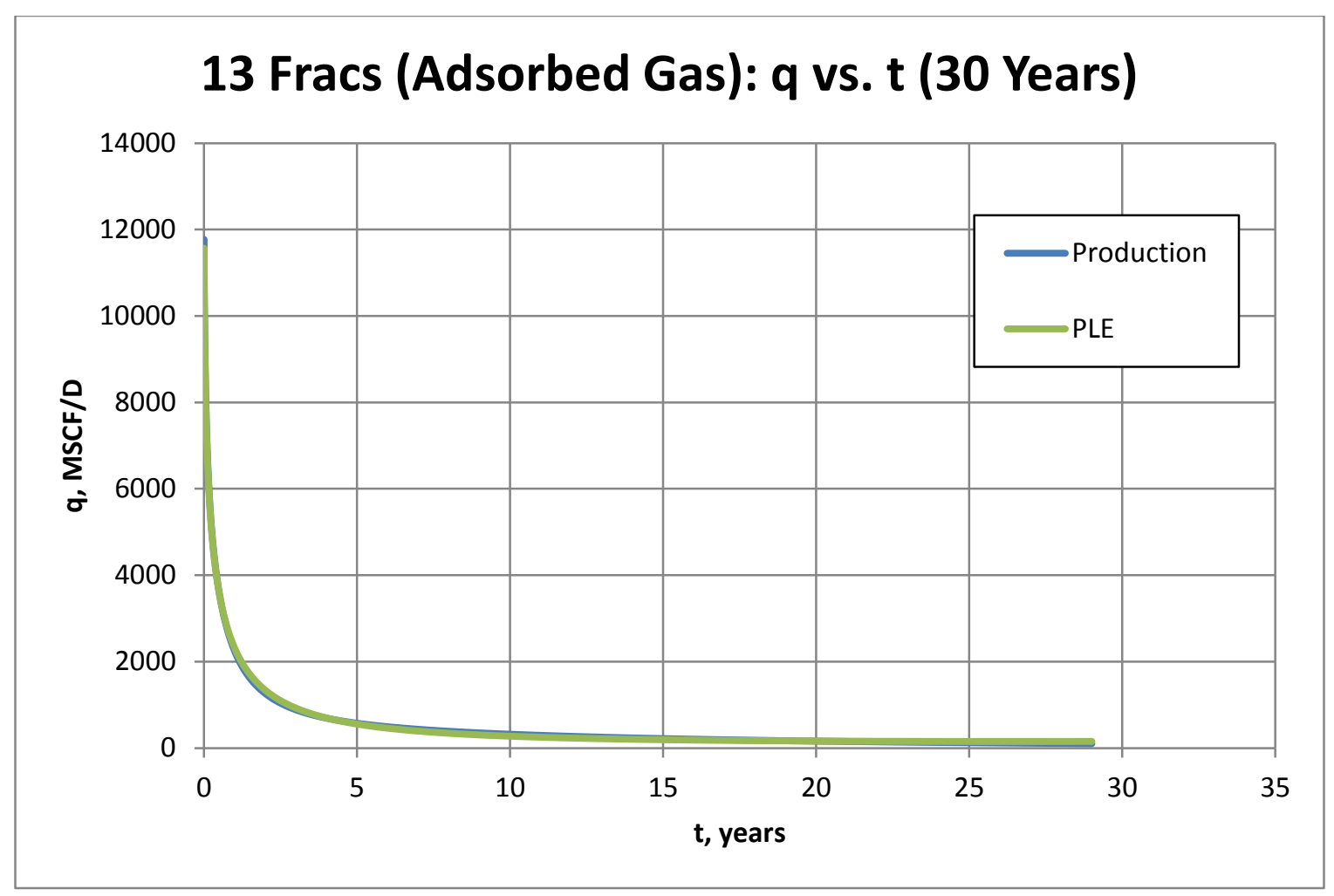

Figure 17: 13 Fracs (Ads. Gas) PLE q vs. t (30 Years)

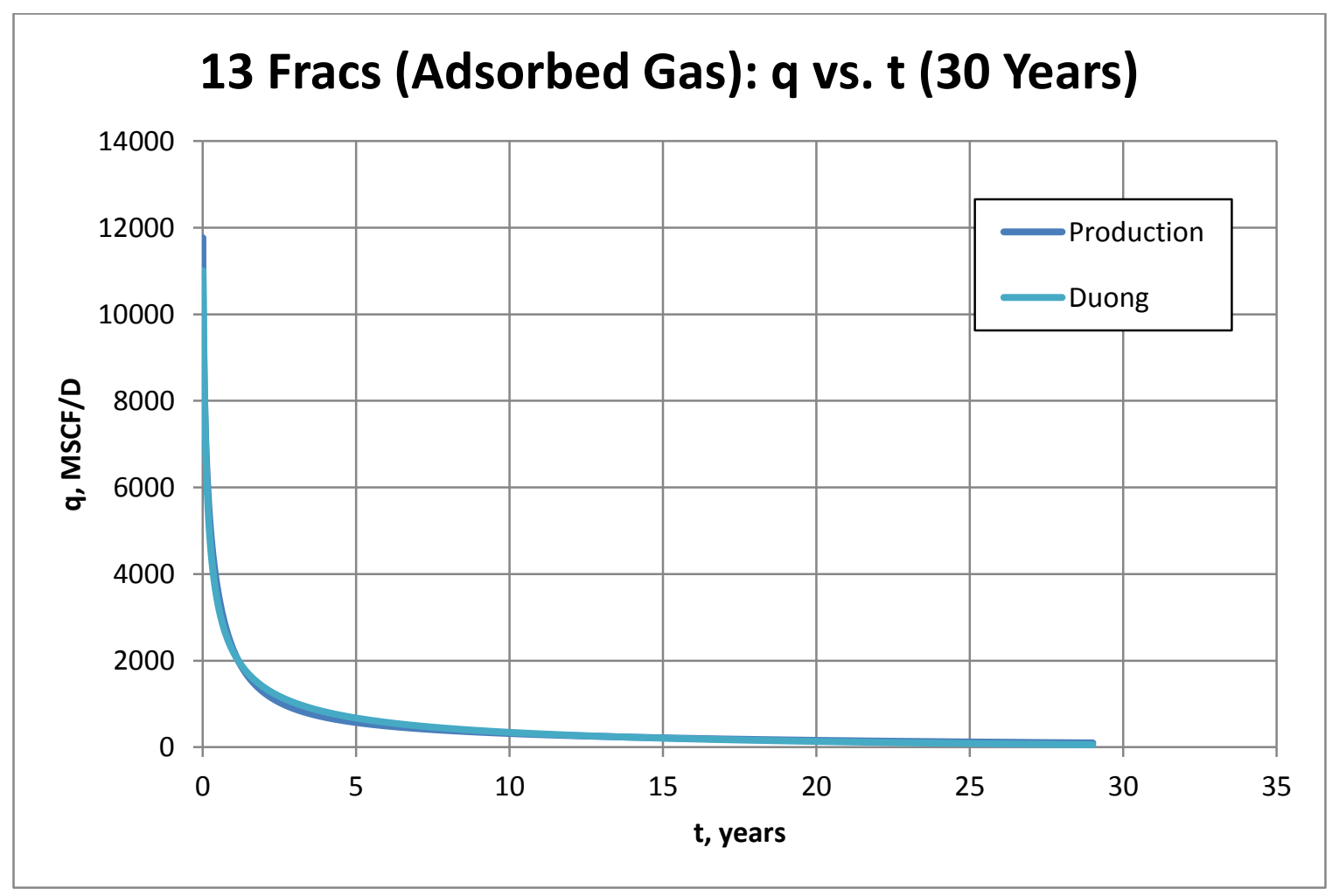

Figure 18: 13 Fracs (Ads. Gas) Duong q vs. t (30 Years) 


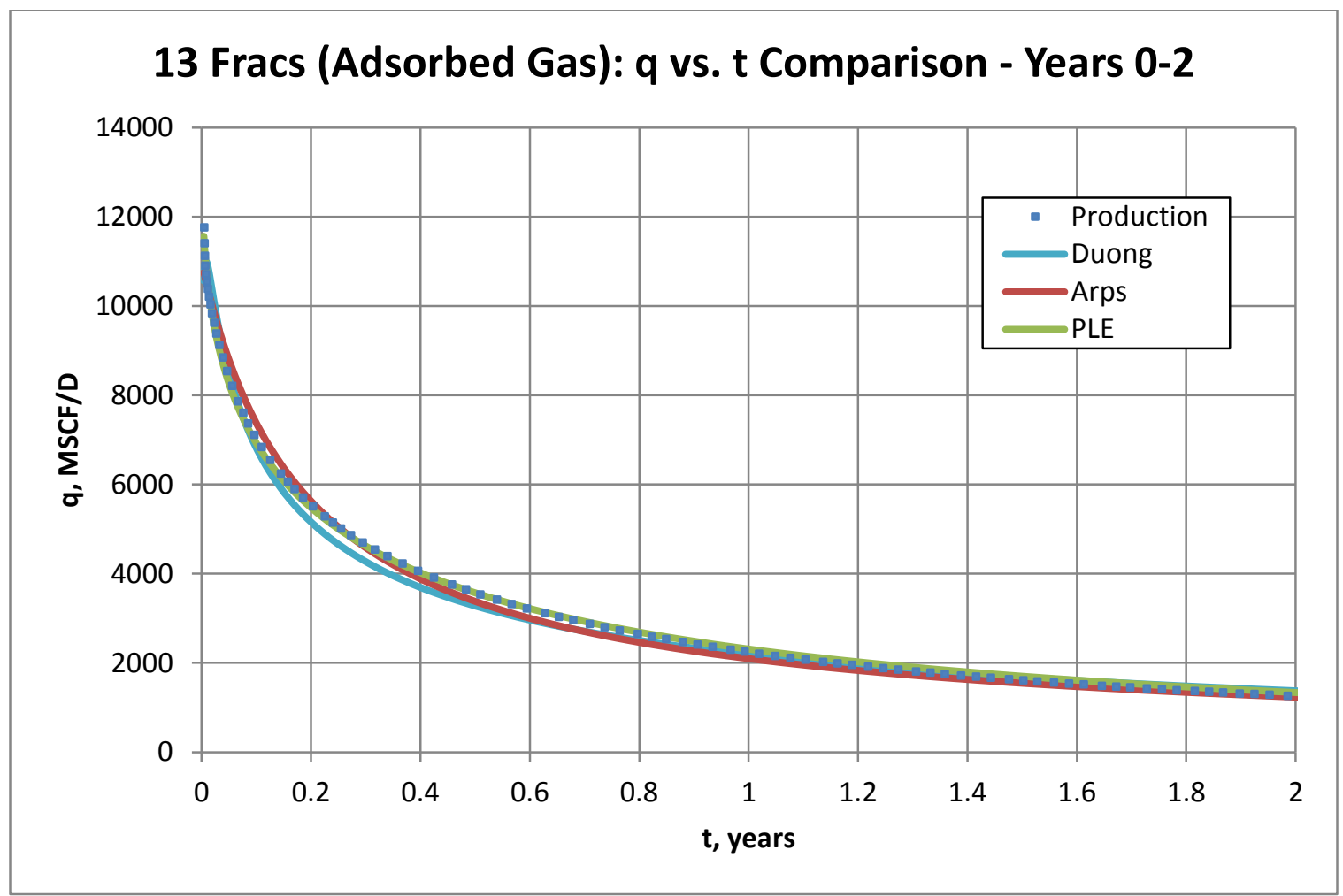

Figure 19: 13 Fracs (Ads. Gas) q vs. t Comparison - Years 0-2

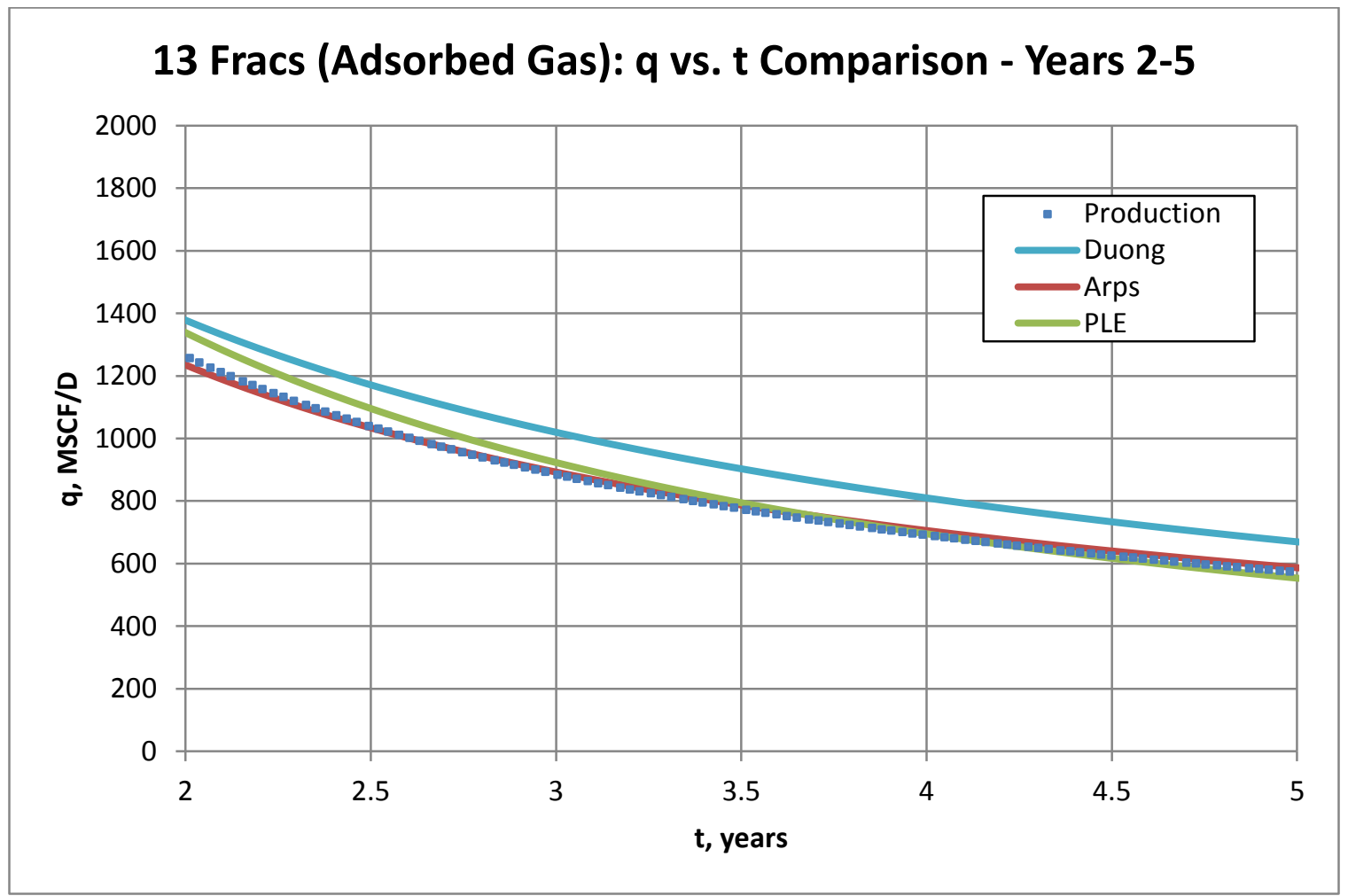

Figure 20: 13 Fracs (Ads. Gas) q vs. t Comparison - Years 2-5 


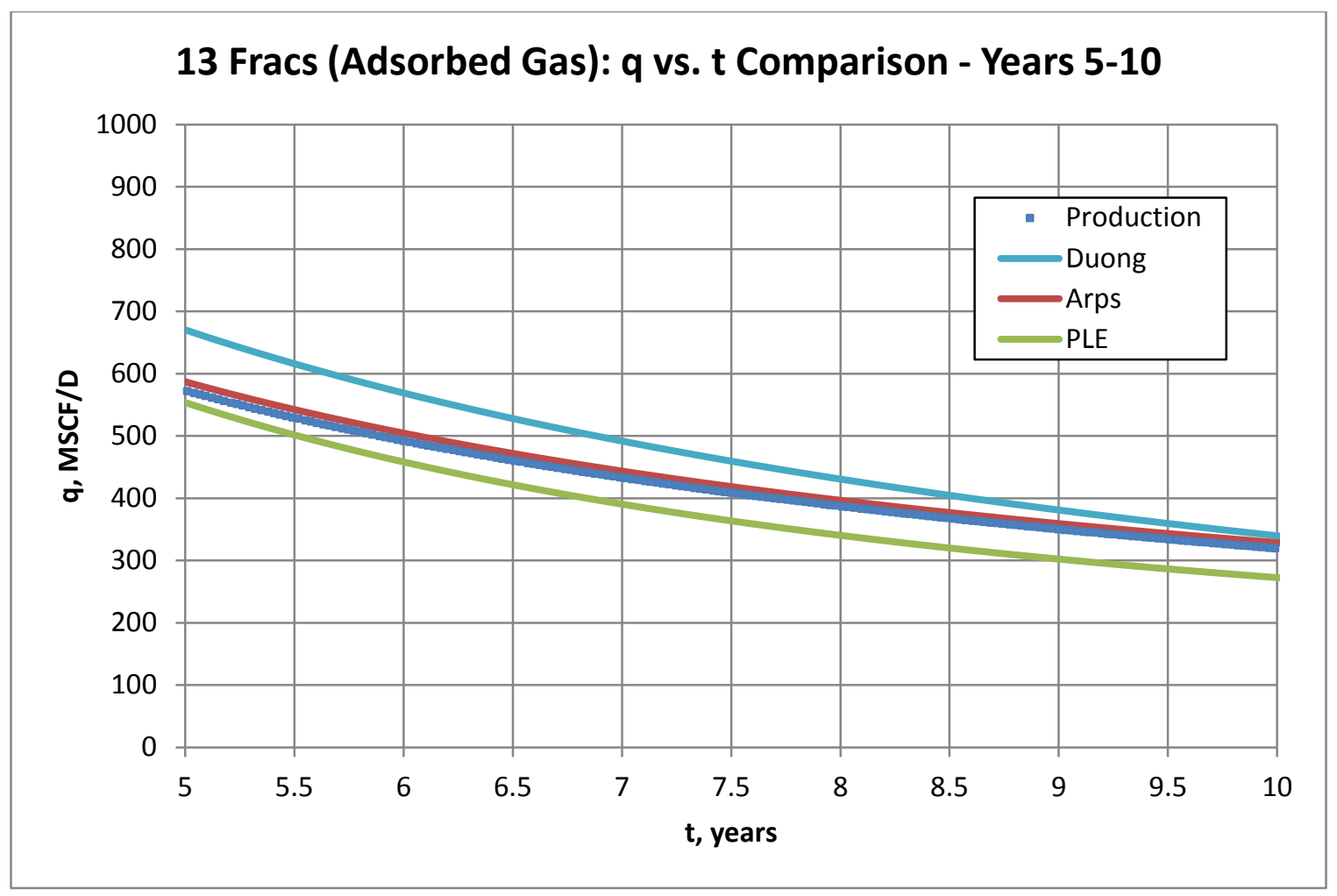

Figure 21: 13 Fracs (Ads. Gas) q vs. t Comparison - Years 5-10

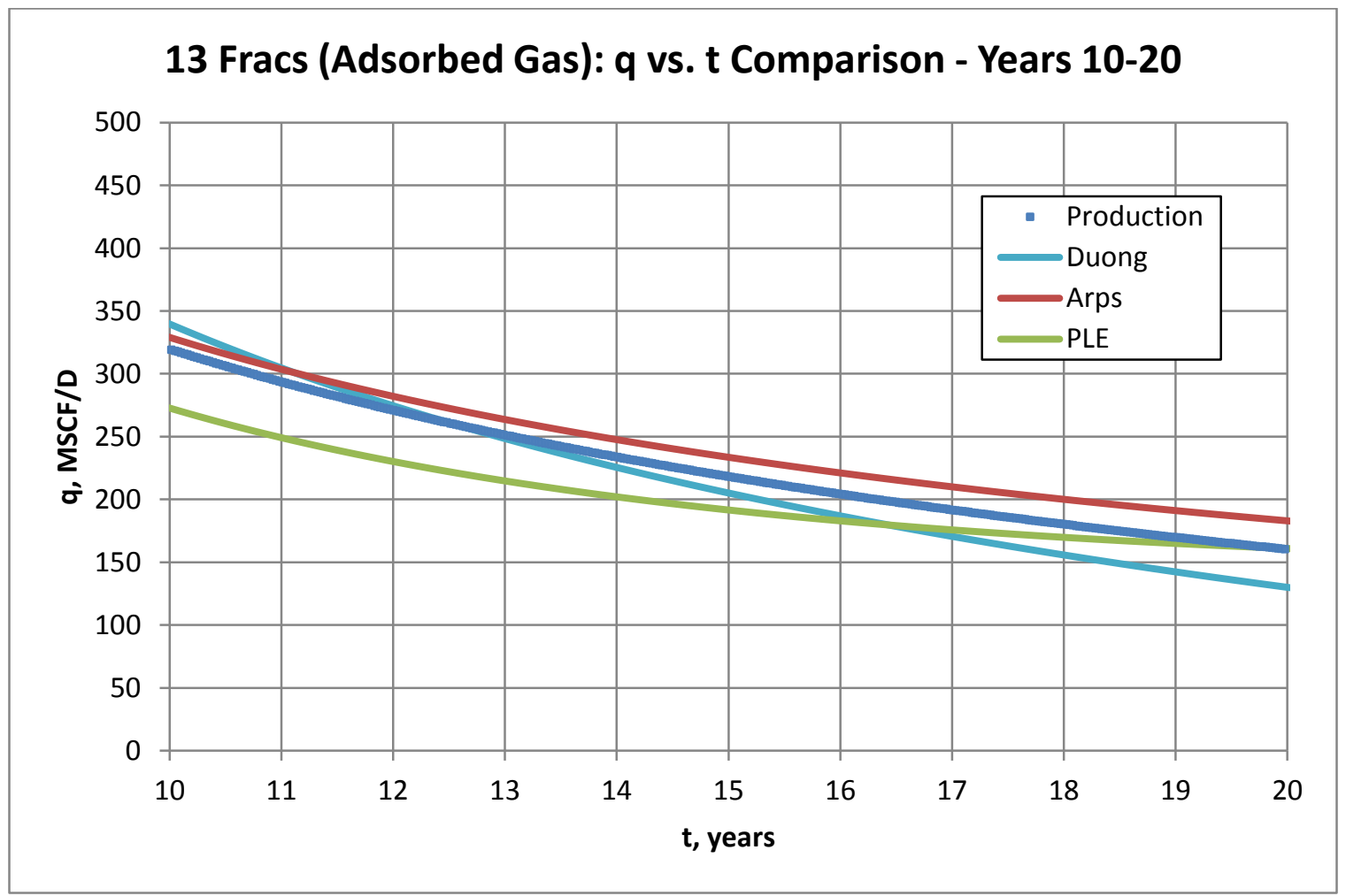

Figure 22: 13 Fracs (Ads. Gas) q vs. t Comparison - Years 10-20 


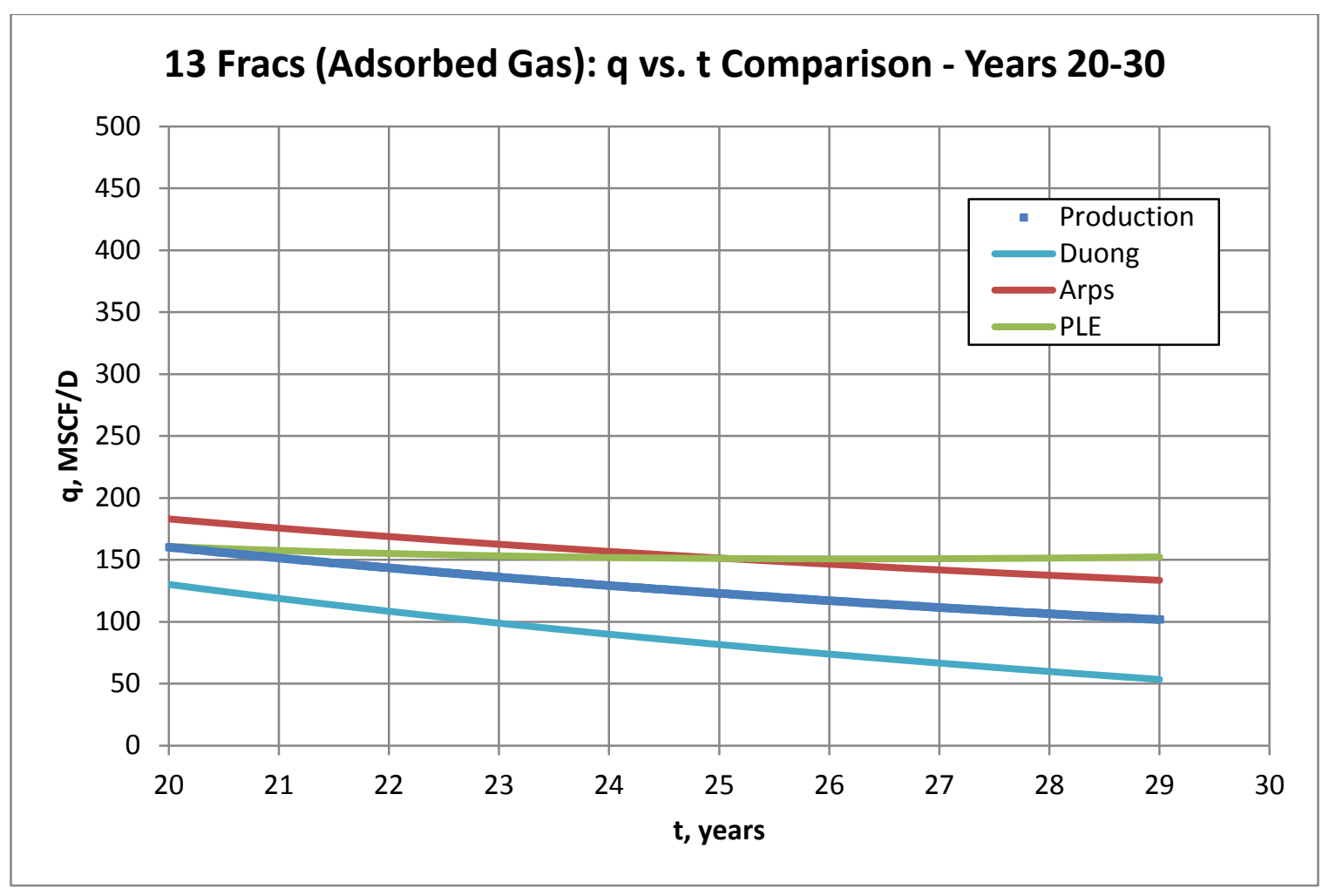

Figure 23: 13 Fracs (Ads. Gas) q vs. t Comparison - Years 20-30

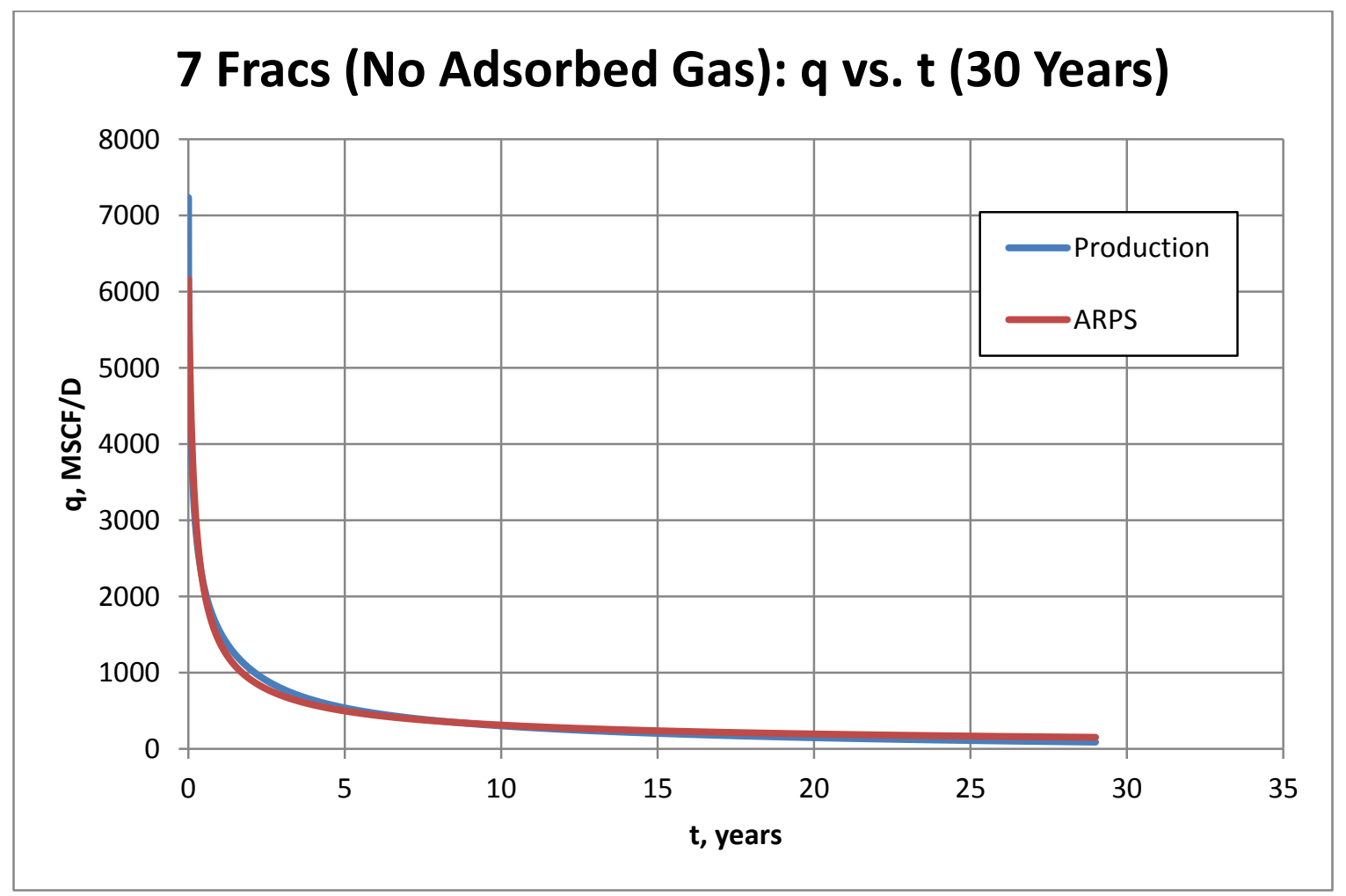

Figure 24: 7 Fracs (No Ads. Gas) Arps q vs. t (30 Years) 


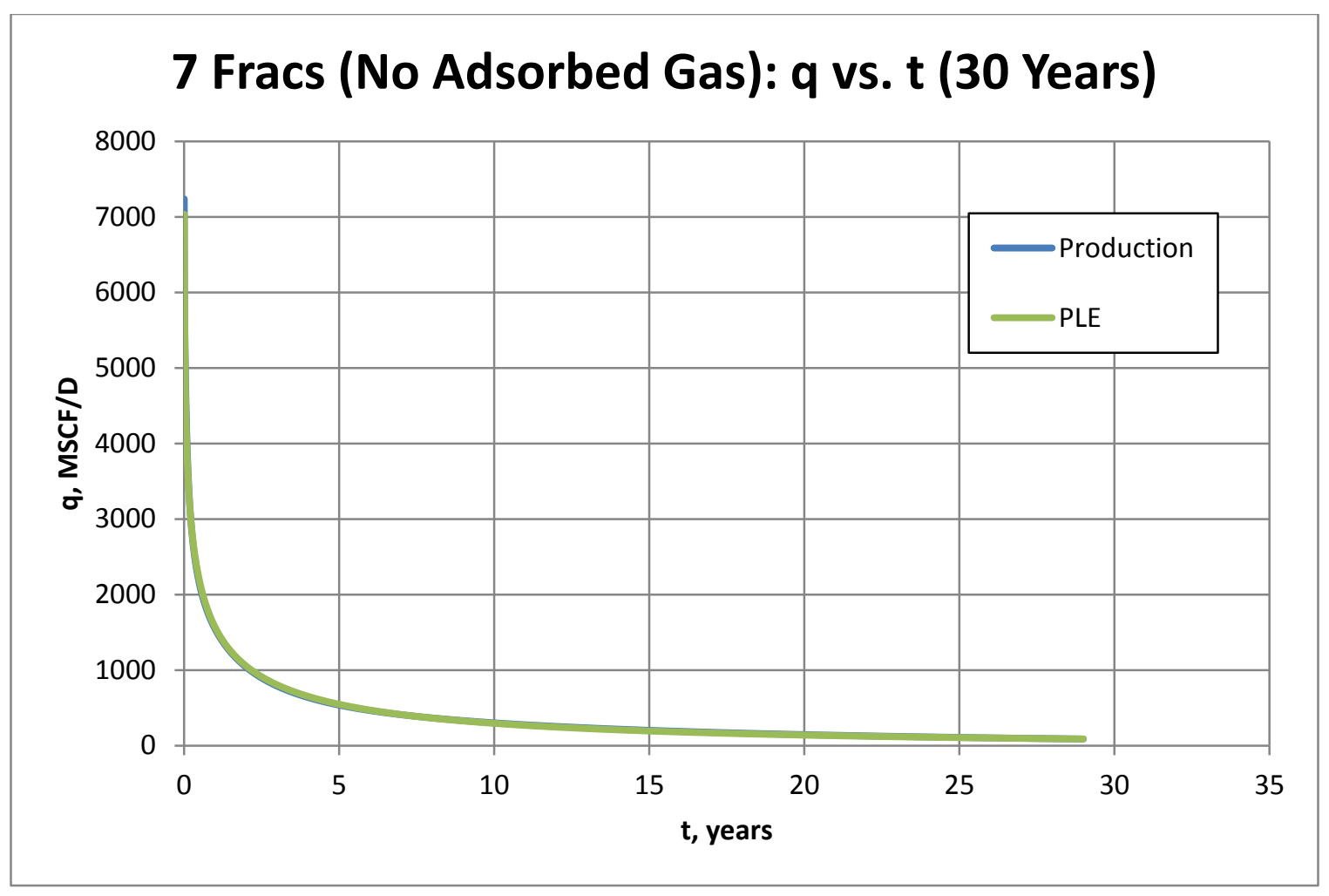

Figure 25: 7 Fracs (No Ads. Gas) PLE q vs. t (30 Years)

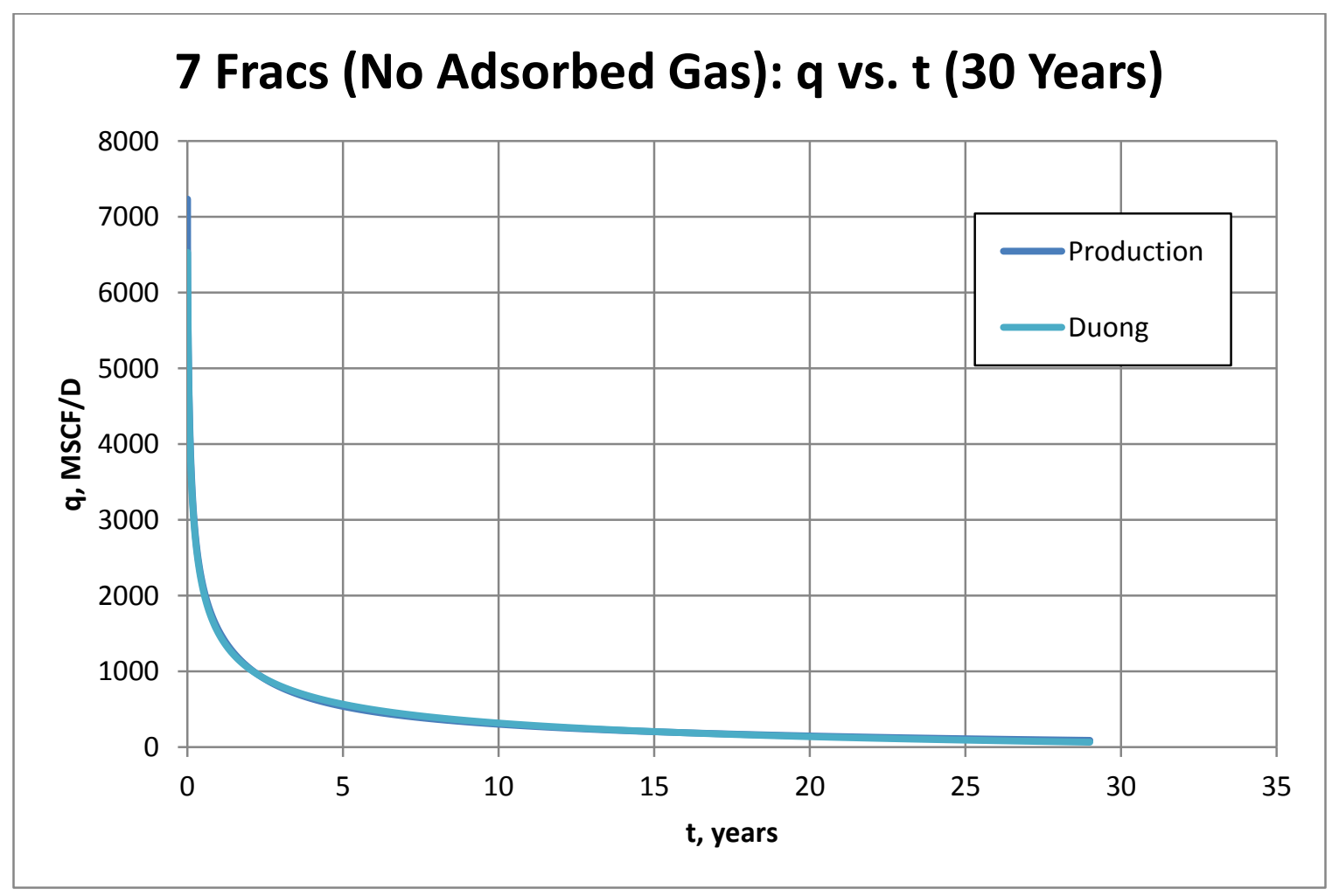

Figure 26: 7 Fracs (No Ads. Gas) Duong q vs. t (30 Years) 


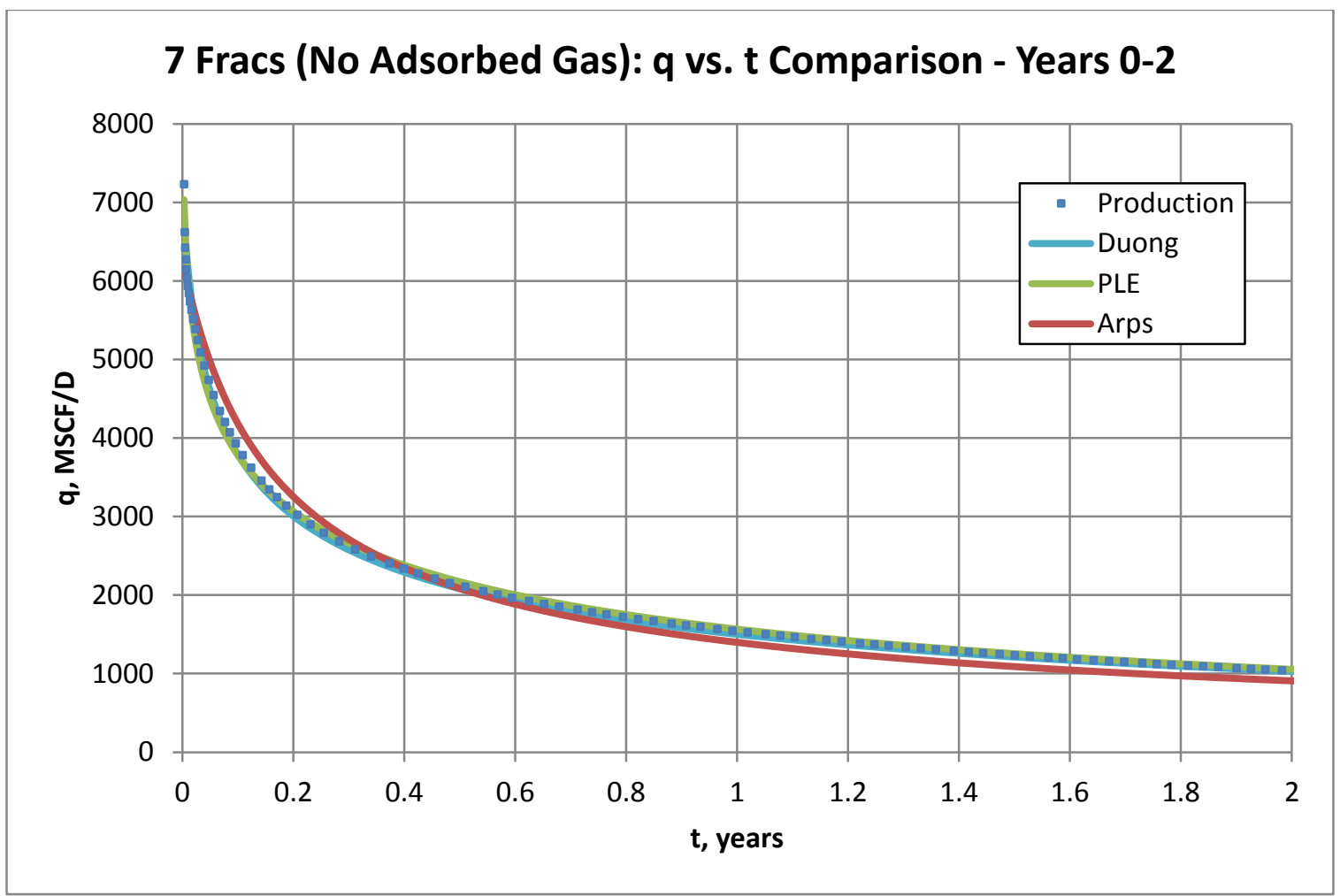

Figure 27: 7 Fracs (No Ads. Gas) q vs. t Comparison - Years 0-2

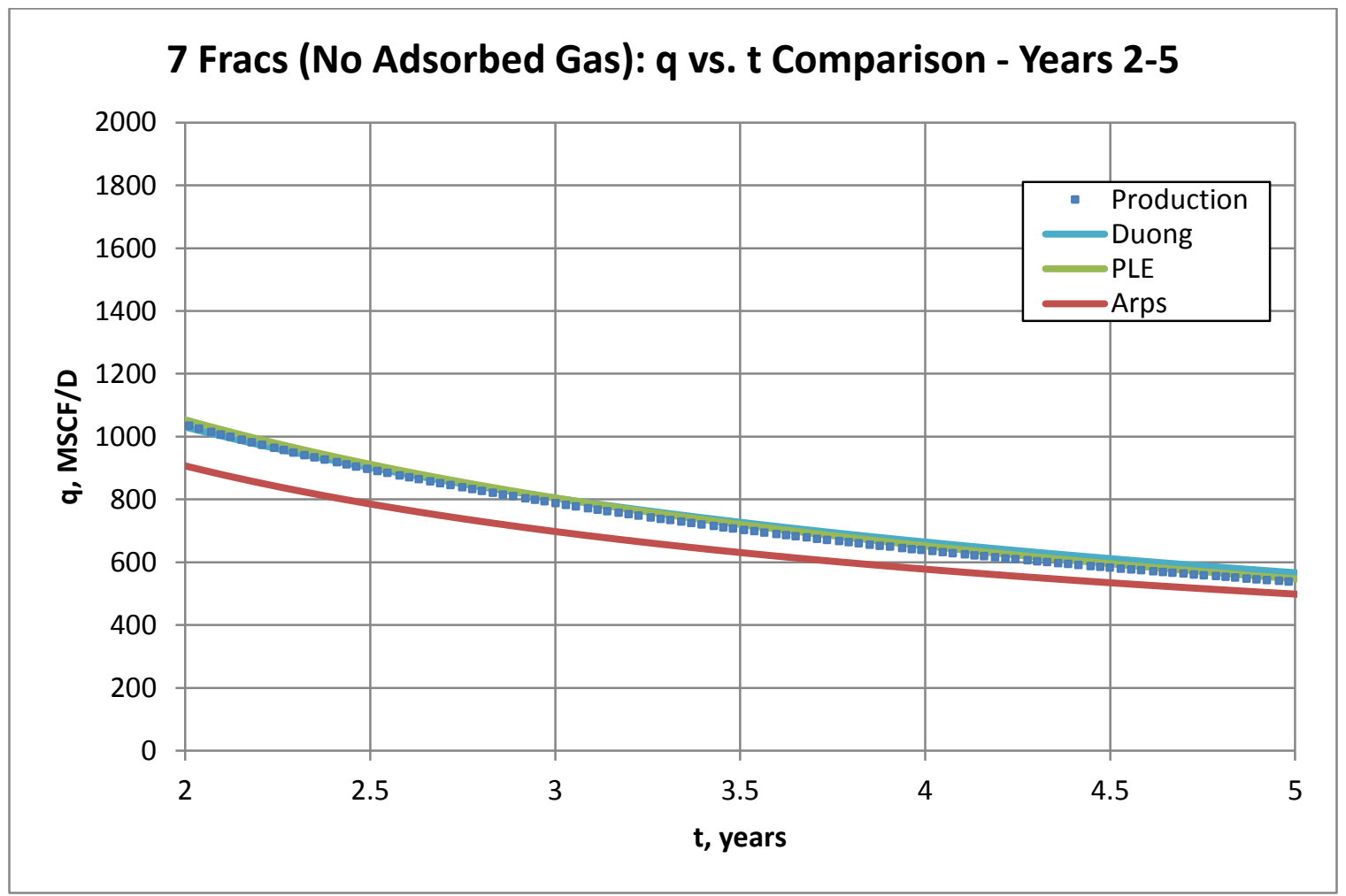

Figure 28: 7 Fracs (No Ads. Gas) q vs. t Comparison - Years 2-5 


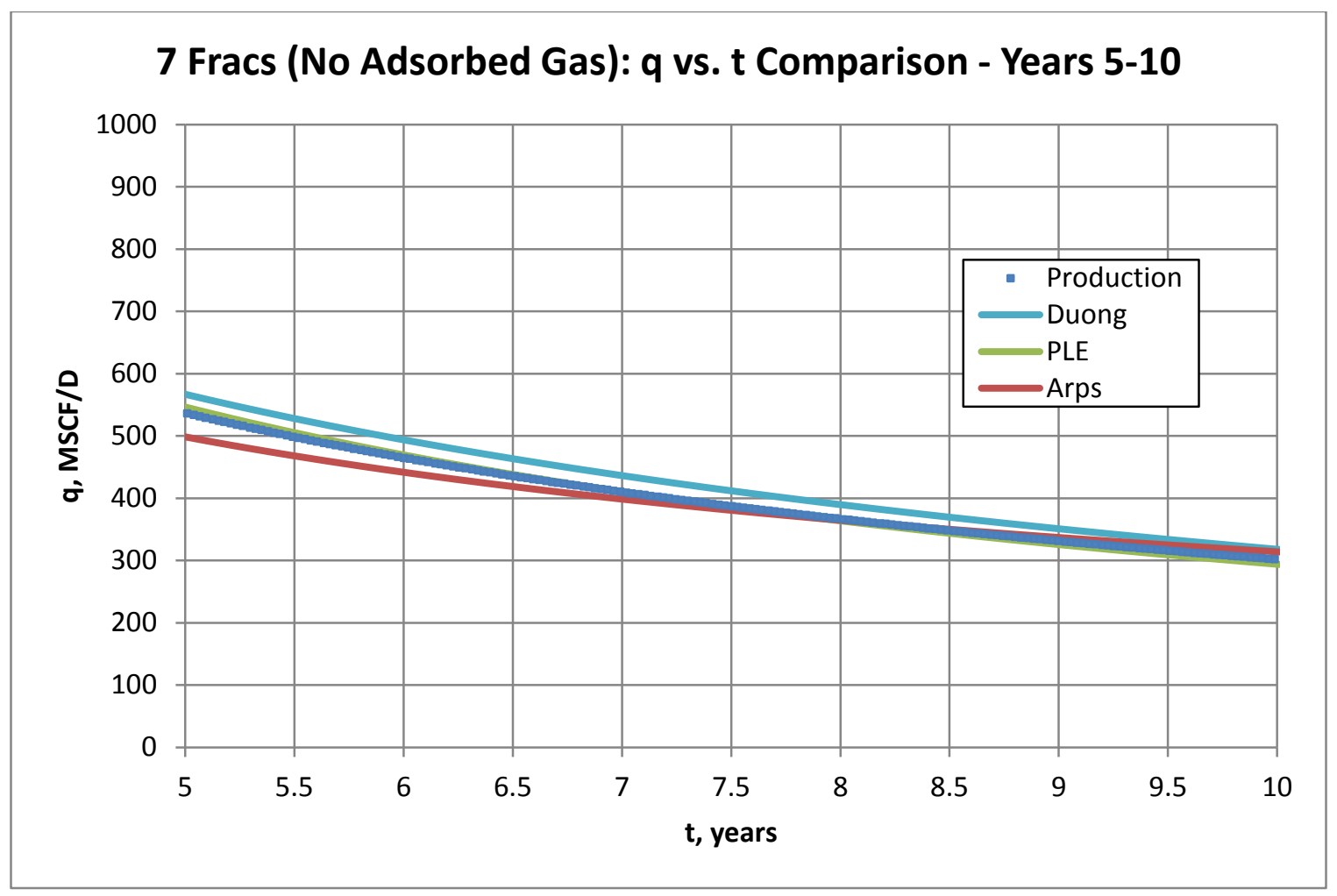

Figure 29: 7 Fracs (No Ads. Gas) q vs. t Comparison - Years 5-10

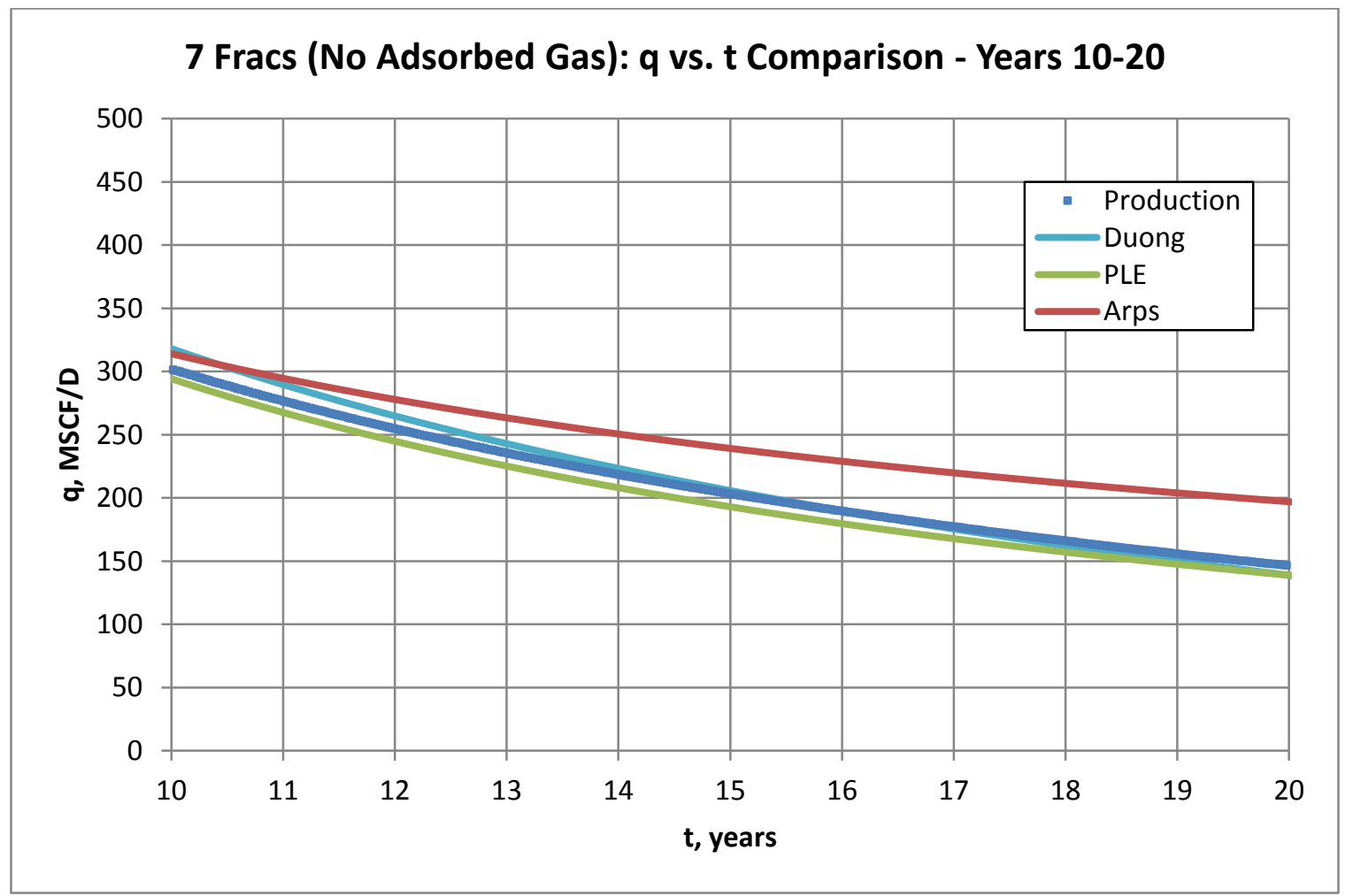

Figure 30: 7 Fracs (No Ads. Gas) q vs. t Comparison - Years 10-20 


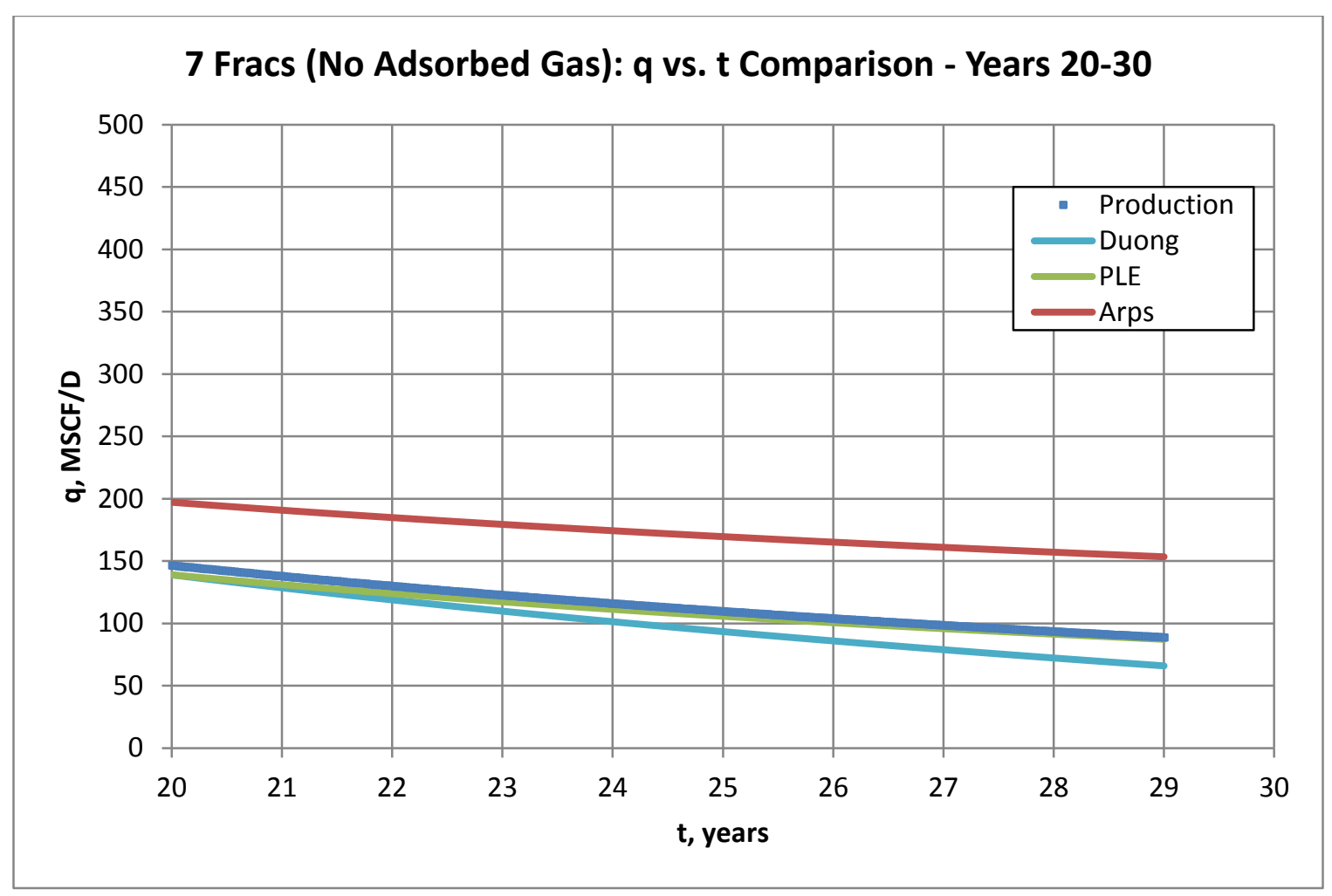

Figure 31: 7 Fracs (No Ads. Gas) q vs. t Comparison - Years 20-30

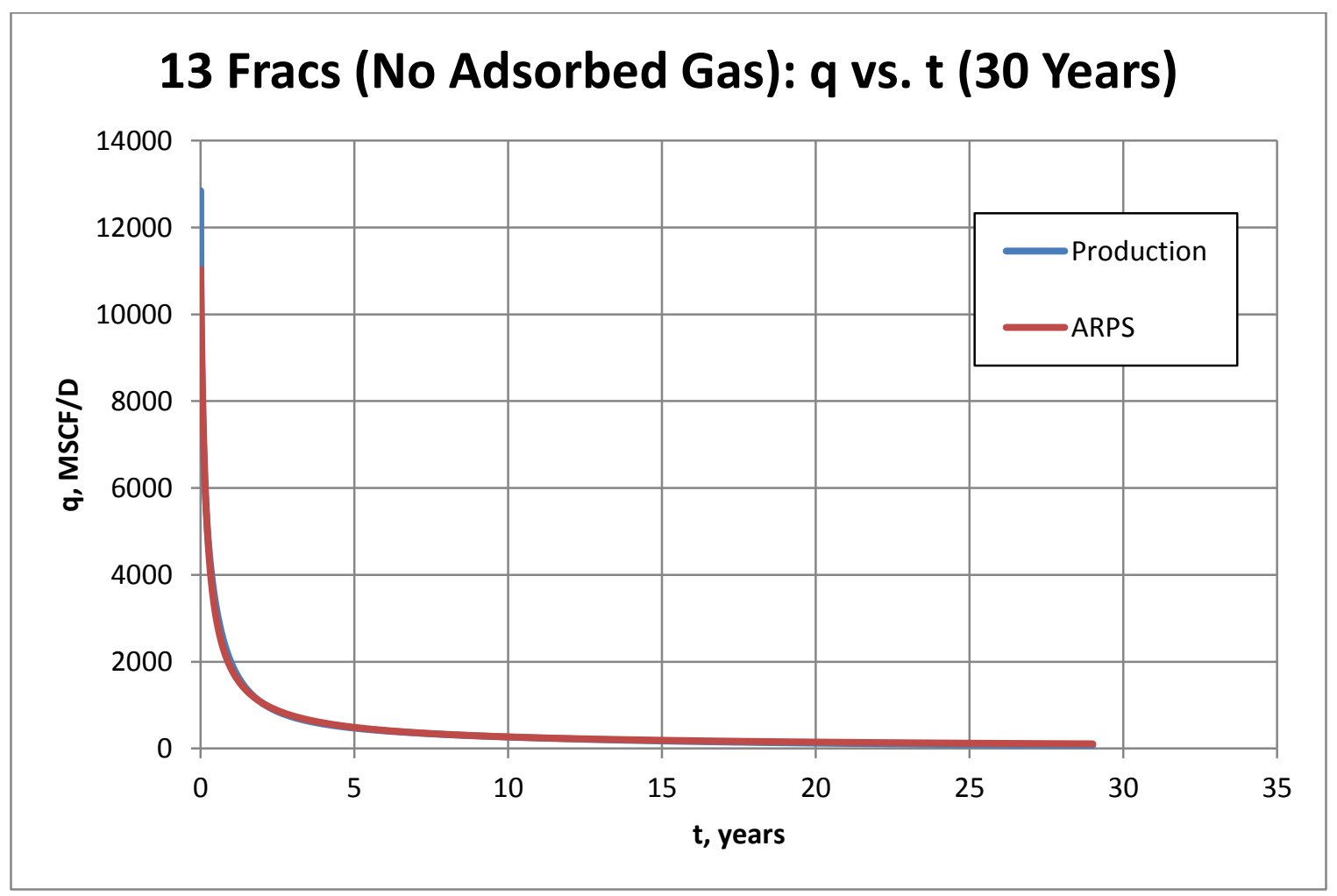

Figure 32: 13 Fracs (No Ads. Gas) Arps q vs. t (30 Years) 


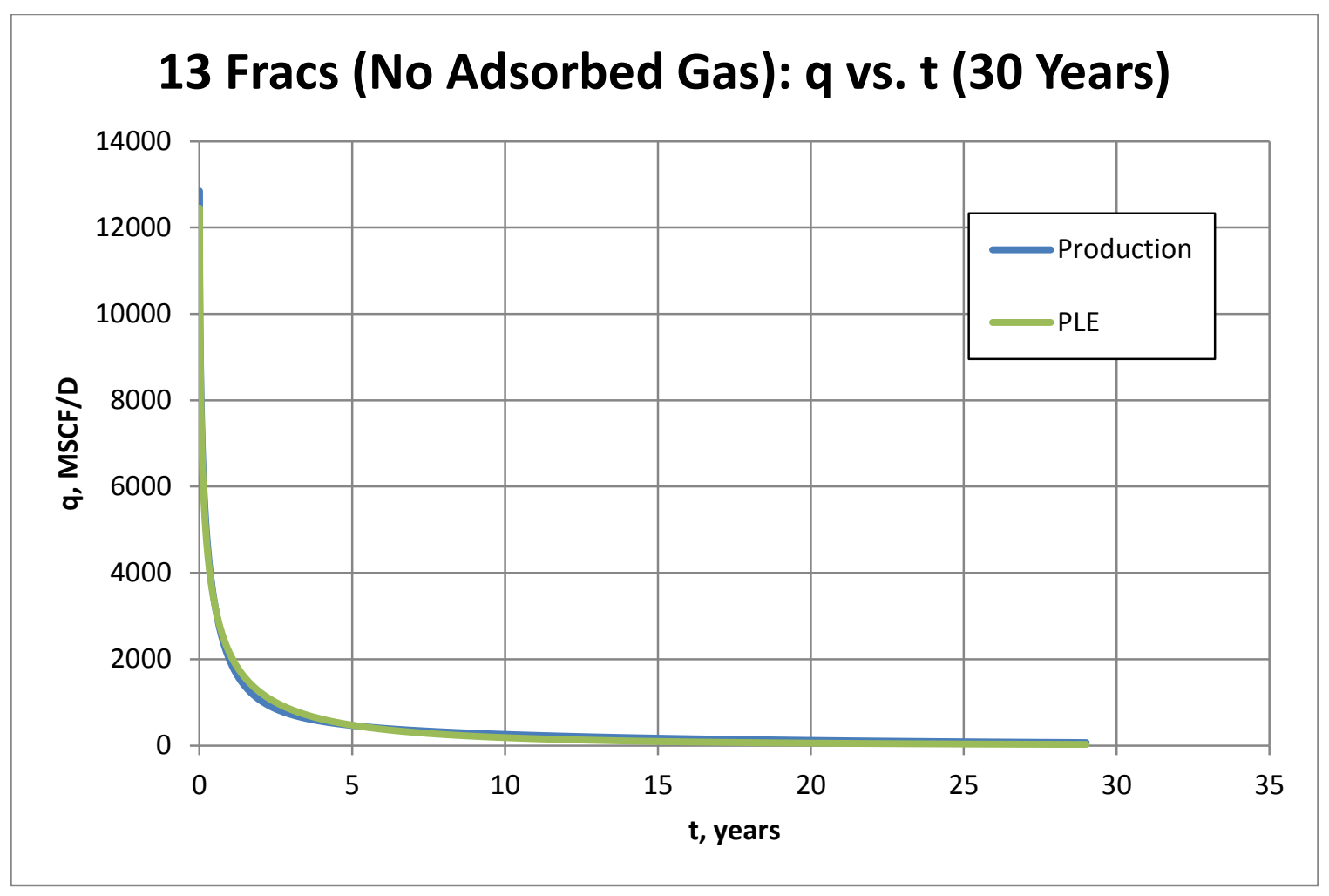

Figure 33: 13 Fracs (No Ads. Gas) PLE q vs. t (30 Years)

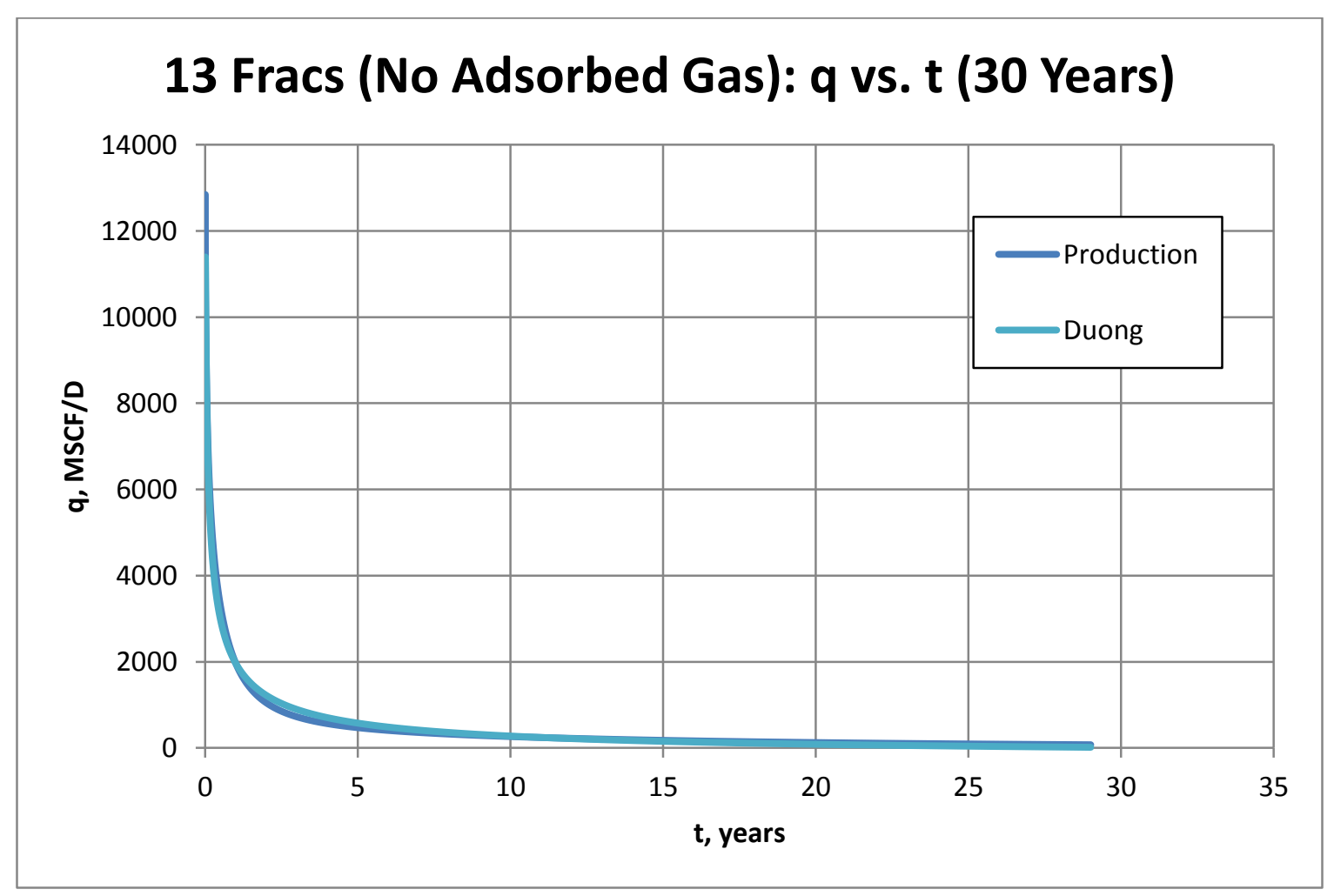

Figure 34: 13 Fracs (No Ads. Gas) Duong q vs. t (30 Years) 


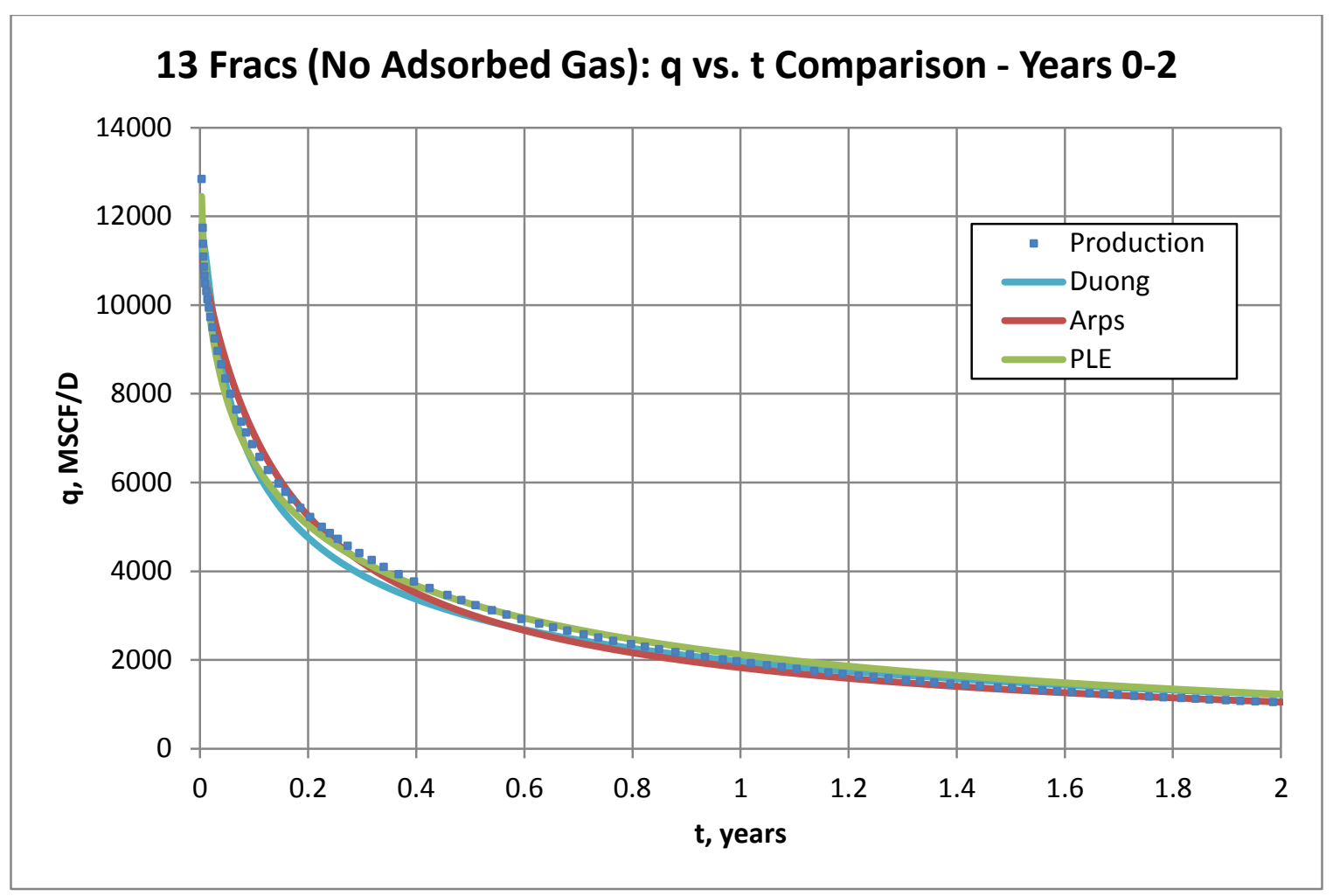

Figure 35: 13 Fracs (No Ads. Gas) q vs. t Comparison - Years 0-2

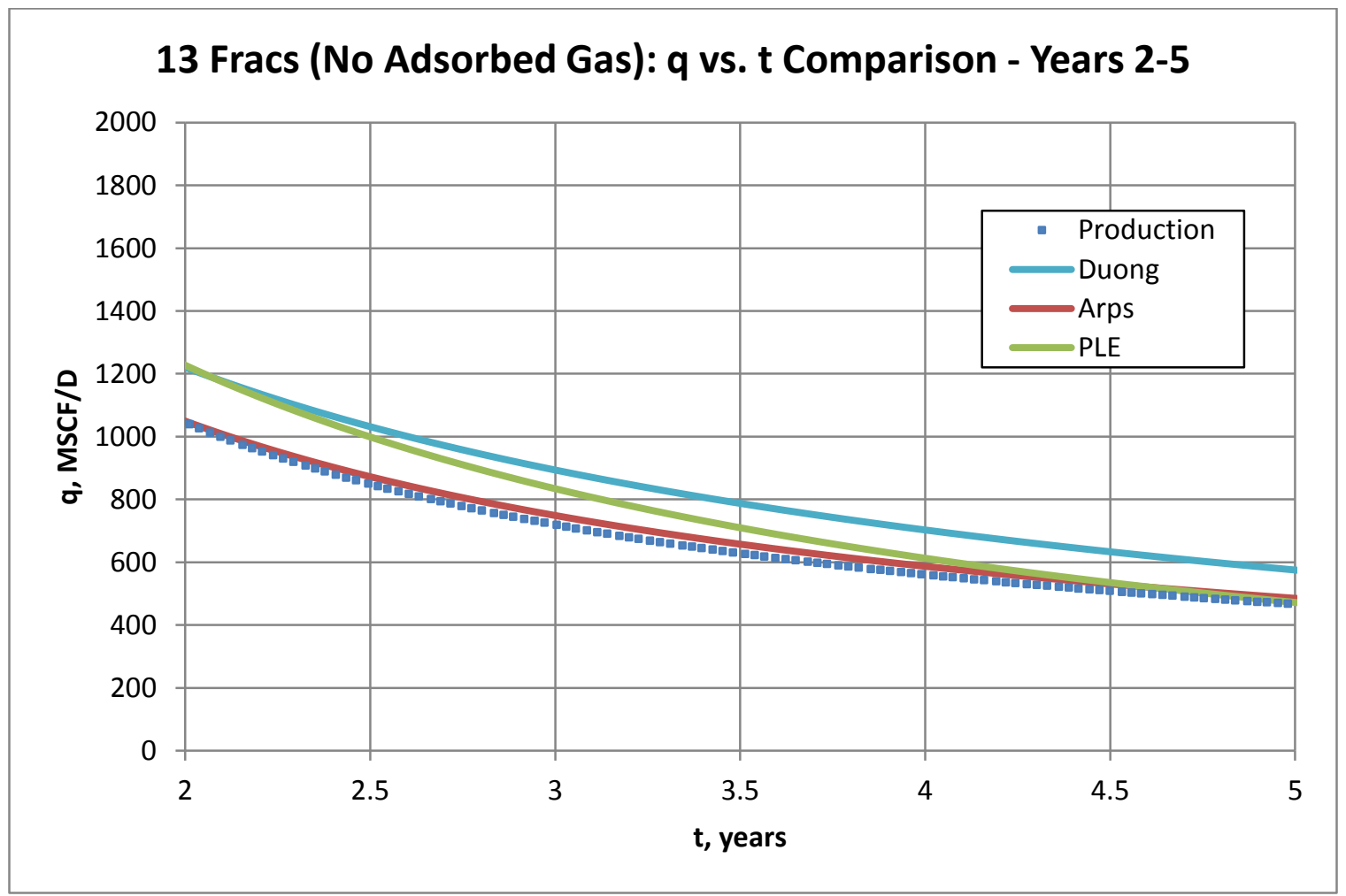

Figure 36: 13 Fracs (No Ads. Gas) q vs. t Comparison - Years 2-5 


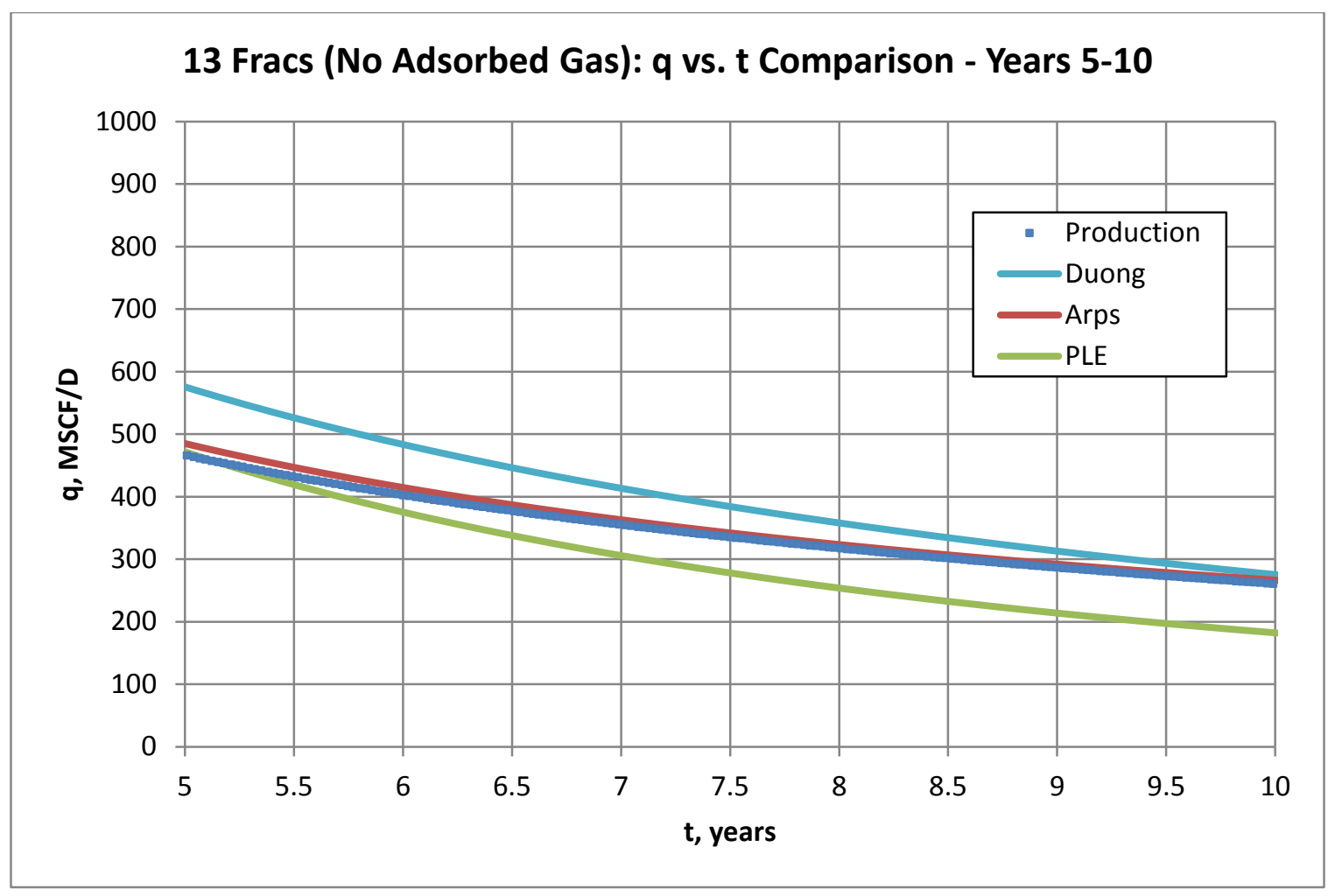

Figure 37: 13 Fracs (No Ads. Gas) q vs. t Comparison - Years 5-10

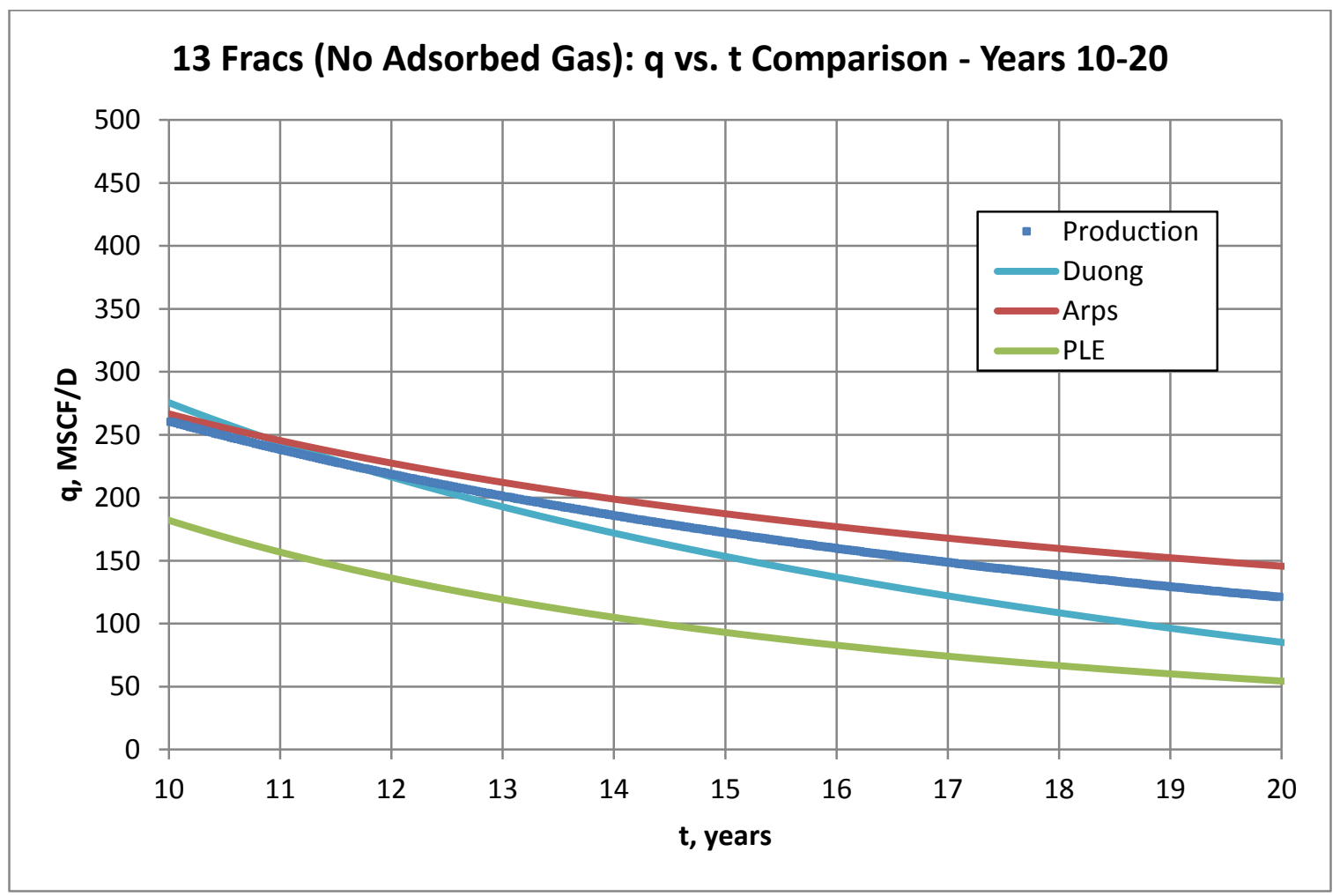

Figure 38: 13 Fracs (No Ads. Gas) q vs. t Comparison - Years 10-20 


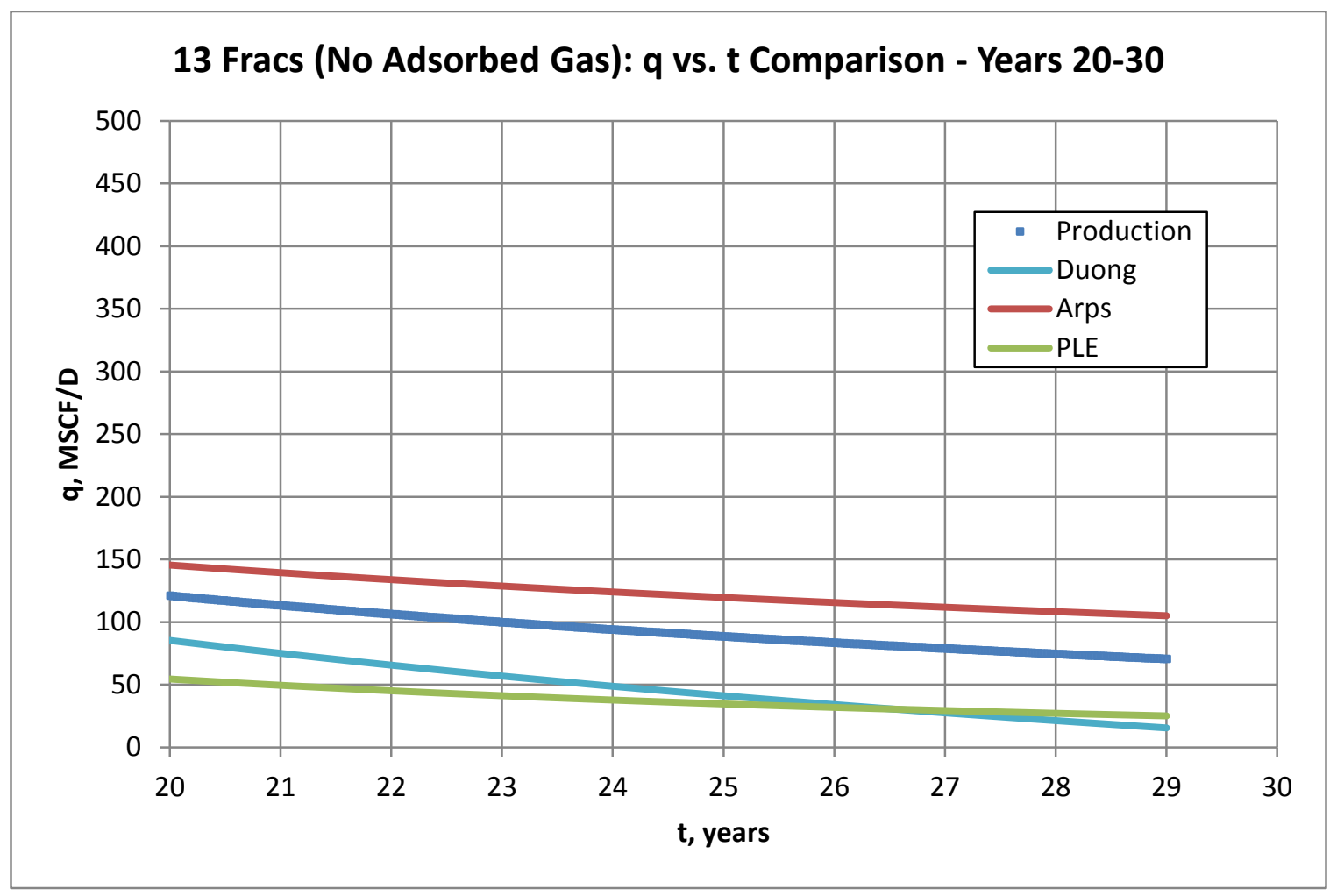

Figure 39: 13 Fracs (No Ads. Gas) q vs. t Comparison - Years 20-30

When comparing Figure 8 through Figure 15, the best match was seen using the Arps, PLE, and Duong models for seven fractures with adsorbed gas. Comparing Figure 16 through Figure 23 for thirteen fractures with adsorbed gas had the best match using the Arps, PLE, and Duong models. In Figure 24 through Figure 31 for seven fractures without adsorbed gas, the best match was found with the Arps, PLE, and Duong models. For thirteen fractures without adsorbed gas, Figure 32 through Figure 39 show the best match with the Arps, PLE, and Duong models.

\subsection{Application of Selected DCA Models to Varying Simulated Production Times:}

After selecting the best models for each of the four scenarios, production times were varied in each case. For seven fractures with adsorbed gas, the Arps, PLE, and Duong models were analyzed. The Arps DCA model depends on three parameters: " $n$ ", " $d_{\mathrm{i}}$ ", and " $q_{\mathrm{i}}$ ". The PLE model depends on four variables: " $D_{\infty}$ ", " $n$ ", " $q_{i}$ ", and " $D_{1}$ ". Two, three, four, five, seven, ten, 
fifteen, twenty, twenty-five, and thirty years of production data were analyzed for the Arps and PLE models. The Duong model also depends on four variables: " $a$ ", " $m$ ", " $q 1$ ", and " $q_{\infty}$ ". Two, five, seven, ten, eleven, twelve, fifteen, twenty, twenty-five, and thirty years of production data were analyzed for the Duong model. Results using the Arps, PLE, and Duong models are shown in Table 2, Table 3, and Table 4, respectively, for seven fractures with adsorbed gas.

For thirteen fractures with adsorbed gas the Arps, PLE, and Duong models were again compared. Two, three, four, five, seven, ten, fifteen, twenty, twenty-five, and thirty years of production data were analyzed for the Arps and PLE models. Two, five, seven, ten, fifteen, twenty, twenty-five, and thirty years of data were compared with the Duong model. The results for the Arps, PLE, and Duong models are shown in Table 5, Table 6, and Table 7, respectively.

Both seven and thirteen fractures without adsorbed gas were again compared using the Arps, PLE, and Duong models. Two, five, seven, ten, twenty, and thirty years of simulated production data were analyzed with Arps. Two, three, four, five, seven, ten, fifteen, twenty, twenty-five, and thirty years of data were analyzed with the PLE and Duong models. Table 8 through Table 10 show results for seven fractures without adsorbed gas and Table 11 through Table 13 show the results for thirteen fractures without adsorbed gas. 
Table 2: 7 Fracs (Ads. Gas) Arps Model

\begin{tabular}{|l|c|c|c|c|}
\hline \multicolumn{5}{|c|}{7 Fracs (Adsorbed Gas) } \\
\hline \multicolumn{1}{|c|}{ ARPS } & $\boldsymbol{n}$ & $\boldsymbol{d}_{\boldsymbol{i}}$ & $\boldsymbol{q}_{\boldsymbol{i}}$ & $\boldsymbol{R}^{\mathbf{2}}$ \\
\hline 2 Years & 2.144855936 & 0.023323937 & 6520.488341 & 0.998834611 \\
\hline 3 Years & 2.042163839 & 0.021646549 & 6476.017301 & 0.998576706 \\
\hline 4 Years & 1.962762569 & 0.02031234 & 6437.09575 & 0.998217044 \\
\hline 5 Years & 1.903433321 & 0.019303388 & 6405.356372 & 0.997875624 \\
\hline 7 Years & 1.817050449 & 0.017824757 & 6354.676966 & 0.997286163 \\
\hline 10 Years & 1.733880926 & 0.016399972 & 6300.464878 & 0.996613984 \\
\hline 15 Years & 1.647740081 & 0.014933675 & 6238.021762 & 0.995750559 \\
\hline 20 Years & 1.590509014 & 0.013972554 & 6192.740423 & 0.995014608 \\
\hline 25 Years & 1.547212709 & 0.013256256 & 6156.393177 & 0.994334127 \\
\hline 30 Years & 1.519207088 & 0.012799688 & 6131.925950 & 0.993825899 \\
\hline
\end{tabular}

Table 3: 7 Fracs (Ads. Gas) PLE Model

\begin{tabular}{|c|c|c|c|c|c|}
\hline \multicolumn{7}{|c|}{ 7 Fracs (Adsorbed Gas) } \\
\hline \multicolumn{1}{|c|}{$\boldsymbol{P L E}$} & $\boldsymbol{D}_{\infty}$ & $\boldsymbol{n}$ & $\boldsymbol{q}_{\boldsymbol{i}}$ & $\boldsymbol{D}_{\boldsymbol{1}}$ & $\boldsymbol{R}^{\mathbf{2}}$ \\
\hline 2 Years & -0.001060577 & 0.455555 & 7587.815433 & 0.059637167 & 0.999582646 \\
\hline 3 Years & -0.000612477 & 0.411413 & 7854.131534 & 0.065066909 & 0.999539920 \\
\hline 4 Years & -0.000419918 & 0.387526 & 8038.112229 & 0.068504608 & 0.999507431 \\
\hline 5 Years & -0.000351313 & 0.379033 & 8108.669242 & 0.069690837 & 0.999489516 \\
\hline 7 Years & -0.000240756 & 0.360519 & 8286.192814 & 0.072832119 & 0.999487612 \\
\hline 10 Years & -0.000171505 & 0.34550 & 8468.215065 & 0.075866152 & 0.999496479 \\
\hline 15 Years & -0.000116956 & 0.33014 & 8696.955258 & 0.079448935 & 0.999496872 \\
\hline 20 Years & -0.000090539 & 0.321551 & 8838.912585 & 0.081584919 & 0.999478933 \\
\hline 25 Years & -0.000072642 & 0.31490 & 8959.725708 & 0.083346378 & 0.999452656 \\
\hline 30 Years & -0.000062095 & 0.310592 & 9043.501566 & 0.084538706 & 0.999430138 \\
\hline
\end{tabular}


Table 4: 7 Fracs (Ads. Gas) Duong Model

\begin{tabular}{|l|c|c|c|c|c|}
\hline \multicolumn{7}{|c|}{ 7 Fracs (Adsorbed Gas) } \\
\hline Duong & $\boldsymbol{a}$ & $\boldsymbol{m}$ & $\boldsymbol{q}_{\mathbf{1}}$ & $\boldsymbol{q}_{\infty}$ & $\boldsymbol{R}^{\mathbf{2}}$ \\
\hline $\mathbf{2}$ Years & 1.0771146892 & 1.069985 & $7,116.28$ & -690.322432 & 0.999200446 \\
\hline 5 Years & 1.0929486760 & 1.07651 & $6,869.91$ & -483.457811 & 0.999496556 \\
\hline 7 Years & 1.1019813153 & 1.07970 & $6,773.57$ & -413.393955 & 0.999538557 \\
\hline 10 Years & 1.1140512051 & 1.08361 & $6,662.00$ & -342.999951 & 0.999746676 \\
\hline 11 Years & 1.1172691178 & 1.084627 & $6,633.15$ & -326.152667 & 0.999528545 \\
\hline 12 Years & 1.1201824032 & 1.08560 & $6,611.08$ & -310.034424 & 0.999518890 \\
\hline 15 Years & 1.1293618969 & 1.088262 & $6,539.14$ & -274.123495 & 0.999488182 \\
\hline 20 Years & 1.1397740910 & 1.091312 & $6,465.78$ & -236.301148 & 0.999439289 \\
\hline 25 Years & 1.1476539303 & 1.093538 & $6,415.76$ & -212.017110 & 0.999396050 \\
\hline 30 Years & 1.1538573351 & 1.095169 & $6,374.92$ & -196.847078 & 0.999363747 \\
\hline
\end{tabular}

Table 5: 13 Fracs (Ads. Gas) Arps Model

\begin{tabular}{|l|c|c|c|c|}
\hline \multicolumn{5}{|c|}{ 13 Fracs (Adsorbed Gas) } \\
\hline \multicolumn{1}{|c|}{ ARPS } & $\boldsymbol{n}$ & $\boldsymbol{d}_{\boldsymbol{i}}$ & $\boldsymbol{q}_{\boldsymbol{i}}$ & $\boldsymbol{R}^{\mathbf{2}}$ \\
\hline 2 Years & 1.422064191 & 0.017251735 & 11234.63942 & 0.997048288 \\
\hline 3 Years & 1.325103771 & 0.016051587 & 11155.88033 & 0.997134777 \\
\hline 4 Years & 1.277739321 & 0.015444181 & 11112.21741 & 0.997257213 \\
\hline 5 Years & 1.252331888 & 0.015108133 & 11086.7214 & 0.9973699 \\
\hline 7 Years & 1.226070863 & 0.014749212 & 11058.26552 & 0.997549767 \\
\hline 10 Years & 1.208618895 & 0.014499816 & 11037.59537 & 0.997717969 \\
\hline 15 Years & 1.19369613 & 0.014276593 & 11018.37142 & 0.997854533 \\
\hline 20 Years & 1.183097781 & 0.014112406 & 11003.79476 & 0.997903495 \\
\hline 25 Years & 1.174041049 & 0.013969303 & 10990.81183 & 0.997907167 \\
\hline 30 Years & 1.167637628 & 0.013867125 & 10981.408409 & 0.997890572 \\
\hline
\end{tabular}


Table 6: 13 Fracs (Ads. Gas) PLE Model

\begin{tabular}{|c|c|c|c|c|c|}
\hline \multicolumn{7}{|c|}{ 13 Fracs (Adsorbed Gas) } \\
\hline \multicolumn{1}{|c|}{$\boldsymbol{P L E}$} & $\boldsymbol{D}_{\infty}$ & $\boldsymbol{n}$ & $\boldsymbol{q}_{\boldsymbol{i}}$ & $\boldsymbol{D}_{\mathbf{1}}$ & $\boldsymbol{R}^{\mathbf{2}}$ \\
\hline 2 Years & -0.000409892 & 0.473872 & 13168.63809 & 0.055397864 & 0.999758742 \\
\hline 3 Years & -0.000626938 & 0.491115 & 13037.16271 & 0.053729096 & 0.999798162 \\
\hline 4 Years & -0.000761042 & 0.502337 & 12951.86106 & 0.052582096 & 0.999814484 \\
\hline 5 Years & -0.000827258 & 0.508167 & 12906.73397 & 0.051957722 & 0.999826135 \\
\hline 7 Years & -0.000849465 & 0.510194 & 12891.02573 & 0.051734013 & 0.999844835 \\
\hline 10 Years & -0.000774572 & 0.502046 & 12963.14091 & 0.052763787 & 0.999844686 \\
\hline 15 Years & -0.000618370 & 0.481849 & 13168.09880 & 0.055649911 & 0.999752186 \\
\hline 20 Years & -0.000501011 & 0.463693 & 13382.83652 & 0.058576838 & 0.999589374 \\
\hline 25 Years & -0.000417719 & 0.448829 & 13582.56459 & 0.061209155 & 0.999403020 \\
\hline 30 Years & -0.000368812 & 0.439178 & 13725.22332 & 0.063034074 & 0.999255790 \\
\hline
\end{tabular}

Table 7: 13 Fracs (Ads. Gas) Duong Model

\begin{tabular}{|l|c|c|c|c|c|}
\hline \multicolumn{7}{|c|}{ 13 Fracs (Adsorbed Gas) } \\
\hline Duong & $\boldsymbol{a}$ & $\boldsymbol{m}$ & $\boldsymbol{q}_{\boldsymbol{1}}$ & $\boldsymbol{q}_{\infty}$ & $\boldsymbol{R}^{\mathbf{2}}$ \\
\hline $\mathbf{2}$ Years & 1.055818401 & 1.05438086 & $15,370.37$ & $-3,978.723716$ & 0.999063438 \\
\hline 3 Years & 1.103435989 & 1.07418246 & $13,413.14$ & $-2,274.862123$ & 0.998695403 \\
\hline 4 Years & 1.14010187 & 1.08754631 & $12,511.28$ & $-1,563.759830$ & 0.998280884 \\
\hline 5 Years & 1.167973398 & 1.0970169 & $11,997.09$ & -1185.253278 & 0.997908205 \\
\hline 7 Years & 1.211459104 & 1.11065168 & $11,364.61$ & -774.743511 & 0.997289043 \\
\hline 10 Years & 1.254029268 & 1.12295323 & $10,873.86$ & -502.531506 & 0.996663122 \\
\hline 15 Years & 1.294907790 & 1.1340316 & $10,479.17$ & -317.430071 & 0.996101843 \\
\hline 20 Years & 1.318141938 & 1.13998117 & $10,275.13$ & -238.005781 & 0.995832166 \\
\hline 25 Years & 1.334348771 & 1.143967 & $10,143.83$ & -193.746928 & 0.995685513 \\
\hline 30 Years & 1.343002362 & 1.14606886 & $10,074.80$ & -171.696022 & 0.995611151 \\
\hline
\end{tabular}


Table 8: 7 Fracs (No Ads. Gas) Arps Model

\begin{tabular}{|l|c|c|c|c|}
\hline \multicolumn{5}{|c|}{7 Fracs (No Adsorbed Gas) } \\
\hline ARPS & $n$ & $d_{i}$ & $q_{i}$ & $\boldsymbol{R}^{\mathbf{2}}$ \\
\hline 2 Years & 2.149795050 & 0.02920 & 6695.836929 & 0.996567215 \\
\hline 5 Years & 1.870119847 & 0.023225 & 6549.526835 & 0.995936693 \\
\hline 7 Years & 1.778589557 & 0.021287 & 6492.100706 & 0.995413841 \\
\hline 10 Years & 1.692905226 & 0.019494 & 6433.075136 & 0.994805695 \\
\hline 20 Years & 1.546688743 & 0.016508 & 6318.684594 & 0.993204363 \\
\hline 30 Years & 1.473641425 & 0.015075 & 6254.665180 & 0.991905457 \\
\hline
\end{tabular}

Table 9: 7 Fracs (No Ads. Gas) PLE Model

\begin{tabular}{|c|c|c|c|c|c|}
\hline \multicolumn{7}{|c|}{ 7 Fracs (No Adsorbed Gas) } \\
\hline PLE & $\boldsymbol{D}_{\infty}$ & $\boldsymbol{n}$ & $\boldsymbol{q}_{\boldsymbol{i}}$ & $\boldsymbol{D}_{\mathbf{1}}$ & $\boldsymbol{R}^{\mathbf{2}}$ \\
\hline 2 Years & -0.000565458 & 0.379411800 & 8380.688847 & 0.077233471 & 0.998813822 \\
\hline 3 Years & -0.000358894 & 0.358422535 & 8582.247962 & 0.080325179 & 0.999022764 \\
\hline 4 Years & -0.000251029 & 0.344871266 & 8736.963321 & 0.082614841 & 0.999126327 \\
\hline 5 Years & -0.000198069 & 0.337175861 & 8835.187418 & 0.084031512 & 0.999191823 \\
\hline 7 Years & -0.000149211 & 0.328941520 & 8951.357620 & 0.085680948 & 0.999278277 \\
\hline 10 Years & -0.000119280 & 0.322889834 & 9045.995295 & 0.087011798 & 0.999350297 \\
\hline 15 Years & -0.000091291 & 0.315982957 & 9166.027226 & 0.088684431 & 0.999402231 \\
\hline 20 Years & -0.000071093 & 0.310079017 & 9278.875013 & 0.090228949 & 0.999413703 \\
\hline 25 Years & -0.000055694 & 0.305002022 & 9383.508828 & 0.091630964 & 0.999406587 \\
\hline 30 Years & -0.000046167 & 0.301581887 & 9458.065489 & 0.092611844 & 0.999395231 \\
\hline
\end{tabular}


Table 10: 7 Fracs (No Ads. Gas) Duong Model

\begin{tabular}{|l|c|c|c|c|c|}
\hline \multicolumn{7}{|c|}{ 7 Fracs (No Adsorbed Gas) } \\
\hline Duong & $\boldsymbol{a}$ & $\boldsymbol{m}$ & $\boldsymbol{q}_{\mathbf{1}}$ & $\boldsymbol{q}_{\infty}$ & $\boldsymbol{R}^{\mathbf{2}}$ \\
\hline $\mathbf{2}$ Years & 1.0048595176 & 1.049280450 & $8,097.03$ & $-1,289.889330$ & 0.998087228 \\
\hline 3 Years & 1.0153609167 & 1.055426159 & $7,761.95$ & -976.961800 & 0.998410712 \\
\hline 4 Years & 1.0253061164 & 1.060158962 & $7,560.73$ & -802.347290 & 0.998580933 \\
\hline 5 Years & 1.0311745608 & 1.062961556 & $7,453.50$ & -708.306389 & 0.998665628 \\
\hline 7 Years & 1.0438532564 & 1.068349330 & $7,277.16$ & -564.278320 & 0.998720680 \\
\hline 10 Years & 1.0604132400 & 1.074675705 & $7,102.19$ & -433.689099 & 0.998689170 \\
\hline 15 Years & 1.0782662614 & 1.081012306 & $6,947.58$ & -329.820729 & 0.998588041 \\
\hline 20 Years & 1.0902598708 & 1.084966637 & $6,859.65$ & -277.707437 & 0.998505073 \\
\hline 25 Years & 1.0994828702 & 1.087867757 & $6,798.75$ & -245.001347 & 0.998436188 \\
\hline 30 Years & 1.1055616221 & 1.089715269 & $6,760.70$ & -226.394471 & 0.998384385 \\
\hline
\end{tabular}

Table 11: 13 Fracs (No Ads. Gas) Arps Model

\begin{tabular}{|c|c|c|c|c|}
\hline \multicolumn{5}{|c|}{ 13 Fracs (No Adsorbed Gas) } \\
\hline ARPS & $n$ & $d_{i}$ & $q_{i}$ & $\boldsymbol{R}^{\mathbf{2}}$ \\
\hline 2 Years & 1.374379279 & 0.020422 & 11471.82352 & 0.994176469 \\
\hline 5 Years & 1.206277136 & 0.017818 & 11314.63079 & 0.995422964 \\
\hline 7 Years & 1.185086745 & 0.017469 & 11290.7255 & 0.995808338 \\
\hline 10 Years & 1.172206623 & 0.017247 & 11274.99281 & 0.996127757 \\
\hline 20 Years & 1.149794019 & 0.016840 & 11244.79385 & 0.996479636 \\
\hline 30 Years & 1.133843025 & 0.016540 & 11221.65087 & 0.996501102 \\
\hline
\end{tabular}


Table 12: 13 Fracs (No. Ads Gas) PLE Model

\begin{tabular}{|c|c|c|c|c|c|}
\hline \multicolumn{7}{|c|}{ 13 Fracs (No Adsorbed Gas) } \\
\hline PLE & $\boldsymbol{D}_{\infty}$ & $\boldsymbol{n}$ & $\boldsymbol{q}_{\boldsymbol{i}}$ & $\boldsymbol{D}_{\mathbf{1}}$ & $\boldsymbol{R}^{\mathbf{2}}$ \\
\hline 2 Years & 0.000406027 & 0.384232990 & 14601.31366 & 0.073366475 & 0.998927468 \\
\hline 3 Years & -0.000115679 & 0.429922235 & 14027.84804 & 0.067655535 & 0.999034412 \\
\hline 4 Years & -0.000450412 & 0.459029456 & 13714.86083 & 0.064006382 & 0.999073103 \\
\hline 5 Years & -0.000647232 & 0.476182672 & 13543.93886 & 0.061842302 & 0.999101520 \\
\hline 7 Years & -0.000814733 & 0.491106361 & 13400.48432 & 0.059924980 & 0.999163291 \\
\hline 10 Years & -0.000810162 & 0.490497714 & 13407.46653 & 0.060024438 & 0.999230991 \\
\hline 15 Years & -0.000665095 & 0.473781593 & 13594.29060 & 0.062601177 & 0.999210144 \\
\hline 20 Years & -0.000540371 & 0.456882643 & 13810.76346 & 0.065499473 & 0.999083931 \\
\hline 25 Years & -0.000451017 & 0.443109423 & 14008.96447 & 0.068066815 & 0.998924400 \\
\hline 30 Years & -0.000398608 & 0.434266780 & 14147.54847 & 0.069813027 & 0.998797460 \\
\hline
\end{tabular}

Table 13: 13 Fracs (No. Ads Gas) Duong Model

\begin{tabular}{|l|c|c|c|c|c|}
\hline \multicolumn{7}{|c|}{ 13 Fracs (No Adsorbed Gas) } \\
\hline Duong & $\boldsymbol{a}$ & $\boldsymbol{m}$ & $\boldsymbol{q}_{\mathbf{1}}$ & $\boldsymbol{q}_{\infty}$ & $\boldsymbol{R}^{\mathbf{2}}$ \\
\hline $\mathbf{2}$ Years & 1.0055464162 & 1.039769764 & $17,421.52$ & $-5,413.112895$ & 0.997826101 \\
\hline 3 Years & 1.0450989975 & 1.061640607 & $14,603.78$ & $-2,776.432774$ & 0.997233777 \\
\hline 4 Years & 1.0777849559 & 1.076368221 & $13,522.86$ & $-1,830.089152$ & 0.996580366 \\
\hline 5 Years & 1.1049010056 & 1.087271964 & $12,922.21$ & -1343.569673 & 0.996005728 \\
\hline 7 Years & 1.1449713816 & 1.102045474 & $12,268.73$ & -859.668671 & 0.995083570 \\
\hline 10 Years & 1.1844416155 & 1.115341983 & $11,786.57$ & -548.427933 & 0.994208223 \\
\hline 15 Years & 1.2211160591 & 1.126867124 & $11,425.28$ & -347.036449 & 0.993493461 \\
\hline 20 Years & 1.2422541230 & 1.133099165 & $11,242.47$ & -262.052133 & 0.993179995 \\
\hline 25 Years & 1.2559344364 & 1.137017436 & $11,133.71$ & -215.908279 & 0.993015426 \\
\hline 30 Years & 1.2640243273 & 1.139277328 & $11,071.21$ & -191.932125 & 0.992930736 \\
\hline
\end{tabular}

The Duong and Arps models were selected as the best correlated match with simulated data for both seven fractures with and without adsorbed gas (500 feet hydraulic fracture spacing) and thirteen fractures with and without adsorbed gas (250 feet hydraulic fracture spacing). This 
was due to the trends of constants plotted versus time as shown in Appendix Figure 58 through Figure 101. Each of the three DCA models matched limited simulated production history accurately. However, when the values of constants obtained for varying production histories were plotted versus time, trends for some models were not visible until later in the production history.

For seven fractures with adsorbed gas, the best trend in simulated data occurs after two years of production history using the Arps and PLE models, while the Duong model trends well with all simulated production history. For thirteen fractures with adsorbed gas, Arps has a trend after a production history of two years, while Duong trends well with all simulated production data and the PLE model has a trend after five years.

Simulated data for seven fractures without adsorbed gas most closely correlated with the Arps and Duong models using all production history, and after two years using the PLE model. Values of " $n$ " in the Arps model for seven fractures without adsorbed gas begin at approximately two, indicating linear flow. When applying the Arps model to thirteen fractures without adsorbed gas, a better trend is obtained after two years of simulated production data. The " $n$ " values approach a harmonic decline $(n=1)$ as time progresses. The PLE model had a trend for the thirteen fractures without adsorbed gas model after five years of production history, while the Duong correlated well with all production history.

\subsection{Validation Against Field Data:}

The Well 1 data was first matched to each DCA model and values of constants were obtained for this time interval. Next, the correlations derived above were applied at the Well 1 production history time interval of 4.274 years and predicted into the future. Each of the four scenarios yielded significantly different constant values from the actual Well 1 DCA match and 
future predictions were inaccurate. In order to overcome this barrier, a dimensionless ratio was used. This allowed for the conversion of constants in each of the four DCA models obtained by simulated data to the Well 1 data. By using the DCA constant values obtained in Table 2 through Table 13, a ratio was obtained by using the following formula:

$$
\text { Ratio }=\frac{\text { Value of DCA constant at } t=\text { Available production history }}{\text { Value of DCA constant at } t=30 \text { years }}
$$

The ratio was then plotted versus time on a log-log scale for each DCA constant. Log-log plots have successfully been used as a dimensionless conversion between sets of data in other petroleum engineering applications. Reservoir parameters affect the value of dimensionless numbers, such as permeability and size. In this analysis, the reservoir parameters were kept constant in all simulated data. A correlation was then derived for this log-log plot. By entering the production history of Well 1 (4.274 years) into this $\log -\log$ correlation, a value of the ratio at this point in time was obtained. Dividing the actual Well 1 value of the constant obtained via the nonlinear-regression method in Microsoft Excel at 4.274 years by the value of the ratio at 4.274 years, a predicted value was calculated which was able to determine future reservoir performance. Table 14 through Table 16 show the results for ratio calculations derived from seven fractures having adsorbed gas. Thirteen fractures with adsorbed gas can be found in Table 35 through Table 40, located in the Appendix. Well 1 is an eight fracture horizontal well (a hydraulic fracture spacing of 429 feet) with adsorbed gas, which is most similar to a seven fracture well (a hydraulic fracture spacing of 500 feet) with adsorbed gas. 
Table 14: 7 Fracs (Ads. Gas) Arps Table of Ratios

\begin{tabular}{|l|c|c|c|}
\hline \multicolumn{4}{|c|}{7 Fracs (Adsorbed Gas) Table of Ratios } \\
\hline \multicolumn{1}{|c|}{ ARPS } & $n$ & $\boldsymbol{d}_{\boldsymbol{i}}$ & $\boldsymbol{q}_{\boldsymbol{i}}$ \\
\hline 2 Years & 1.411825914 & 1.822226936 & 1.063367104 \\
\hline 3 Years & 1.344230063 & 1.691177835 & 1.056114727 \\
\hline 4 Years & 1.291965121 & 1.586940188 & 1.049767366 \\
\hline 5 Years & 1.252912348 & 1.508113884 & 1.044591279 \\
\hline 7 Years & 1.196051850 & 1.392593016 & 1.036326436 \\
\hline 10 Years & 1.141306501 & 1.281279046 & 1.027485480 \\
\hline 15 Years & 1.084605314 & 1.166721769 & 1.017302201 \\
\hline 20 Years & 1.046933645 & 1.091632373 & 1.009917679 \\
\hline 25 Years & 1.018434367 & 1.035670180 & 1.003990138 \\
\hline All & 1.000000000 & 1.000000000 & 1.000000000 \\
\hline
\end{tabular}

Table 15: 7 Fracs (Ads. Gas) PLE Table of Ratios

\begin{tabular}{|l|c|c|c|c|}
\hline \multicolumn{5}{|c|}{ 7 Fracs (Adsorbed Gas) Table of Ratios } \\
\hline \multicolumn{1}{|c|}{ PLE } & $\boldsymbol{D}_{\infty}$ & $\boldsymbol{n}$ & $\boldsymbol{q}_{\boldsymbol{i}}$ & $\boldsymbol{D}_{\boldsymbol{1}}$ \\
\hline 2 Years & 17.07980826 & 1.466729 & 0.839035121 & 0.705442158 \\
\hline 3 Years & 9.863485554 & 1.324607 & 0.868483460 & 0.769670035 \\
\hline 4 Years & 6.762465855 & 1.24770 & 0.888827427 & 0.810334237 \\
\hline 5 Years & 5.657635636 & 1.220355 & 0.896629384 & 0.824366027 \\
\hline 7 Years & 3.877190089 & 1.160747 & 0.916259344 & 0.861523940 \\
\hline 10 Years & 2.761965094 & 1.112385 & 0.936386753 & 0.897413208 \\
\hline 15 Years & 1.883486136 & 1.062935 & 0.961680074 & 0.939793602 \\
\hline 20 Years & 1.458063288 & 1.035283 & 0.977377238 & 0.965059942 \\
\hline 25 Years & 1.169850138 & 1.013872 & 0.990736347 & 0.985896065 \\
\hline All & 1.000000000 & 1.00000 & 1.000000000 & 1.000000000 \\
\hline
\end{tabular}


Table 16: 7 Fracs (Ads. Gas) Duong Table of Ratios

\begin{tabular}{|l|c|c|c|c|}
\hline \multicolumn{5}{|c|}{7 Fracs (Adsorbed Gas) Table of Ratios } \\
\hline Duong & $\boldsymbol{a}$ & $\boldsymbol{m}$ & $\boldsymbol{q}_{\boldsymbol{1}}$ & $\boldsymbol{q}_{\boldsymbol{\infty}}$ \\
\hline 2 Years & 0.933490351 & 0.97700 & 1.116292700 & 3.506897020 \\
\hline 5 Years & 0.947213007 & 0.982959 & 1.077645898 & 2.456007042 \\
\hline $\mathbf{7}$ Years & 0.955041219 & 0.985877 & 1.062533762 & 2.100076659 \\
\hline 10 Years & 0.965501688 & 0.989445 & 1.045032798 & 1.742469097 \\
\hline 11 Years & 0.968290519 & 0.990374 & 1.040505833 & 1.656883453 \\
\hline 12 Years & 0.970815342 & 0.991262 & 1.037045089 & 1.575001402 \\
\hline 15 Years & 0.978770826 & 0.993693 & 1.025760197 & 1.392570808 \\
\hline 20 Years & 0.987794640 & 0.996478 & 1.014251783 & 1.200430051 \\
\hline 25 Years & 0.994623768 & 0.998511 & 1.006405524 & 1.077065060 \\
\hline All & 1.000000000 & 1.00000 & 1.000000000 & 1.000000000 \\
\hline
\end{tabular}

Figure 40 through Figure 50 below show plots of the dimensionless ratio versus time when plotted on log-log scale for every constant of the Arps, PLE, and Duong DCA models having seven fractures with adsorbed gas. Thirteen fractures with adsorbed gas can be found in Figure 102 through Figure 112, located in the Appenidx.

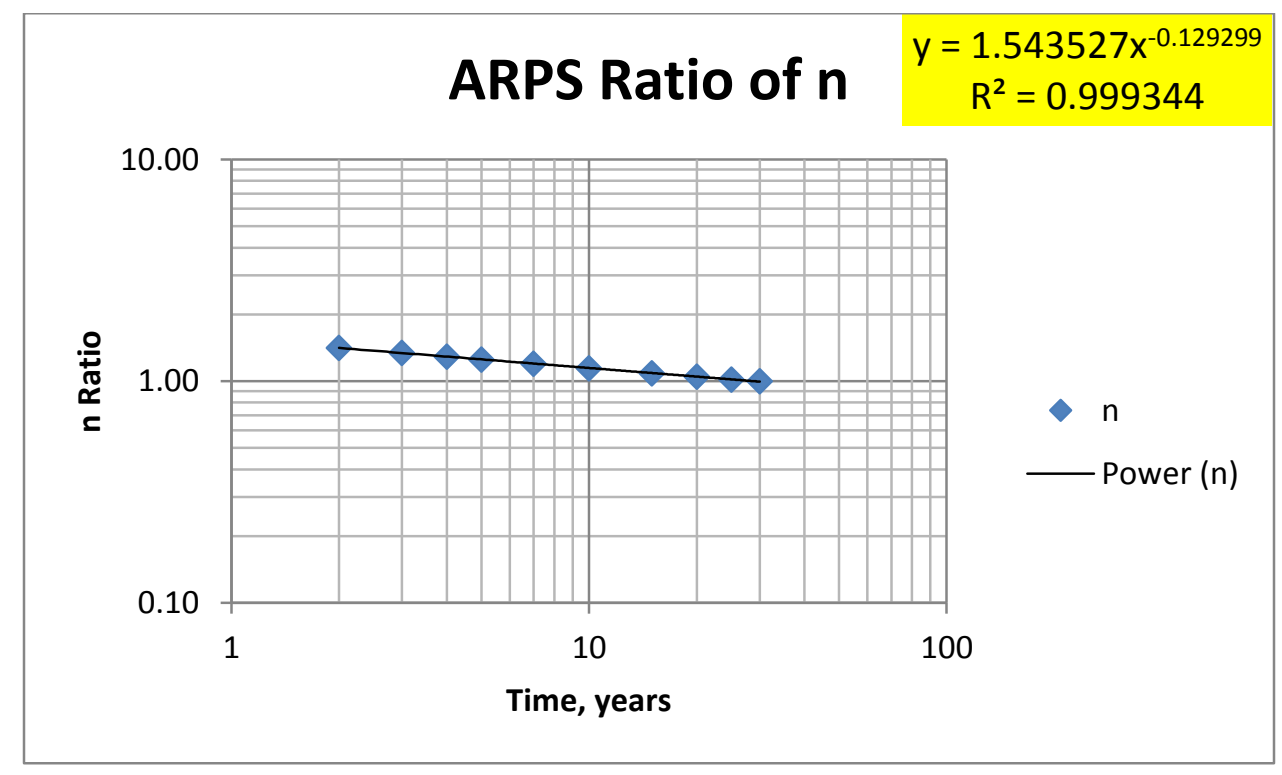

Figure 40: 7 Fracs (Ads. Gas) Arps Ratio of $n$ vs. Time 


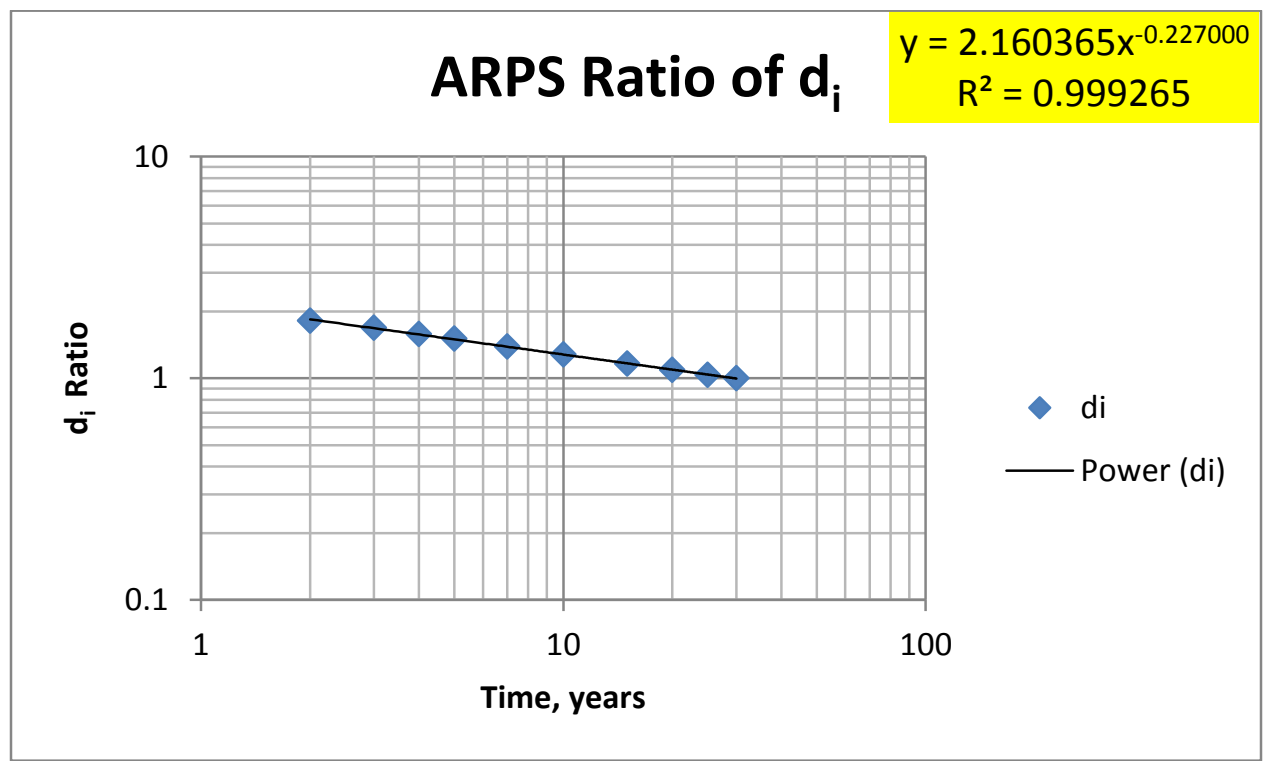

Figure 41: 7 Fracs (Ads. Gas) Arps Ratio of di vs. Time

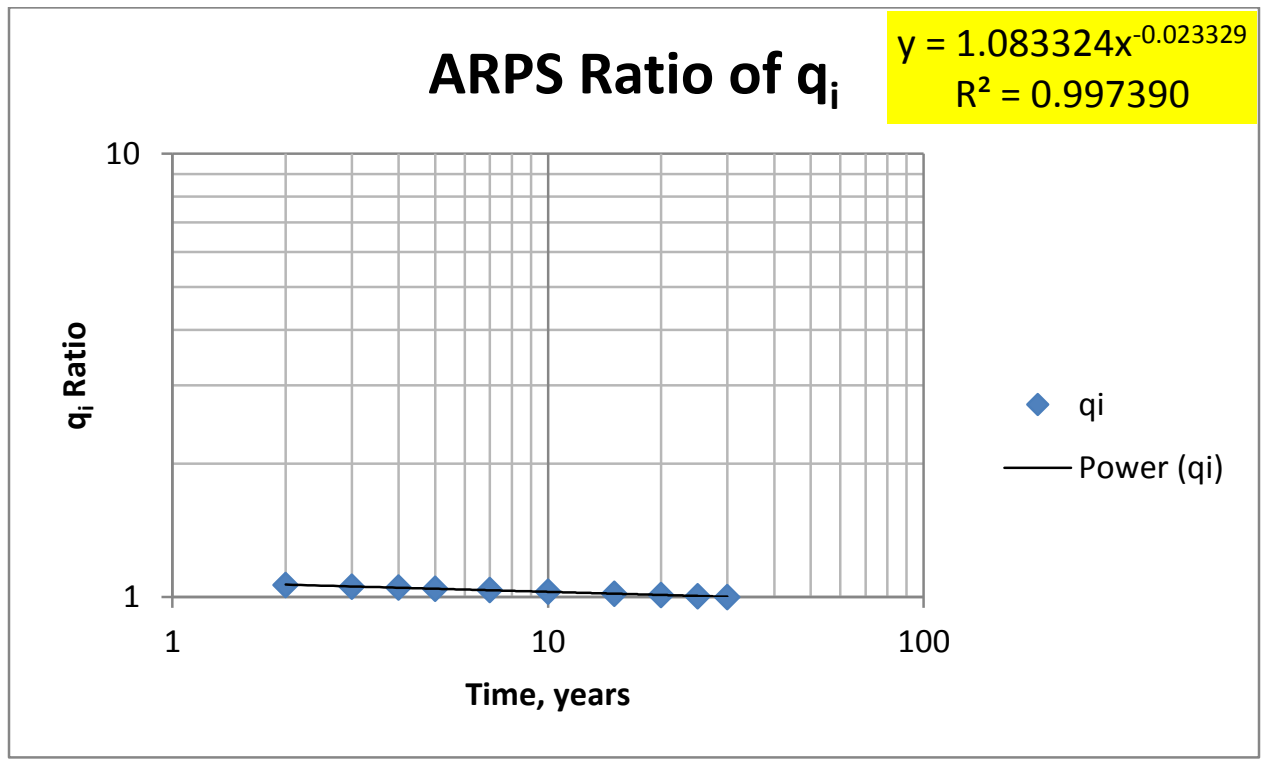

Figure 42: 7 Fracs (Ads. Gas) Arps Ratio of $q_{i}$ vs. Time 


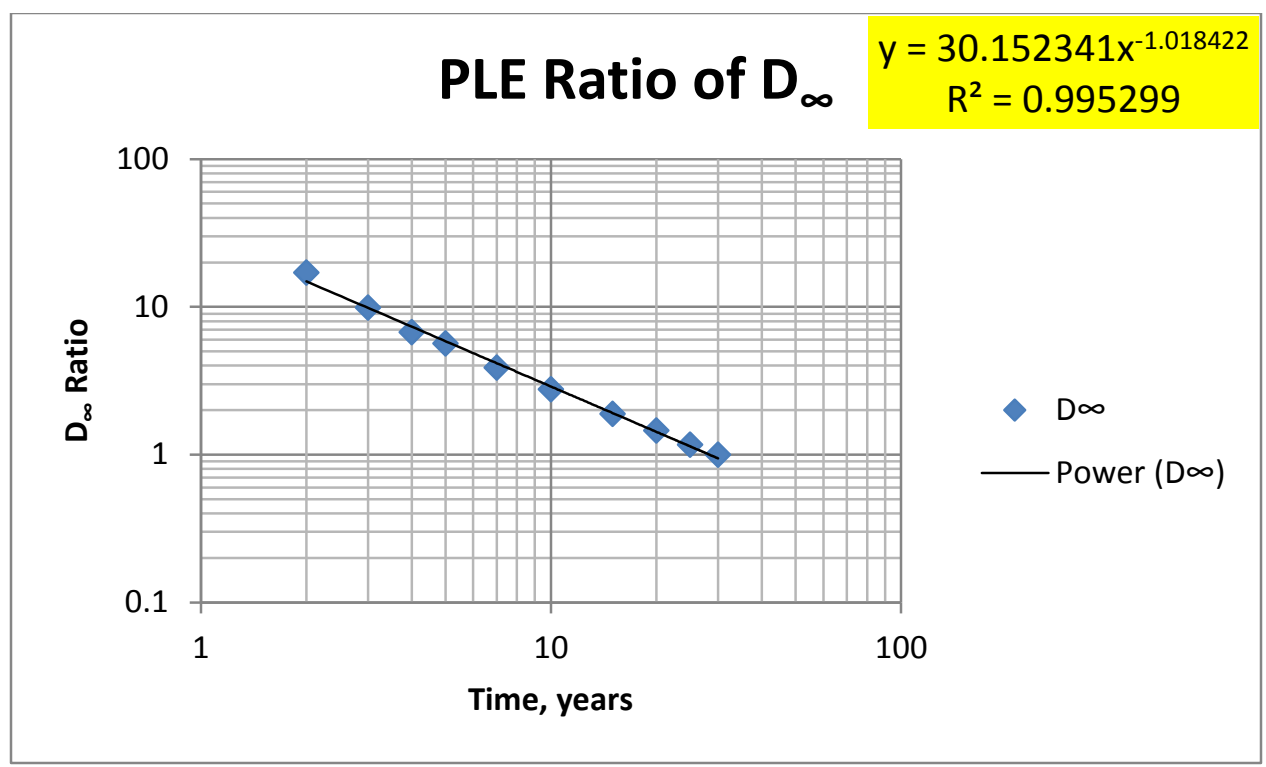

Figure 43: 7 Fracs (Ads. Gas) PLE Ratio of $D_{\infty}$ vs. Time

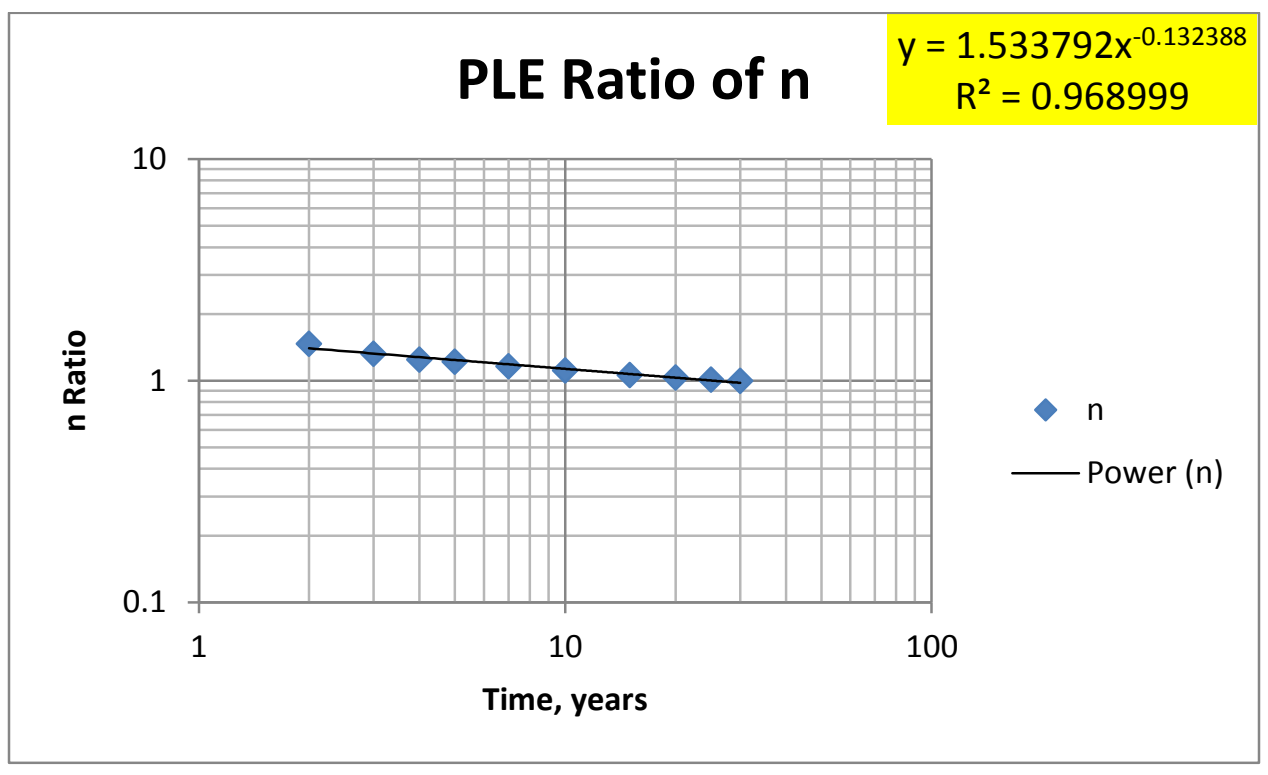

Figure 44: 7 Fracs (Ads. Gas) PLE Ratio of n vs. Time 


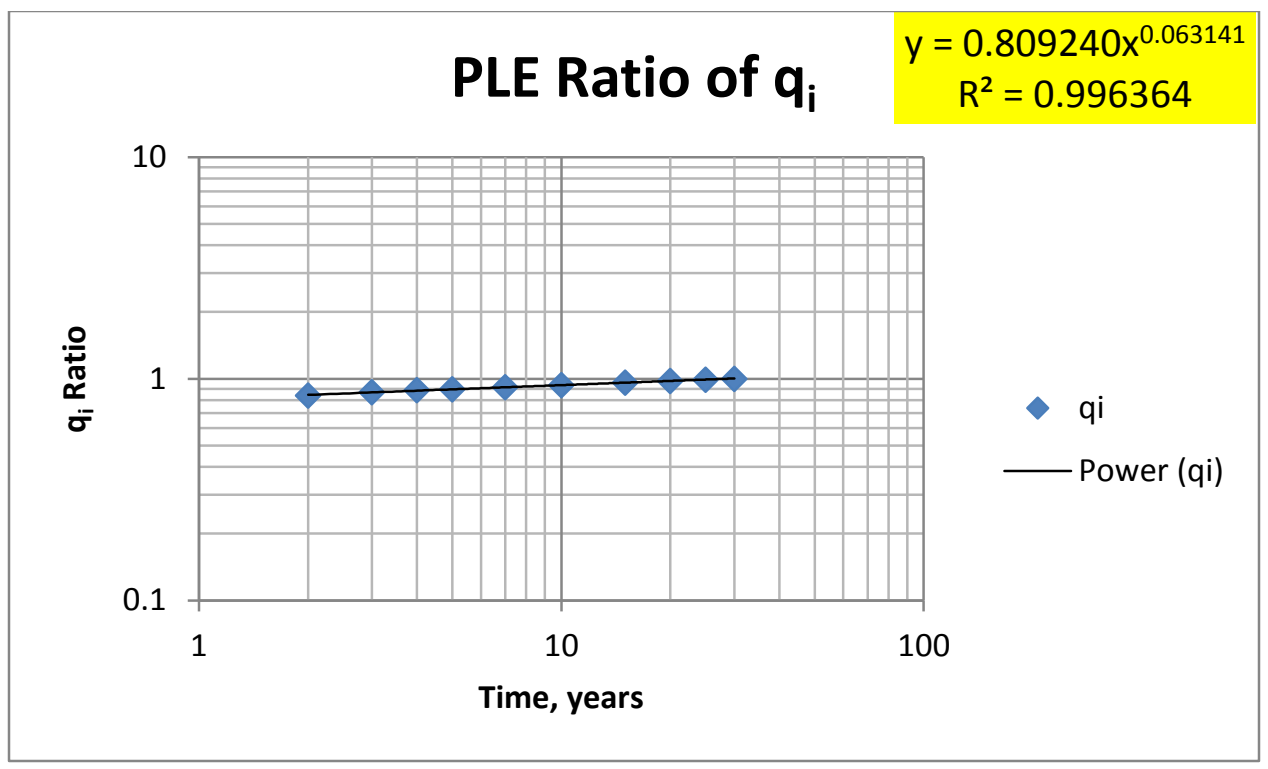

Figure 45: 7 Fracs (Ads. Gas) PLE Ratio of $q_{i}$ vs. Time

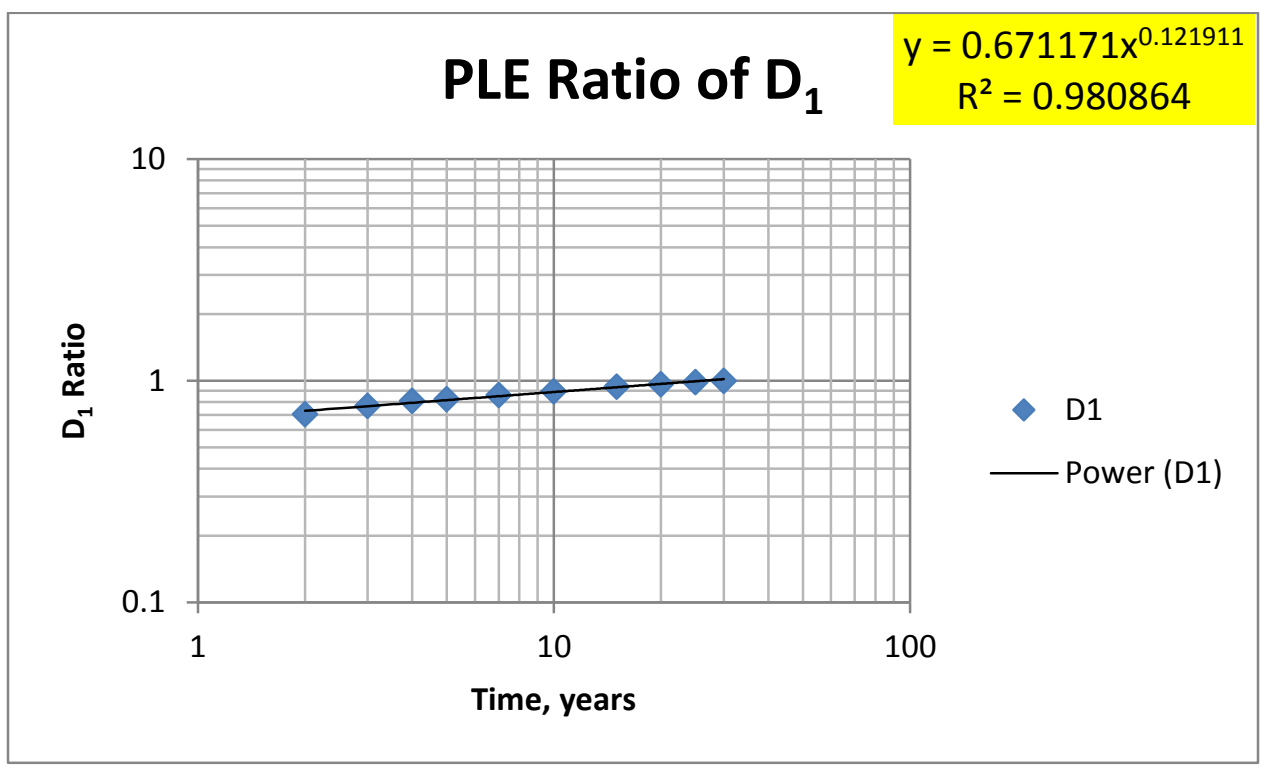

Figure 46: 7 Fracs (Ads. Gas) PLE Ratio of $D_{1}$ vs. Time 


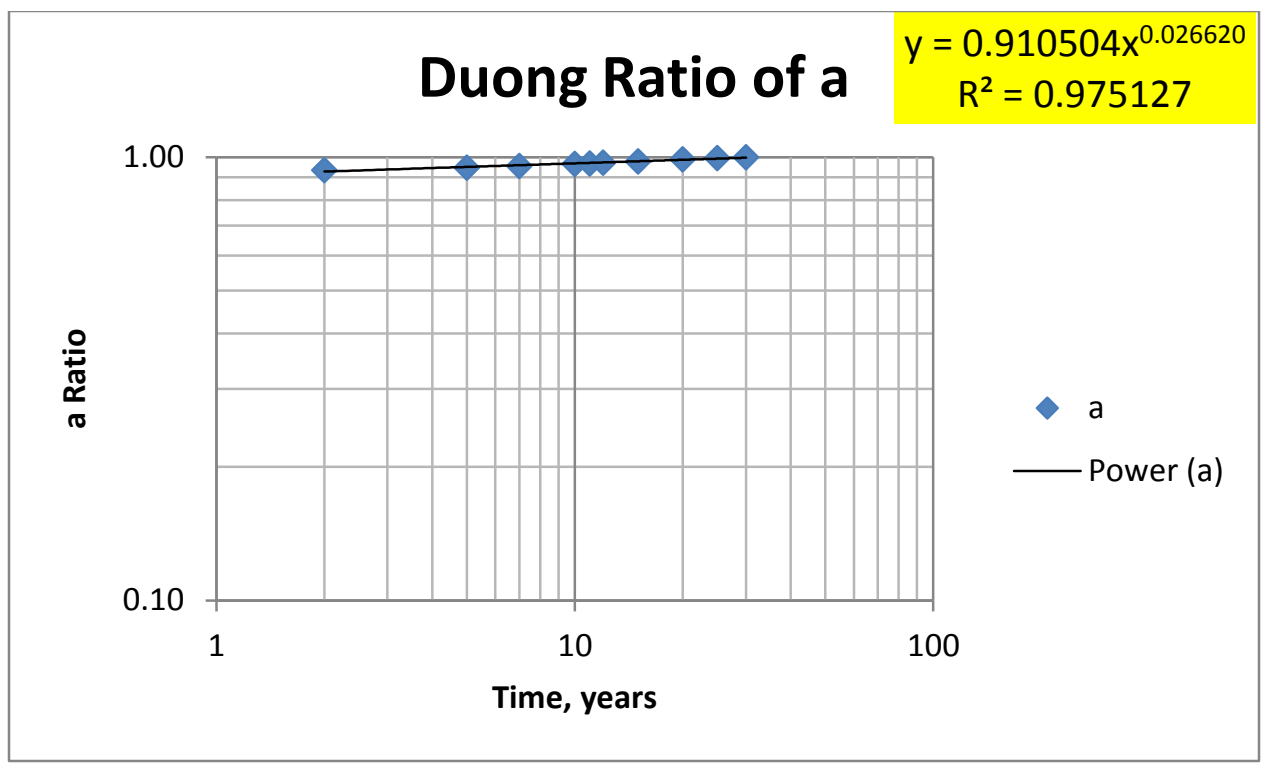

Figure 47: 7 Fracs (Ads. Gas) Duong Ratio of a vs. Time

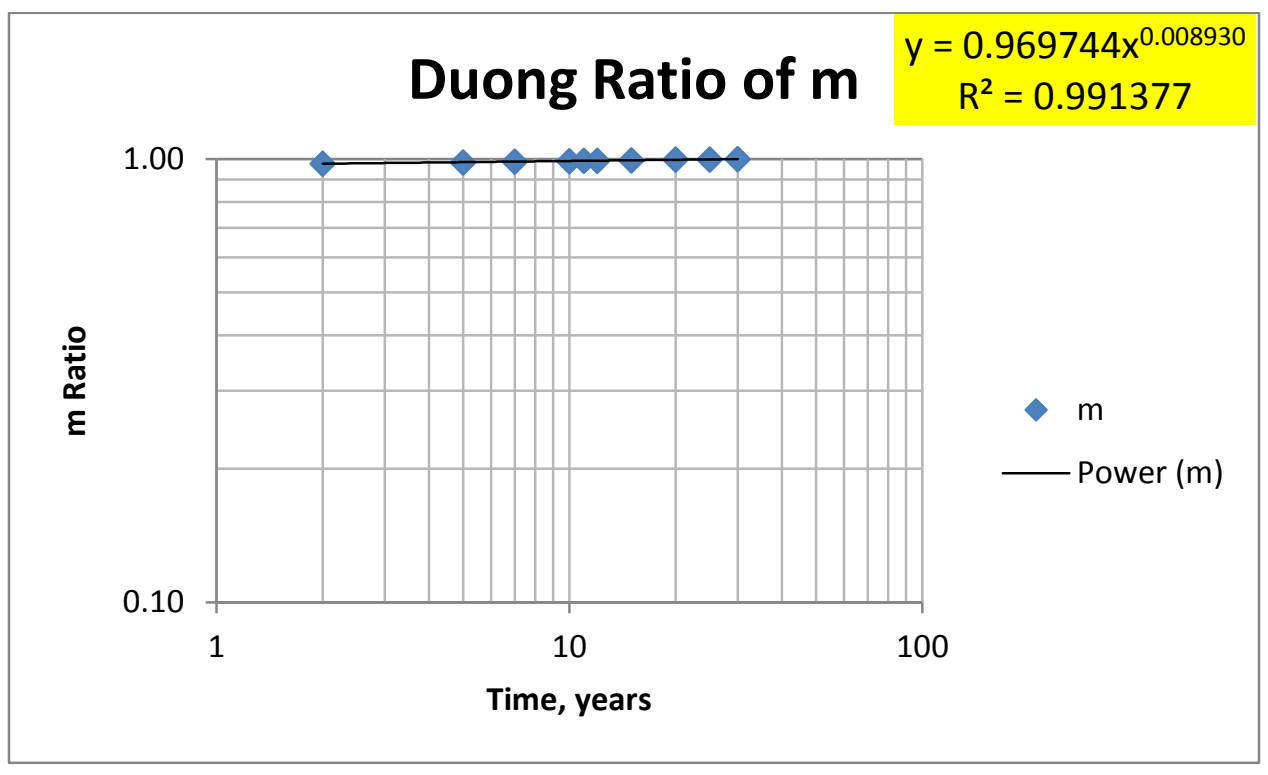

Figure 48: 7 Fracs (Ads. Gas) Duong Ratio of $m$ vs. Time 


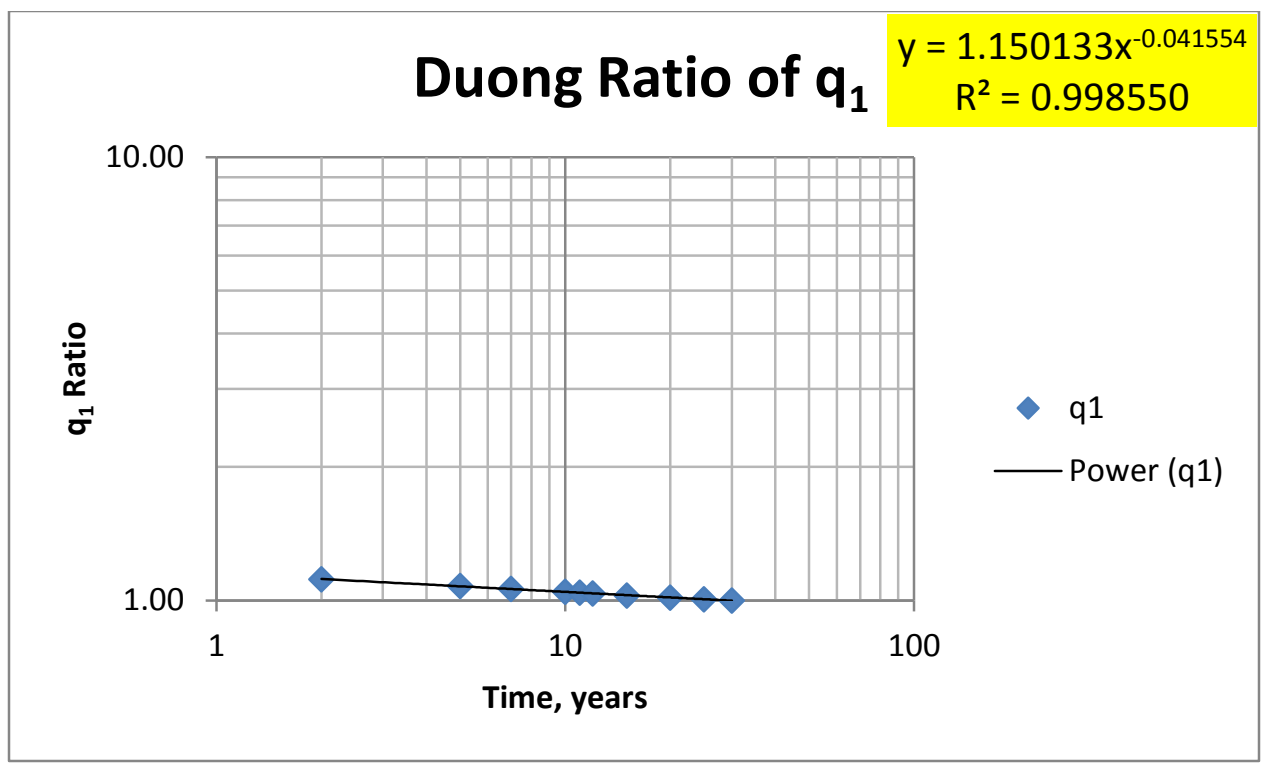

Figure 49: 7 Fracs (Ads. Gas) Duong Ratio of q1 vs. Time

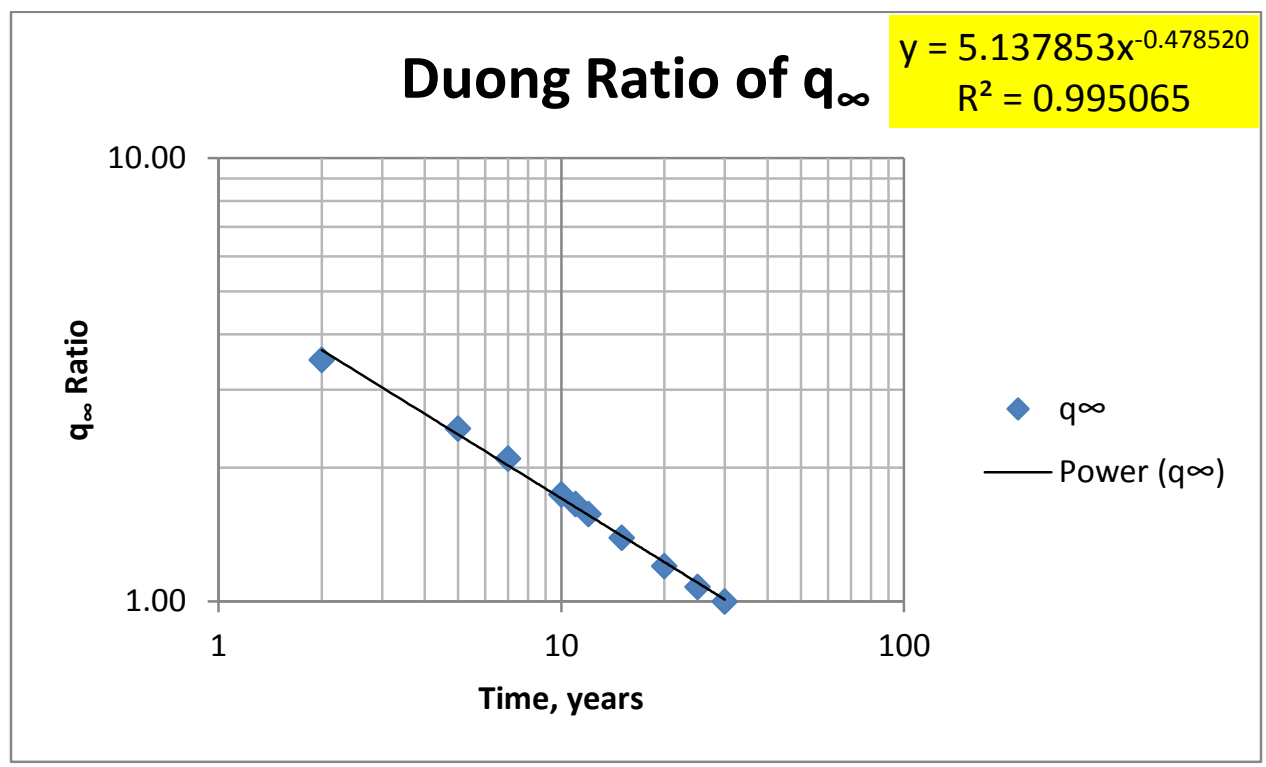

Figure 50: 7 Fracs (Ads. Gas) Duong Ratio of $q_{\infty}$ vs. Time

The following results in Table 17 through Table 19 show values of the log-log ratio when computed at 4.274 years of production history using the Arps, PLE, and Duong DCA models derived from seven fractures with adsorbed gas (a hydraulic fracture spacing of 500 feet). Log- 
$\log$ ratios evaluated at 4.274 years for thirteen fractures with gas adsorption (a hydraulic fracture spacing of 250 feet) can be seen in Table 38 through Table 40, located in the Appendix.

Table 17: 7 Fracs (Ads. Gas) Arps Well 1 Ratio Values

\begin{tabular}{|c|c|c|c|}
\hline \multicolumn{4}{|c|}{7 Fracs (Adsorbed Gas) Arps Well 1 Ratio Values } \\
\hline Well 1 (Years) & $n$ & $d_{i}$ & $q_{i}$ \\
\hline 4.273972603 & 1.279229065 & 1.553561067 & 1.047229074 \\
\hline
\end{tabular}

Table 18: 7 Fracs (Ads. Gas) PLE Well 1 Ratio Values

\begin{tabular}{|c|c|c|c|c|}
\hline \multicolumn{5}{|c|}{7 Fracs (Adsorbed Gas) PLE Well 1 Ratio Values } \\
\hline Well 1 (Years) & $D_{\infty}$ & $n$ & $\boldsymbol{q}_{i}$ & $\boldsymbol{D}_{1}$ \\
\hline 4.273972603 & 6.86859833 & 1.265470183 & 0.88697 & 0.801196 \\
\hline
\end{tabular}

Table 19: 7 Fracs (Ads. Gas) Duong Well 1 Ratio Values

\begin{tabular}{|c|c|c|c|c|}
\hline \multicolumn{5}{|c|}{7 Fracs (Adsorbed Gas) Duong Well 1 Ratio Values } \\
\hline Well 1 (Years) & $\boldsymbol{q}_{\infty}$ & $\boldsymbol{a}$ & $\boldsymbol{q}_{1}$ & $\boldsymbol{m}$ \\
\hline 4.273972603 & 2.563988501 & 0.946399711 & 1.082766 & 0.981634 \\
\hline
\end{tabular}

The actual values of constants using the Arps, PLE, and Duong models were obtained and are shown graphically in Figure 51 through Figure 53. 


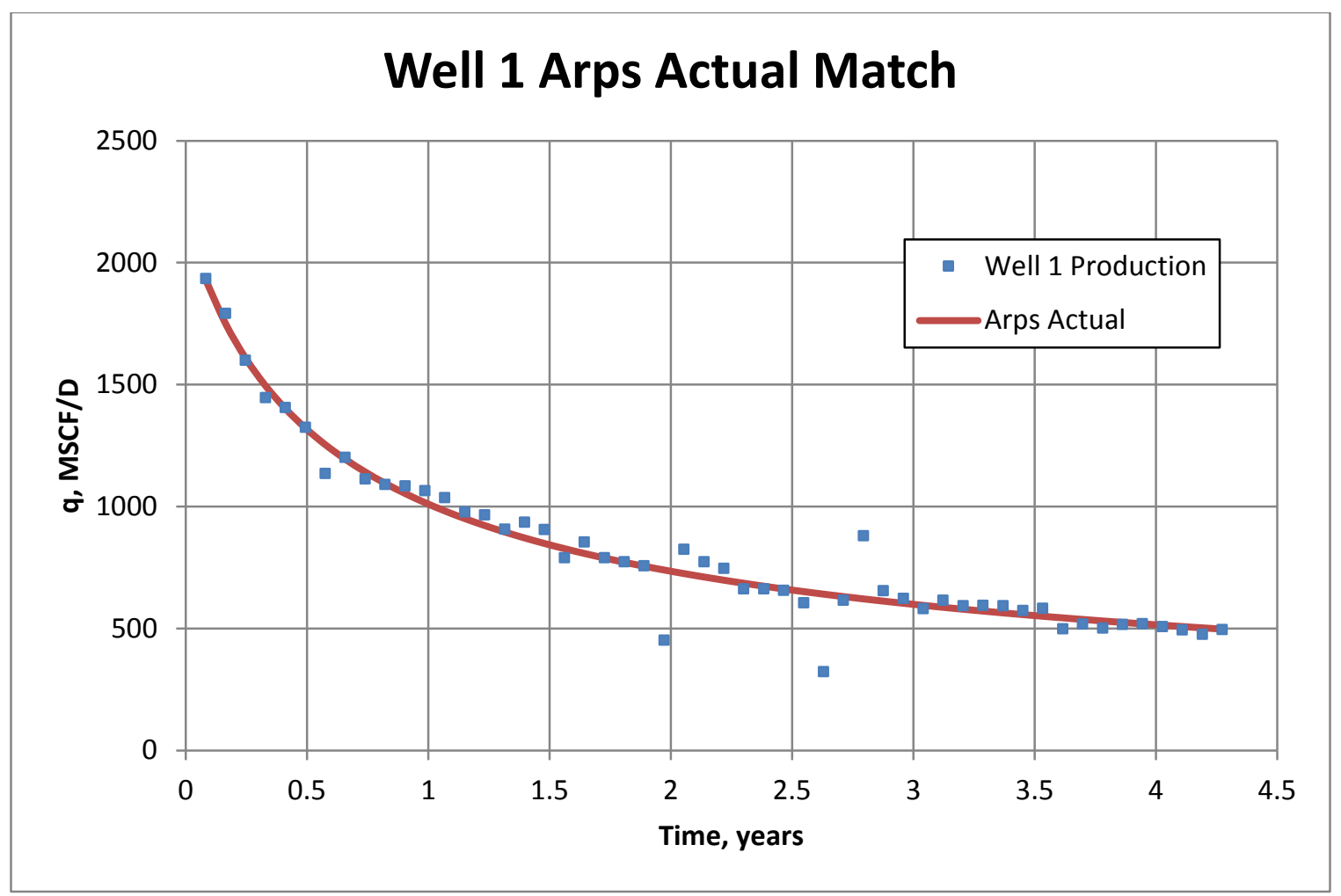

Figure 51: Well 1 Arps Actual Match

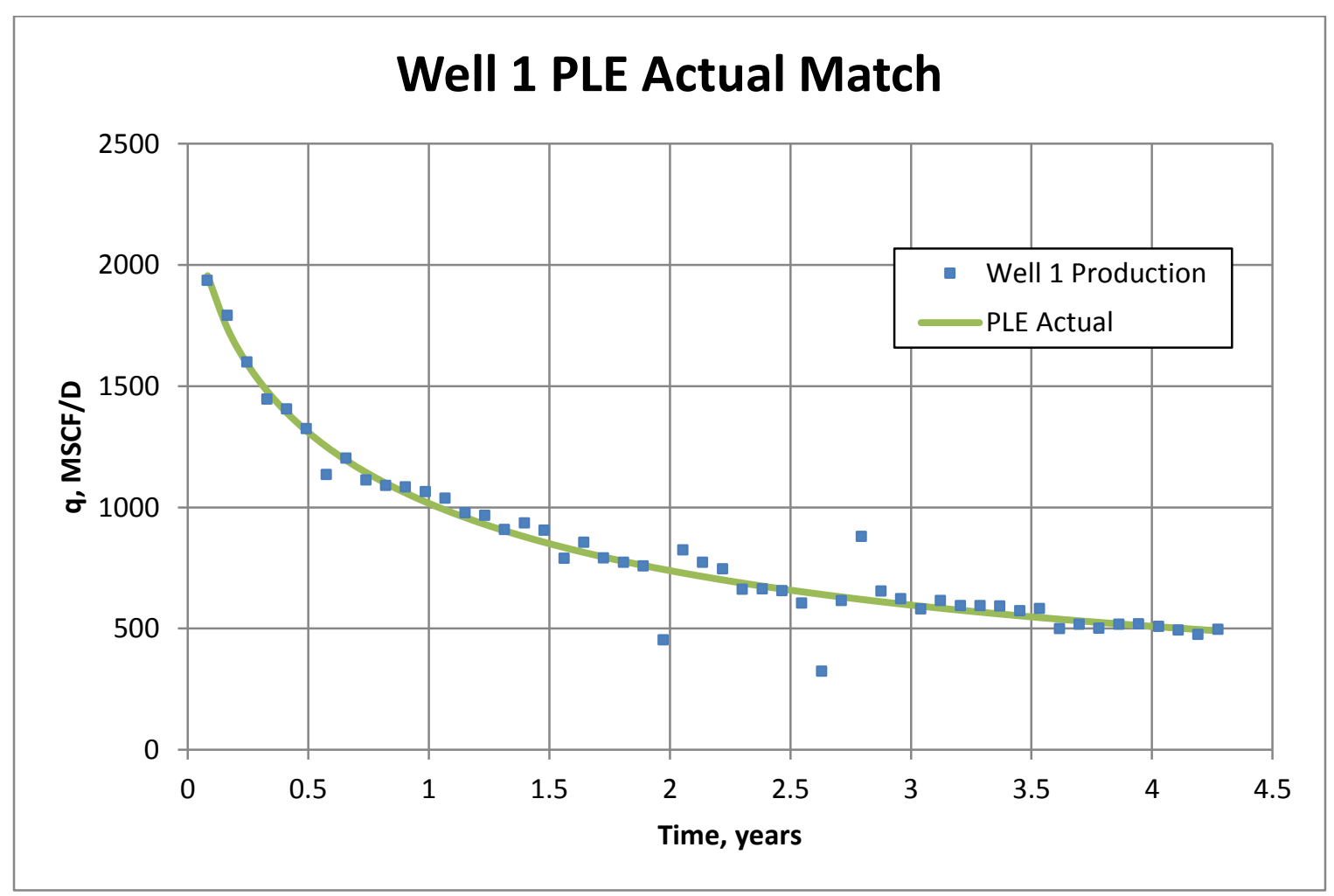

Figure 52: Well 1 PLE Actual Match 


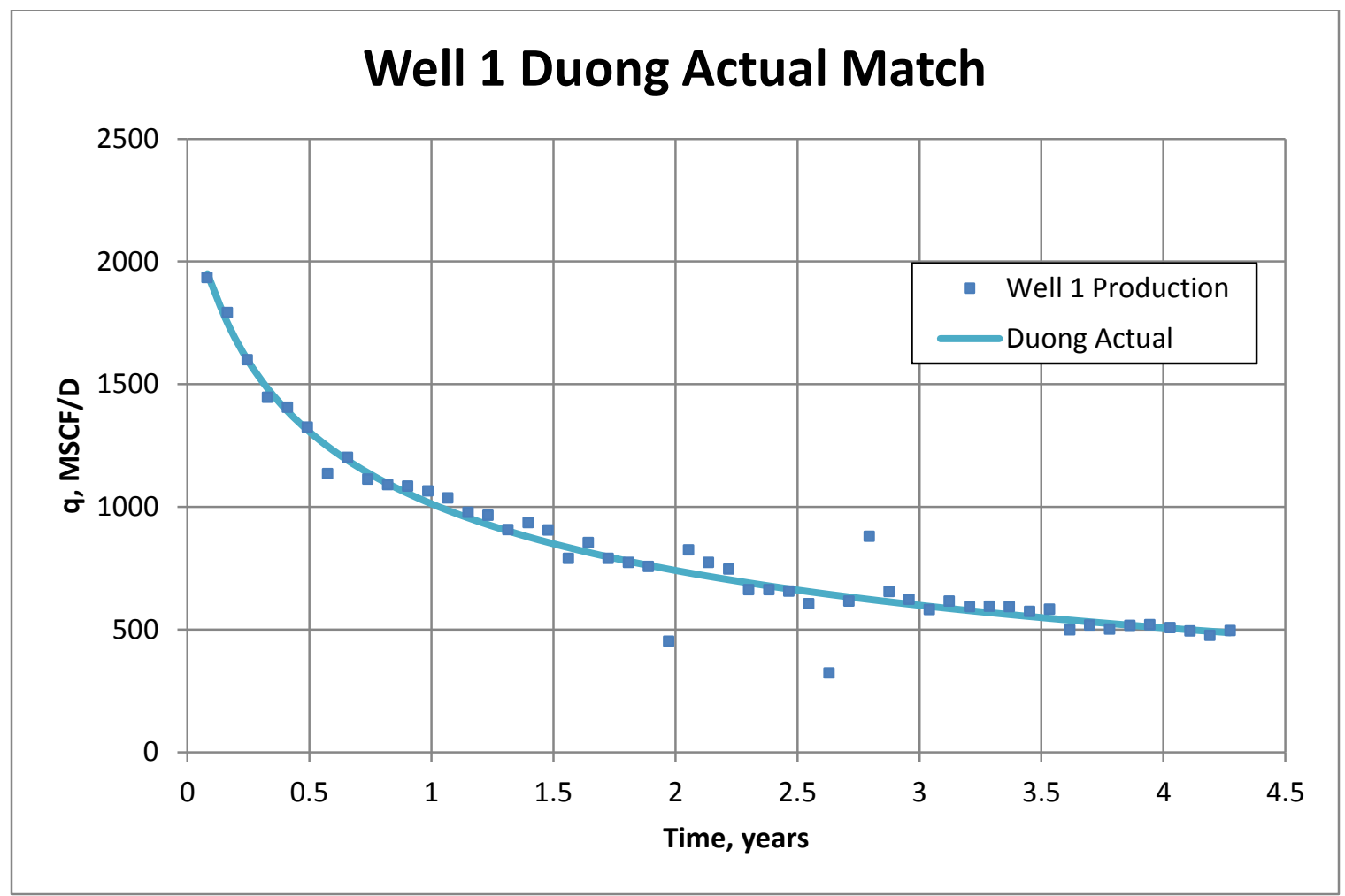

Figure 53: Well 1 Duong Actual Match

Actual values are shown numerically in Table 20 through Table 22 along with the predicted values. As stated previously, the predicted values are obtained by dividing the actual value by the ratio value from Table 17 through Table 19 for seven fractures with adsorbed gas. Corresponding tables are shown for thirteen fractures with adsorbed gas in Table 41 through Table 43, found in the Appendix.

Table 20: 7 Fracs (Ads. Gas) Arps Well 1 Actual and Predicted Values

\begin{tabular}{|c|c|c|}
\hline Well 1 & Actual & Predicted \\
\hline$n$ & 1.726571773 & $\mathbf{1 . 3 4 9 6 9 7 1 1}$ \\
\hline$d_{i}$ & 0.004360324 & $\mathbf{0 . 0 0 2 8 0 6 6 6 4}$ \\
\hline$q_{i}$ & $2,171.430282$ & $\mathbf{2 0 7 3 . 5 0 0 7 6 1}$ \\
\hline
\end{tabular}


Table 21: 7 Fracs (Ads. Gas) PLE Well 1 Actual and Predicted Values

\begin{tabular}{|c|c|c|}
\hline Well 1 & Actual & Predicted \\
\hline$D_{\infty}$ & -0.000382914 & $-\mathbf{0 . 0 0 0 0 5 5 7 4 9}$ \\
\hline$n$ & 0.506990695 & $\mathbf{0 . 4 0 0 6 3 4 2 4 8}$ \\
\hline$q_{i}$ & 2627.174227 & $\mathbf{2 9 6 1 . 9 6 6 8 0 6}$ \\
\hline$D_{1}$ & 0.027735762 & $\mathbf{0 . 0 3 4 6 1 7 9 7}$ \\
\hline
\end{tabular}

Table 22: 7 Fracs (Ads. Gas) Duong Well 1 Actual and Predicted Values

\begin{tabular}{|c|r|r|}
\hline Well 1 & \multicolumn{1}{|c|}{ Actual } & \multicolumn{1}{c|}{ Predicted } \\
\hline $\boldsymbol{a}$ & 1.482659542 & 1.56663144 \\
\hline $\boldsymbol{m}$ & 1.113649238 & $\mathbf{1 . 1 3 4 4 8 4 7 0 4}$ \\
\hline$q_{1}$ & $1,414.02$ & 1305.935384 \\
\hline$q_{\infty}$ & -148.7245961 & $-\mathbf{5 8 . 0 0 5 1 7 2 8 3}$ \\
\hline
\end{tabular}

Predicted values were then extrapolated to thirty years of production. The predictions can be seen graphically in Figure 54 through Figure 56 for the Arps, PLE, and Duong models derived from seven with adsorbed gas. Predictions for thirteen fractures with adsorbed gas be seen in Figure 113 through Figure 115, located in the Appenidx. 


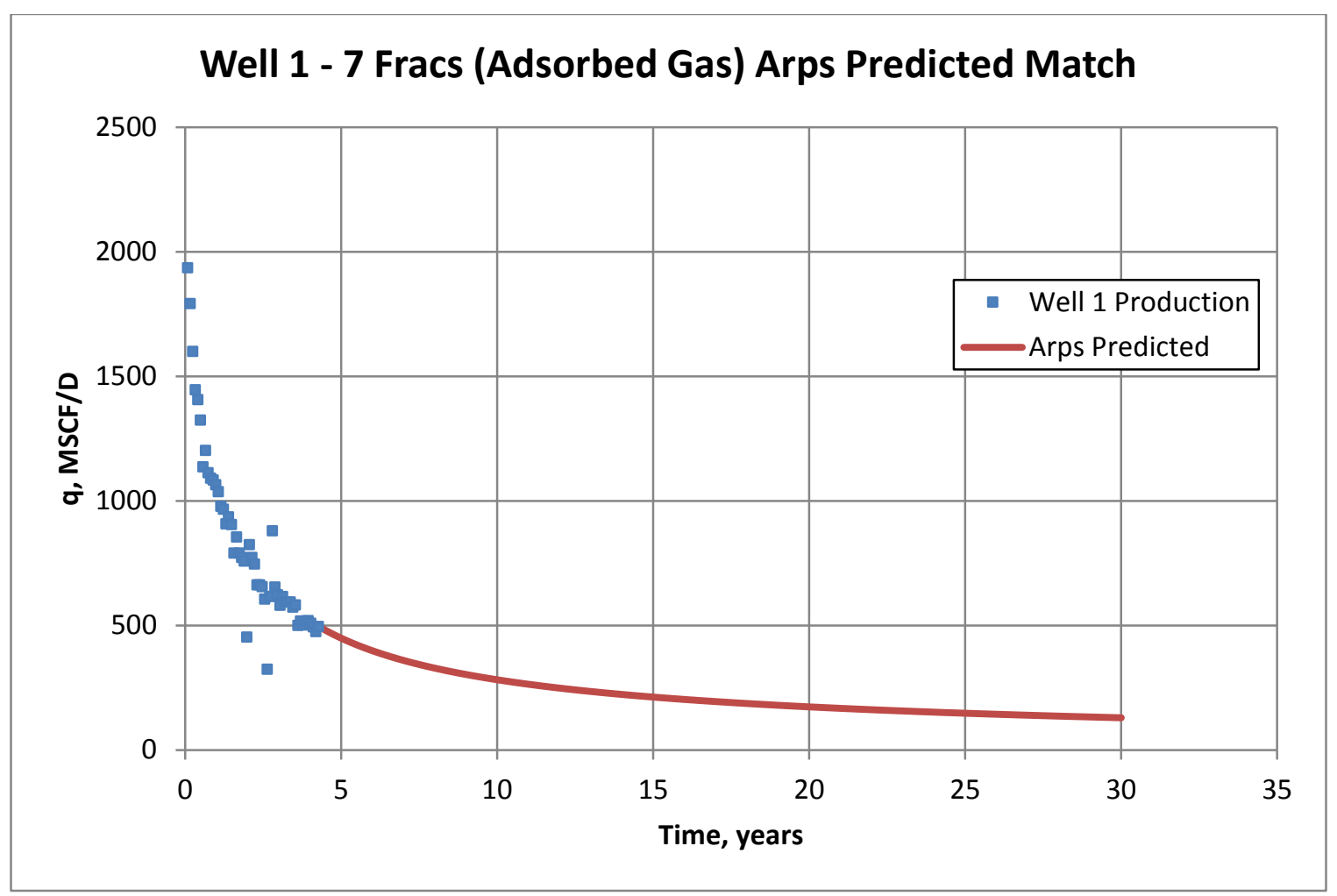

Figure 54: Well 1 - 7 Fracs (Ads. Gas) Arps Predicted Match

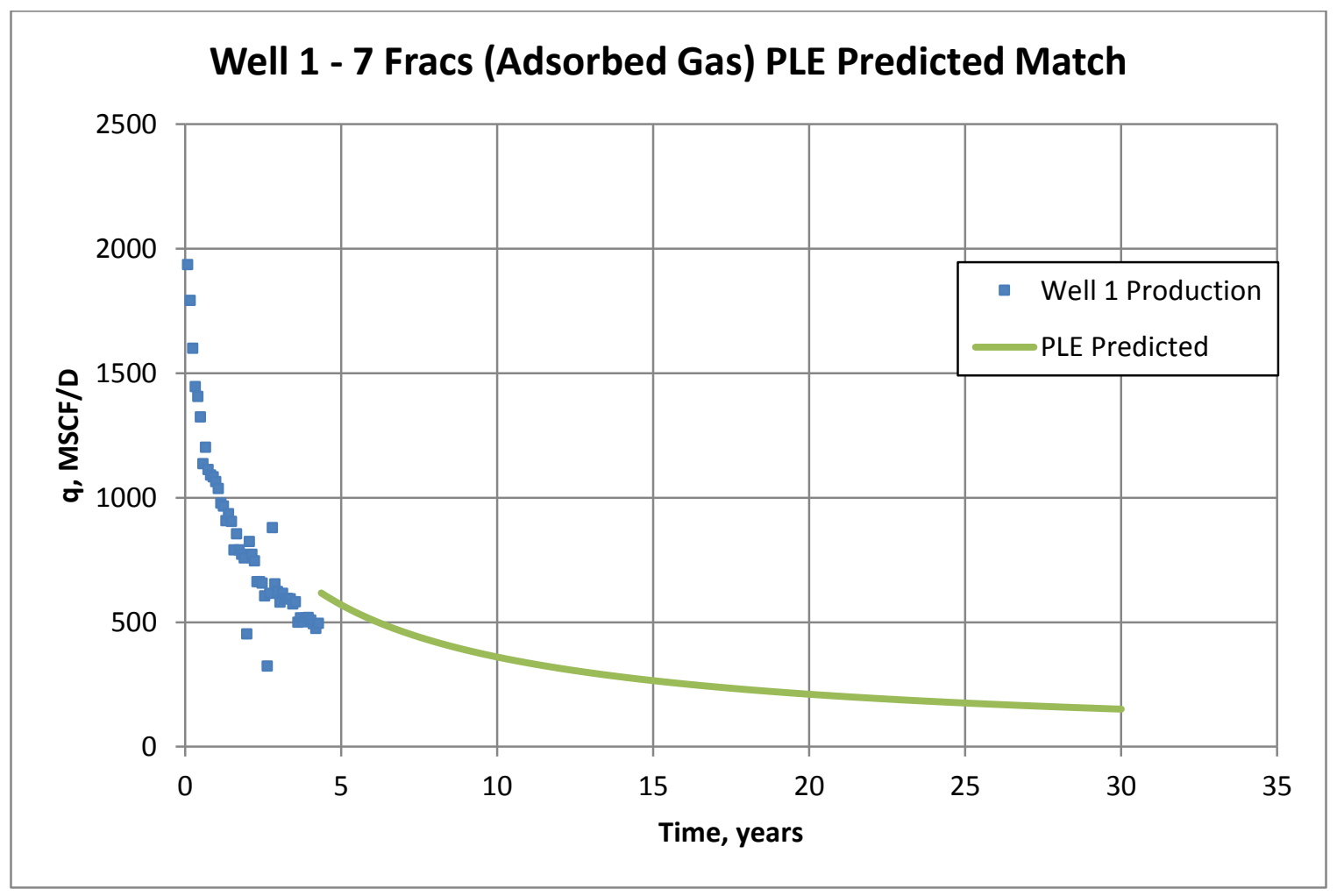

Figure 55: Well 1 - 7 Fracs (Ads. Gas) PLE Predicted Match 


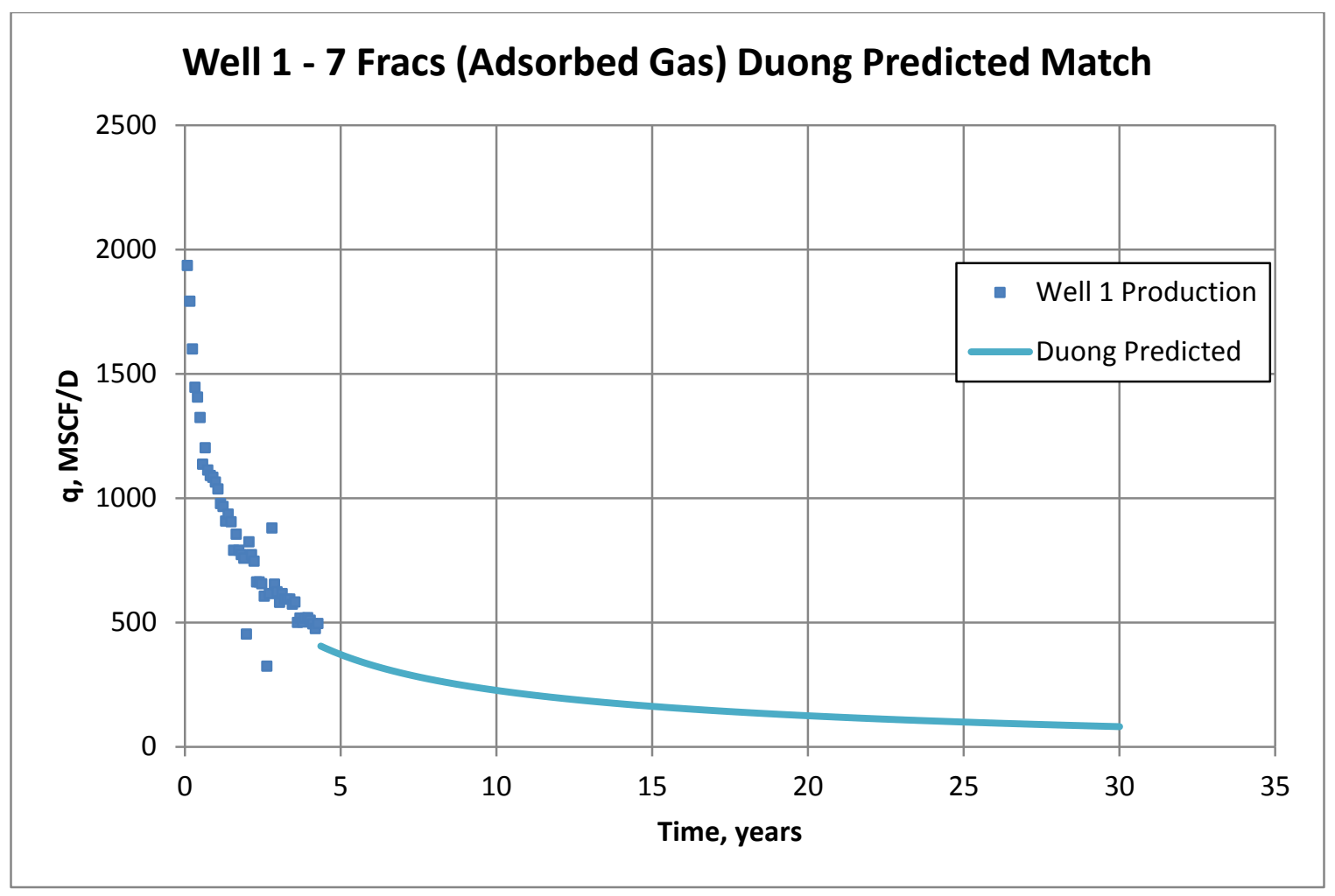

Figure 56: Well 1 - 7 Fracs (Ads. Gas) Duong Predicted Match

To confirm predicted results for Well 1 (hydraulic fracture spacing of 429 feet) obtained via the method of ratios described above, the Well 1 history match data generated from Eclipse earlier was used (also a hydraulic fracture spacing of 429 feet). Comparing the predicted values for Well 1 to the simulated data will enable the determination of which DCA model matches most closely. Figure 57 below shows the comparison between Well 1 predicted values and the Eclipse simulator data from 4.274 years until 30 years of production history. The Well 1 predicted values for thirteen fractures with adsorbed gas can be seen in Figure 116, located in the Appenix. 


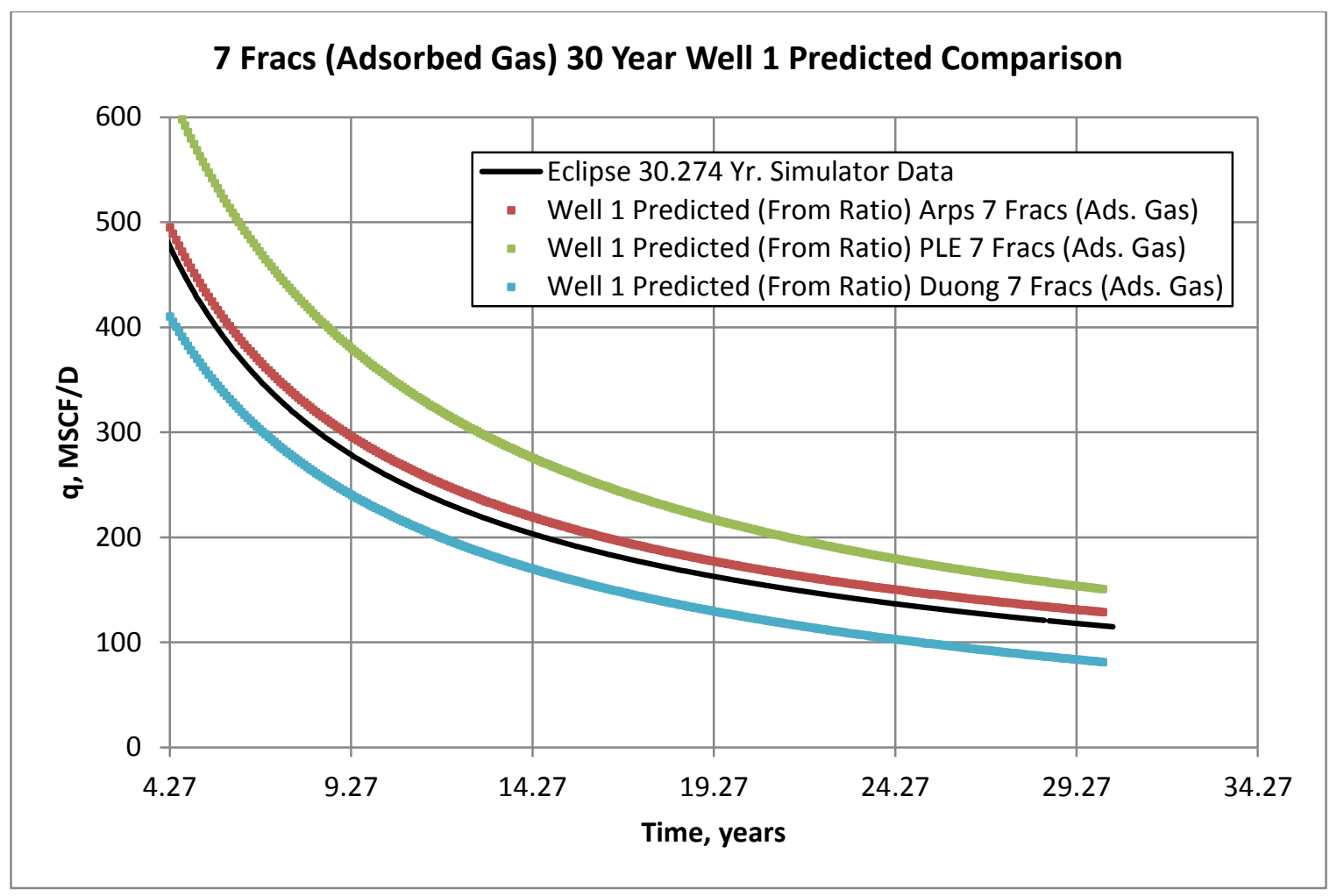

Figure 57: 7 Fracs (Ads. Gas) 30 Year Well 1 Predicted Comparison

As Figure 57 and Figure 116 show, the best match for Well 1 (429 feet hydraulic fracture spacing) to the Eclipse simulator data (429 feet fracture spacing) occurs with the Arps DCA model derived by the method of ratios from seven fractures and adsorbed gas (500 feet fracture spacing). The PLE and Duong models for both seven and thirteen fractures having adsorbed gas overestimated and underestimated, respectively, when compared to the Eclipse data. The Well 1 predicted value using Arps for thirteen fractures having adsorbed gas also overestimates simulator data to a greater extent than Arps for seven fractures having adsorbed gas.

The results obtained confirm the idea that hydraulic fracture spacing in field data should be closer to correlations and ratios derived from simulator data nearest to that spacing value. In the analysis performed above, the hydraulic fracture spacing of Well 1 was given as 429 feet, which is much closer to the value of the initial Eclipse reservoir model having seven fractures 
and a hydraulic fracture spacing of 500 feet than thirteen fracture Eclipse model with hydraulic fracture spacing of 250 feet.

The Arps model when applied to thirteen fractures (a hydraulic fracture spacing of 250 feet) initially matches the additional Eclipse simulator data. However, shortly thereafter the prediction varies significantly. The decrease in spacing between fractures attributes to interference between them, resulting in deviation from simulator predictions. A thirteen fracture reservoir (a hydraulic fracture spacing of 250 feet) will produce gas at a greater rate initially than a seven fracture (a hydraulic fracture spacing of 500 feet) or an eight fracture reservoir (a hydraulic fracture spacing of 429 feet), as seen in both Well 1 and its Eclipse simulator data. After this point, as reservoir boundaries are slowly approached, deviations between a seven, eight, and thirteen fracture reservoir begin to diminish. 


\section{Conclusions and Recommendations}

1) The technique of developing a correlation based on dual porosity simulated production history, applying the method of ratios to simulated data, and confirming results with field and separate dual porosity simulator data proved successful in this analysis. Limited Well 1 Marcellus data (a hydraulic fracture spacing of 429 feet) matched most closely with the correlations and ratios derived from seven fractures having adsorbed gas (a hydraulic fracture spacing of 500 feet) using the Arps DCA model than other models for both seven and thirteen fractures (a hydraulic fracture spacing of 250 feet).

2) Additional analysis could be performed on actual field production data. The limited availability of Marcellus horizontal well production history is at present a hindrance to histories greater than approximately six years. With time, more production history will enhance and broaden the scope of results and analysis presented within this report.

3) Further investigation of actual well data obtained from a geographically diverse area within the Marcellus boundary would increase the applicability of methodologies presented to a wider geological realm. Varying inherent properties of the Marcellus shale will undoubtedly cause results obtained via the method of ratios to differ slightly when applied to different geographical locations. Which specific Marcellus characteristics affect these differences remains to be seen.

4) Adjustments to simulator data when obtaining correlations would also have significant impact in results obtained. Narrowing and defining model parameters to more accurately simulate Marcellus wells would improve accuracy. Changing the length of the horizontal fracture spacing and reservoir area dimensions are two such examples. 


\section{$\underline{\text { 6. References }}$}

Arps, J.J. 1945. Analysis of Decline Curves. Trans. AIME 160: 228-247.

Belvalkar, R. and Oyewole, S. Development of Marcellus Shale in Pennsylvania. Paper 134852MS presented at the SPE Annual Technical Conference and Exhibition, Florence, Italy, 19-22 September 2010. doi: 10.2118/134852-MS.

Belyadi, A et. al. 2010. Performance of the Hydraulically Fractured Horizontal Wells in Low Permeability Formation. Paper 139082-MS presented at the SPE Eastern Regional Meeting, Morgantown, West Virginia, USA, 12-14 October 2010. doi: 10.2118/139082MS.

Duong, A.N. 2011. Rate-Decline Analysis for Fracture-Dominated Shale Reservoirs. SPE Reservoir Evaluation \& Engineering (3): pp. 377-387. doi: 10.2118/137748-PA.

Fetkovitch, M.J., Fetkovitch, E.J., and Fetkovitch, M.D. 1996. Useful Concepts for Decline Curve Forecasting, Reserve Estimation, and Analysis. SPE Reservoir Engineering 11 (1): $13-22$.

Hassett, K.A. and Mathur, A. 2013. Benefits of Hydraulic Fracking. Oxford Energy Forum. February 2013. pp. 11-13. 
Ilk, D. et. al. 2008. Exponential vs. Hyperbolic Decline in Tight Gas Sands: Understanding the Origin and Implications for Reserve Estimates Using Arps' Decline Curves. Paper 116731-MS presented at the SPE Annual Technical Conference and Exhibition, Denver, Colorado, USA, 21-24 September 2008. doi: 10.2118/116731-MS.

Joshi, K. and Lee, J. 2013. Comparison of Various Deterministic Forecasting Techniques in Shale Gas Reservoirs. Paper 163870-MS presented at the 2013 SPE Hydraulic Fracturing Technology Conference, The Woodlands, Texas, USA, 04-06 February 2013. doi: 10.2118/163870-MS.

Joshi, K.J. 2012. Comparison of Various Deterministic Forecasting Techniques in Shale Gas Reservoirs with Emphasis on the Duong Method. MS Thesis, Department of Petroleum Engineering, Texas A\&M University.

Kanfar, M.S. and Wattenbarger, R.A. 2012. Comparison of Empirical Decline Curve Methods for Shale Wells. Paper SPE 162648-MS presented at the SPE Canadian Unconventional Resources Conference, Calgary, Alberta, Canada, 30 October-01 November 2012. doi: 10.2118/162648-MS.

Mishra, S. 2012. A New Approach to Reserves Estimation in Shale Gas Reservoirs Using Multiple Decline Curve Analysis Models. Paper 161092-MS presented at the SPE Eastern Regional Meeting, Lexington, Kentucky, USA, 03-05 October 2012. doi: 10.2118/161092-MS. 
Okouma, V. et. al. 2012. Practical Considerations for Decline Curve Analysis in Unconventional Reservoirs --- Application of Recently Developed Rate-Time Relations. Paper 162910MS presented at the SPE Hydrocarbon Economics and Evaluation Symposium, Calgary, Alberta, Canada, 24-25 September 2012. doi: 10.2118/162910-MS.

Seshadri, J. and Mattar, L. 2010. Comparison of Power Law and Modified Hyperbolic Decline Methods. Paper 137320-MS presented at the Canadian Unconventional Resources and International Petroleum Conference, Calgary, Alberta, Canada, 19-21 October 2010. doi: 10.2118/137320-MS.

Towler, Brian F. 2002. Fundamental Principles of Reservoir Engineering. Richardson, Texas: Henry L. Doherty Memorial Fund of AIME, Society of Petroleum Engineers.

Valko, P.P. 2009. Assigning Value to Stimulation in the Barnett Shale: A Simultaneous Analysis of 7000 Plus Production Histories and Well Completion Records. Paper 119369-MS presented at the SPE Hydraulic Fracturing Technology Conference, The Woodlands, Texas, USA, 19-21 January 2009. doi: 10.2118/119369-MS.

Valko, P.P. and Lee, W.J. 2010. A Better Way to Forecast Production from Unconventional Gas Wells. Paper SPE 134231 presented at the SPE Annual Technical Conference and Exhibition, Florence, Italy, 19-22 September. doi: 10.2118/134231-MS. 


\section{Appendix}

\subsection{Correlations and Simulator Match}

As stated previously, using the appropriate models for each of the four scenarios, the constants in each equation were plotted as a function of time. A linear regression analysis was performed to determine trends. For seven fractures with adsorbed gas, the correlations were obtained in Figure 58 to Figure 60 using Arps, in Figure 61 to Figure 64 using PLE, and in Figure 65 to Figure 68 using Duong.

For thirteen fractures with adsorbed gas, the correlations were obtained as shown in Figure 69 through Figure 71 using Arps, in Figure 72 through Figure 75 using PLE, and in Figure 76 through Figure 79 using Duong.

Using the Arps model for seven fractures and without adsorbed gas, the correlations were obtained in Figure 80 through Figure 82 using Arps, in Figure 83 through Figure 86 using PLE, and in Figure 87 through Figure 90 using Duong.

Finally, using the Arps model for thirteen fractures and without adsorbed gas, the following correlations were obtained in Figure 91 through Figure 93 using Arps, in Figure 94 through Figure 97 using PLE, and in Figure 98 through Figure 101 using Duong. 


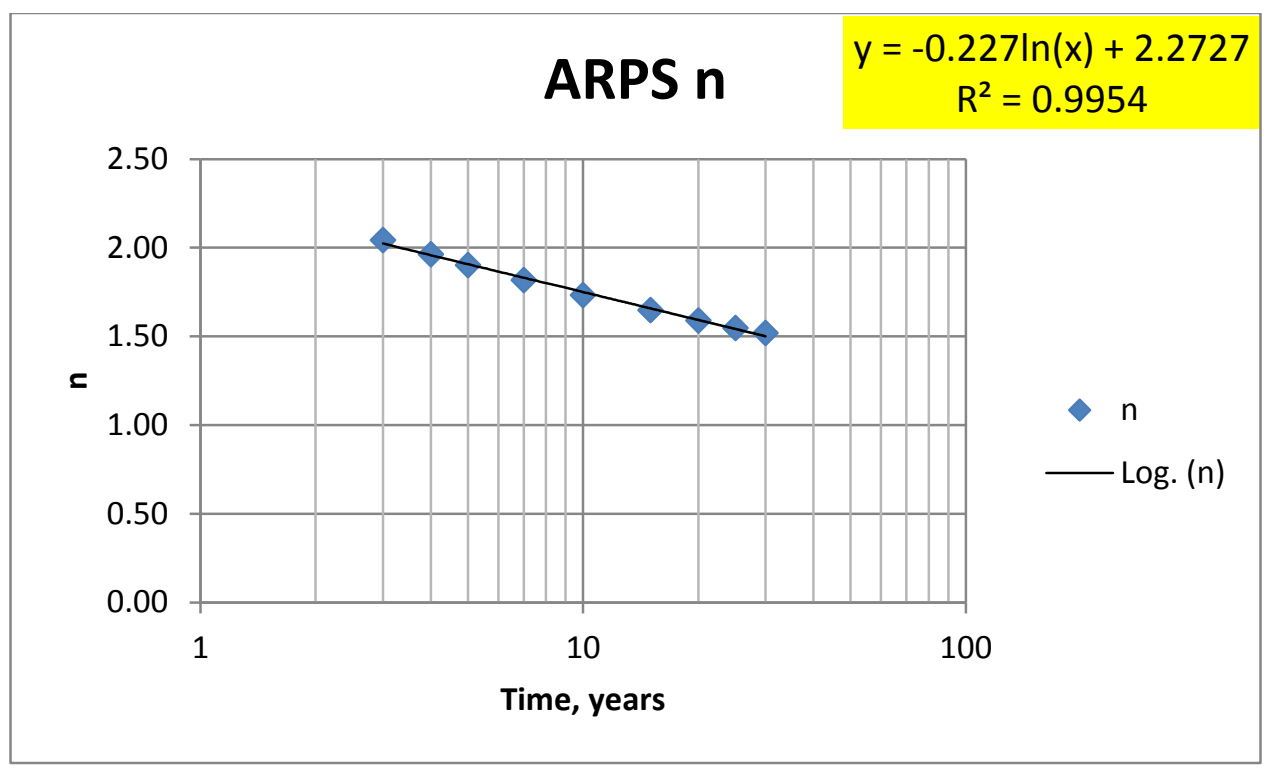

Figure 58: 7 Fracs (Ads. Gas) Arps n Correlation

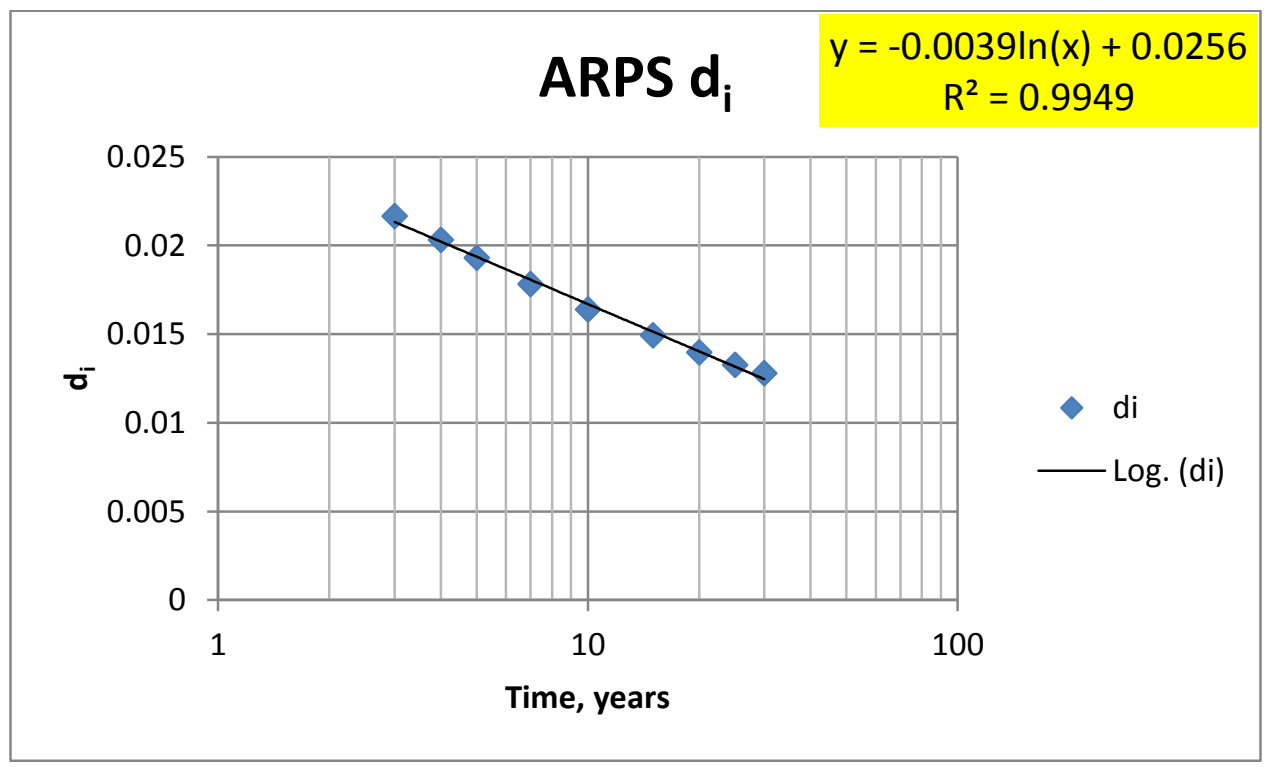

Figure 59: 7 Fracs (Ads. Gas) Arps di Correlation 


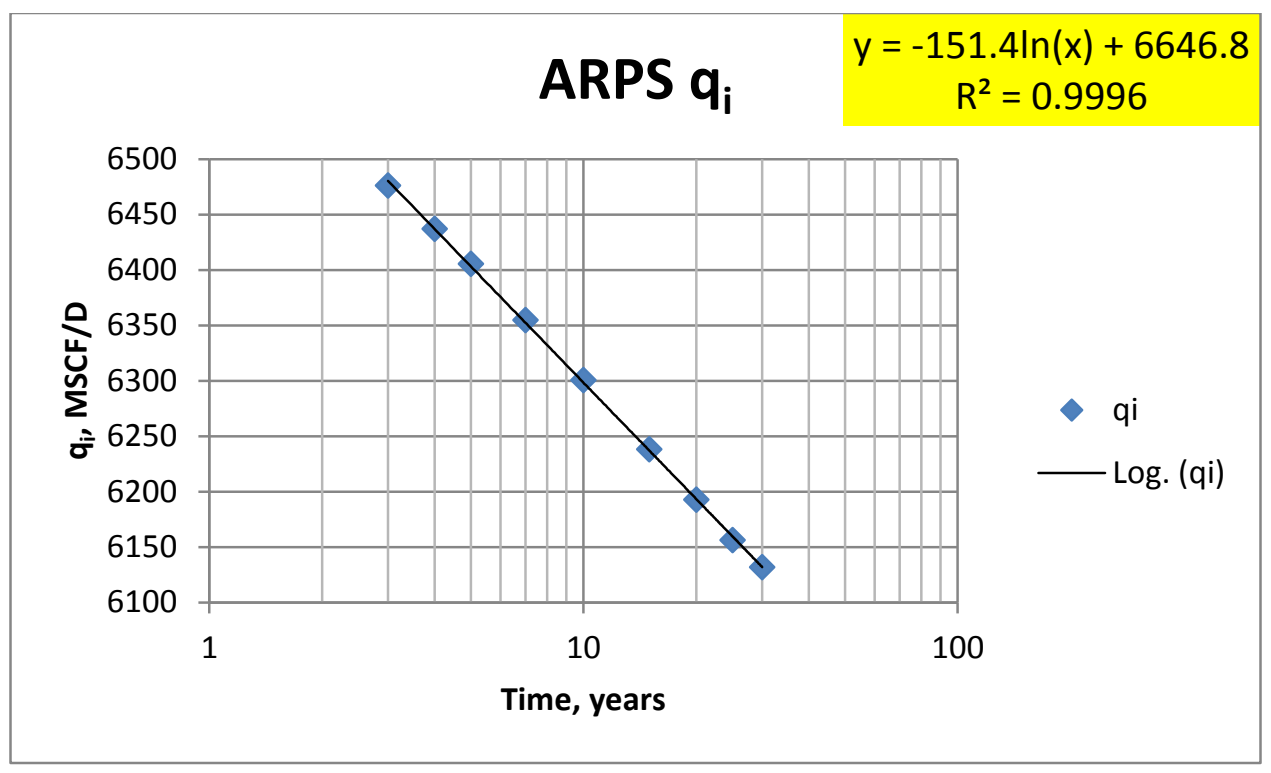

Figure 60: 7 Fracs (Ads. Gas) Arps qi Correlation

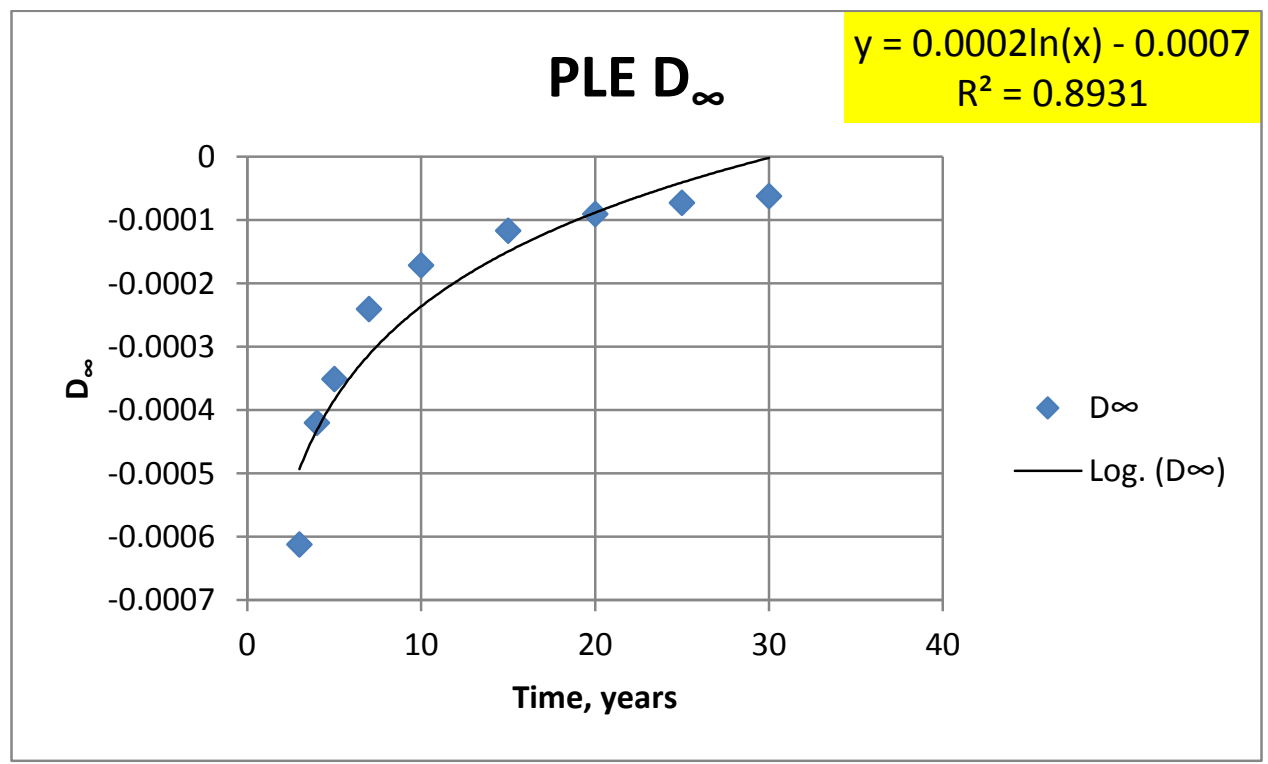

Figure 61: 7 Fracs (Ads. Gas) PLE $D_{\infty}$ Correlation 


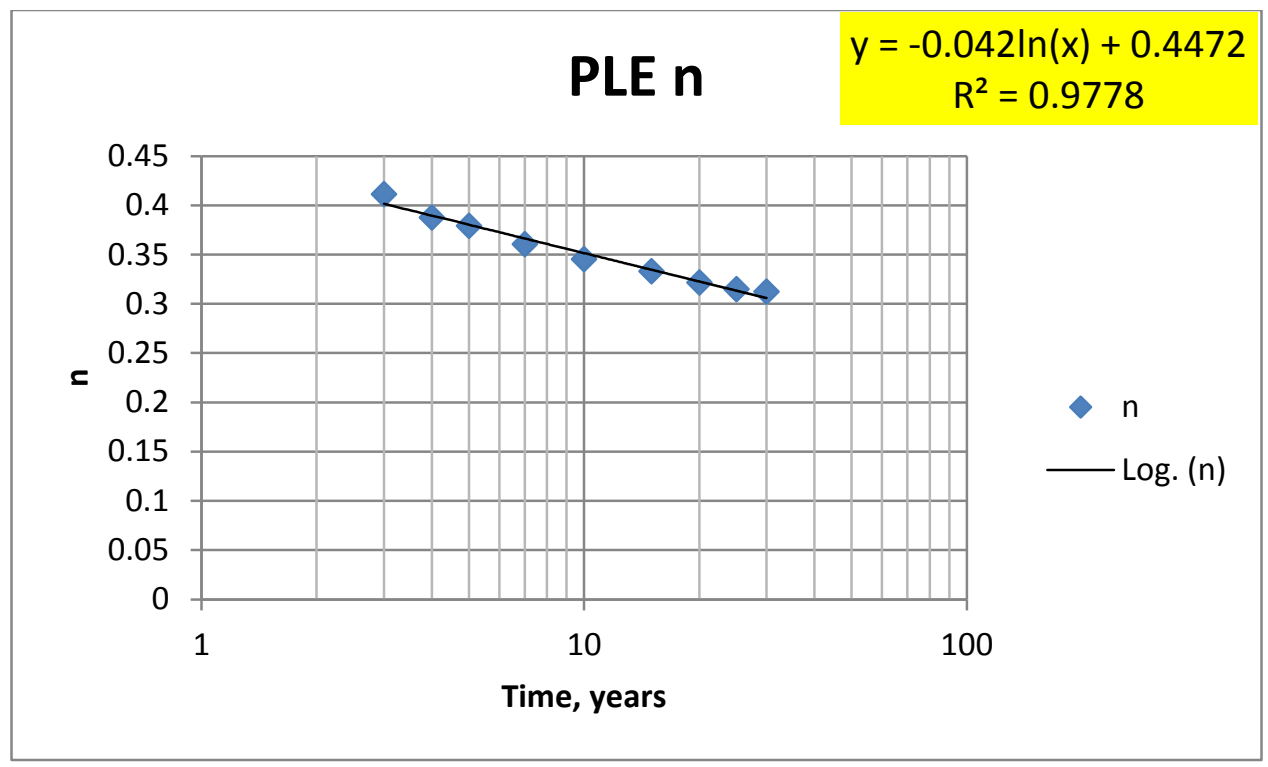

Figure 62: 7 Fracs (Ads. Gas) PLE n Correlation

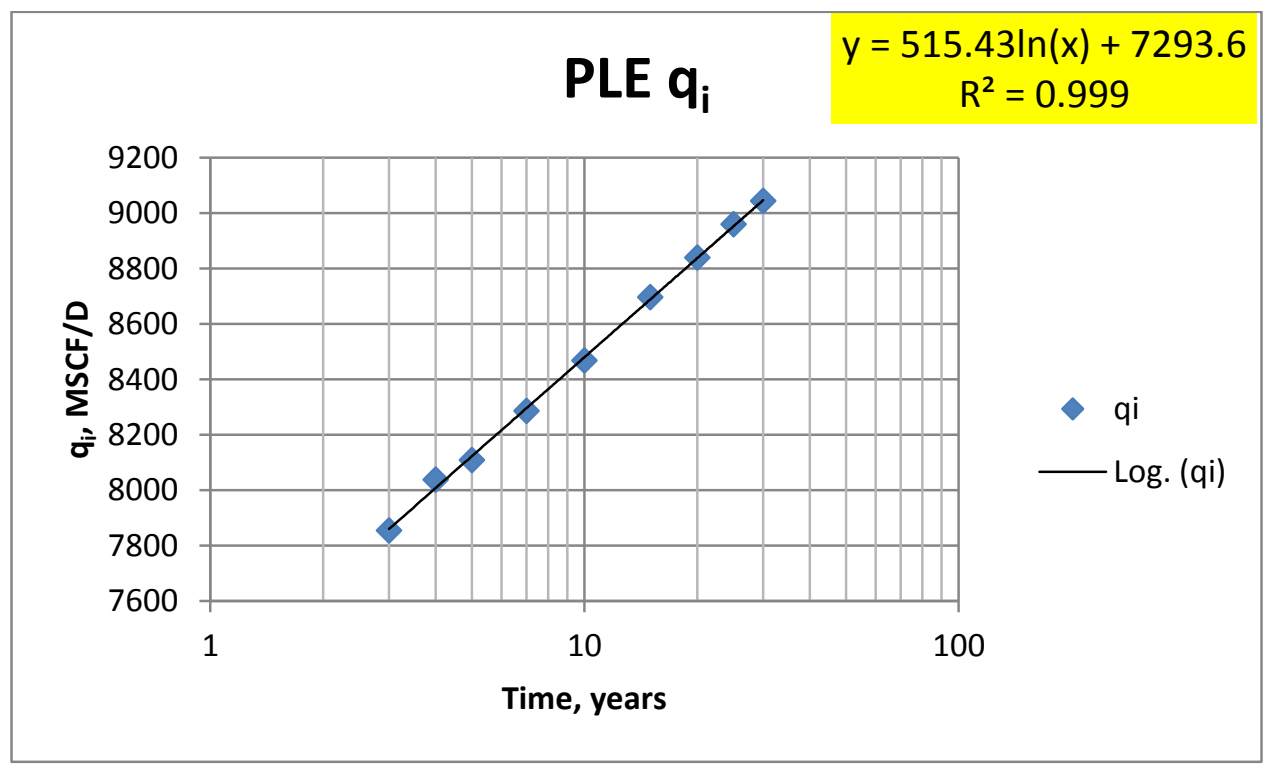

Figure 63: 7 Fracs (Ads. Gas) PLE qi Correlation 


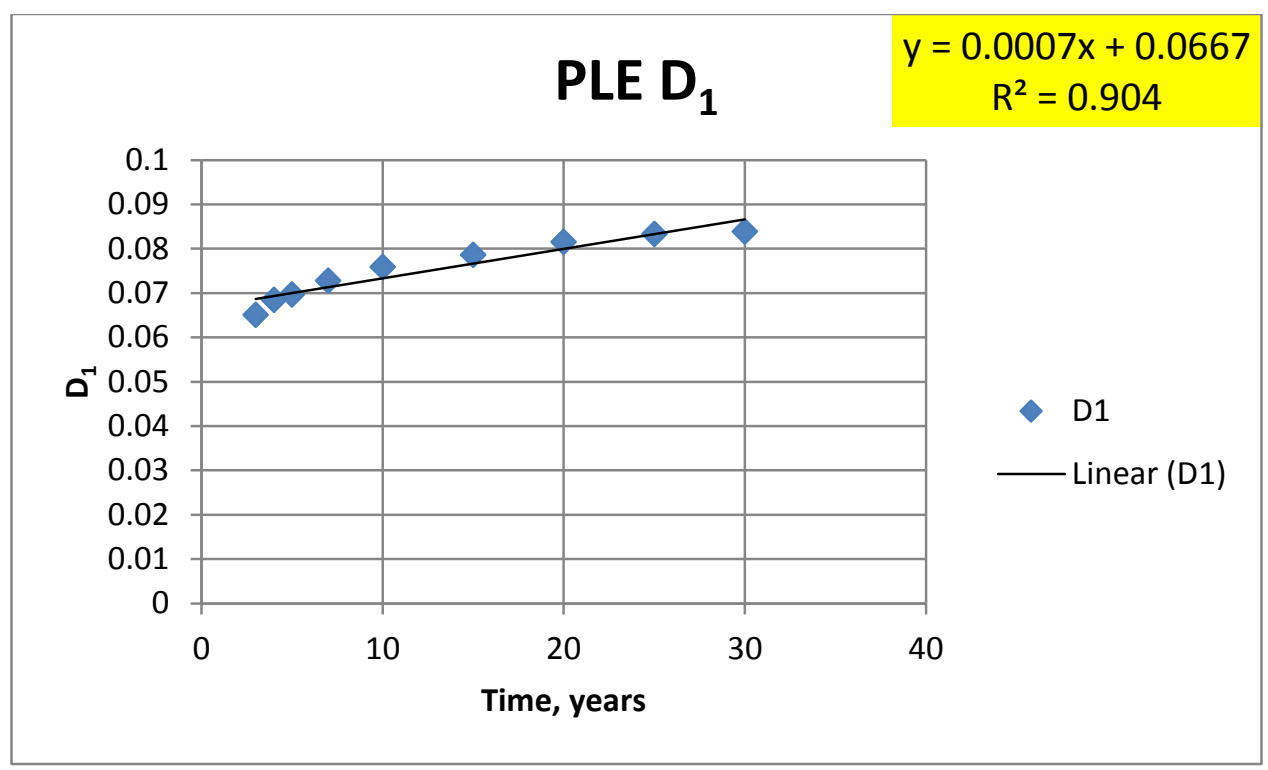

Figure 64: 7 Fracs (Ads. Gas) PLE D1 Correlation

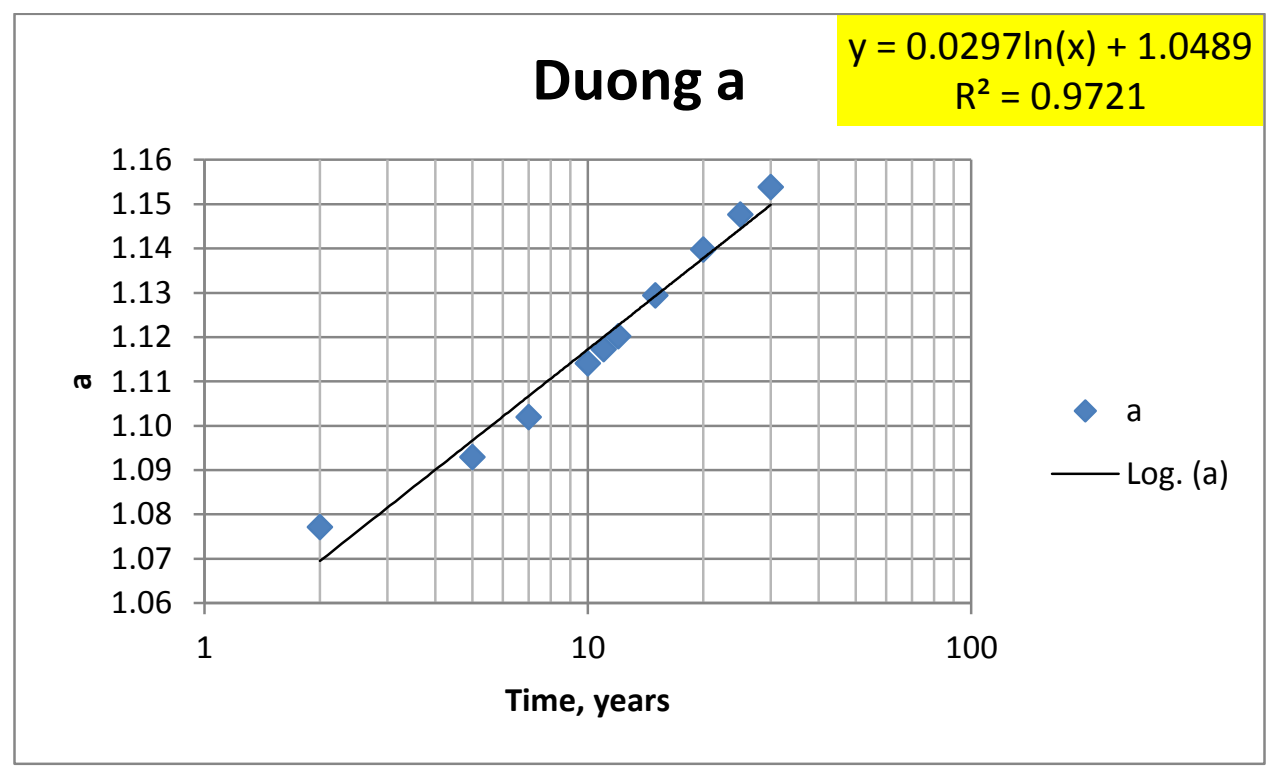

Figure 65: 7 Fracs (Ads. Gas) Duong a Correlation 


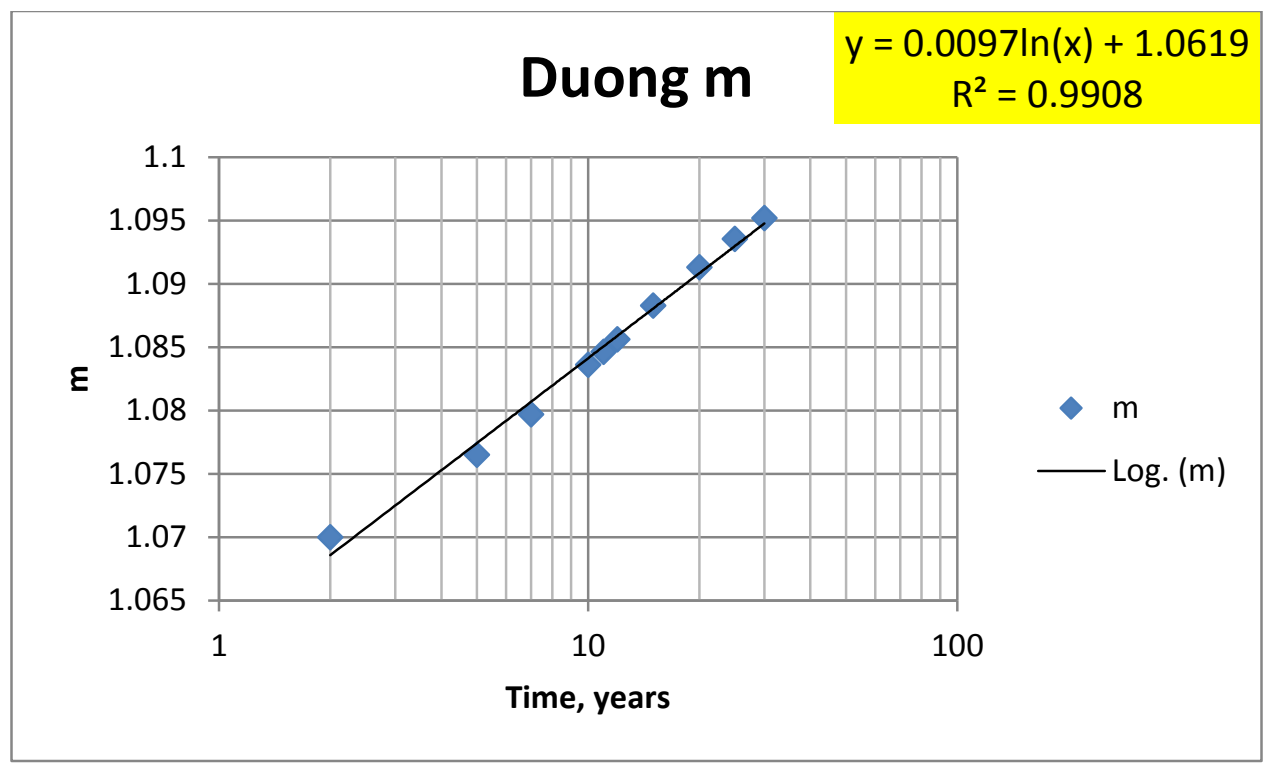

Figure 66: 7 Fracs (Ads. Gas) Duong m Correlation

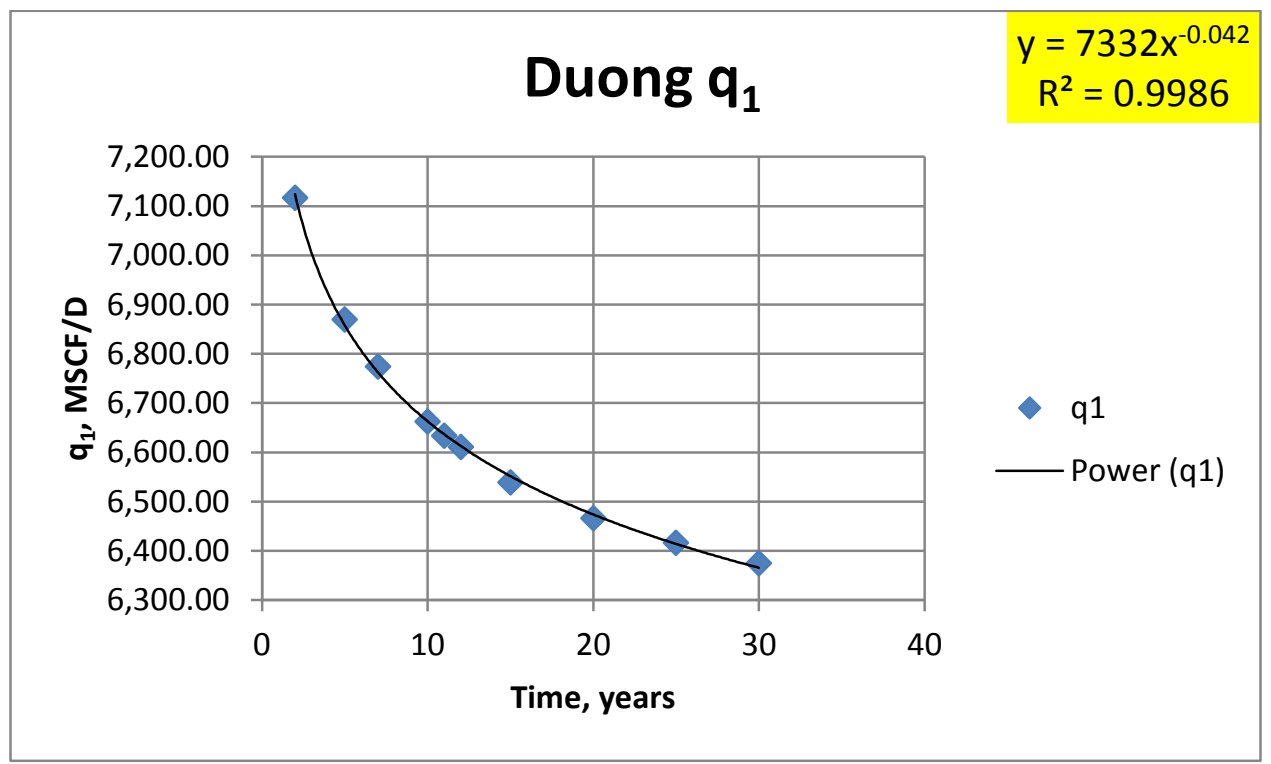

Figure 67: 7 Fracs (Ads. Gas) Duong q1 Correlation 


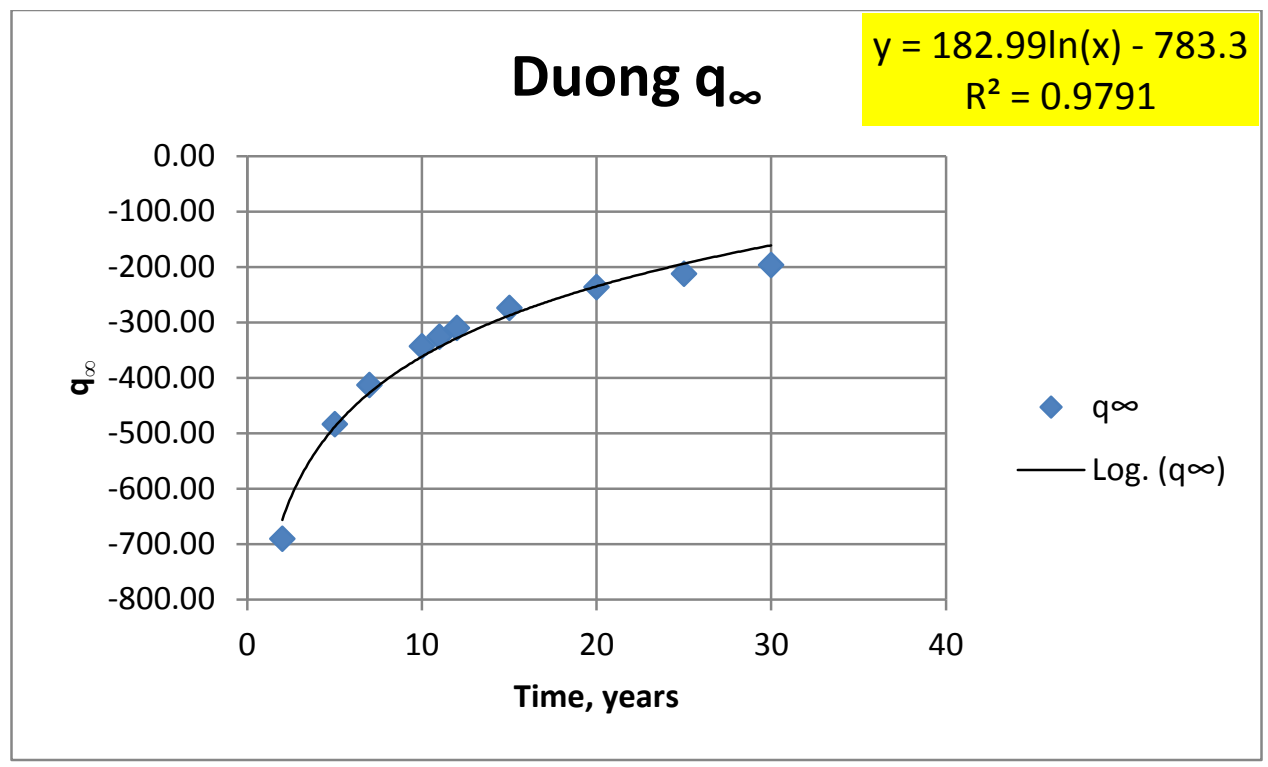

Figure 68: 7 Fracs (Ads. Gas) Duong $q_{\infty}$ Correlation

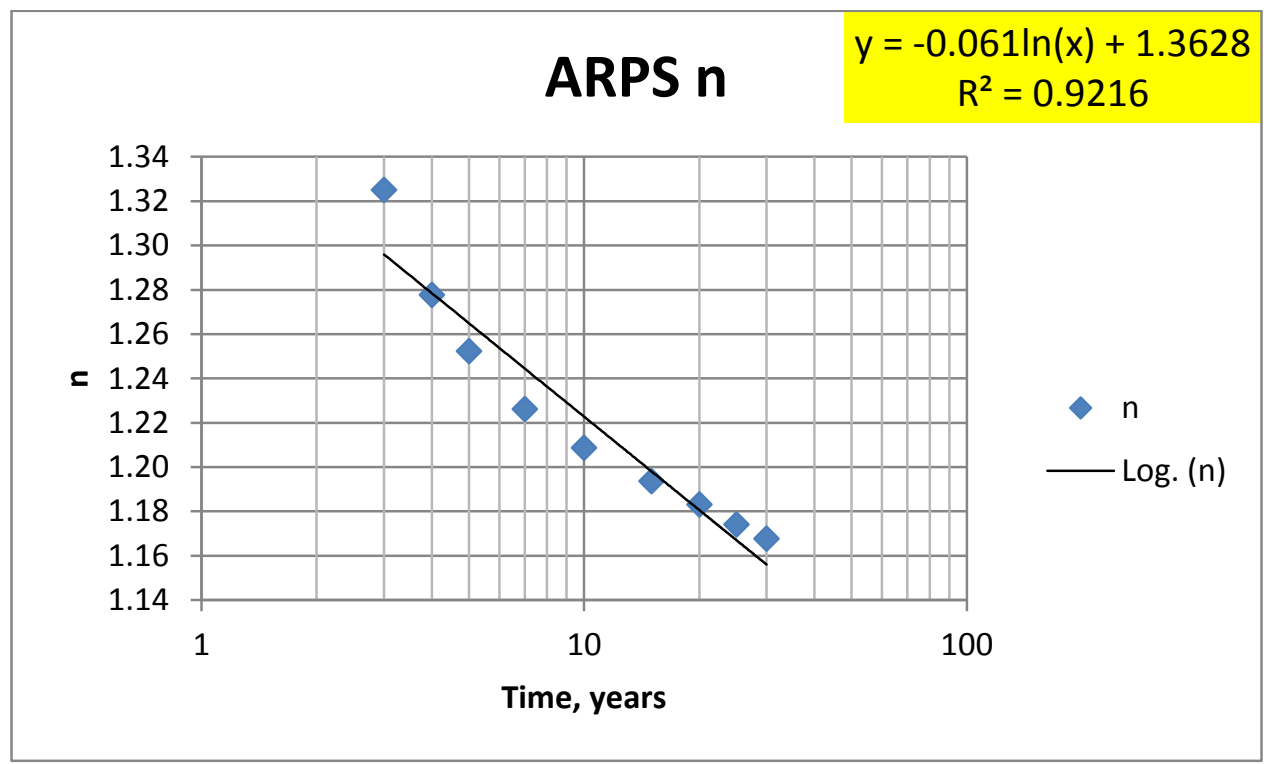

Figure 69: 13 Fracs (Ads. Gas) Arps n Correlation 


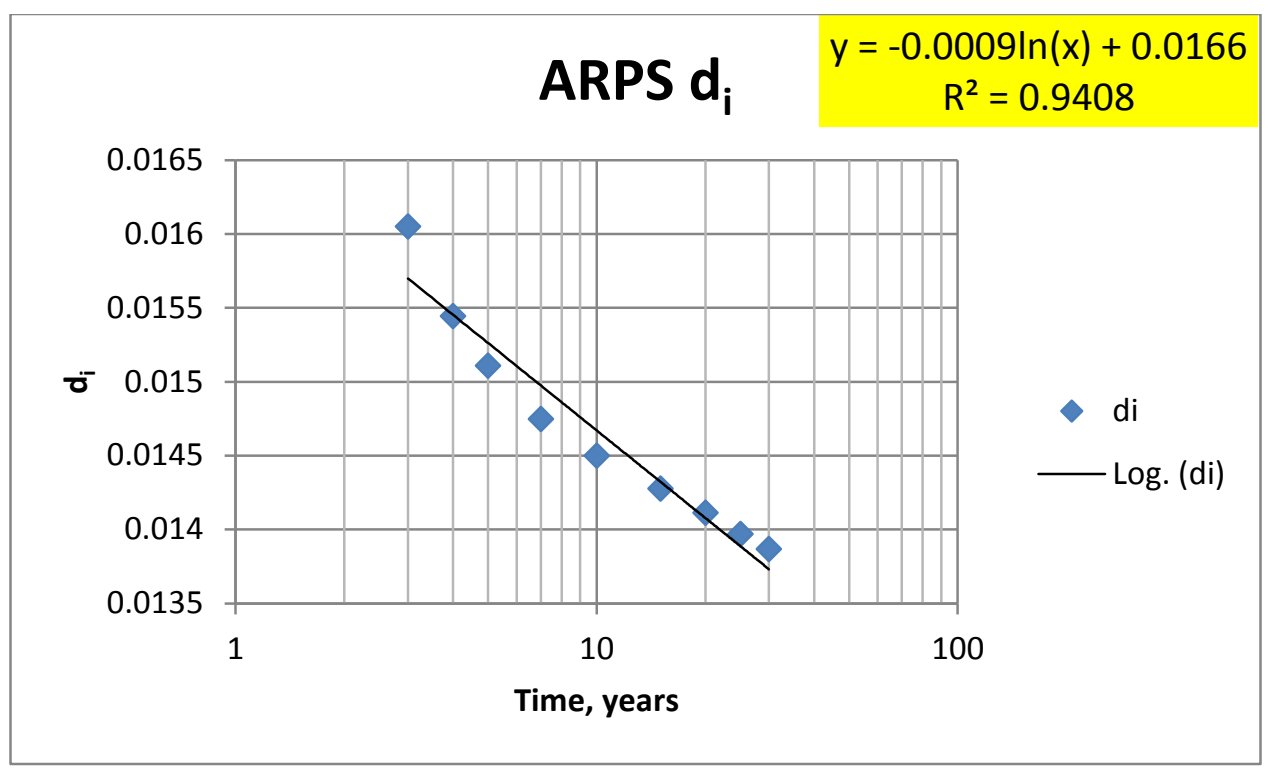

Figure 70: 13 Fracs (Ads. Gas) Arps di Correlation

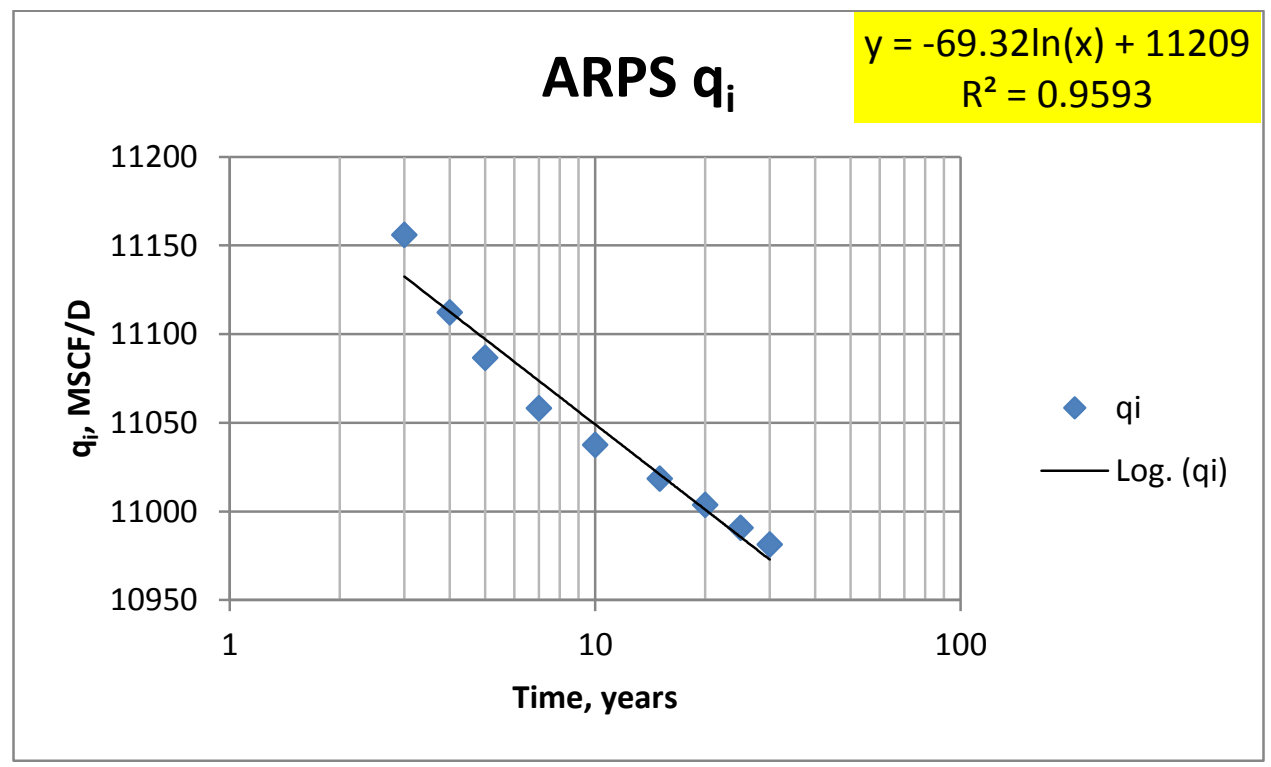

Figure 71: 13 Fracs (Ads. Gas) Arps $q_{i}$ Correlation 


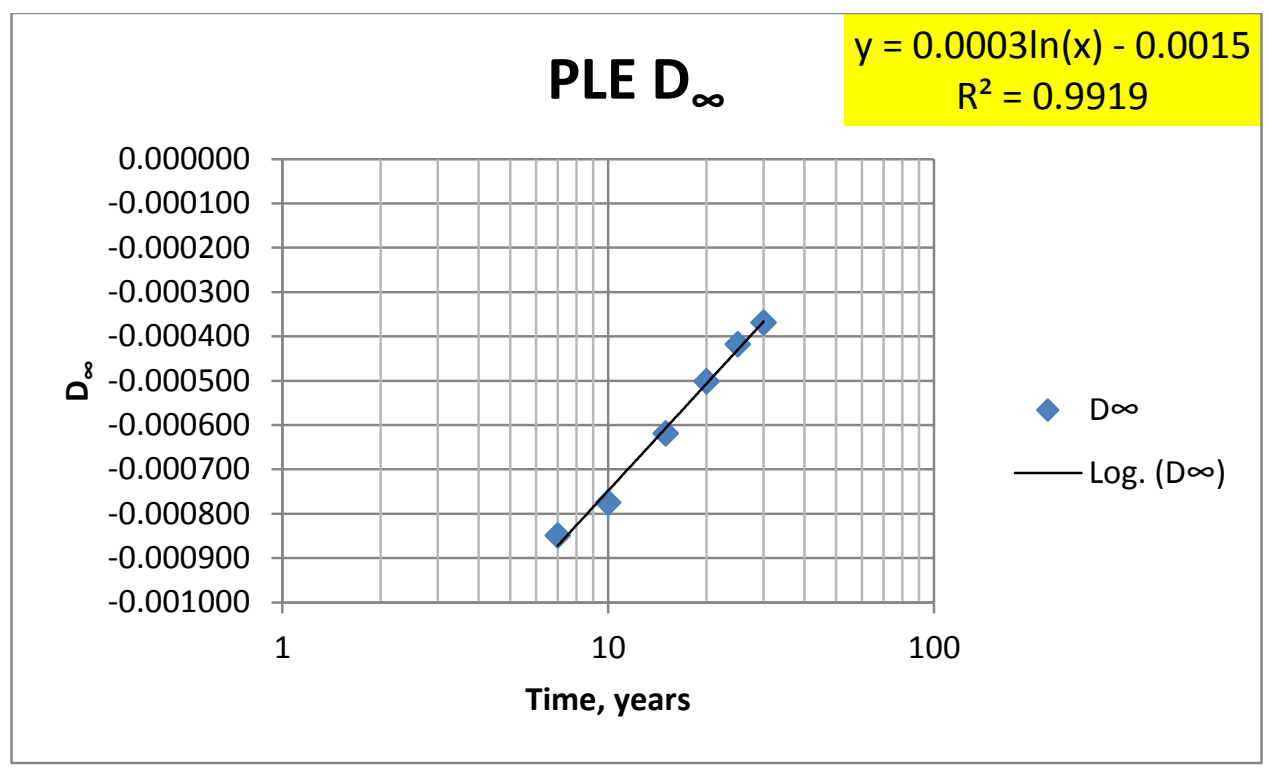

Figure 72: 13 Fracs (Ads. Gas) PLE $D_{\infty}$ Correlation

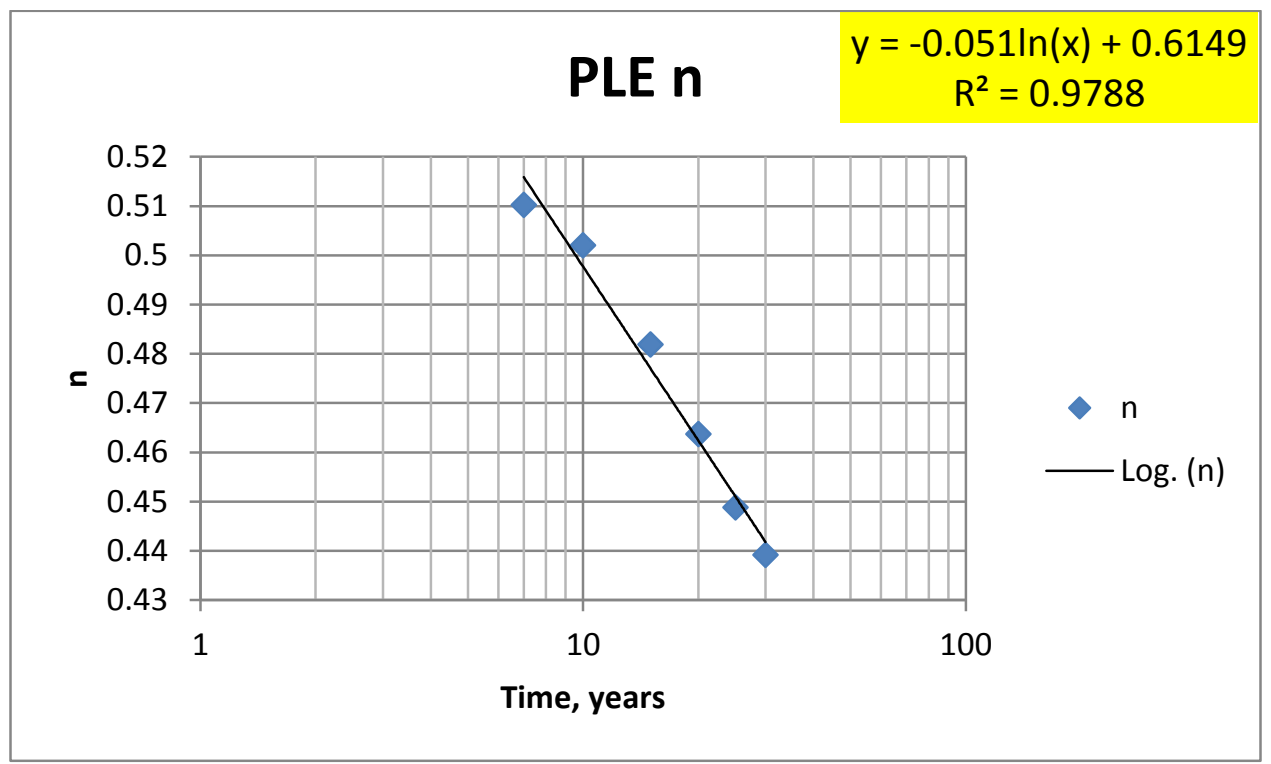

Figure 73: 13 Fracs (Ads. Gas) PLE n Correlation 


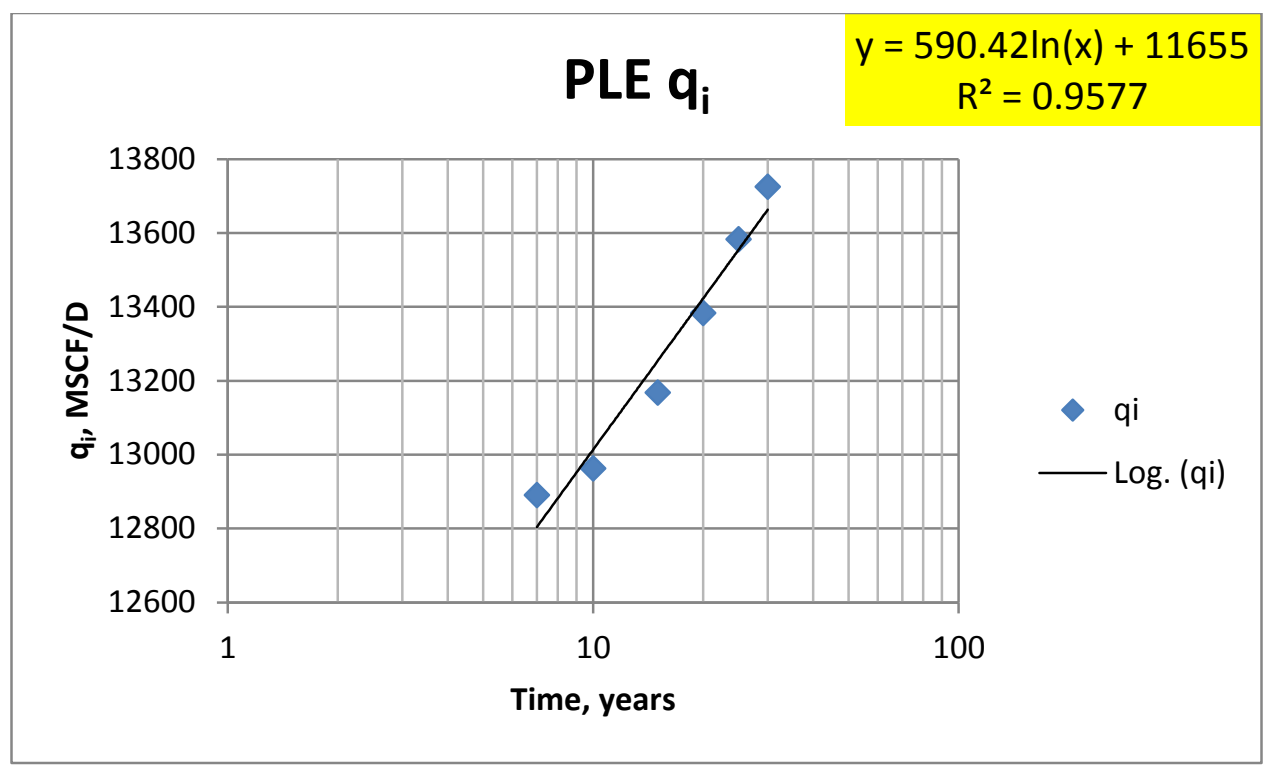

Figure 74: 13 Fracs (Ads. Gas) PLE qi Correlation

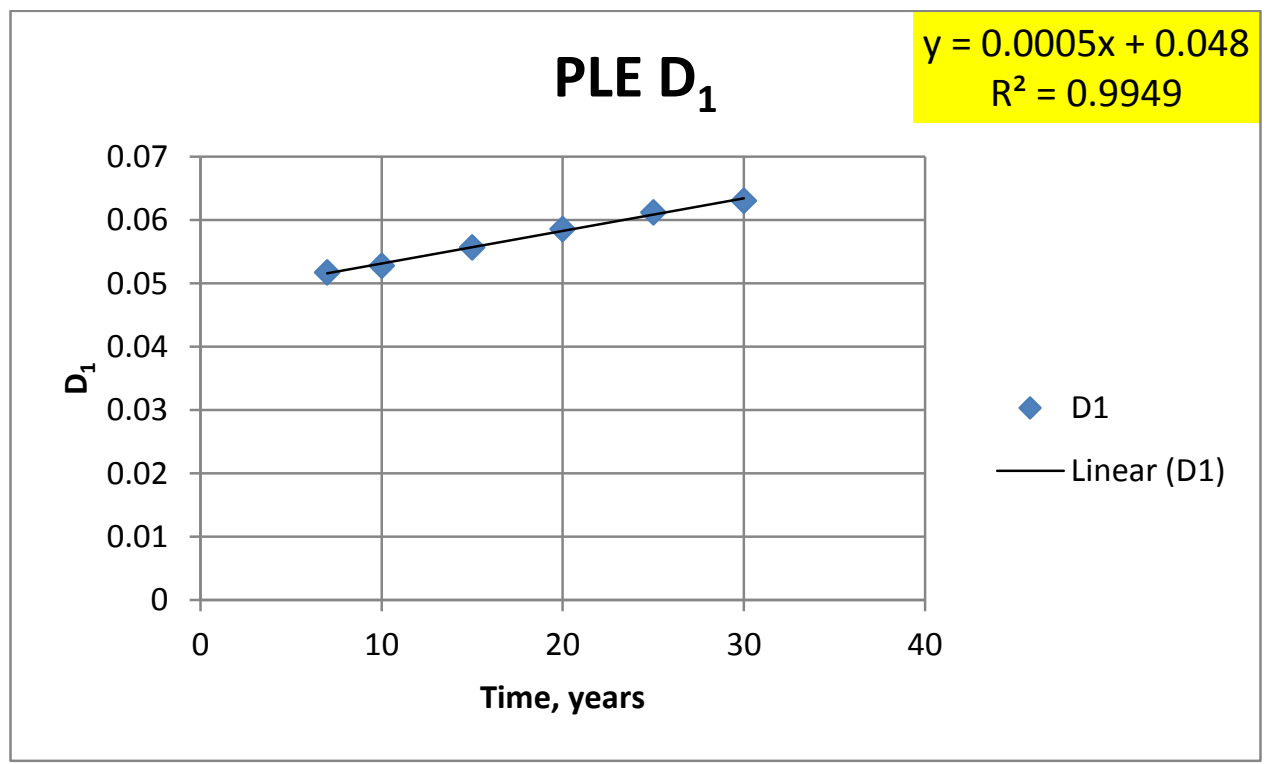

Figure 75: 13 Fracs (Ads. Gas) PLE $D_{1}$ Correlation 


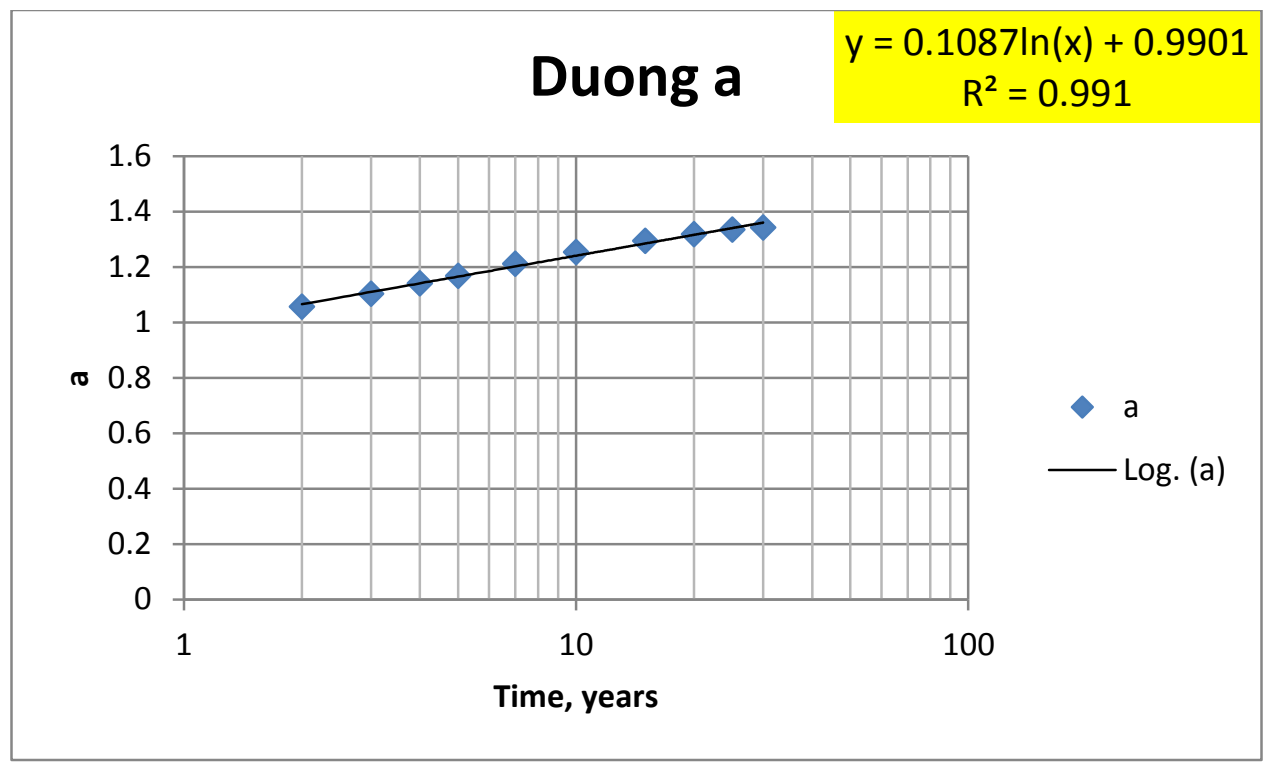

Figure 76: 13 Fracs (Ads. Gas) Duong a Correlation

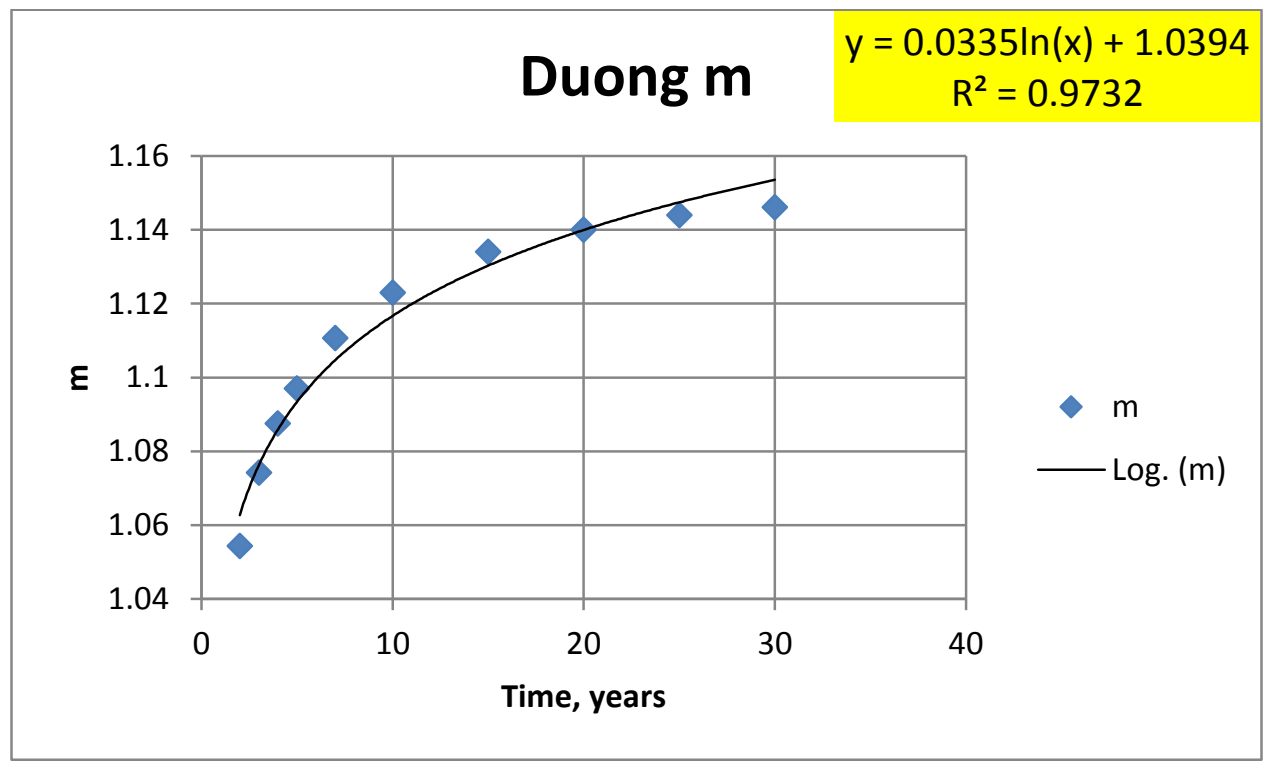

Figure 77: 13 Fracs (Ads. Gas) Duong m Correlation 


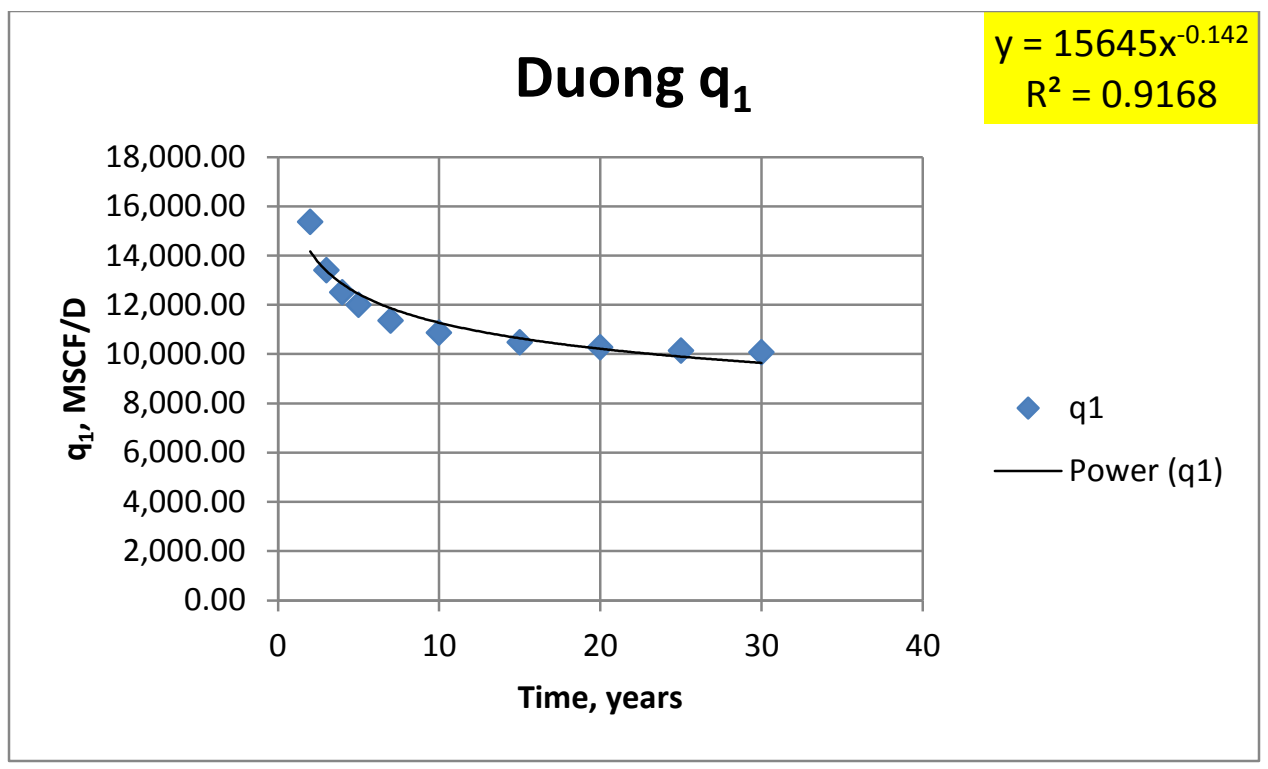

Figure 78: 13 Fracs (Ads. Gas) Duong q1 Correlation

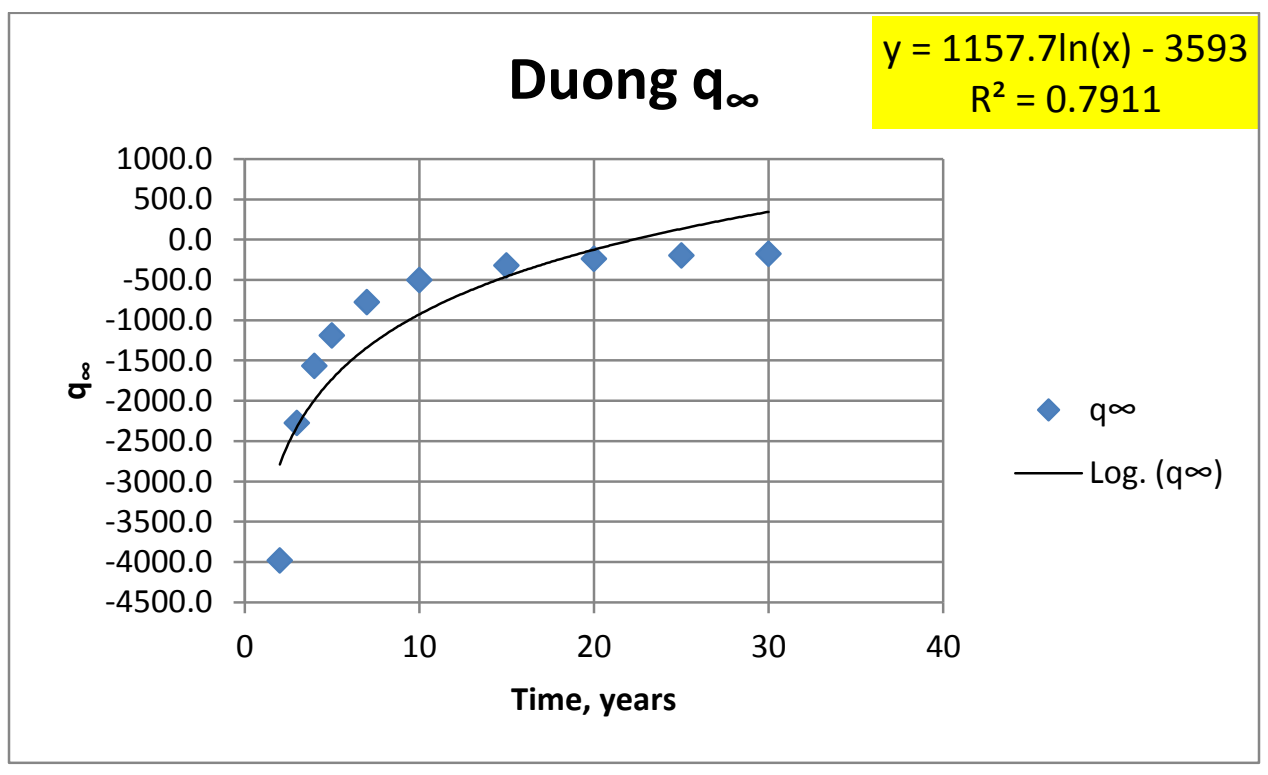

Figure 79: 13 Fracs (Ads. Gas) Duong $q_{\infty}$ Correlation 


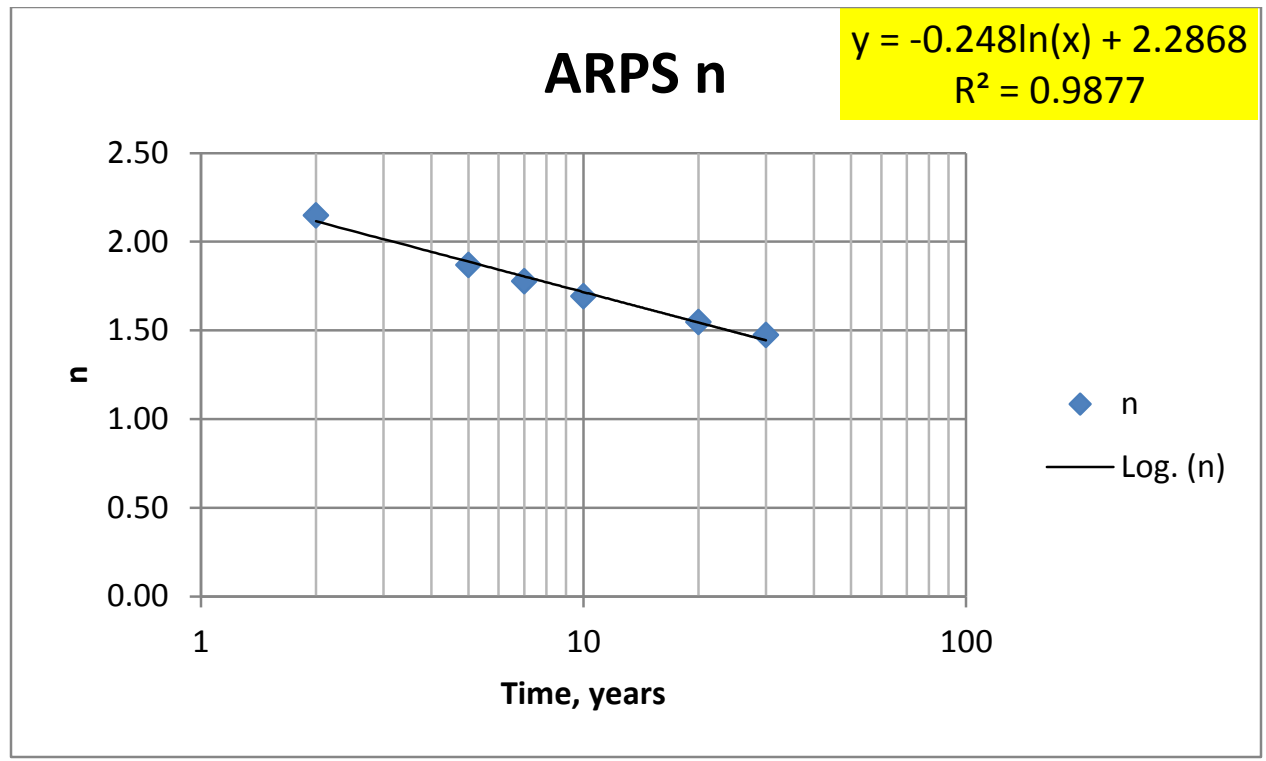

Figure 80: 7 Fracs (No Ads. Gas) Arps n Correlation

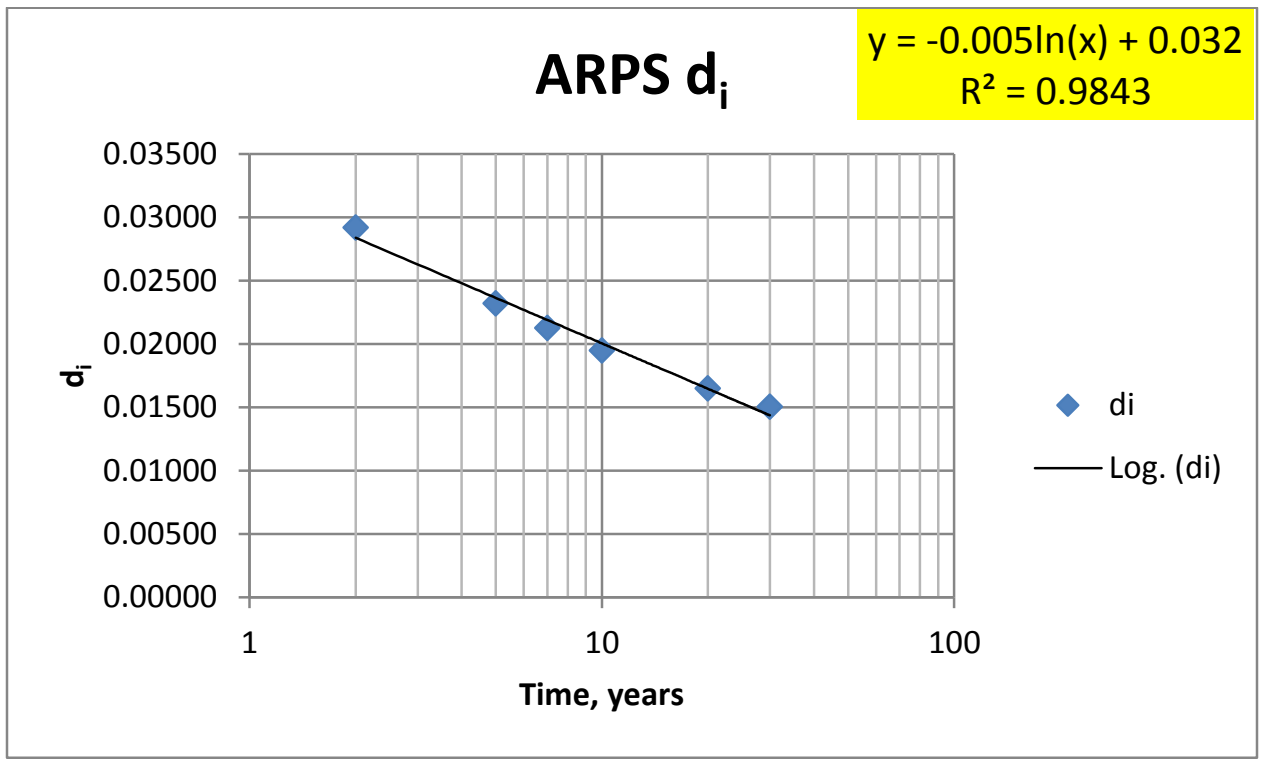

Figure 81: 7 Fracs (No Ads. Gas) Arps di Correlation 


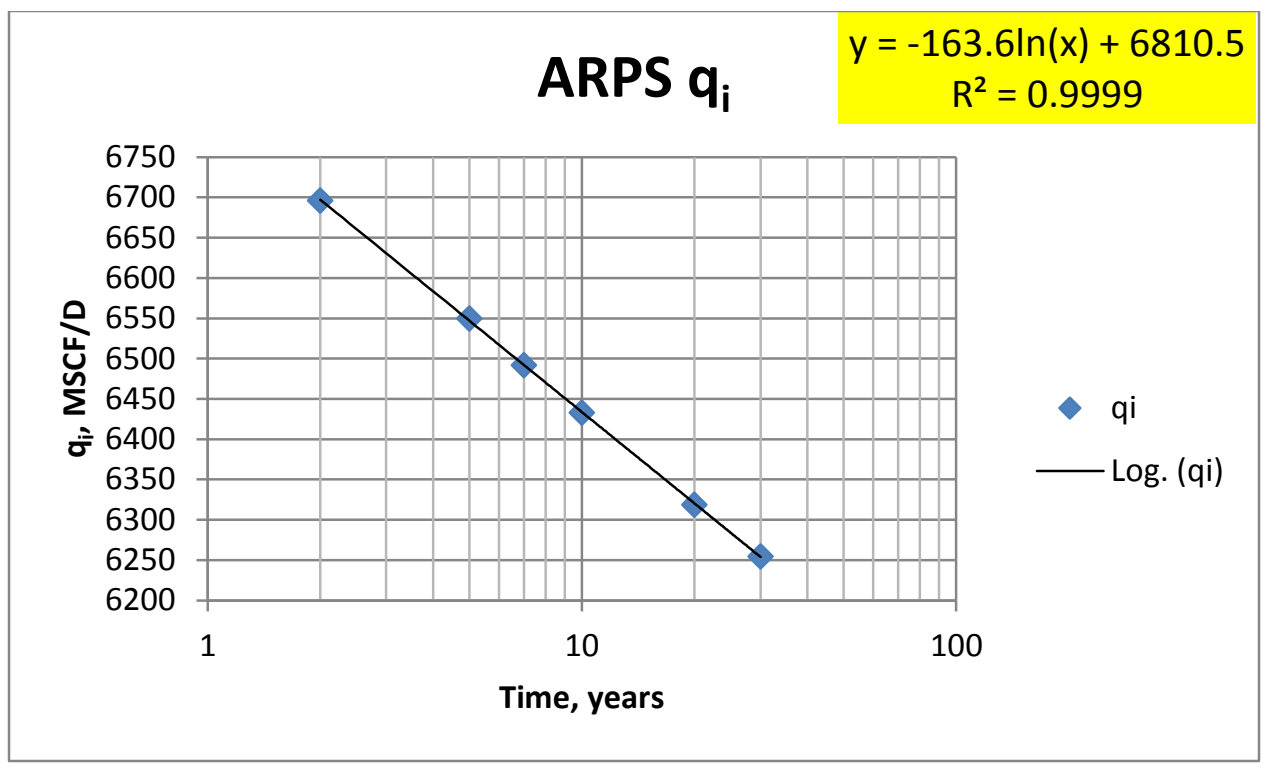

Figure 82: 7 Fracs (No Ads. Gas) Arps qi Correlation

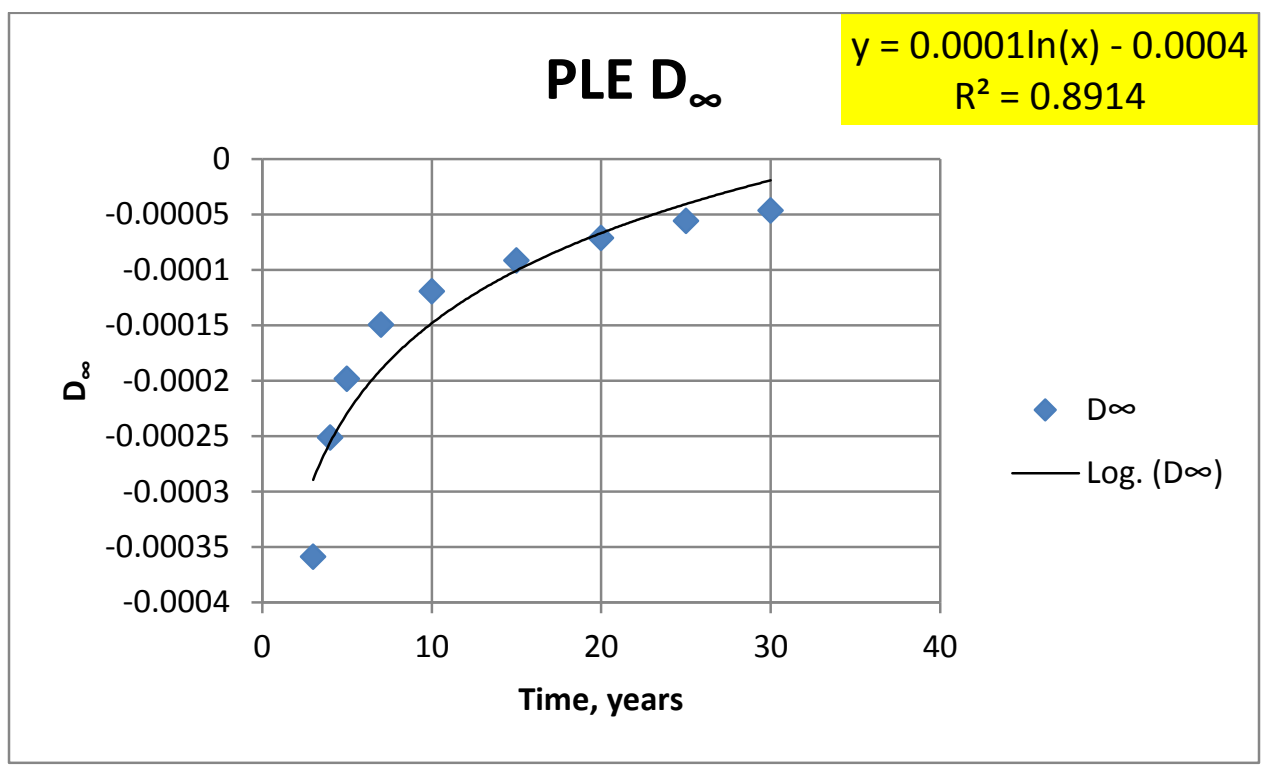

Figure 83: 7 Fracs (No Ads. Gas) PLE $D_{\infty}$ Correlation 


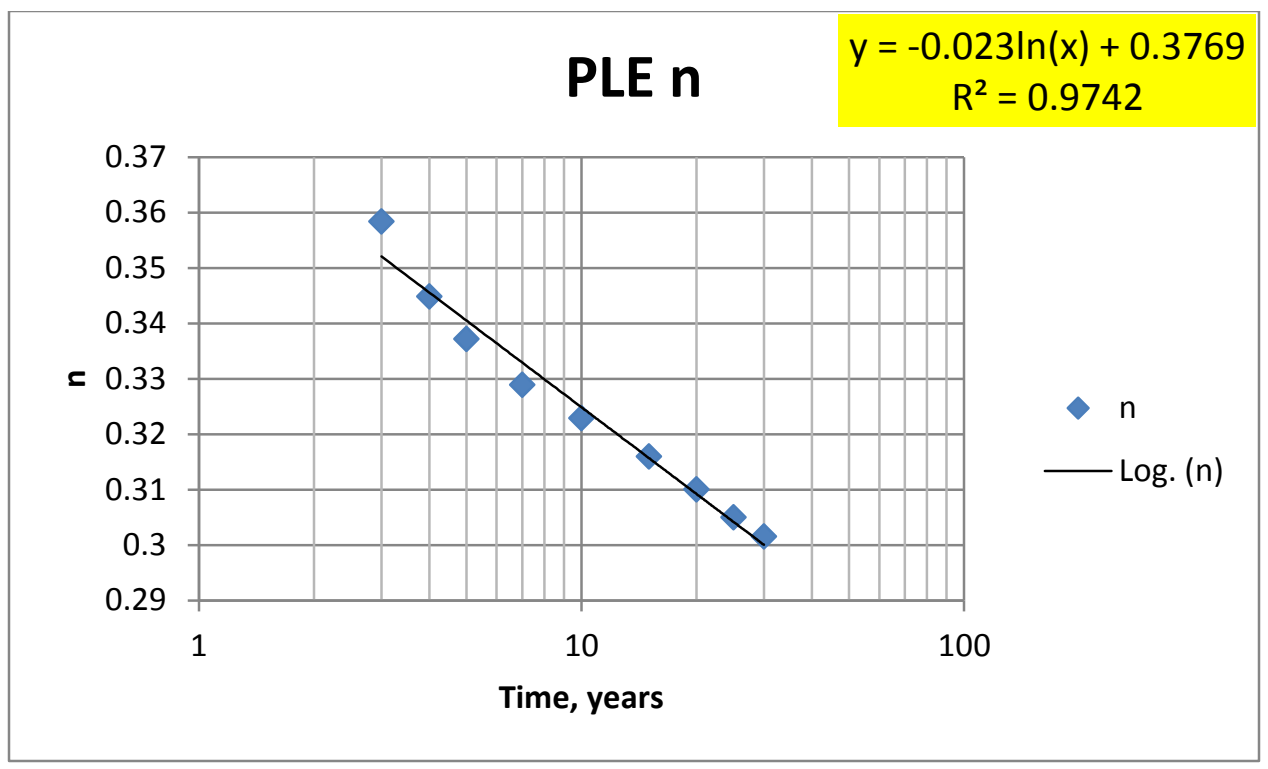

Figure 84: 7 Fracs (No Ads. Gas) PLE n Correlation

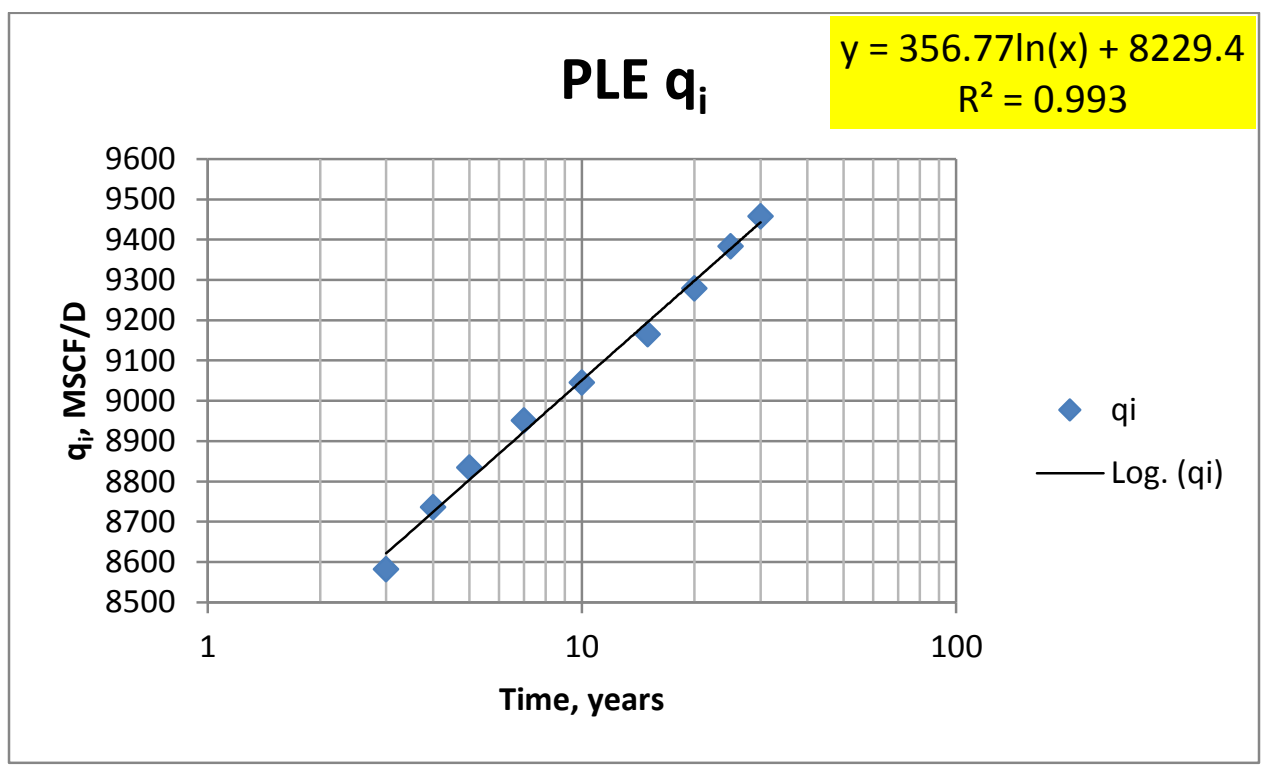

Figure 85: 7 Fracs (No Ads. Gas) PLE qi Correlation 


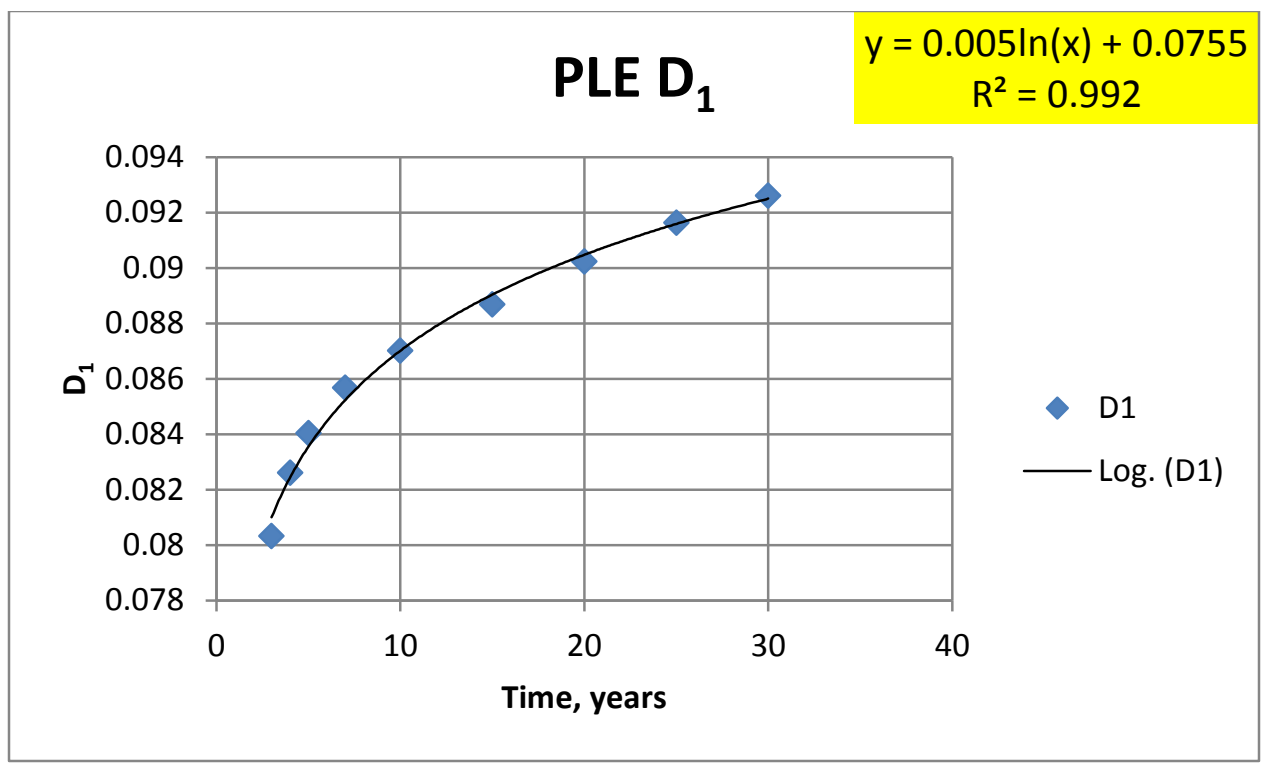

Figure 86: 7 Fracs (No Ads. Gas) PLE $D_{1}$ Correlation

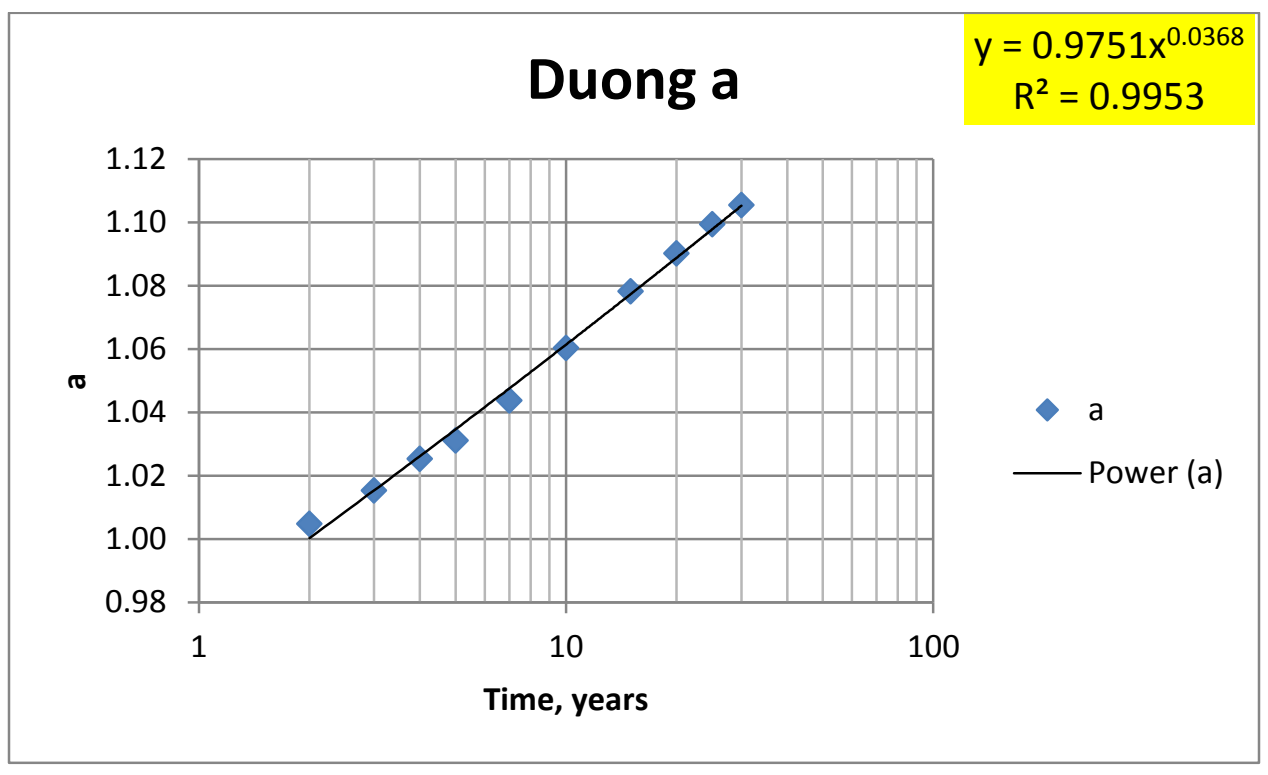

Figure 87: 7 Fracs (No Ads. Gas) Duong a Correlation 


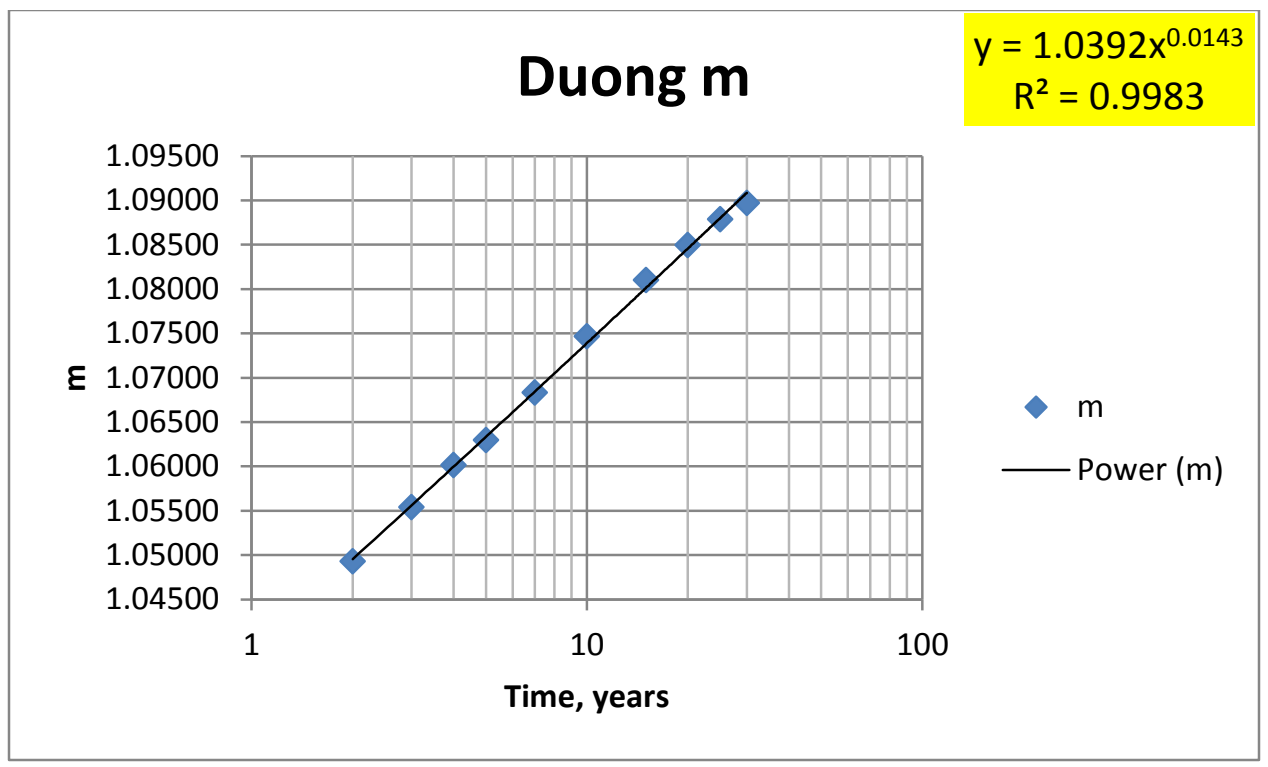

Figure 88: 7 Fracs (No Ads. Gas) Duong m Correlation

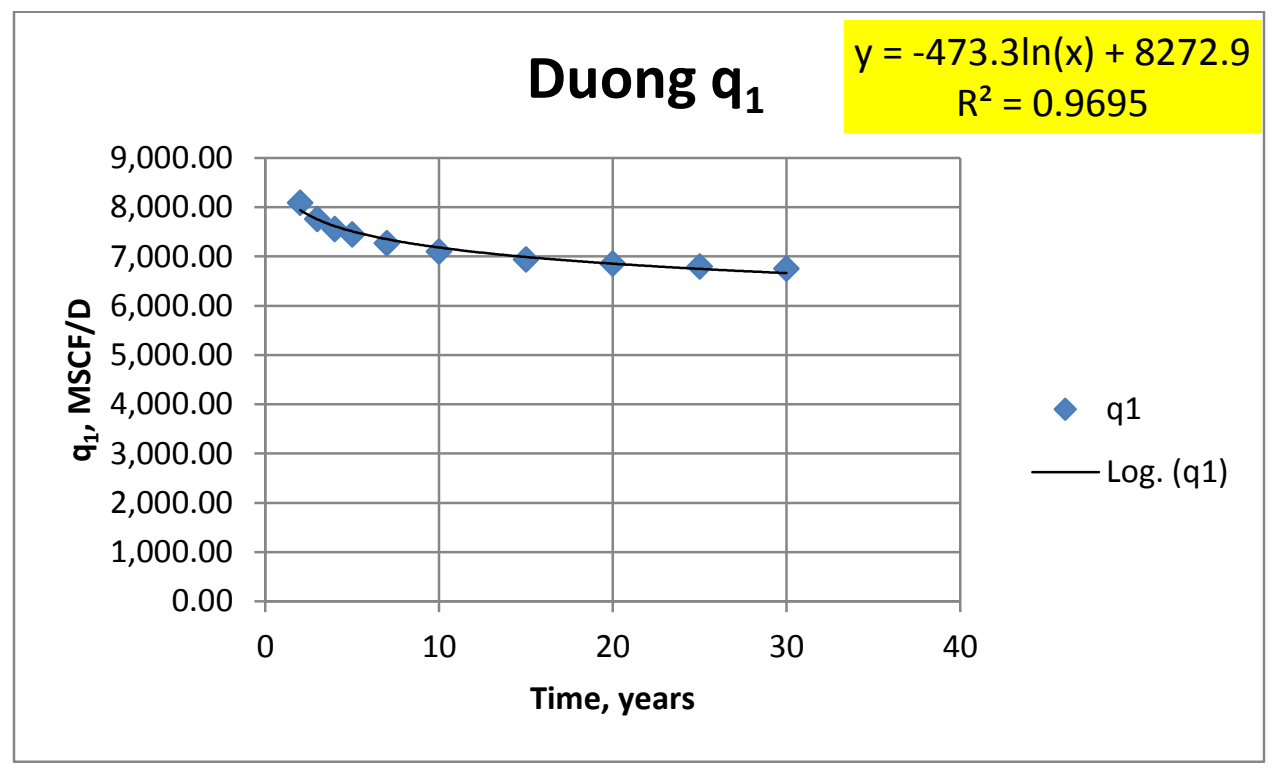

Figure 89: 7 Fracs (No Ads. Gas) Duong q1 Correlation 


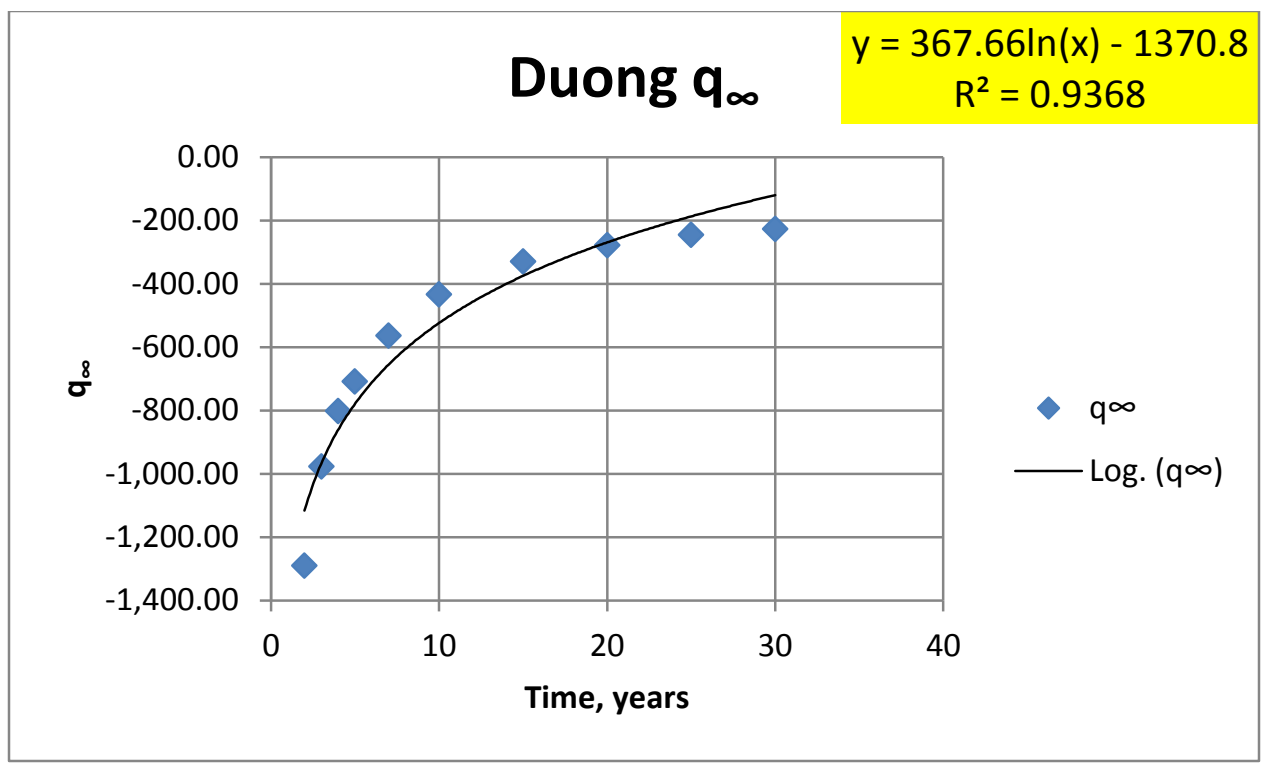

Figure 90: 7 Fracs (No Ads. Gas) Duong q Correlation

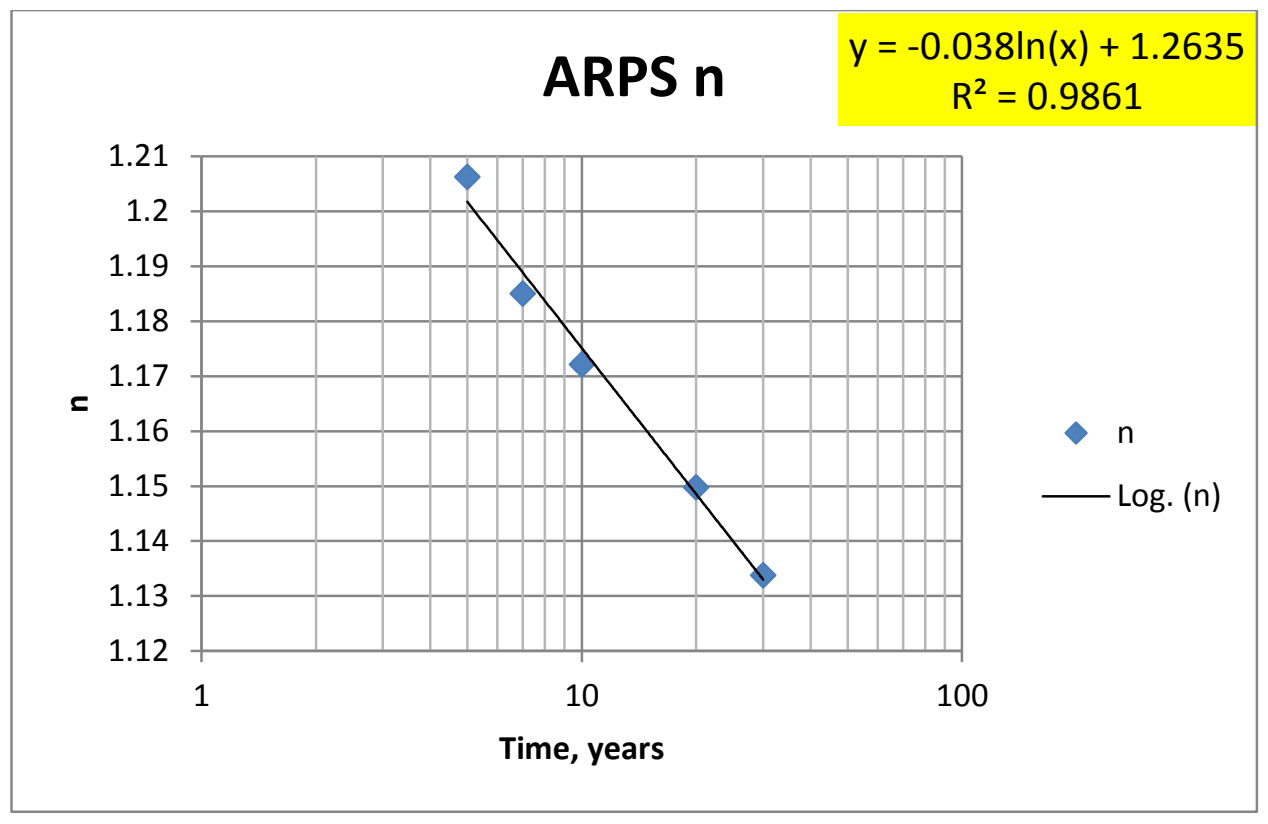

Figure 91: 13 Fracs (No Ads. Gas) Arps n Correlation 


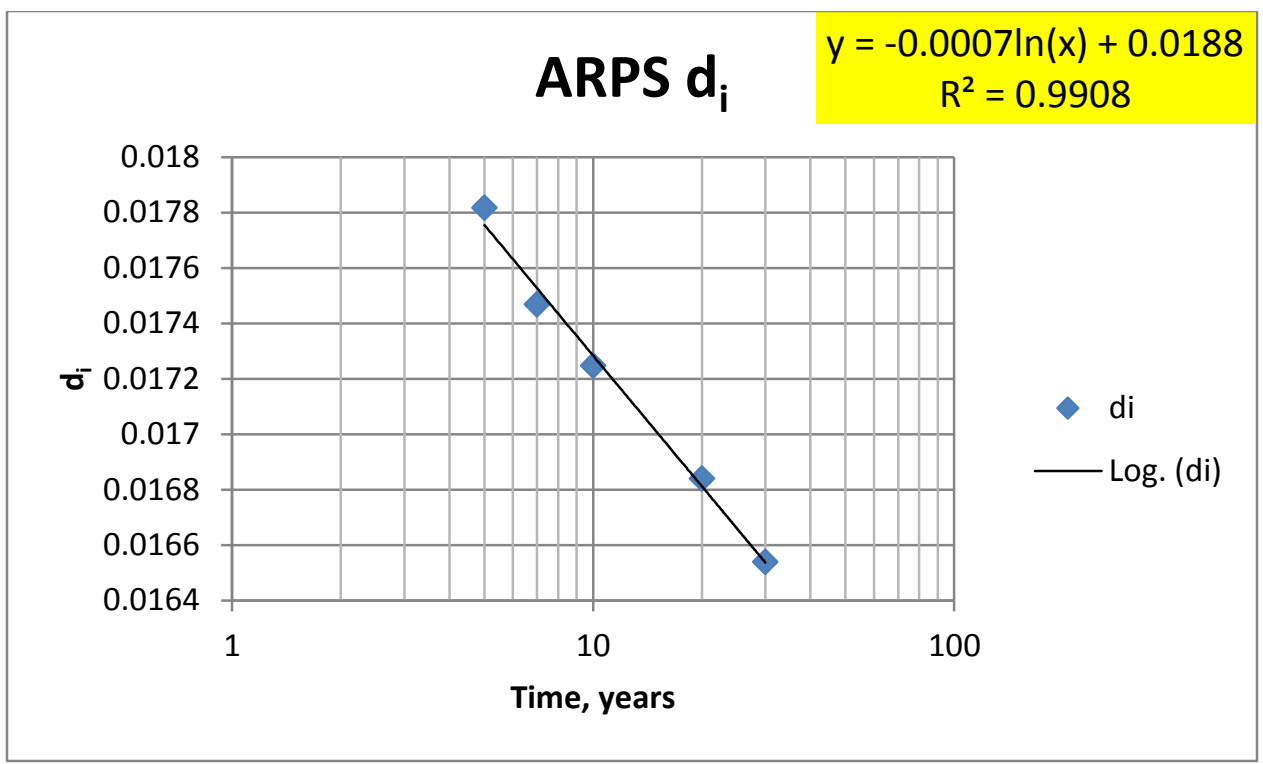

Figure 92: 13 Fracs (No Ads. Gas) Arps d $d_{i}$ Correlation

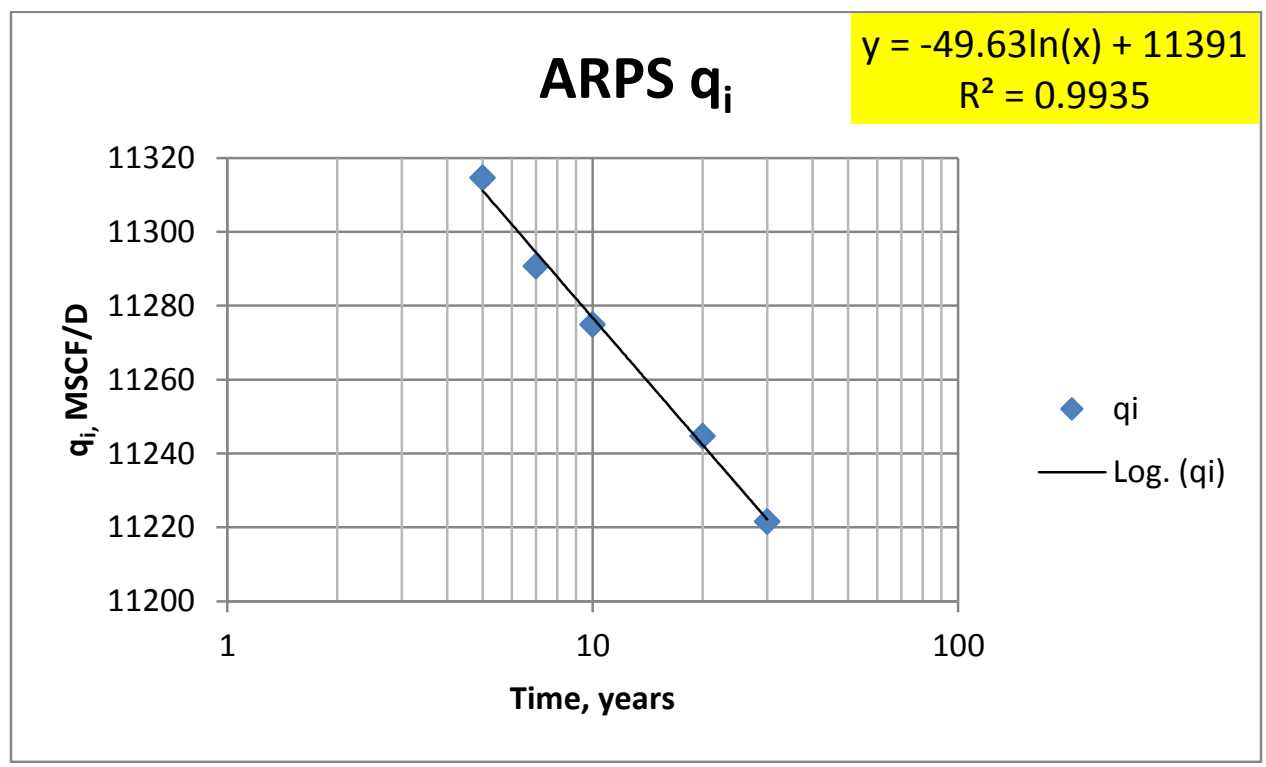

Figure 93: 13 Fracs (No Ads. Gas) Arps qi Correlation 


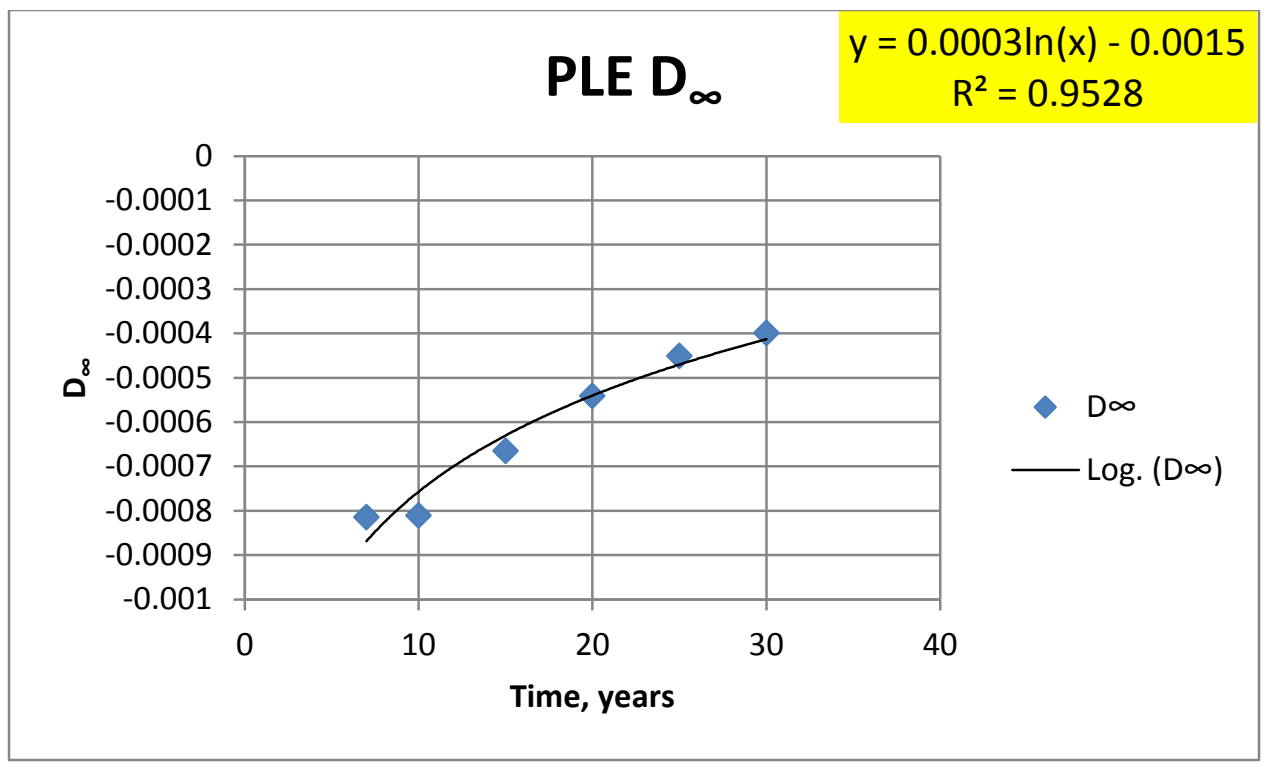

Figure 94: 13 Fracs (No Ads. Gas) PLE $D_{\infty}$ Correlation

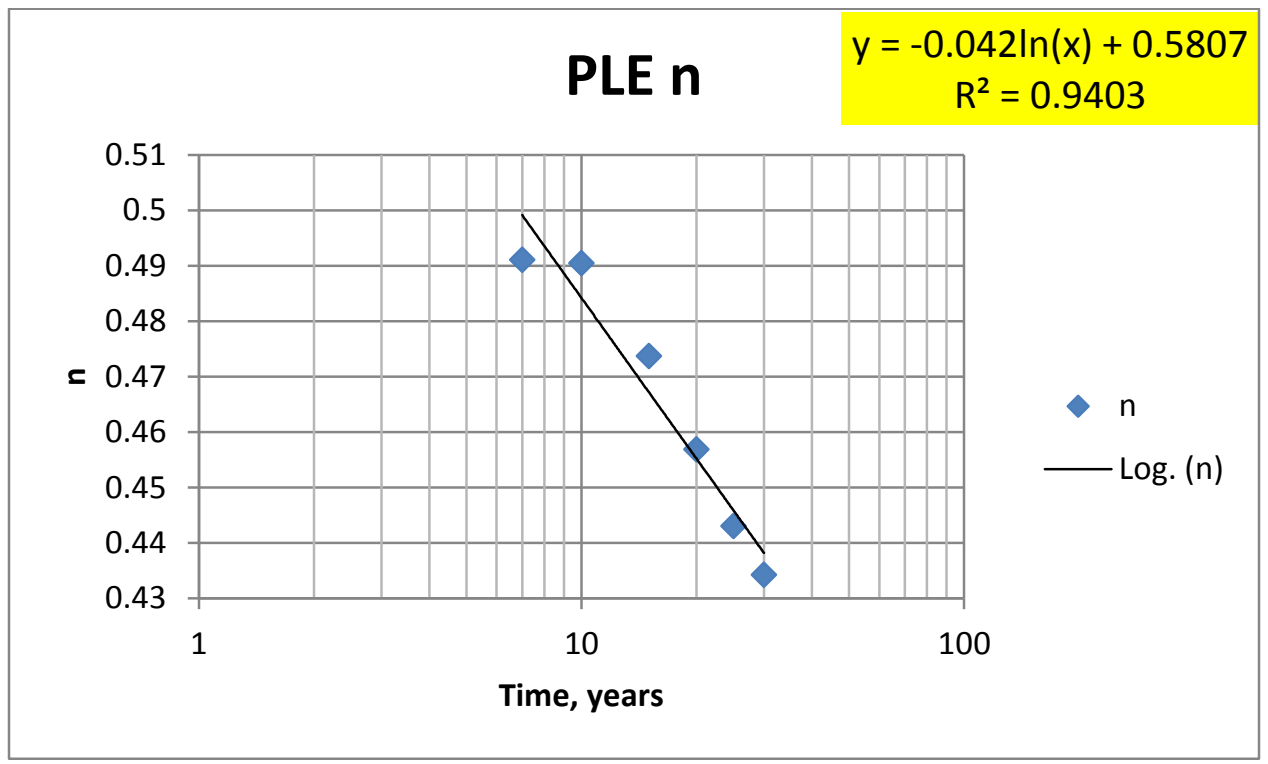

Figure 95: 13 Fracs (No Ads. Gas) PLE n Correlation 


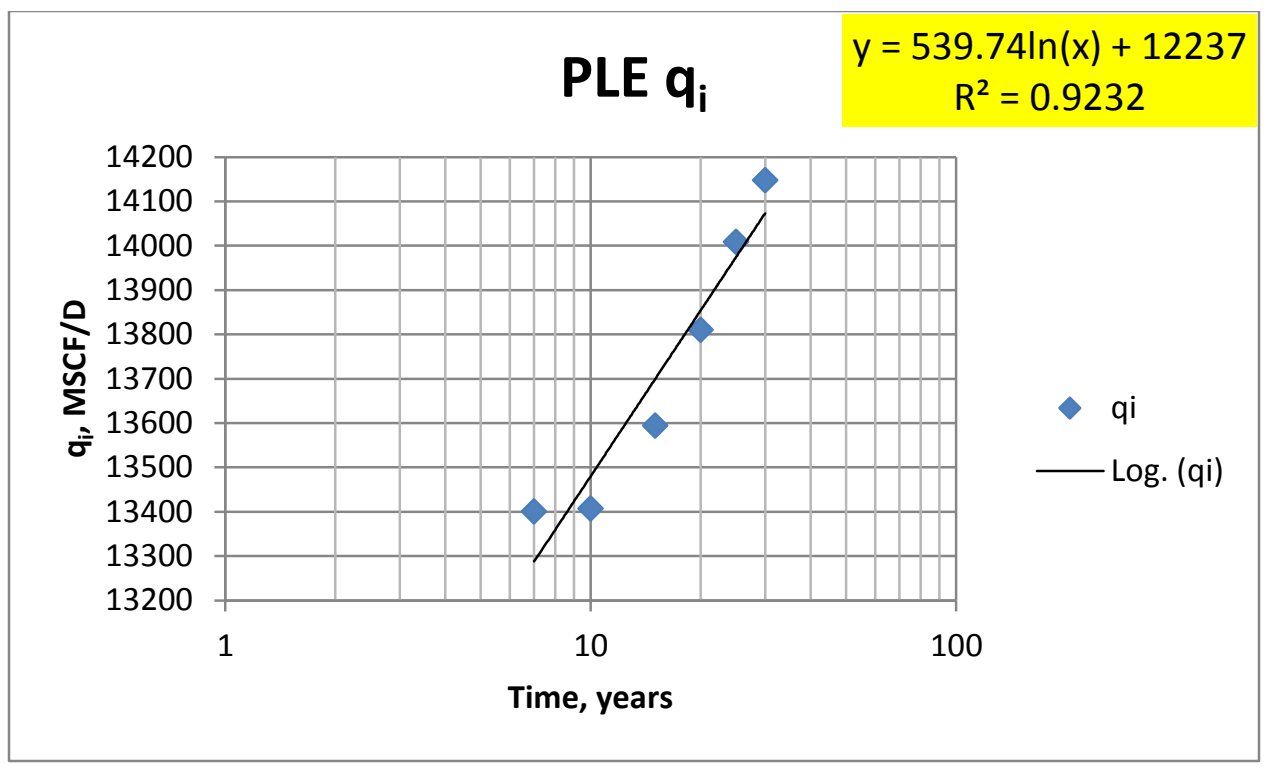

Figure 96: 13 Fracs (No Ads. Gas) PLE q Correlation

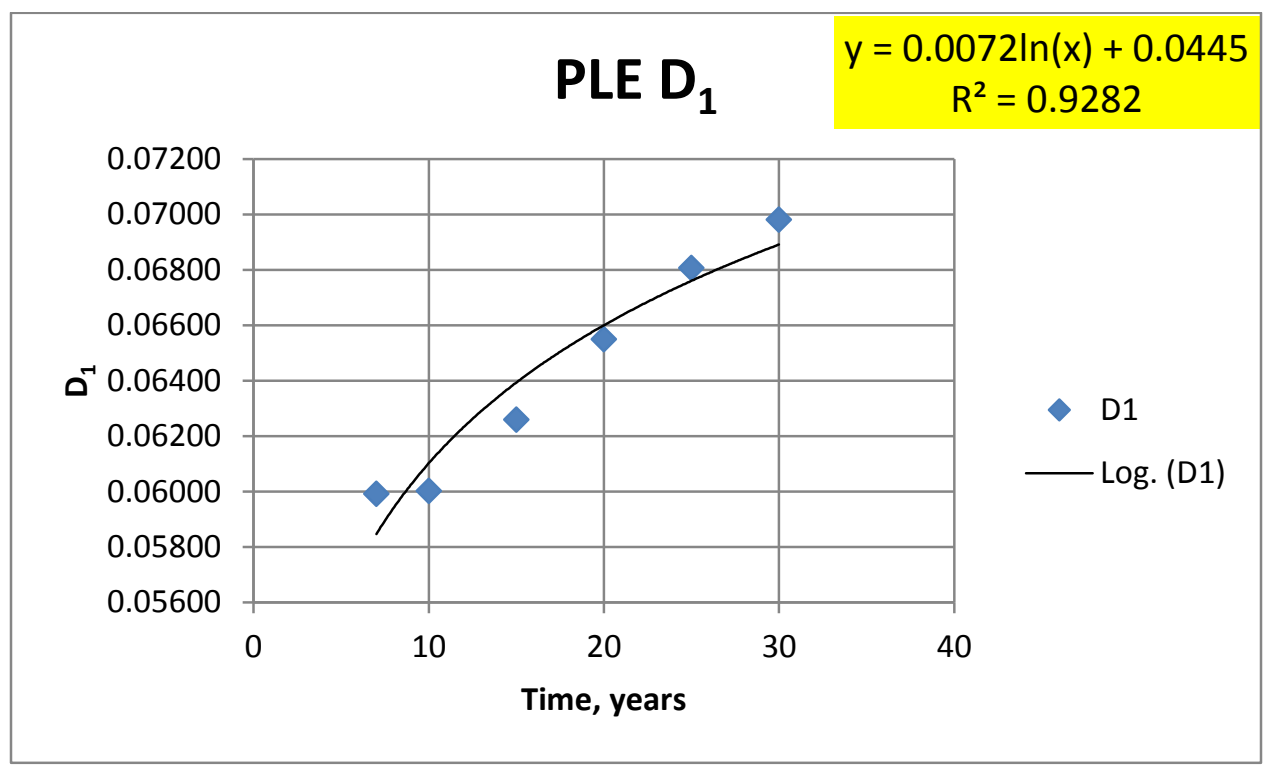

Figure 97: 13 Fracs (No Ads. Gas) PLE $D_{1}$ Correlation 


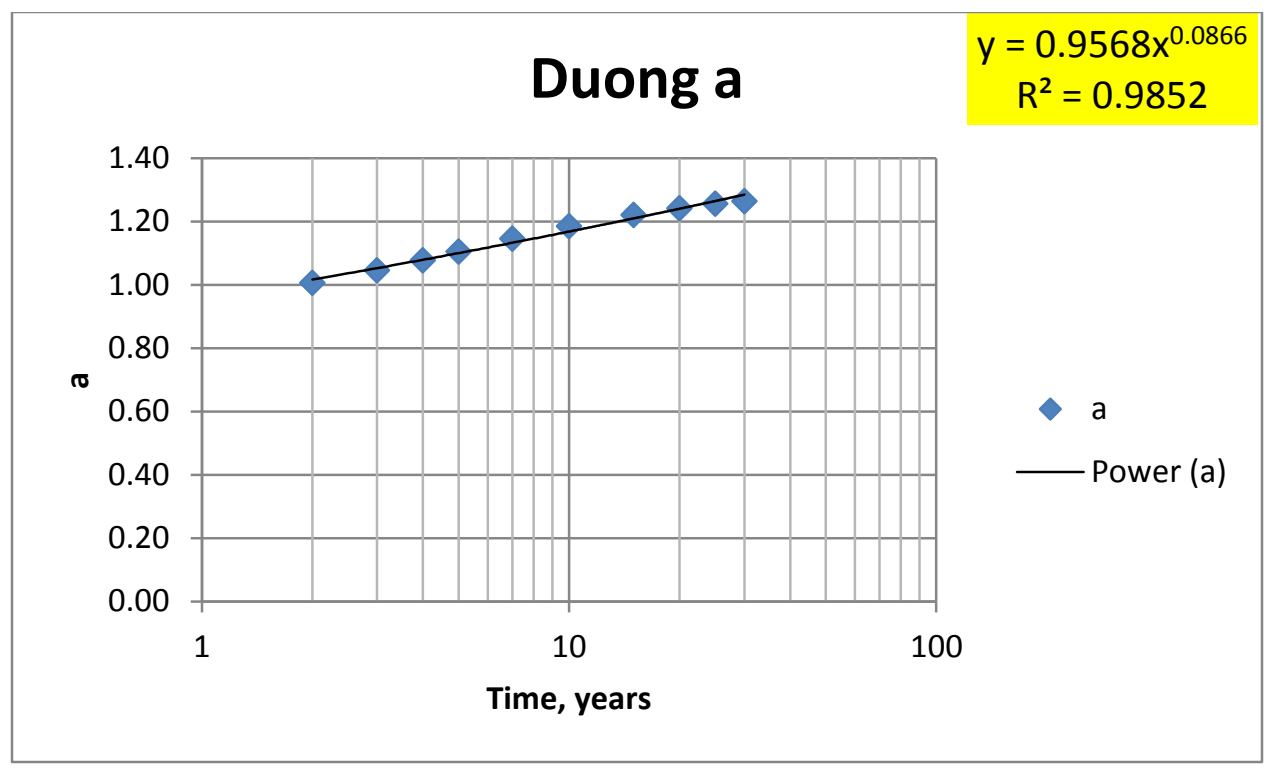

Figure 98: 13 Fracs (No Ads. Gas) Duong a Correlation

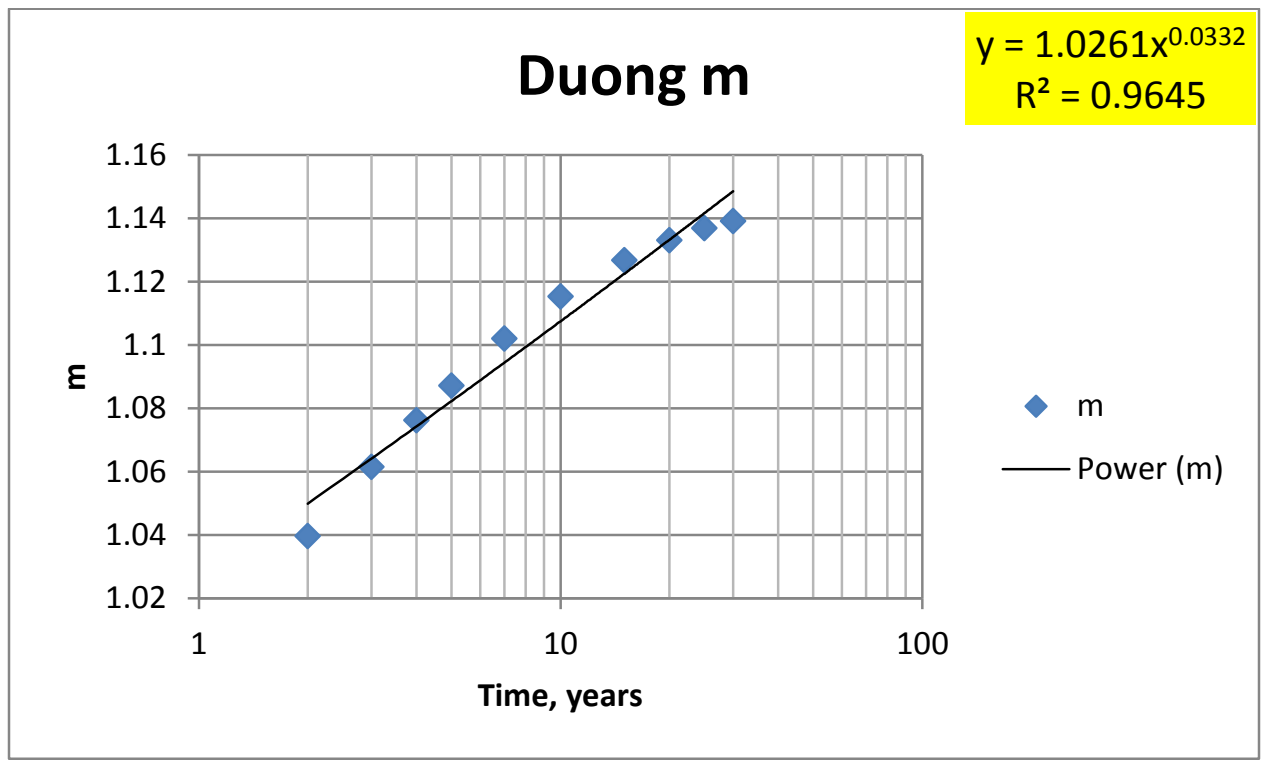

Figure 99: 13 Fracs (No Ads. Gas) Duong m Correlation 


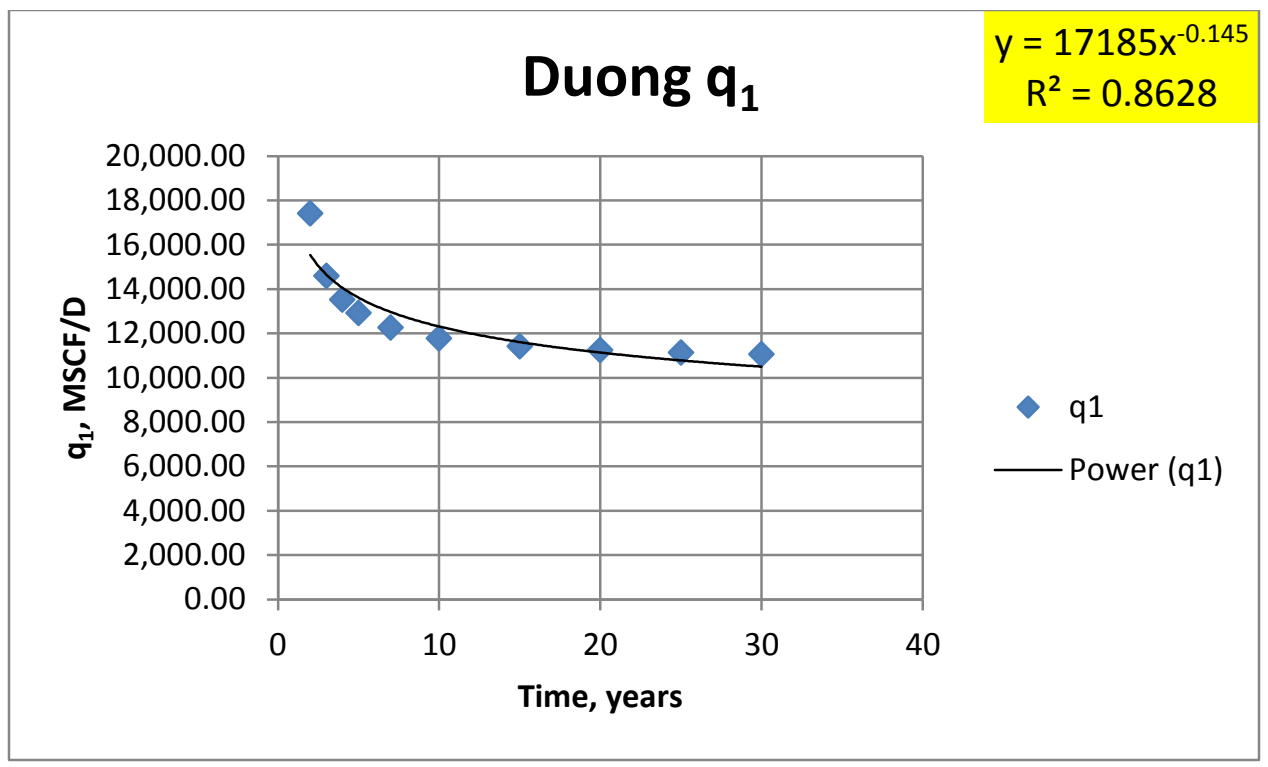

Figure 100: 13 Fracs (No Ads. Gas) Duong q1 Correlation

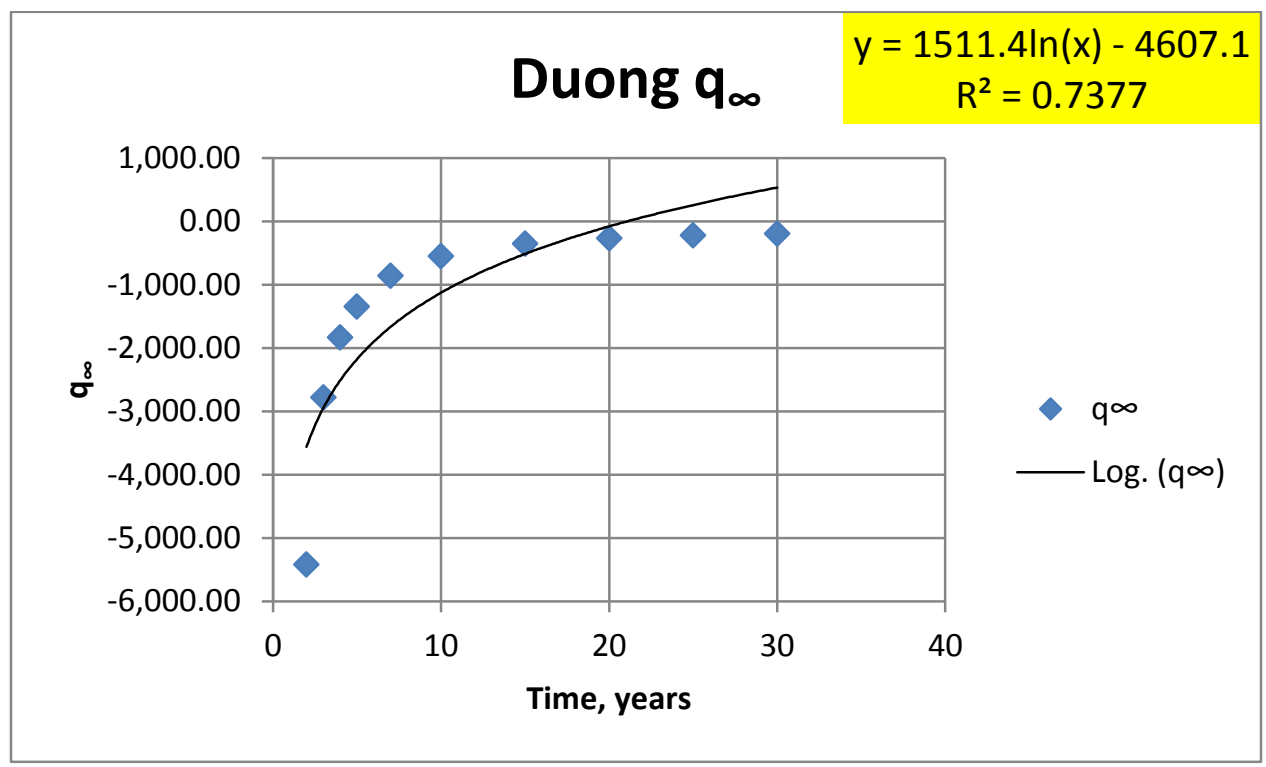

Figure 101: 13 Fracs (No Ads. Gas) Duong q Correlation

Using the correlations obtained, predicting the values of constants at a future point in time was performed to confirm their accuracy to simulated Marcellus shale data. Thirty years of simulated production data was chosen. Table 23, Table 24, and Table 25 show results for the Arps, PLE, and Duong methods with seven fractures with adsorbed gas. Table 26, Table 27, and 
Table 28 show results for the Arps, PLE, and Duong methods with thirteen fractures with adsorbed gas. Table 29, Table 30, and Table 31 show results for the Arps, PLE, and Duong methods with seven fractures and without adsorbed gas. Finally, Table 32, Table 33, and Table 34 show results for the Arps, PLE, and Duong methods with thirteen fractures without adsorbed gas.

Table 23: Simulator Predicted 7 Fracs (Ads. Gas) Arps

\begin{tabular}{|c|c|c|c|r|}
\hline \multicolumn{5}{|c|}{ Simulator Predicted 7 Fracs (Adsorbed Gas) } \\
\hline ARPS & $n$ & $d_{i}$ & $q_{i}$ & $R^{2}(30$ yr. Match) \\
\hline 30 Years & 1.500628194 & 0.01233533 & 6131.858716 & 0.993757754 \\
\hline
\end{tabular}

Table 24: Simulator Predicted 7 Fracs (Ads. Gas) PLE

\begin{tabular}{|c|c|c|c|c|c|}
\hline \multicolumn{7}{|c|}{ Simulator Predicted 7 Fracs (Adsorbed Gas) } \\
\hline PLE & $\boldsymbol{D}_{\infty}$ & $\boldsymbol{n}$ & $\boldsymbol{q}_{\boldsymbol{i}}$ & $\boldsymbol{D}_{\boldsymbol{1}}$ & $\boldsymbol{R}^{\mathbf{2}}$ (30 Yr. Match) \\
\hline 30 Years & -0.000019761 & 0.30435 & 9046.679166 & 0.087700000 & 0.994403338 \\
\hline
\end{tabular}

Table 25: Simulator Predicted 7 Fracs (Ads. Gas) Duong

\begin{tabular}{|c|c|c|c|c|r|}
\hline \multicolumn{7}{|c|}{ Simulator Predicted 7 Fracs (Adsorbed Gas) } \\
\hline Duong & $\boldsymbol{a}$ & $\boldsymbol{m}$ & $\boldsymbol{q}_{1}$ & $\boldsymbol{q}_{\infty}$ & $\boldsymbol{R}^{\mathbf{2}}$ (30 Yr. Match) \\
\hline 30 Years & 1.149915562 & 1.09489 & 6355.992317 & -160.9148911 & 0.998362788 \\
\hline
\end{tabular}

Table 26: Simulator Predicted 13 Fracs (Ads. Gas) Arps

\begin{tabular}{|c|c|c|c|r|}
\hline \multicolumn{5}{|c|}{ Simulator Predicted 13 Fracs (Adsorbed Gas) } \\
\hline ARPS & $n$ & $d_{i}$ & $q_{i}$ & $R^{2}(30$ yr. Match) \\
\hline 30 Years & 1.15532696 & 0.013538922 & 10973.229 & 0.997865002 \\
\hline
\end{tabular}


Table 27: Simulator Predicted 13 Fracs (Ads Gas.) PLE

\begin{tabular}{|c|c|c|c|c|r|}
\hline \multicolumn{6}{|c|}{ Simulator Predicted 13 Fracs (Adsorbed Gas) } \\
\hline PLE & $\boldsymbol{D}_{\infty}$ & $\boldsymbol{n}$ & $\boldsymbol{q}_{\boldsymbol{i}}$ & $\boldsymbol{D}_{1}$ & $\boldsymbol{R}^{2}$ (30 Yr. Match) \\
\hline 30 Years & -0.000479641 & 0.44143893 & $13,663.13$ & 0.063000 & 0.953070029 \\
\hline
\end{tabular}

Table 28: Simulator Predicted 13 Fracs (Ads. Gas) Duong

\begin{tabular}{|c|c|c|c|c|r|}
\hline \multicolumn{5}{|c|}{ Simulator Predicted 13 Fracs (Adsorbed Gas) } \\
\hline Duong & $\boldsymbol{a}$ & $\boldsymbol{m}$ & $\boldsymbol{q}_{1}$ & $\boldsymbol{q}_{\infty}$ & $\boldsymbol{R}^{\mathbf{2}}$ (30 Yr. Match) \\
\hline 30 Years & 1.358446683 & 1.149853 & $9,917.55$ & -54.314969 & 0.991845400 \\
\hline
\end{tabular}

Table 29: Simulator Predicted 7 Fracs (No Ads. Gas) Arps

\begin{tabular}{|c|c|c|c|r|}
\hline \multicolumn{5}{|c|}{ Simulator Predicted 7 Fracs (No Adsorbed Gas) } \\
\hline ARPS & $n$ & $d_{i}$ & $q_{i}$ & $R^{2}(30$ yr. Match) \\
\hline 30 Years & 1.443303049 & 0.014994 & 6254.064108 & 0.991649027 \\
\hline
\end{tabular}

Table 30: Simulator Predicted 7 Fracs (No Ads. Gas) PLE

\begin{tabular}{|c|c|c|c|c|r|}
\hline \multicolumn{6}{|c|}{ Simulator Predicted 7 Fracs (No Adsorbed Gas) } \\
\hline PLE & $\boldsymbol{D}_{\infty}$ & $\boldsymbol{n}$ & $\boldsymbol{q}_{\boldsymbol{i}}$ & $\boldsymbol{D}_{\boldsymbol{1}}$ & $\boldsymbol{R}^{\mathbf{2}}$ (30 Yr. Match) \\
\hline 30 Years & -0.000059880 & 0.29867 & 9442.84519 & 0.092505987 & 0.998147686 \\
\hline
\end{tabular}

Table 31: Simulator Predicted 7 Fracs (No Ads. Gas) Duong

\begin{tabular}{|c|c|c|c|c|r|}
\hline \multicolumn{7}{|c|}{ Simulator Predicted 7 Fracs (No Adsorbed Gas) } \\
\hline Duong & $\boldsymbol{a}$ & $\boldsymbol{m}$ & $\boldsymbol{q}_{1}$ & $\boldsymbol{q}_{\infty}$ & $\boldsymbol{R}^{\mathbf{2}}$ (30 Yr. Match) \\
\hline 30 Years & 1.105114351 & 1.09099 & 6663.113279 & -120.315770658 & 0.990487269 \\
\hline
\end{tabular}

Table 32: Simulator Predicted 13 Fracs (No Ads. Gas) Arps

\begin{tabular}{|c|c|c|c|r|}
\hline \multicolumn{5}{|c|}{ Simulator Predicted 13 Fracs (No Adsorbed Gas) } \\
\hline ARPS & $n$ & $d_{i}$ & $q_{i}$ & $R^{2}$ (30 yr. Match) \\
\hline 30 Years & 1.134254499 & 0.016419 & 11222.19857 & 0.996492721 \\
\hline
\end{tabular}


Table 33: Simulator Predicted 13 Fracs (No Ads. Gas) PLE

\begin{tabular}{|c|c|c|c|c|r|}
\hline \multicolumn{6}{|c|}{ Simulator Predicted 13 Fracs (No Adsorbed Gas) } \\
\hline PLE & $\boldsymbol{D}_{\infty}$ & $\boldsymbol{n}$ & $\boldsymbol{q}_{\boldsymbol{i}}$ & $\boldsymbol{D}_{1}$ & $\boldsymbol{R}^{2}$ (30 Yr. Match) \\
\hline 30 Years & -0.000479641 & 0.43785 & 14072.76227 & 0.068988621 & 0.996208105 \\
\hline
\end{tabular}

Table 34: Simulator Predicted 13 Fracs (No Ads. Gas) Duong

\begin{tabular}{|c|c|c|c|c|r|}
\hline \multicolumn{6}{|c|}{ Simulator Predicted 13 Fracs (No Adsorbed Gas) } \\
\hline Duong & $\boldsymbol{a}$ & $\boldsymbol{m}$ & $\boldsymbol{q}_{1}$ & $\boldsymbol{q}_{\infty}$ & $\boldsymbol{R}^{2}$ (30 Yr. Match) \\
\hline 30 Years & 1.284517032 & 1.14876 & 10494.62572 & 533.4697226 & 0.820740249 \\
\hline
\end{tabular}




\subsection{Well 1 - 13 Fracs (Adsorbed Gas) Predictions}

Table 35: 13 Fracs (Ads. Gas) Arps Table of Ratios

\begin{tabular}{|l|c|c|c|}
\hline \multicolumn{4}{|c|}{ 13 Fracs (Adsorbed Gas) Table of Ratios } \\
\hline \multicolumn{1}{|c|}{ ARPS } & $\boldsymbol{n}$ & $\boldsymbol{d}_{\boldsymbol{i}}$ & $\boldsymbol{q}_{\boldsymbol{i}}$ \\
\hline $\mathbf{2}$ Years & 1.217898565 & 1.244074369 & 1.023059976 \\
\hline 3 Years & 1.134858744 & 1.157528115 & 1.015887936 \\
\hline 4 Years & 1.094294403 & 1.113726250 & 1.011911860 \\
\hline 5 Years & 1.072534713 & 1.089492814 & 1.009590117 \\
\hline 7 Years & 1.050043981 & 1.063609890 & 1.006998839 \\
\hline 10 Years & 1.035097590 & 1.045625226 & 1.005116553 \\
\hline 15 Years & 1.022317285 & 1.029527938 & 1.003365963 \\
\hline 20 Years & 1.013240541 & 1.017687914 & 1.002038568 \\
\hline 25 Years & 1.005484083 & 1.007368313 & 1.000856304 \\
\hline All & 1.000000000 & 1.000000000 & 1.000000000 \\
\hline
\end{tabular}

Table 36: 13 Fracs (Ads. Gas) PLE Table of Ratios

\begin{tabular}{|l|c|c|c|c|}
\hline \multicolumn{5}{|c|}{ 13 Fracs (Adsorbed Gas) Table of Ratios } \\
\hline \multicolumn{1}{|c|}{ PLE } & $\boldsymbol{D}_{\infty}$ & $\boldsymbol{n}$ & $\boldsymbol{q}_{\boldsymbol{i}}$ & $\boldsymbol{D}_{\boldsymbol{1}}$ \\
\hline 2 Years & 1.111384885 & 1.07899338 & 0.959439202 & 0.878858218 \\
\hline 3 Years & 1.699886887 & 1.11824919 & 0.949859356 & 0.852382315 \\
\hline 4 Years & 2.063494445 & 1.14381284 & 0.943640869 & 0.834189228 \\
\hline 5 Years & 2.243034026 & 1.15708648 & 0.940361644 & 0.824281769 \\
\hline 7 Years & 2.303247076 & 1.1616984 & 0.939205982 & 0.820735541 \\
\hline 10 Years & 2.100181394 & 1.14314014 & 0.944450434 & 0.837076178 \\
\hline 15 Years & 1.67665366 & 1.09715735 & 0.959398974 & 0.88285719 \\
\hline 20 Years & 1.358447499 & 1.05581263 & 0.975050456 & 0.929292862 \\
\hline 25 Years & 1.132610275 & 1.02197154 & 0.989614083 & 0.971055433 \\
\hline All & 1.000000000 & 1.0000000 & 1.000000000 & 1.000000000 \\
\hline
\end{tabular}


Table 37: 13 Fracs (Ads. Gas) Duong Table of Ratios

\begin{tabular}{|l|c|r|c|c|}
\hline \multicolumn{5}{|c|}{ 13 Fracs (Adsorbed Gas) Table of Ratios } \\
\hline Duong & \multicolumn{1}{|c|}{$\boldsymbol{a}$} & \multicolumn{1}{c|}{$\boldsymbol{m}$} & \multicolumn{1}{c|}{$\boldsymbol{q}_{1}$} & $\boldsymbol{q}_{\infty}$ \\
\hline 2 Years & 0.786162728 & 0.92000 & 1.525624844 & 23.17306877 \\
\hline 3 Years & 0.82161880 & 0.93727566 & 1.331354809 & 13.24935838 \\
\hline 4 Years & 0.848920227 & 0.94893626 & 1.241838909 & 9.107723145 \\
\hline 5 Years & 0.869673376 & 0.95720 & 1.190801855 & 6.903207581 \\
\hline 7 Years & 0.902052847 & 0.96910 & 1.128023157 & 4.512297396 \\
\hline 10 Years & 0.933750605 & 0.9798305 & 1.079312544 & 2.926867500 \\
\hline 15 Years & 0.964188766 & 0.98950 & 1.040136204 & 1.848791067 \\
\hline 20 Years & 0.981488920 & 0.9946882 & 1.019883966 & 1.386204405 \\
\hline 25 Years & 0.993556533 & 0.99816602 & 1.006851353 & 1.128429921 \\
\hline All & 1.000000000 & 1.00000 & 1.000000000 & 1.000000000 \\
\hline
\end{tabular}

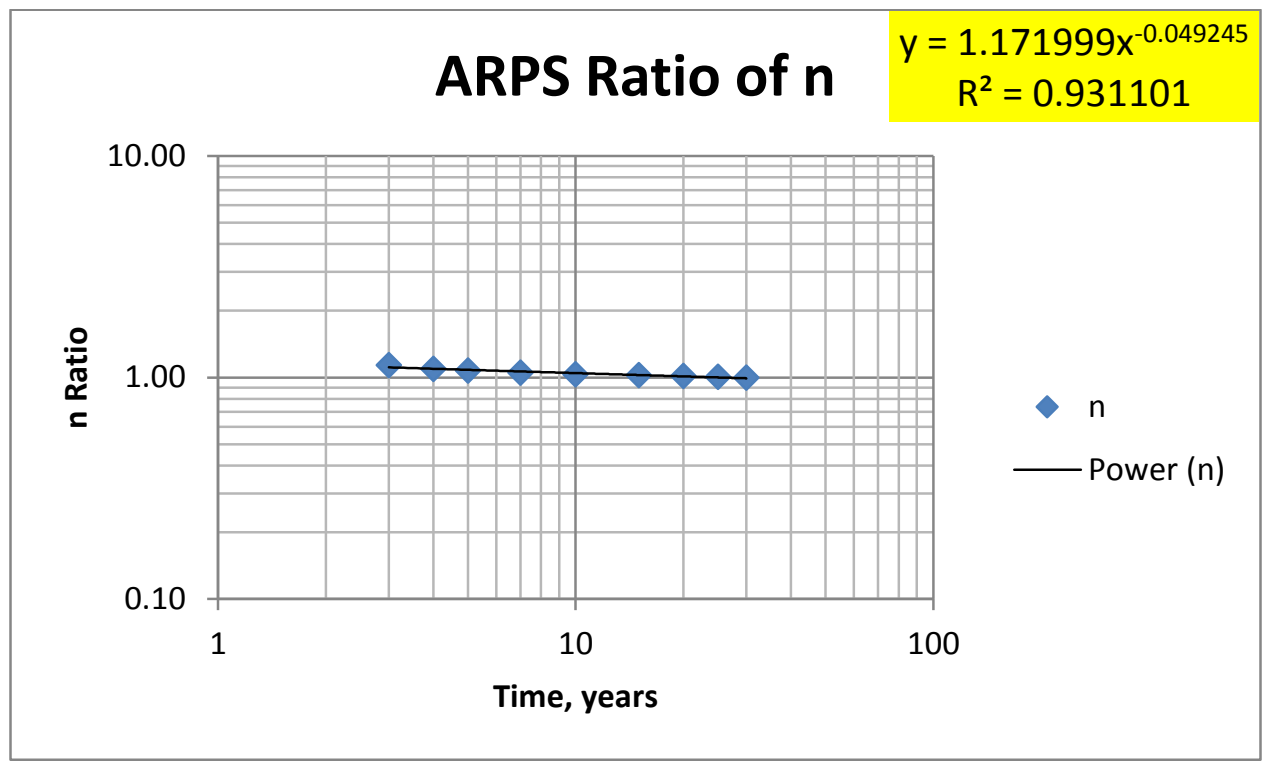

Figure 102: 13 Fracs (Ads. Gas) Arps Ratio of n vs. Time 


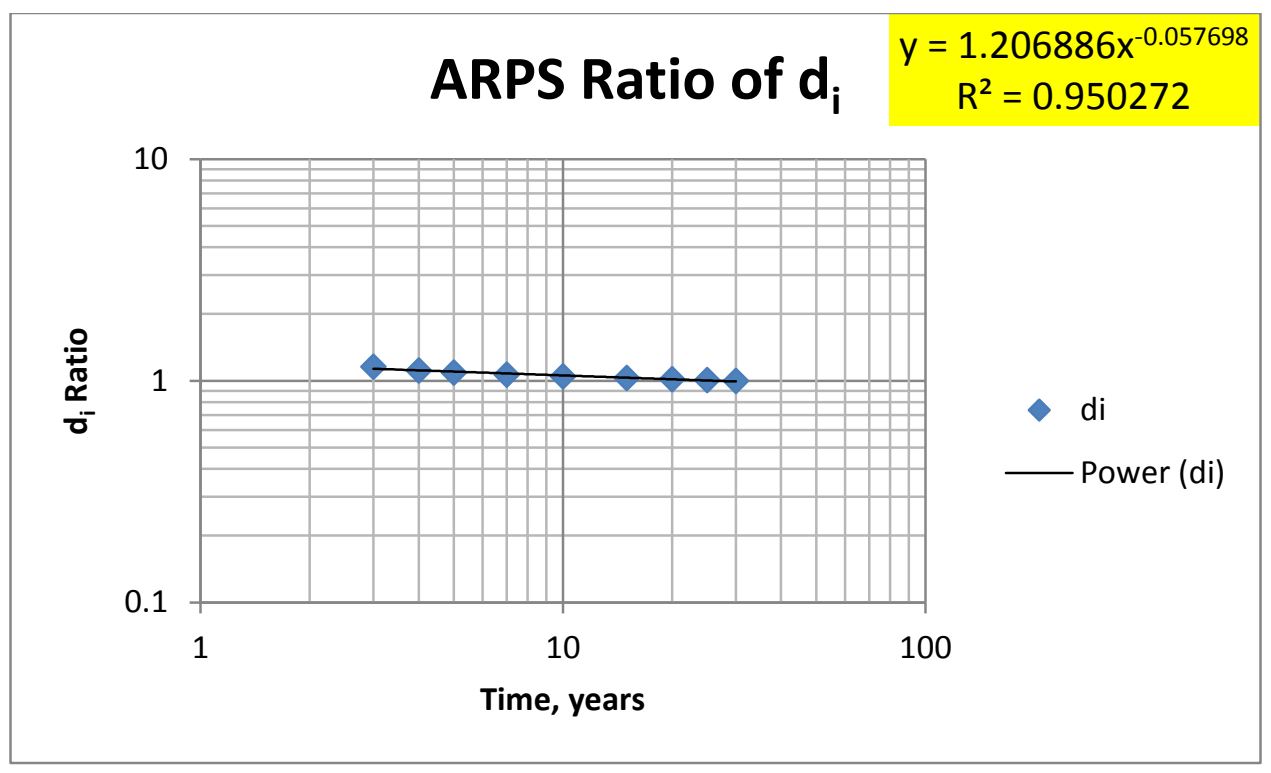

Figure 103: 13 Fracs (Ads. Gas) Arps Ratio of di vs. Time

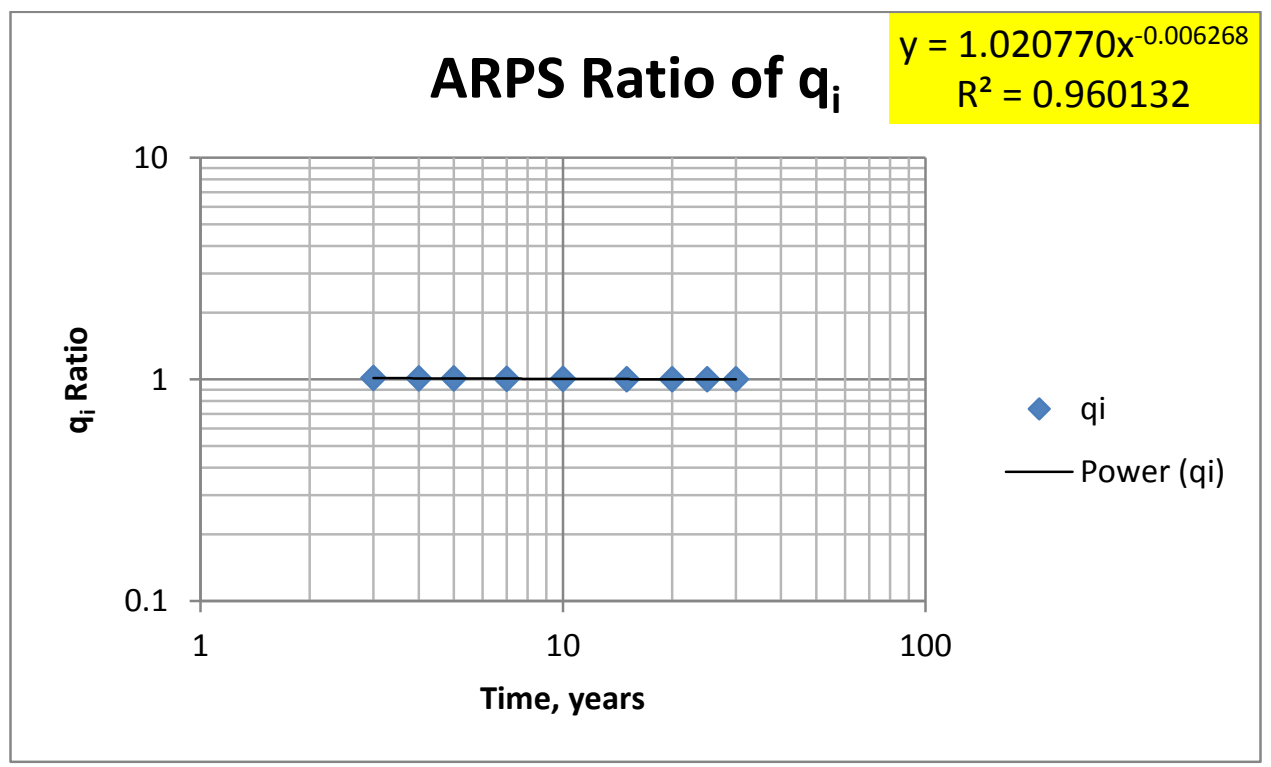

Figure 104: 13 Fracs (Ads. Gas) Arps Ratio of $q_{i}$ vs. Time 


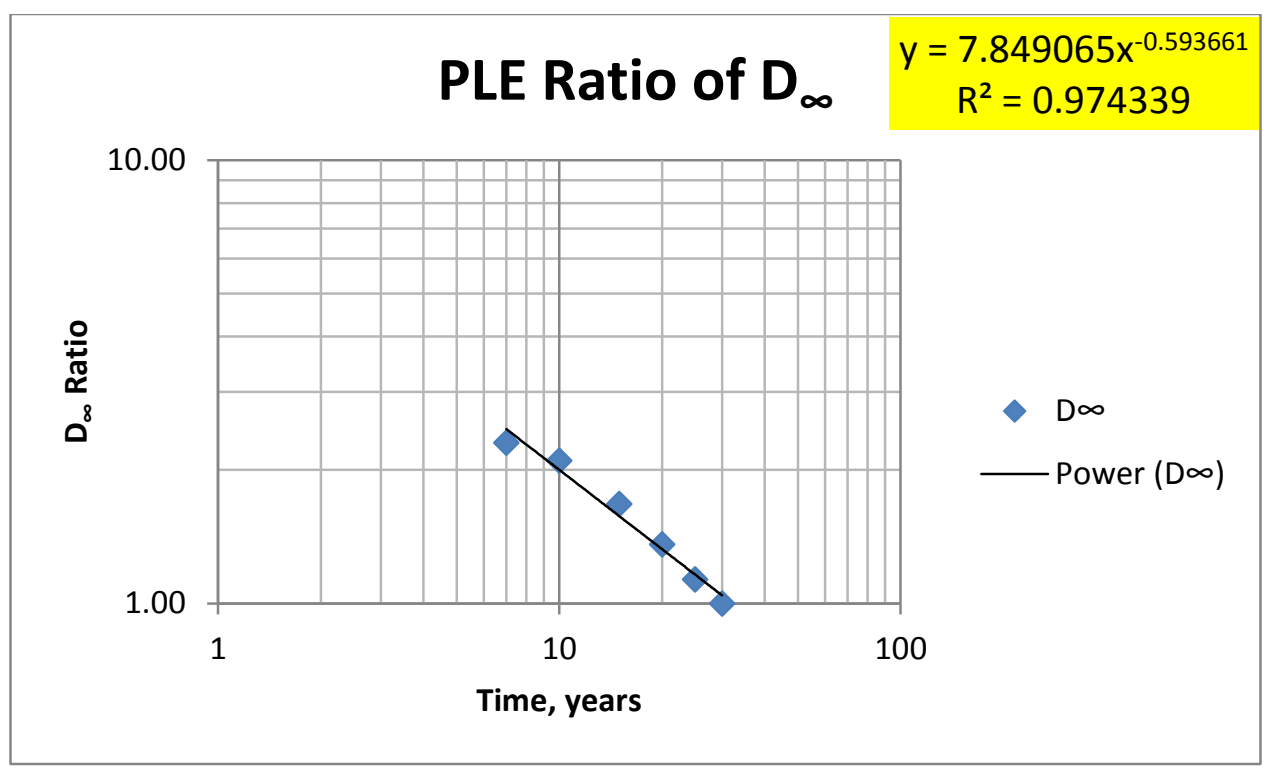

Figure 105: 13 Fracs (Ads. Gas) PLE Ratio of $D_{\infty}$ vs. Time

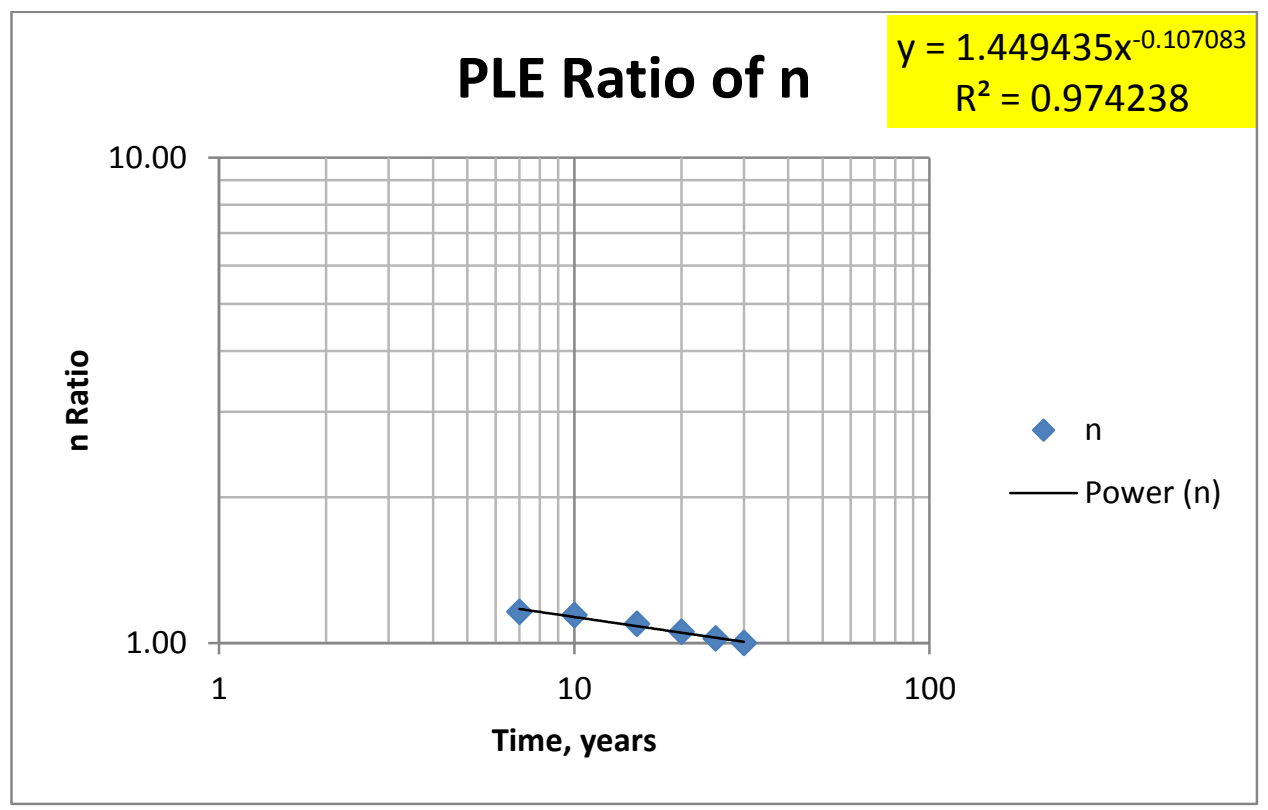

Figure 106: 13 Fracs (Ads. Gas) PLE Ratio of $n$ vs. Time 


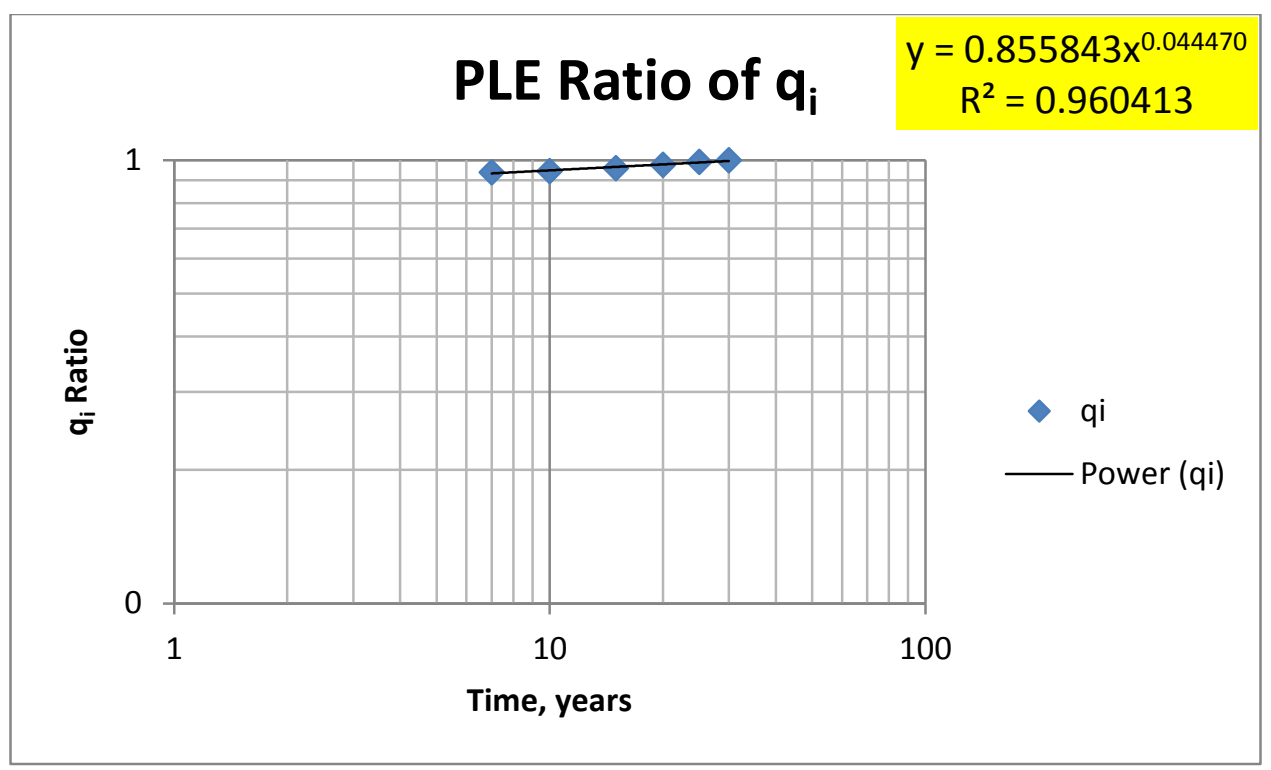

Figure 107: 13 Fracs (Ads. Gas) PLE Ratio of qi vs. Time

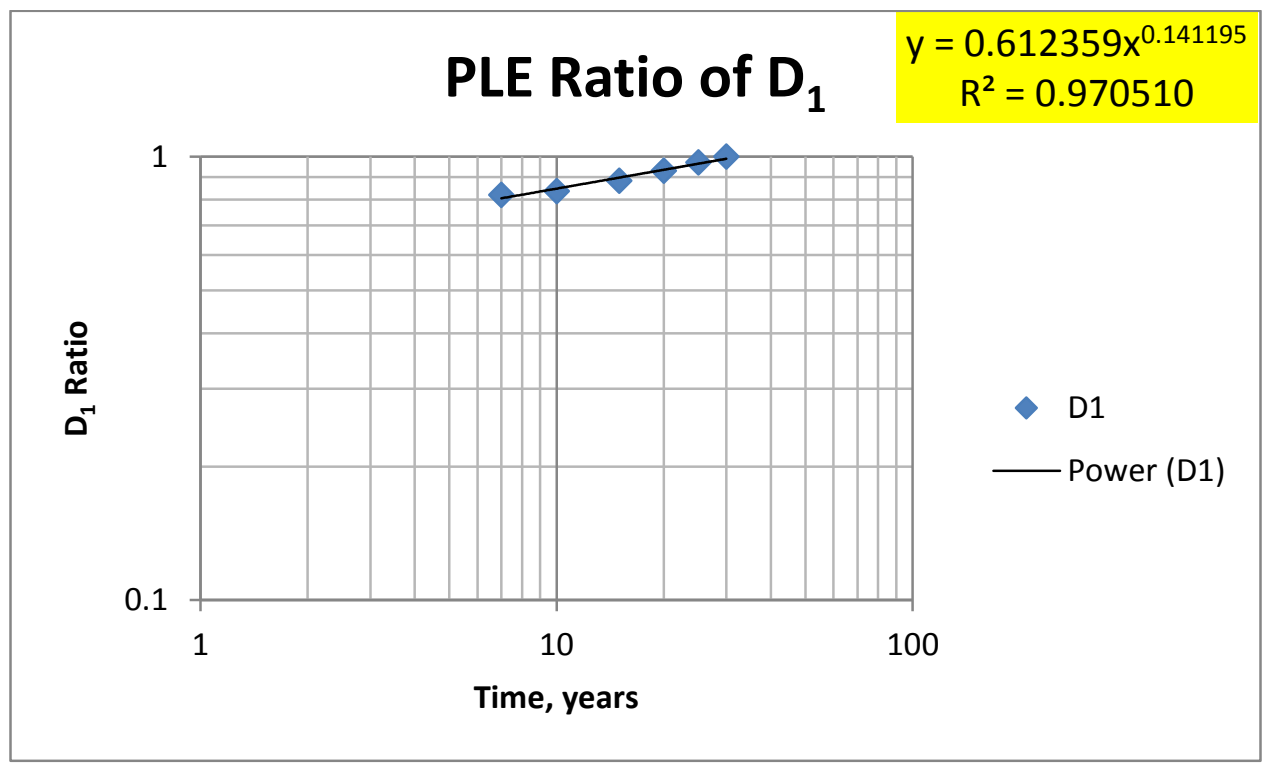

Figure 108: 13 Fracs (Ads. Gas) PLE Ratio of $D_{1}$ vs. Time 


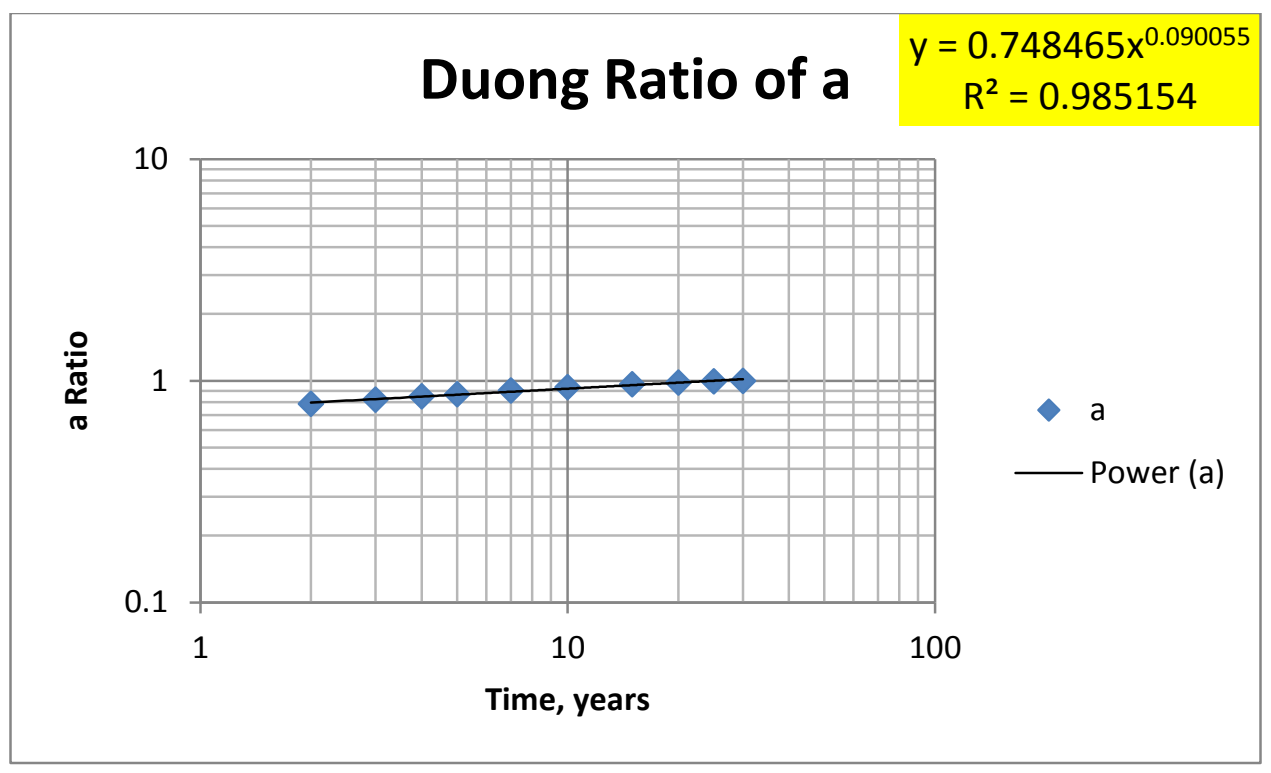

Figure 109: 13 Fracs (Ads. Gas) Duong Ratio of a vs. Time

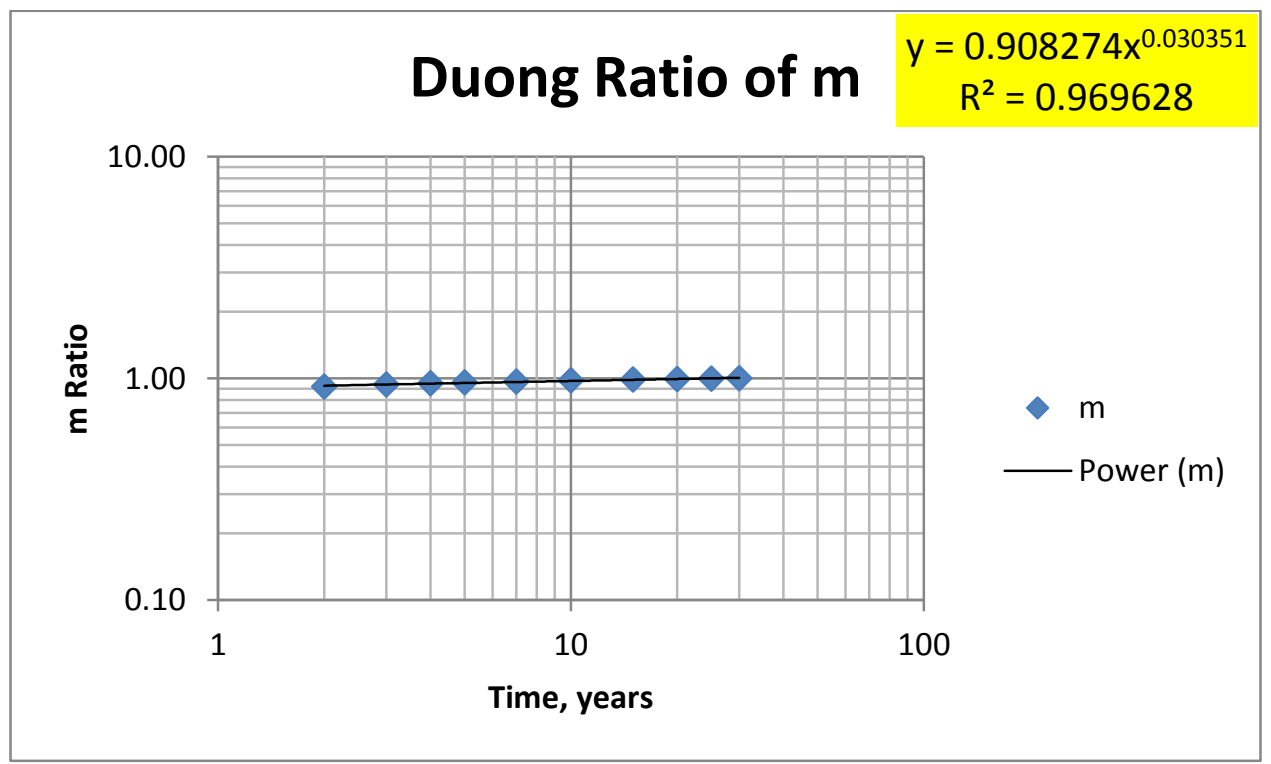

Figure 110: 13 Fracs (Ads. Gas) Duong Ratio of m vs. Time 


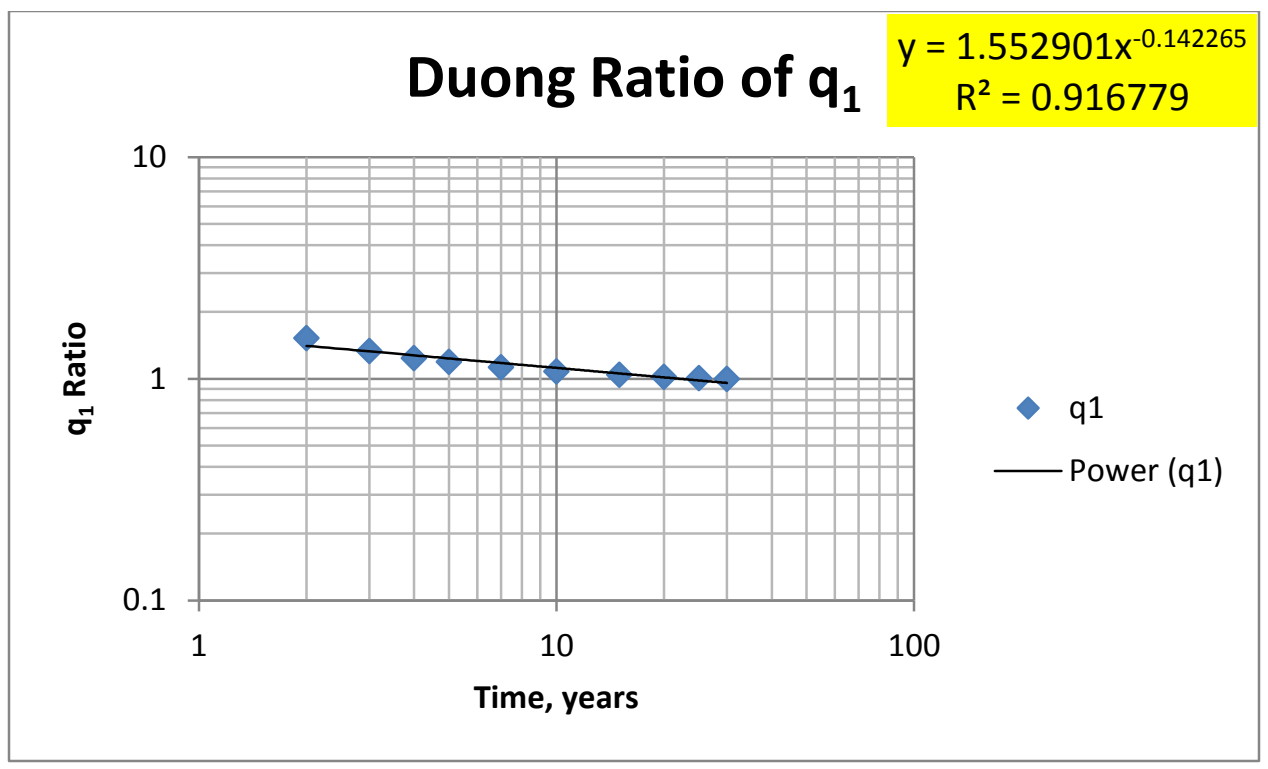

Figure 111: 13 Fracs (Ads. Gas) Duong Ratio of $q_{1}$ vs. Time

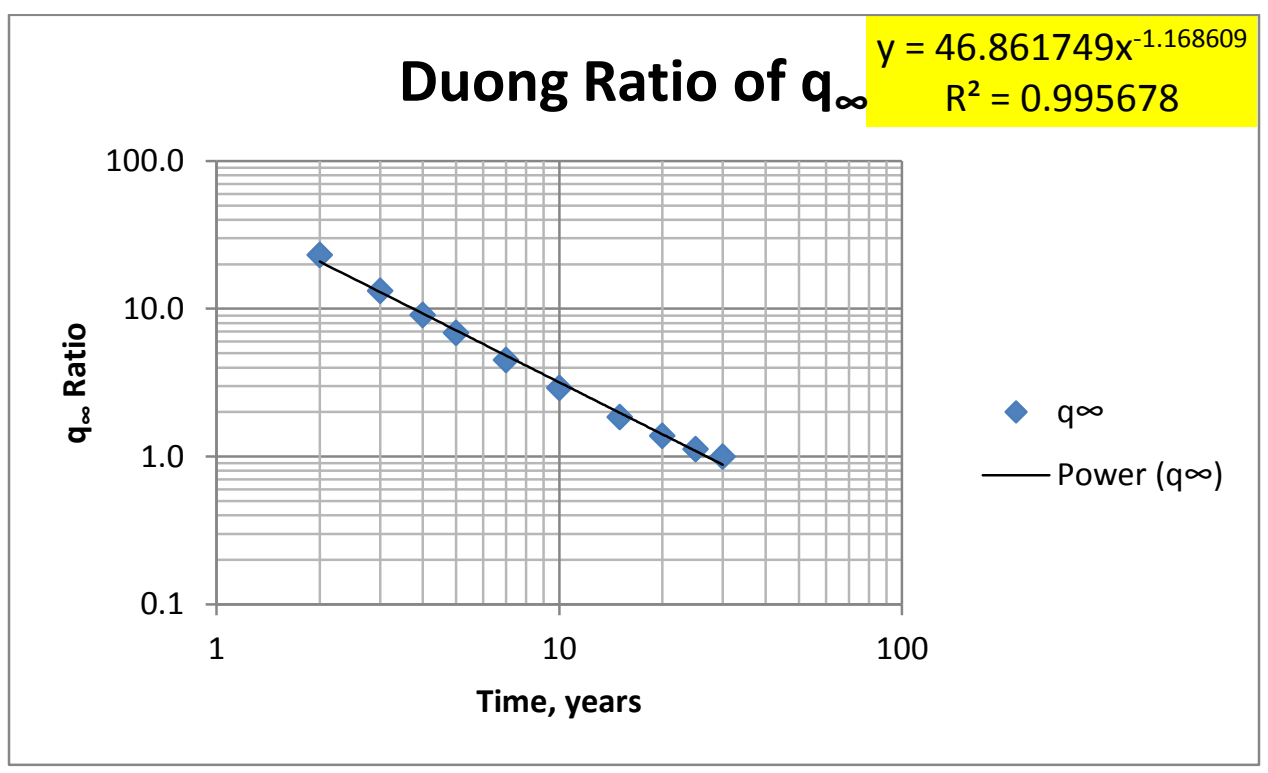

Figure 112: 13 Fracs (Ads. Gas) Duong Ratio of $q_{\infty} v \mathbf{v s . ~ T i m e ~}$

Table 38: 13 Fracs (Ads. Gas) Arps Well 1 Ratio Values

\begin{tabular}{|r|c|c|c|}
\hline \multicolumn{4}{|c|}{13 Fracs (Adsorbed Gas) Arps Well 1 Ratio Values } \\
\hline Well 1 (Years) & $n$ & $d_{i}$ & $q_{i}$ \\
\hline 4.273972603 & 1.091093409 & 1.109860819 & 1.011518534 \\
\hline
\end{tabular}


Table 39: 13 Fracs (Ads. Gas) PLE Well 1 Ratio Values

\begin{tabular}{|r|c|c|c|c|}
\hline \multicolumn{5}{|c|}{13 Fracs (Adsorbed Gas) PLE Well 1 Ratio Values } \\
\hline Well 1 (Years) & $D_{\infty}$ & $n$ & $\boldsymbol{q}_{\boldsymbol{i}}$ & $\boldsymbol{D}_{1}$ \\
\hline 4.273972603 & 3.31373464 & 1.2406446 & 0.912950414 & 0.751755115 \\
\hline
\end{tabular}

Table 40: 13 Fracs (Ads. Gas) Duong Well 1 Ratio Values

\begin{tabular}{|r|c|c|c|c|}
\hline \multicolumn{5}{|c|}{ 13 Fracs (Adsorbed Gas) Duong Well 1 Ratio Values } \\
\hline Well 1 (Years) & $\boldsymbol{q}_{\infty}$ & $\boldsymbol{a}$ & $\boldsymbol{q}_{1}$ & $\boldsymbol{m}$ \\
\hline 4.273972603 & 8.582678644 & 0.85306289 & 1.262985874 & 0.949212079 \\
\hline
\end{tabular}

Table 41: 13 Fracs (Ads. Gas) Arps Well 1 Actual and Predicted Values

\begin{tabular}{|c|r|c|}
\hline Well 1 & \multicolumn{1}{|c|}{ Actual } & \multicolumn{1}{c|}{ Predicted } \\
\hline$n$ & 1.726571773 & $\mathbf{1 . 5 8 2 4 2 3 4 2 8}$ \\
\hline$d_{i}$ & 0.004360324 & $\mathbf{0 . 0 0 3 9 2 8 7 1 2}$ \\
\hline$q_{i}$ & $2,171.43$ & $\mathbf{2 1 4 6 . 7 0 3 4 0 7}$ \\
\hline
\end{tabular}

Table 42: 13 Fracs (Ads. Gas) PLE Well 1 Actual and Predicted Values

\begin{tabular}{|c|r|r|}
\hline Well 1 & \multicolumn{1}{|c|}{ Actual } & \multicolumn{1}{c|}{ Predicted } \\
\hline$D_{\infty}$ & -0.000380832 & -0.00011493 \\
\hline$n$ & 0.506473221 & $\mathbf{0 . 4 0 8 2 3 3 9 3}$ \\
\hline $\boldsymbol{q}_{i}$ & $2,627.55$ & $\mathbf{2 8 7 8 . 0 8 5 0 2}$ \\
\hline$D_{1}$ & 0.02777503 & $\mathbf{0 . 0 3 6 9 4 6 9 1}$ \\
\hline
\end{tabular}


Table 43: 13 Fracs (Ads. Gas) Duong Well 1 Actual and Predicted Values

\begin{tabular}{|c|r|r|}
\hline Well 1 & \multicolumn{1}{|c|}{ Actual } & \multicolumn{1}{c|}{ Predicted } \\
\hline$a$ & 1.482659542 & 1.73804249 \\
\hline$m$ & 1.113649238 & 1.17323543 \\
\hline$q_{1}$ & $1,414.02$ & 1119.58657 \\
\hline$q_{\infty}$ & -148.7245961 & -17.3284591 \\
\hline
\end{tabular}

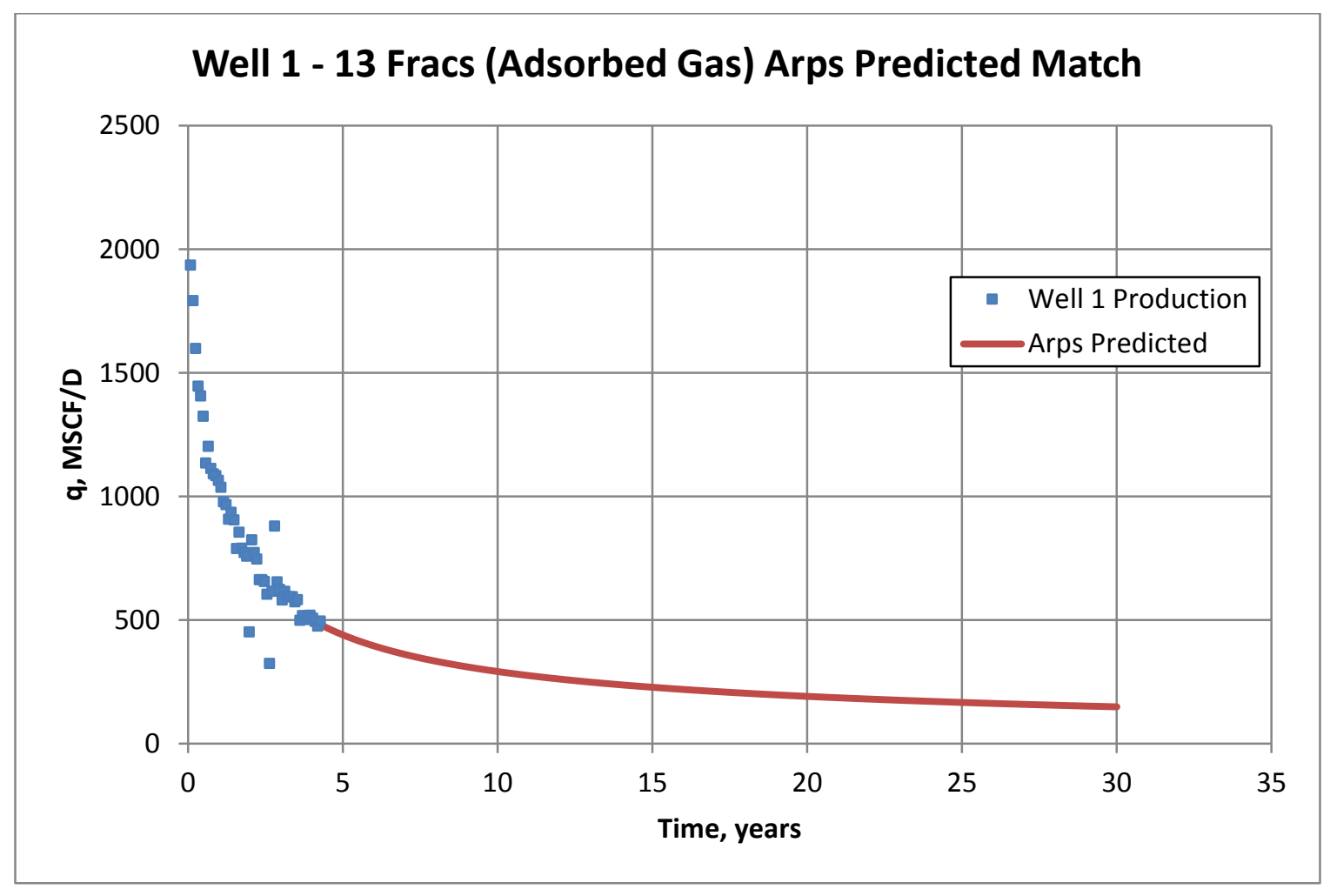

Figure 113: Well 1 - 13 Fracs (Ads. Gas) Arps Predicted Match 


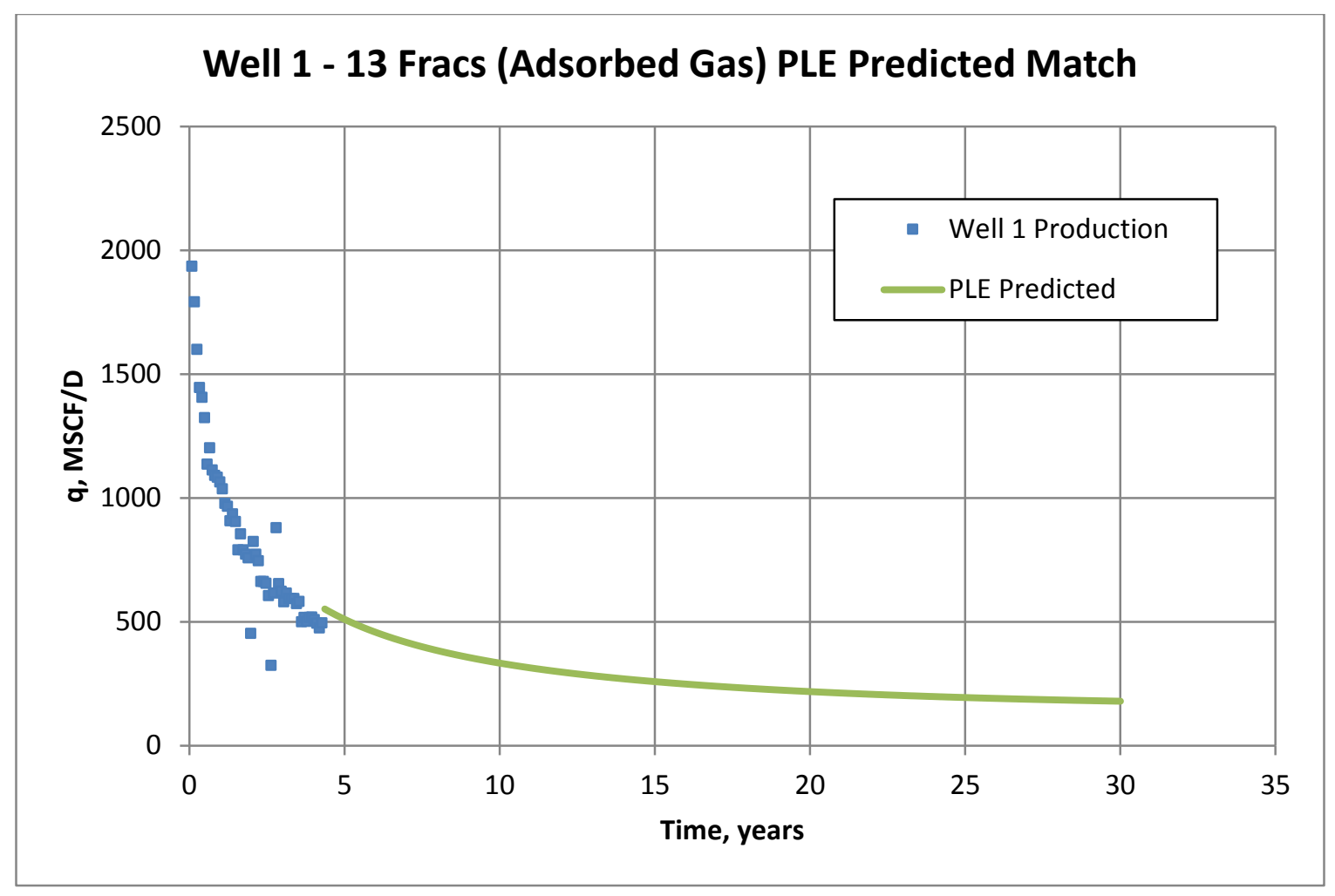

Figure 114: Well 1 - 13 Fracs (Ads. Gas) PLE Predicted Match

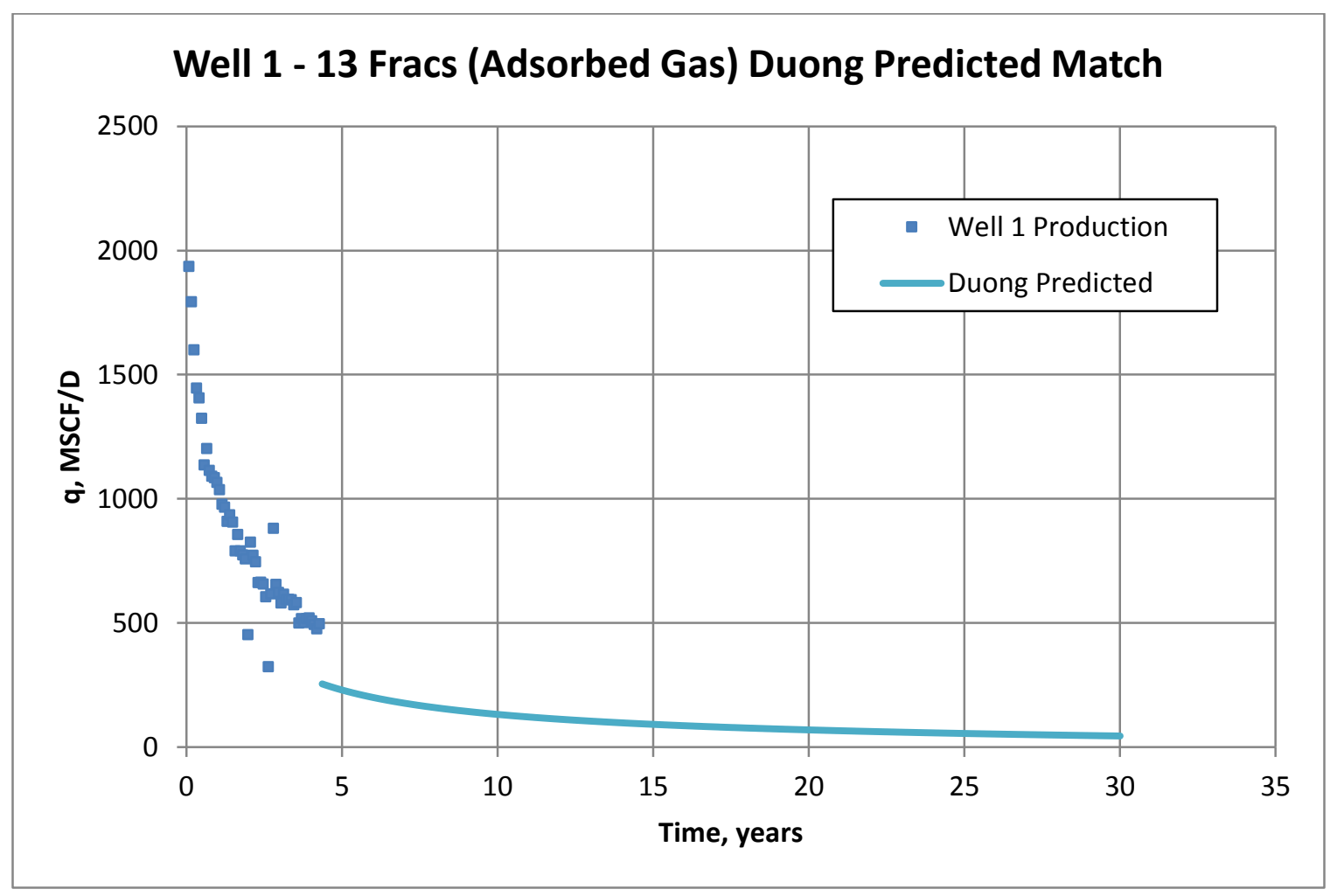

Figure 115: Well 1 - 13 Fracs (Ads. Gas) Duong Predicted Match 


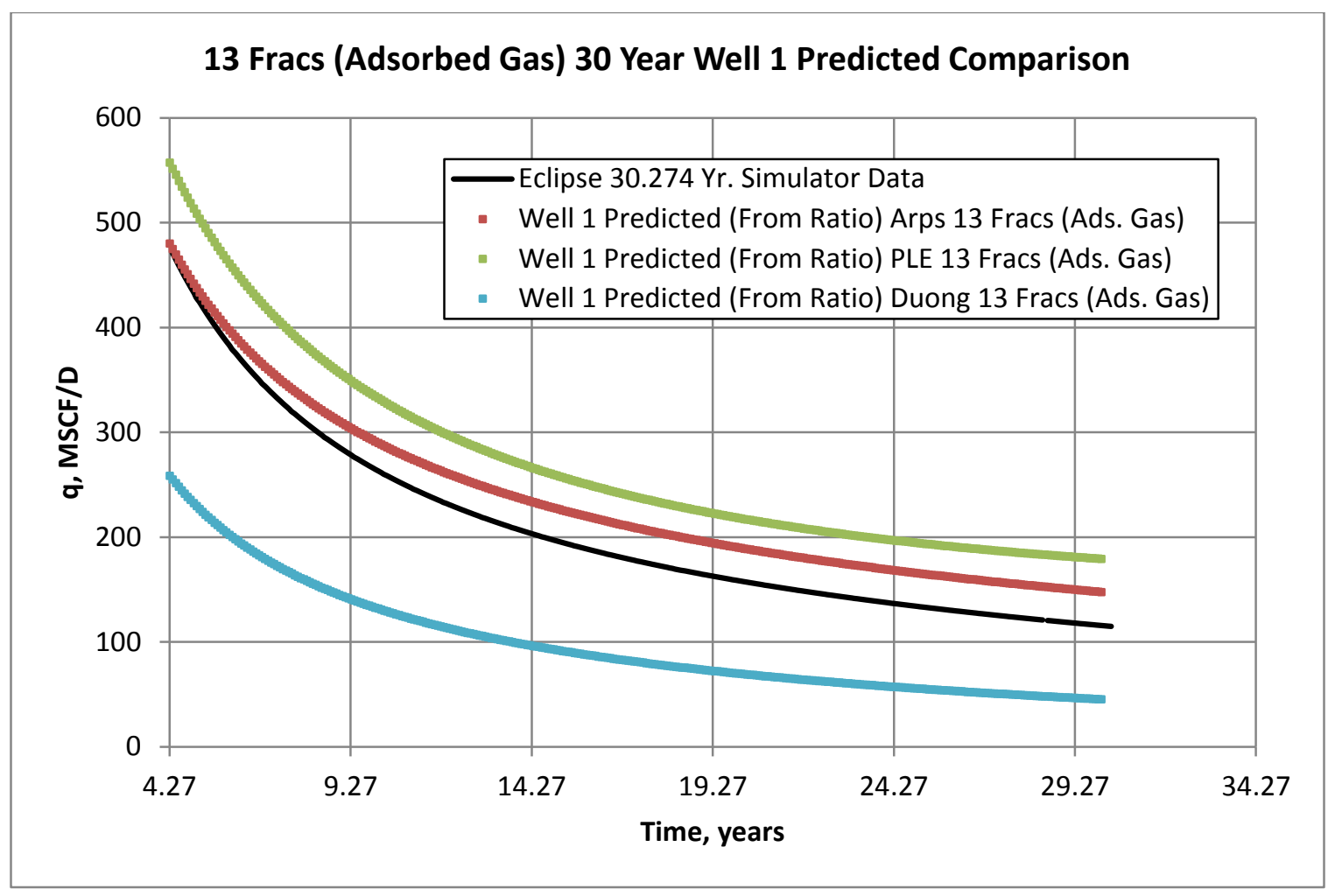

Figure 116: 13 Fracs (Ads. Gas) 30 Year Well 1 Predicted Comparison 